INSTITUTO DE PESQUISAS ENERGÉTICAS E NUCLEARES

Autarquia associada à Universidade de São Paulo

MODELAGEM DA FRATURA POR CORROSÃO SOB TENSÃO NOS BOCAIS DO MECANISMO DE ACIONAMENTO DAS BARRAS DE CONTROLE DE REATOR DE ÁGUA PRESSURIZADA

OMAR FERNANDES ALY

Tese apresentada como parte dos requisitos para obtenção do grau de Doutor em Ciências na Área de Tecnologia Nuclear - Materiais

Orientador: Dr. Arnaldo Homobono Paes de Andrade

SÃO PAULO

2006 


\section{DEDICATÓRIA}

A meus pais,

À minha família,

A meu País.

À memória do saudoso colega Pedro A.L.D.P.L.P. Moreira do CDTN.

“FILALETO (DISCÍPULO DE JOHN LOCKE): -...Assim sendo, acredito que podemos enumerar três espécies de conhecimento: o intuitivo, 0 demonstrativo e o sensitivo.

TEÓFILO (DISCÍPULO DE G. W. LEIBNIZ): -Creio que tendes razão. Penso até que a estas espécies de certeza ou ao conhecimento certo poderíeis acrescentar o conhecimento do provável. Assim sendo, haverá duas espécies de conhecimento, como existem duas espécies de provas, das quais umas terminam na certeza, as outras na probabilidade..."

(de "Novos Ensaios sobre o Entendimento Humano" de Leibniz, coleção Os Pensadores $n^{0}$ 52, ed. Abril Cultural, São Paulo, 1980, p. 299, tradução de Luiz João Baraúna)

A lannis Xenakis que soube como artista e cientista modelar de modo genial seu pensamento musical 


\section{AGRADECIMENTOS}

Ao Dr. Arnaldo H. P. de Andrade, meu orientador no IPEN, pelas sugestões sempre oportunas e pela especial amizade e consideração.

Ao Dr. Miguel Mattar Neto, do IPEN pelas sugestões sempre oportunas e pela especial amizade e consideração.

À Dra. Idalina Vieira Aoki, da EPUSP, pelas sugestões sempre oportunas e pela especial amizade e consideração.

À Dra. Mônica M.A.M. Schvartzman, do CDTN, pelas sugestões sempre oportunas e pela especial amizade e consideração.

Ao Dr. Moyses Szajnbok, da EPUSP, pelas sugestões sempre oportunas e pela especial amizade e consideração.

À Dra. Dora de Castro Rubio Poli, amiga, colega e incentivadora.

Ao Dr. Yogen Garud da Aptech, CA, USA, pelos importantes comentários sobre esta pesquisa.

Ao Dr. Roger W. Staehle da Universidade de Minnesota, USA, pelo apoio na pesquisa bibliográfica.

Ao prof. Wanderley de Lima, Coordenador do Centro de Laboratórios de Cíclotrons.

A todos os colegas e professores do IPEN e do CDTN por sua dedicação e competência sem as quais seria difícil a elaboração deste trabalho. Menção especial aos colegas Adalberto Matias, Celeste Alentejano, Célia F.C.Neves, Herbert Jakstas Toth, Francisco J. Breda, Gerson Marinucci, Osmar de Moraes, Raquel M. Lobo, Sidney J. Buso, Silvanna Maranhão.

Ao CNPq pela bolsa e atenção dispensada ao meu trabalho. IPEN-CNEN/SP pela oportunidade de poder ter realizado este trabalho. 


\title{
MODELAGEM DA FRATURA POR CORROSÃO SOB TENSÃO NOS BOCAIS DO MECANISMO DE ACIONAMENTO DAS BARRAS DE CONTROLE DE REATOR DE ÁGUA PRESSURIZADA
}

\author{
RESUMO
}

Um dos principais mecanismos de falha que causam riscos de fratura a reatores de água pressurizada é a corrosão sob tensão de ligas metálicas em água do circuito primário (CSTAP). É causada por uma combinação das tensões de tração, meio ambiente em temperatura e microestruturas metalúrgicas susceptíveis. Ela pode ocorrer, dentre outros locais, nos bocais do mecanismo de acionamento das barras de controle. Essa fratura pode causar acidentes que comprometem a segurança nuclear através do bloqueio das barras de controle e vazamentos de água do circuito primário reduzindo a confiabilidade e a vida útil do reator.

O objetivo desta Tese de Doutorado é o estudo de modelos e uma proposta de modelagem para fraturas por corrosão sob tensão em liga 75Ni15Cr9Fe (liga 600), em água de circuito primário de reator de água pressurizada nesses bocais. São superpostos modelos eletroquímicos e de mecânica da fratura e validados com dados obtidos em experimentos e na literatura. Na parte experimental foram utilizados resultados obtidos pelo CDTN no equipamento recém-instalado de ensaio por taxa de deformação lenta.

$\mathrm{Na}$ literatura está proposto um diagrama que exprime a condição termodinâmica de ocorrerem diversos modos de CSTAP na liga 600: partiu-se de diagramas de potencial x pH (diagramas de Pourbaix), para a liga 600 imersa em água primária à alta temperatura $\left(300^{\circ} \mathrm{C}\right.$ a $\left.350^{\circ} \mathrm{C}\right)$. Sobre ele, determinaram-se os submodos de corrosão, a partir de dados experimentais. Em seguida acrescentou-se uma dimensão adicional ao diagrama, correlacionando uma variável a que se denominou "fração de resistência à corrosão sob tensão". No entanto, é possível acrescentar-se outras variáveis que exprimem a cinética de iniciação e/ou crescimento de trinca, provenientes de outras modelagens de CSTAP.

A contribuição original deste trabalho se insere nessa fase: partindo-se de uma condição de ensaio de potencial versus $\mathrm{pH}$, foram iniciadas as modelagens de um modelo empírico-comparativo, um semi-empírico-probabilístico, um de tempo de iniciação e um de taxa de deformação, a partir dos ensaios experimentais e superpostas a essa condição. Esses exprimem respectivamente a susceptibilidade à CSTAP, o tempo de falha, e nos dois últimos o tempo de iniciação de falha por corrosão sob tensão. Os resultados foram comparados com os da literatura e se mostraram coerentes. Através desse trabalho, obteve-se uma metodologia de modelagem a partir de dados experimentais. 


\title{
MODELING OF PRIMARY WATER STRESS CORROSION CRACKING AT CONTROL ROD DRIVE MECHANISM NOZZLES OF PRESSURIZED WATER REACTORS
}

\author{
Omar Fernandes Aly
}

\begin{abstract}
One of the main failure mechanisms that cause risks to pressurized water reactors is the primary water stress corrosion cracking (PWSCC) occurring in alloys. It can occurs, besides another places, at the control reactor displacement mechanism nozzles. It is caused by the joint effect of tensile stress, temperature, susceptible metallurgical microstructure and environmental conditions of the primary water. These cracks can cause accidents that reduce nuclear safety by blocking the rod's displacement and may cause leakage of primary water, reducing the reactor's life.

In this work it is proposed a study of the existing models and a modeling proposal to primary water stress corrosion cracking in these nozzles in a nickelbased Alloy 600. It is been superposed electrochemical and fracture mechanics models, and validated using experimental and literature data. The experimental data were obtained at CDTN-Brazilian Nuclear Technology Development Center, in a recent installed slow strain rate testing equipment.

In the literature it is found a diagram that indicates a thermodynamic condition for the occurrence of some PWSCC submodes in Alloy 600: it was used potential $x \mathrm{pH}$ diagrams (Pourbaix diagrams), for Alloy 600 in high temperature primary water $\left(300^{\circ} \mathrm{C}\right.$ till $\left.350^{\circ} \mathrm{C}\right)$. Over it, were located the PWSCC submodes, using experimental data. It was added a third parameter called "stress corrosion strength fraction". However, it is possible to superpose to this diagram, other parameters expressing PWSCC initiation or growth kinetics from other models.

Here is the proposition of the original contribution of this work: from an original experimental condition of potencial versus $\mathrm{pH}$, it was superposed, an empiric-comparative, a semi-empiric-probabilistic, an initiation time, and a strain rate damage models, to quantify respectively the PWSCC susceptibility, the failure time, and in the two lasts, the initiation time of stress corrosion cracking. It was modeling from our experimental data. The results were compared with the literature and it showed to be coherent. From this work was obtained a modeling methodology from experimental data.
\end{abstract}




\section{SUMÁRIO}

\section{Página}

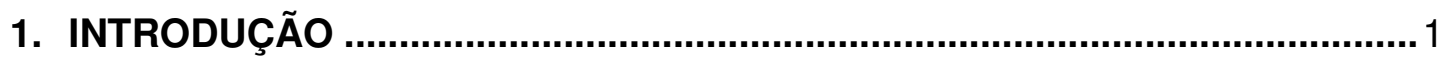

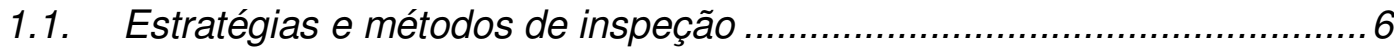

1.2. Histórico das inspeções realizadas ................................................ 7

1.3. Melhoria da resistência a trincas: materiais e projetos.......................... 10

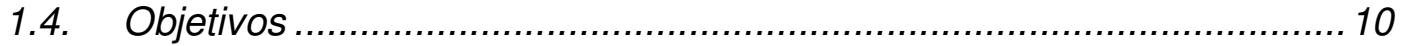

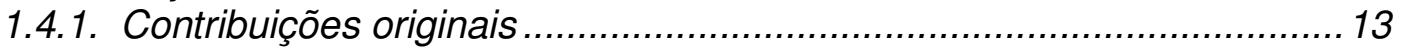

2. O FENÔMENO dA CORROSÃO SOB TENSÃO E A ABORDAGEM DE

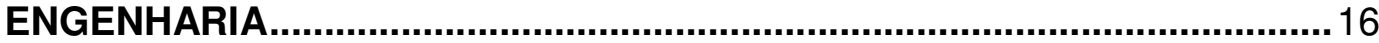

2.1. Conceituação do fenômeno de CST ................................................16

2.2. Morfologia da fratura por CST ..........................................................23

2.2.1. Modos e submodos de corrosão ...................................................26

2.3. Definição da influência ambiental ...................................................28

2.4. Definição da influência do material ..................................................... 32

2.5. Superposição de modo com ambiente ............................................ 34

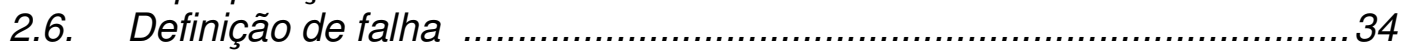

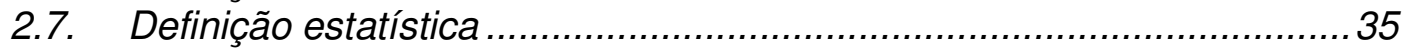

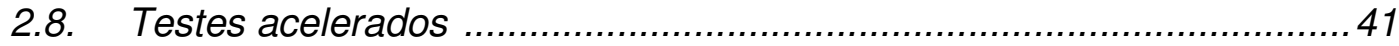

2.9. Previsão ........................................................................... 41

2.10. Modificações e otimização: projetos, materiais, ambientes e operação 42

2.11. Realimentação de informações e correção .........................................43

2.12. Abordagem do projeto baseada em corrosão .................................... 44

3. A CORROSÃo SOB teNSÃo NA LIGA 600 EM ÁGUA dO CIRCUITO

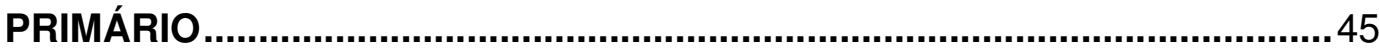

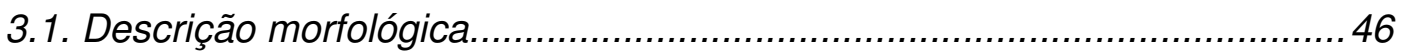

3.2. Composição química e estrutura do filme passivo.................................5 50

3.3. Composição química e estrutura dos óxidos sobre as superfícies de

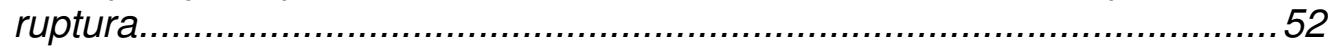

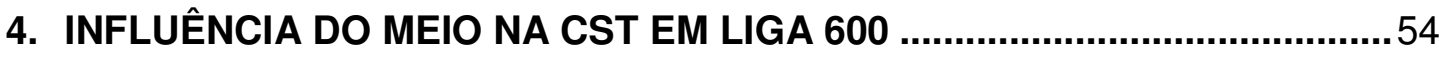

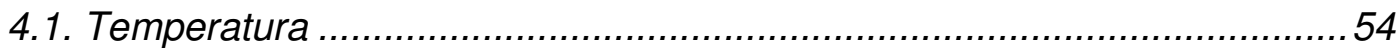

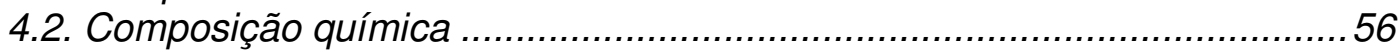

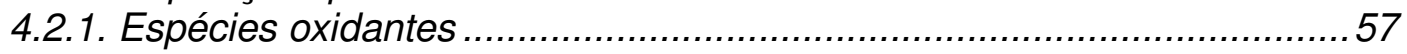

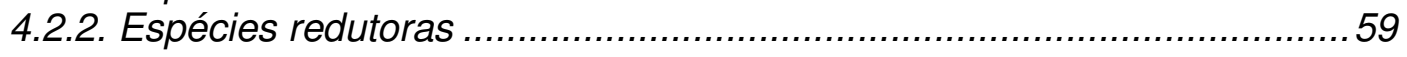


5.1. Influência do hidrogênio sobre a oxidação da liga 600 .............................65

5..2. Propriedades eletroquímicas do óxido da liga 600 ................................6 66

5.3. Hidrogênio absorvido e fragilização das ligas de níquel .............................70

6. INFLUÊNCIA DO MATERIAL NA CST EM LIGA 600 …...............................73

6.1. Parâmetros metalúrgicos .............................................................. 73

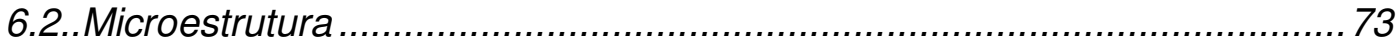

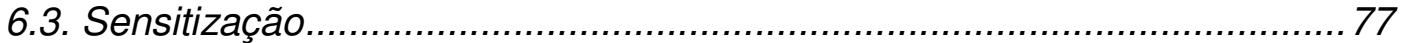

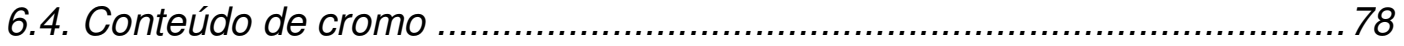

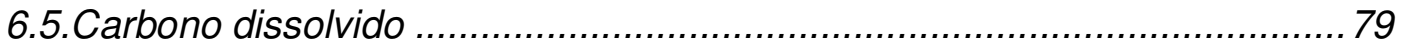

7. INFLUÊNCIA DE PARÂMETROS MECÂNICOS NA CST EM LIGA $600 \ldots . . . . . .80$

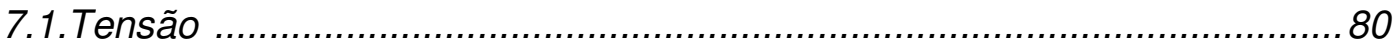

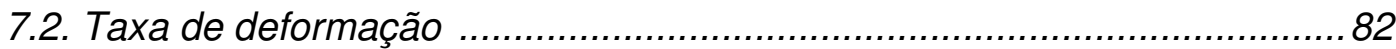

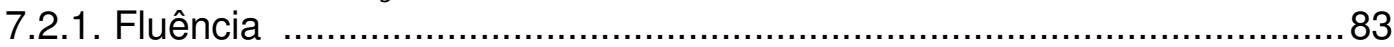

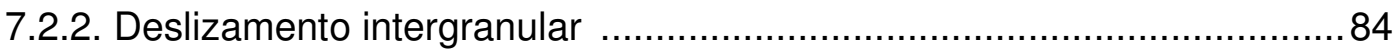

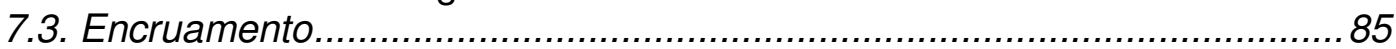

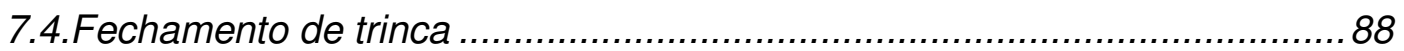

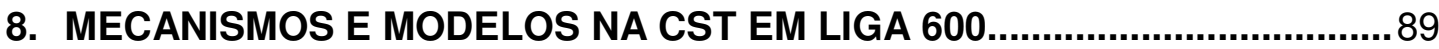

8.1. Mecanismo de dano por fluência .......................................................91

8.2. Mecanismo de dano por deslizamento intergranular ...............................93

8.3. Modelo de dissolução localizada pela ruptura do filme passivo .................94

8.4. Modelo semi-empírico de dano por taxa de deformação .......................... 102

8.5. Modelo de fratura acoplada ao ambiente ........................................... 105

8.6. Mecanismo e modelo de oxidação interna ........................................... 107

8.7. Mecanismos e modelos de trinca assistidos pelo hidrogênio .................... 114

8.7.1. Fragilização por diminuição da energia de superfície ............................116

8.7.2. Fragilização por decoesão …………………................................117

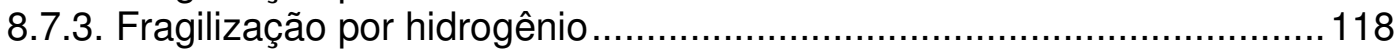

8.8. Mecanismo de formação de pressão interna de hidrogênio..................... 120

8.9. Mecanismos e modelos de interação entre corrosão e deformação.........121

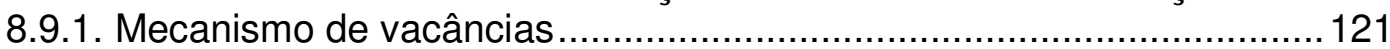

8.9.2. Modelo de corrosão assistida pela plasticidade .................................122

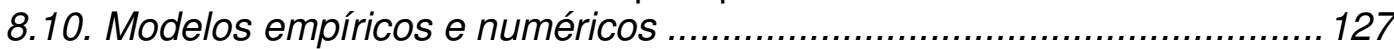

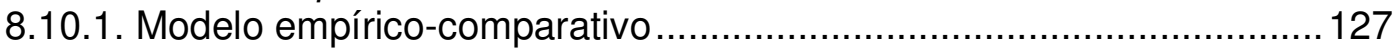

8.10.2. Modelo semi-empírico-probabilístico.............................................. 130

8.10.3. Modelo basedo na teoria da mobilidade acelerada............................. 133

8.10.4. Modelo numérico de Rebak e Smialowska ...................................... 138

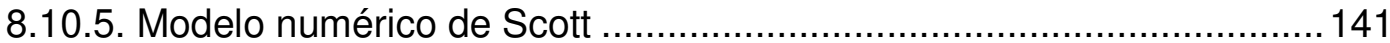

8.10.6. Modelo numérico de Lee e Hwang .................................................. 142

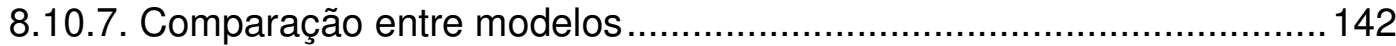


9.1. Construção do diagrama de Pourbaix para alta temperatura.................... 150

9.2. Diagrama tridimensional de resistência à CST ....................................... 153

9.3. Discussão das regiões de submodos ................................................ 154

9.4. Discussão da topografia do diagrama tridimensional.............................. 158

9.5. Vantagens e limitações do uso do diagrama tridimensional ..................... 163

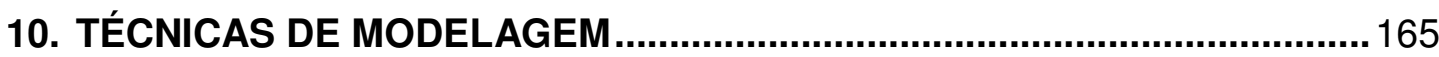

10.1. Técnica de modelagem aplicada ao modelo semi-empírico-probabilístico. 166

10.2. Técnica de modelagem aplicada ao modelo semi-empírico de dano por taxa de deformação 169

10.3. Técnica de modelagem aplicada ao modelo de dano por taxa de deformação simplificado. 180

10.4. Técnica de modelagem aplicada a ensaios de taxa de deformação lenta constante 186

10.5. Técnica de modelagem utilizando o diagrama mecânico-eletroquímico 194

11. CONSTRUÇÃO DOS MODELOS PROPOSTOS 196

11.1. Domínio da aplicação dos modelos ............................................... 196

11.2. Método e hipóteses para construção dos modelos ............................ 198

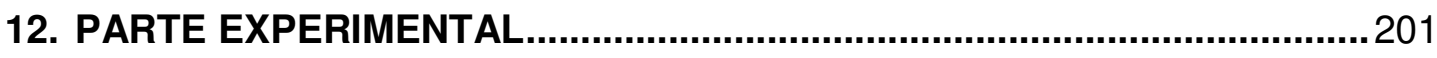

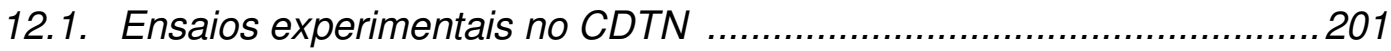

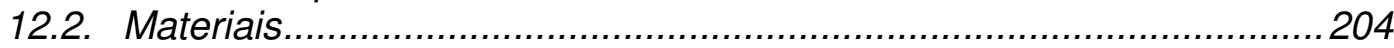

12.3. Resumo dos resultados dos ensaios ...........................................206

12.4. Cálculo estimativo do potencial medido pelo CDTN em relação ao padrão de hidrogênio e observações sobre o valor encontrado.............212

12.5. Dados da literatura utilizados para a representação gráfica de modelagem empírico-probabilistica..................................................217

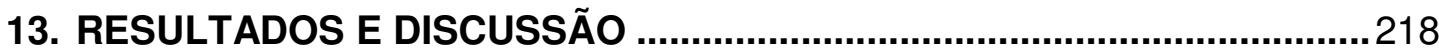

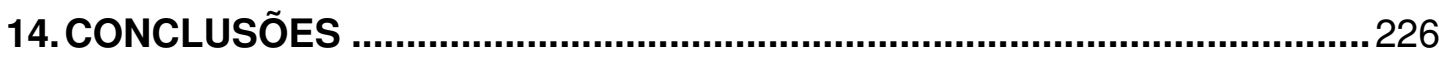

15. RECOMENDAÇÕES PARA PROSSEGUIMENTO DA PESQUISA ..............228

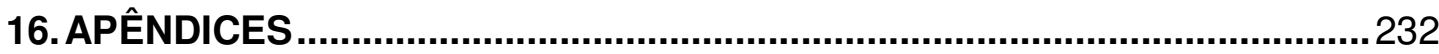

16.1. APÊNDICE 1: Distribuição de Weibull ..............................................233

16.2. APÊNDICE2:Planilha para aplicação em modelagem ..........................236

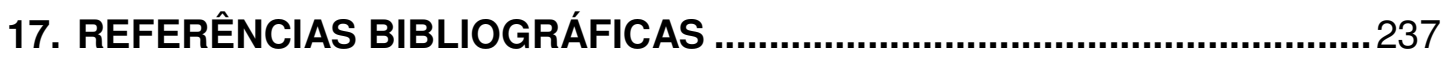




\section{LISTA DE TABELAS}

Página

Tabela 1.1. Composição química dos materiais envolvidos...................................

Tabela 1.2. Comparação entre propriedades mecânicas da liga 600 e do aço

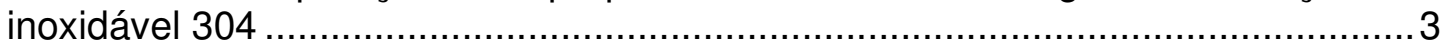

Tabela 2.1. Íons específicos e substâncias que causam CST ……........................ 18

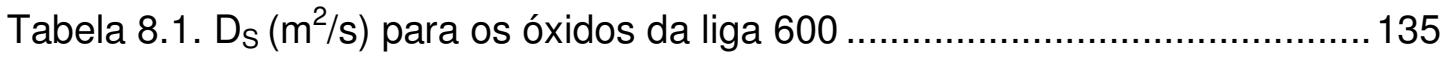

Tabela 8.2. Vantagens e limitações dos principais modelos ............................... 143

Tabela 10.1. Características microestruturais e propriedades de quatro condições

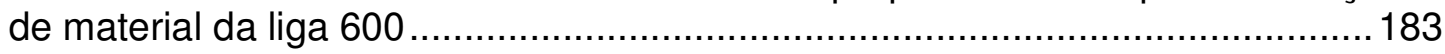

Tabela 10.2. Avaliação da dependência com a temperatura derivada dos tempos de falha através do modelo DTDC para as falhas por CSTAP da liga 600 .........185

Tabela 12.1. Composição química do Inconel 600 MA .......................................204

Tabela 12.2. Propriedades mecânicas do Inconel 600 MA ................................205

Tabela 12.3. Resultados obtidos nos ensaios SSRT do Inconel $600 \mathrm{MA}$ em ambiente de reator nuclear. Taxa de deformação: $3 \times 10^{-7} \mathrm{~s}^{-1}$ 209

Tabela 12.4. Valores do parâmetro de escala de Weibull baseado em inspeção para inclinação de Weibull $b=1,5$.

Tabela 13.1. Parâmetros de avaliação semi-quantitativa da CSTAP de acordo com ensaios do CDTN 


\section{LISTA DE FIGURAS}

\section{Página}

Figura 1.1. Estrutura metalográfica da liga 600 de tubo gerador de vapor, com ataque 2 eletrolítico no ácido ortofosfórico a $10 \%$

Figura 1.2. Perda de massa a $980^{\circ} \mathrm{C}$ da liga 600 comparativamente ao AISI 304.

Figura 1.3. Seção de corpo de prova de Inconel 600 trincado após ensaios de tensão 5 em água a $350^{\circ} \mathrm{C}$

Figura 1.4. Bocal do mecanismo de acionamento das barras de controle num reator tipo 6 RAP fabricado pela Westinghouse

Figura 1.5. Dano por corrosão generalizada causado pelo ácido bórico depositado através de vazamento por CSTAP através de bocal do MAB da Usina D. Besse

Figura 1.6. Diagramas potencial $\mathrm{x} \mathrm{pH}$ para a liga 600 na faixa de $300^{\circ} \mathrm{C}$ para a 15 condição de tratamento laminado e recozido ("mill annealed").

Figura 2.1. Esquema indicando no diagrama tensão $x$ deformação, a região de CSTAP, 16 para o Inconel 600

Figura 2.2. Esquema indicando no diagrama tensão $x$ deformação, a região de CSF 17

Figura 2.3. Ilustração dos processos de CST do mais químico ao mais mecânico 20

Figura 2.4. Esquema ilustrativo da relação entre CST, CSF e FPH. 23

Figura 2.5. Diagrama de diferentes caminhos de trinca como função do nível de tensões 24

Figura 2.6. Variação na velocidade de crescimento de trinca por CST com o fator de 26 intensidade de tensões

Figura 2.7. Esquema de cinco modos intrínsecos de corrosão 26

Figura 2.8. Esquema das regiões de CST em função do potencial relacionado com uma 28 curva de polarização ativa-passiva

Figura 2.9. Esquema do (a)diagrama de modo de corrosão; (b) diagrama da definição do meio; (c) sobreposição de (a) e (b)

Figura 2.10. Nos diagramas são ilustrados o diagrama de fase e as curvas TTT São mostrados também o diagrama de Pourbaix e as curvas de polarização

Figura 2.11. Esquema da concentração versus distância dos contornos de grão para circunstâncias onde os precipitados são formados

Figura 2.12. Esquema mostrando a profundidade de uma trinca por CST como uma 35 mistura de processos determinísticos e estocásticos

Figura 2.13. Função densidade de probabilidade para a distribuição de Weibull 37

Figura 2.14. Distribuição acumulativa linearizada de Weibull 38

Figura 2.15. Efeito da tensão na taxa de falha cumulativa do Zircaloy-2 em iodo gasoso 39

Figura 2.16. (a) Gráfico esquemático da probabilidade acumulativa de curvas para altas 40 temperaturas e para temperatura de referência (b) $1 / T$ versus tempo

Figura 2.17. Exemplo de adição de distribuições acumulativas para os casos distintos de 42 falhas numa usina nuclear

Figura 2.18. Equipamento especial de inspeção para os bocais do mecanismo de 43 
acionamento das barras de controle de reator de água pressurizada

Figura 3.1. Região da solda dissimilar tipo "J", entre os bocais do MAB e a carcaça do 45 tampo do vaso tipo RAP

Figura 3.2. Trincas de CSTAP da liga $600,360^{\circ} \mathrm{C}$, tração lenta 48

Figura 3.3. Evolução em etapas discretas na iniciação e propagação da CST 51

Figura 3.4. Esquema de Gardey da morfologia dos óxidos da Liga 600 em água 52 primária a $325^{\circ} \mathrm{C}$ e $350^{\circ} \mathrm{C}$

Figura 3.5. Esquema representativo dos resultados de observações através de MET 53 numa trinca por CST na liga 600

Figura 4.1. Gráfico da dependência potencial-pH de casos de equilíbrio de oxidação 57 comparados a $25^{\circ} \mathrm{C}$ : adaptado do Atlas de Pourbaix

Figura 4.2. Esquema da corrosão por pite

Figura 5.1. Vários processos envolvidos na fragilização por hidrogênio de ligas ferrosas

Figura 5.2. Esquema mostrando a diferença de trinca de corrosão sob tensão anódica e fragilização por hidrogênio catódica

Figura 5.3. (a) Efeito da pressão parcial de hidrogênio sobre o tempo de indução de CSTIG (b) Efeito da pressão de hidrogênio na CSTIG do Inconel 600

Figura 5.4. Influência do hidrogênio sobre a velocidade de propagação da CST na Liga 600: tubos pré- trincados a $360^{\circ} \mathrm{C}$

Figura 5.5. Influência de sobre tensão catódica sobre a CST da liga 600 em água primária a $350^{\circ} \mathrm{C}$, para pressões parciais de $\mathrm{H}_{2}$ de $5 \mathrm{kPa}$ e de $100 \mathrm{kPa}$

Figura 5.6. Curvas de polarização do $\mathrm{Ni}$, do $\mathrm{Cr}$ e do $\mathrm{Fe}$ e da liga 600 em água primária com ácido bórico $0,01 \mathrm{M} \mathrm{e} \mathrm{T}=350^{\circ} \mathrm{C}$

Figura 5.7. Transitórios de corrente de repassivação da liga 600 em meio primário a $288^{\circ} \mathrm{C}$ após depassivação por tração rápida

Figura 6.1. Diferentes tipos de microestrutura da liga 600 segundo o tratamento térmico. Ataque efetuado com ácido ortofosfórico

Figura 6.2. Efeito dos carbonetos (a) intergranulares e (b) intragranulares sobre as 76 discordâncias

Figura 6.3. Esquema representando a sensitização para aço inoxidável 304

Figura 6.4. Esquema da reatividade química nos grãos e seus contornos de um aço inoxidável quando afetado pela depleção de cromo

Figura 7.1. Localização de trincas em bocal do MAB da Usina de Bugey 3

Figura 7.2. Influência do encruamento superficial sobre a profundidade máxima das trincas da Liga 600 em ensaio à carga constante a $360^{\circ} \mathrm{C}$

Figura 7.3. Dados de velocidade de propagação de trinca de espécimes de Inconel 82 e 600 ensaiados com razão de carga $\mathrm{R}=0,7$ e $1 \mathrm{~Hz}$.

Figura 8.1. Esquema ilustrativo das diferentes etapas do mecanismo de CST induzido por deslizamento intergranular

Figura 8.2. (Acima) Esquema de ruptura de filme passivo (Abaixo) Esquema de deformação plástica na trinca

Figura 8.3. Influência da cinética de repassivação de acordo com Staehle 97

Figura 8.4. Comparação entre valores de velocidade de propagação de trinca preditos 100 pelo modelo de Ford e Andresen e os dados experimentais

Figura 8.5. Comparação entre valores de velocidade de propagação de trinca preditos 108 pelo modelo da oxidação interna e os dados experimentais 
Figura 8.6. Representação esquemática dos mecanismos propostos para o tempo de iniciação à trinca de CSTAP na liga 600

Figura 8.7. Esquema do $\operatorname{MCAP}(\mathrm{CEPM})$, da $1^{\mathrm{a}}$. à $5^{\mathrm{a}}$. etapa e da formação de 124 empilhamento

Figura 8.8. Esquema de uma máquina de ETDL - ensaio por taxa de deformação lenta 128 ou "slow strain rate testing"

Figura 8.9. Gráfico comparativo entre a velocidade de propagação predita pelo modelo 135 de Galvele e dados experimentais

Figura 8.10. Gráfico comparativo entre a velocidade de propagação predita pelo modelo numérico de Rebak \& Smialowska et al. e dados experimentais

Figura 8.11. Dados experimentais recolhidos para o gráfico $\mathrm{V}_{\mathrm{CST}}$ versus $\mathrm{K}_{\mathrm{I}}$ para amostras de tubos de liga 600 ensaiados com carga constante

Figura 9.1. Diagrama modal tridimensional para a Liga 600 em água pura a $300^{\circ} \mathrm{C}, 153$ indicando a resistência útil à CST versus potencial \& pH (base).

Figura 9.2. Diagrama de Pourbaix, potencial versus pH para o níquel em água pura a 155 diversas temperaturas

Figura 9.3. Modos de corrosão para a liga 600 na faixa de $300^{\circ} \mathrm{C}$ plotados num 156 diagrama potencial $\mathrm{pH}$ para o ferro e o níquel

Figura 9.4. Diferentes cortes da Figura 9.1

Figura 9.5. Cortes bi -dimensionais da Figura 9.1, onde é mostrada a fração de tensão de escoamento versus potencial em três valores constantes de $\mathrm{pH}$

Figura 10.1. Relação simplificada para a dependência com a tensão do tempo de iniciação para a CSTAP - modelo de dano por taxa de deformação

Figura 10.2. Relação simplificada para a dependência com a temperatura do tempo de 186 iniciação para a CSTAP - modelo de dano por taxa de deformação

Figura 10.3. Convenção geométrica aplicável a corpos de prova de ensaios de taxa de 187 deformação constante

Figura 10.4. Algumas distribuições de profundidade de traço a partir de ensaio de corpos de prova por taxa de deformação constante $\dot{\mathrm{e}}=2,5.10^{-7} \mathrm{~s}^{-1}$

Figura 10.5. ETDL feitos até a ruptura com diferentes taxas de deformação: representado um conjunto de curvas computadas $\mathrm{N}(\mathrm{I}, \mathrm{T})$

Figura 10.6. Diagrama mecânico-eletroquímico para a CST de um aço inoxidável tipo 195 304 em água a $288^{\circ} \mathrm{C}$

Figura 11.1. Diagrama de Pourbaix bidimensional $\mathrm{E} \times \mathrm{pH}$ para a liga 600 na faixa de 200 $300^{\circ} \mathrm{C}$ sobre a qual foram marcadas as regiões de submodos de corrosão

Figura 12.1. Instalação no CDTN para ensaios de corrosão sob tensão 202

Figura 12.2. Esquema do circuito de água do equipamento de ensaios de CST instalado 202 no CDTN

Figura 12.3. Microestrutura do Inconel 600MA como recebido. Micrografia em ácido 205 fosfórico a $10 \% .100$ vezes

Figura 12.4. Espécime de tração utilizado nos ensaios de taxa de deformação lenta 206 (ETDL)

Figura 12.5. Curva tensão-deformação dos espécimes de Inconel 600 MA 207

Figura 12.6. Curva Tensão-Tempo dos espécimes de Inconel 600 MA 207

$\begin{array}{lll}\text { Figura 12.7. Espécimes de Inconel 600MA } & 208\end{array}$

Figura 12.8. Perfis de fratura dos espécimes de Inconel 600 MA 209 
Figura 12.9. Microfratografias MEV aumento de 500 vezes das superfícies laterais dos 210 espécimes de Inconel 600 MA.

Figura 12.10. Microfratografias MEV, aumento de 500 vezes. Superfícies laterais dos 211 espécimes de Inconel 600 MA

Figura 12.11. Microfratografias MEV, aumento de 20 vezes. Superfícies de fratura dos 211 espécimes de Inconel 600 MA

Figura 12.12. Microfratografias MEV, aumento de 1000 vezes. Superfícies laterais dos 212 espécimes de Inconel 600 MA.

Figura 12.13. Gráfico do $\mathrm{pH}$ em função da temperatura para água do circuito primário 212 fornecido pelo CDTN

Figura 12.14. Reprodução da Figura 11.1 de [STAEHLE, 1992a]: marcado o ponto 216 encontrado nos experimentos eletroquímicos do CDTN.

Figura 13.1. Diagrama das retas plotadas para a Tabela 12.4 comparadas com a reta 221 hipotética a partir da modelagem 'semi-empírica nesta pesquisa

Figura 15.1. Regiões de susceptibilidade à corrosão sob tensão superpostas sobre 230 combinações de temperatura/ teor de oxigênio

Figura 16.1. Curvas da família de distribuições de Weibull para diferentes parâmetros de 234 forma $\beta$ 


\section{LISTA DE ABREVIATURAS, ACRÔNIMOS E SÍMBOLOS}

AEPC Anos Efetivos a plena Carga, correspondente a EFPY = Effective Full Power Years

ASM American Society of Metals

ASME American Society of Mechanical Engineers

b Inclinação de Weibull

CCC Cúbico de Corpo Centrado

CDTN Centro de Desenvolvimento de Tecnologia Nuclear, localizado em Belo Horizonte-MG

CEPM Corrosion Enhanced Plasticity Model=MCAP

CERT Constant Extension Rate Test=ETDL ou SSRT

CNTP Condição Normal de Temperatura e Pressão $\left(25^{\circ} \mathrm{C}, 1 \mathrm{~atm}\right)$

CFC Cúbico de Face Centrada

CSF Corrosão Sob Fadiga

CST Corrosão Sob Tensão

CT Compact Tension especimen =espécime (corpo de prova) de tração compacto

CSTIG Corrosão Sob Tensão Intergranular

CSTTG Corrosão Sob Tensão Transgranular

CSTAP Corrosão Sob Tensão em Água do circuito Primário (também denominada "Água Pura")

Ds Coeficiente de difusividade superficial $\left[\mathrm{m}^{2} / \mathrm{s}\right]$

EAC Environment Assisted Crack (Trinca Assistida pelo Ambiente)

EdF Eletricité de France

EDL Espectroscopia por Descarga Luminescente

EDX Espectroscopia de Energia Dispersa por Raio-X

EFX Espectroscopia Fotoeletrônica por Raio-X (XPS) 
EMIS Espectroscopia de Massa por Íons Secundários

EPRI Electric Power Research Institute

EPUSP Escola Politécnica da Universidade de São Paulo

ETDL Ensaio de Taxa de Deformação Lenta, CERT ou SSRT

$t_{f} \quad$ taxa de falha

F taxa de falha acumulada

FPH Fragilização Por Hidrogênio

HELP Hydrogen Enhanced Localised Plasticity =PLAH, (Plasticidade Localizada Assistida pelo Hidrogênio)

IAEA International Atomic Energy Agency

IPEN Instituto de Pesquisas Energéticas e Nucleares, São Paulo

J Joule.

$\mathrm{K}_{\mathrm{l}} \quad$ fator de intensidade de tensão no modo I (tração)

$\mathrm{K}_{\mathrm{I}}$ fator de intensidade de tensão no modo I crítico

K ICST fator de intensidade de corrosão sob tensão no modo I (tração)

MA Mill Annealed = Laminado e Recozido

MAB Mecanismo de Acionamento das Barras de controle

MCAP Modelo de Corrosão Assistida pela Plasticidade=CEPM

MEA Microscopia Eletrônica Analítica

MET Microscópio Eletrônico de Transmissão

MO Metalografia Óptica

n expoente de tensão

PLAH Plasticidade Localizada Assistida pelo Hidrogênio = HELP (Hydrogen Enhanced Localised Plasticity)

Q Energia de ativação

R constante universal dos gases 


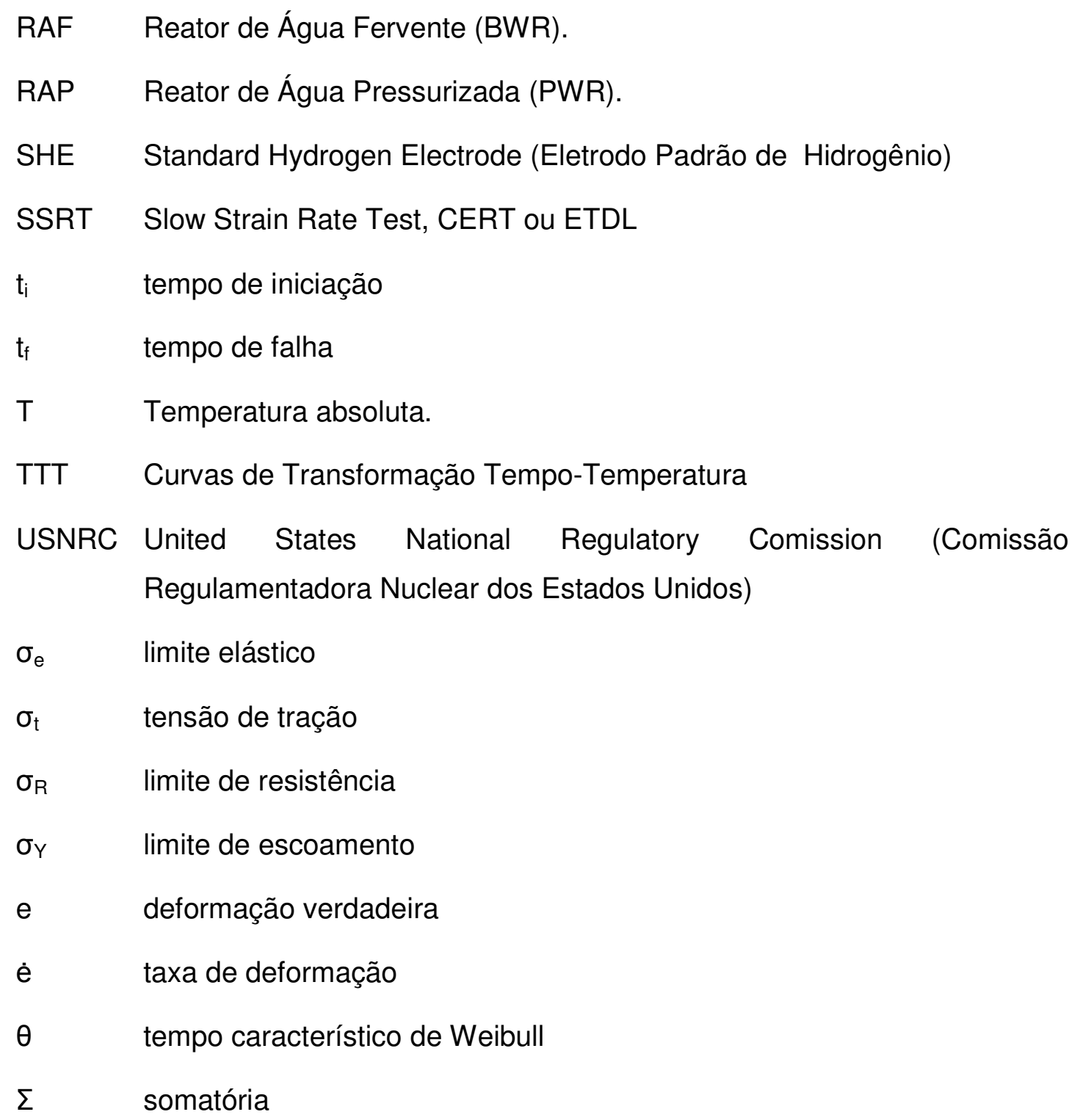

Nota: foram considerados somente os símbolos mais utilizados. A simbologia restante está indicada após as expressões matemáticas envolvendo-as. 


\section{GLOSSÁRIO DE TERMOS E ACRÔNIMOS}

Nota: adaptado de [GORMAN \& STAEHLE, 1989].

AEPC = Anos Efetivos a plena Carga, correspondente a EFPY=Effective Full Power Years. Esse tempo é definido como uma medida da vida de uma planta em anos a $100 \%$ da carga e representa a energia produzida acumulada até o tempo considerado. Por exemplo, 1 AEPC (EFPY) equivale a 365 dias a 100\% da carga ou 730 dias a $50 \%$ da carga, etc. Ou ainda um ano a $100 \%$ da carga seguido de um período parado: se, por exemplo, a planta funciona um ano a plena carga e passa um ano parada, o AEPC considerado para esses dois anos =1 ano.

Barreira de Lomer Cottrell = ou LC: barreira formada quando duas discordâncias deslizantes $B C$ no plano $d=\left(\begin{array}{lll}1 & 1 & 1\end{array}\right)$ e $C D$ no plano $b=\left(\begin{array}{lll}1 & \overline{1} & \overline{1}\end{array}\right)$ colidem e deslizam ao longo da direção AC, conforme Figura 3 "Notação do tetraedro de Thompson para sistemas deslizantes tipo CFC" e Figura 4 de [CAI et al., 2004].

Corrosão em frestas= Tipo de corrosão onde uma condição local (fresta) é suficiente para que ocorra corrosão independente da condição geral do meio. Por exemplo, na região mandrilada de um tubo de trocador de calor, podem ocorrer condições específicas (depósitos locais, menor teor de oxigênio na água, maior $\mathrm{pH}$, maior temperatura, etc.) que produzam uma célula de diferente potencial eletroquímico que venha a causar uma condição especifica de corrosão naquele local.

Corrosão intergranular $(I G)$ = Tipo de corrosão onde os contornos de grão no material são atacados de uma maneira aproximadamente uniforme sobre uma área relativamente grande.

Corrosão por pite = Tipo de corrosão provocada por ataque corrosivo muito localizado, iniciando-se pela quebra do filme passivo em regiões com danos 
mecânicos ou químicos a esse filme, defeitos como inclusões, discordâncias, contornos de grão ou interfaces, provocando perfurações no metal, pequenas e profundas denominadas "pites" (do inglês "poços"). Espécies ácidas como $\circ \mathrm{Cl}$; $\mathrm{SO}_{4}^{--}$, mantém os produtos de corrosão solúveis no interior das perfurações enquanto o pite avança por dissolução do metal: os elétrons decorrentes dessa dissolução combinam por exemplo, com o oxigênio do meio, reduzindo-o à água e formando uma célula de dissolução eletroquímica. A corrosão por pite pode servir como iniciadora de um processo mais amplo de corrosão sob tensão.

Corrosão seletiva ou dissolução de liga = Corresponde ao inglês "dealloying" e é o processo de corrosão onde o componente mais ativo da liga dissolve preferencialmente, deixando uma estrutura do componente de liga mais nobre. No circuito secundário do reator, esse processo pode contribuir para enriquecer o níquel na superfície dos tubos de Inconel 600 e acelerar o par galvânico formado entre o Inconel 600 e os suportes dos tubos de aço carbono.

Corrosão sob tensão (CST) = Tipo de corrosão que ocorre através de um processo no qual as trincas induzidas por corrosão se propagam através de um material exposto a tensões de tração.

Corrosão sob tensão em água do circuito primário (CSTAP) = Tipo de CSTIG que ocorre na água do circuito primário de um reator ou lado de resfriamento (lado interno) de um aquecedor tubular gerador de vapor de um reator. Corresponde ao acrônimo em inglês PWSCC ("primary water stress corrosion cracking"). Esse tipo de corrosão é muito próximo daquele definido como "corrosão sob tensão em água pura", também conhecida como corrosão de Coriou (pesquisador que a identificou em 1959). PWSCC é assim algumas vezes utilizado para designar corrosão sob tensão em água pura tanto quanto para designar corrosão sob tensão em água do circuito primário. .

Corrosão sob tensão intergranular $(C S T I G)=$ Tipo de corrosão sob tensão onde as trincas propagam ao longo dos contornos de grão no material. 
Corrosão sob tensão transgranular (CSTTG) = Tipo de corrosão sob tensão onde as trincas propagam através dos grãos no material.

Corrosão transgranular $(\mathrm{TG})=$ Tipo de corrosão onde os grãos no material são atacados de uma maneira aproximadamente uniforme sobre uma área relativamente grande.

Defeito= Termo que se aplica a quaisquer anomalias em um determinado material que pode levar a uma falha, isto é, ao não cumprimento de uma determinada função de um componente fabricado com esse material.

Deformação convencional (engenharia) = Variação de comprimento em relação a um comprimento inicial de um determinado componente de um determinado material. Matematicamente $\mathrm{e}=\Delta \mathrm{L} / \mathrm{L}_{0}$.

Deformação verdadeira $=$ Matematicamente $\mathrm{e}=\ln \left(\mathrm{L} / \mathrm{L}_{0}\right)$.

Diagrama de Ellingham = variação da função de Gibbs, $\Delta G^{0}=\Delta H^{0}-\mathrm{T} \Delta S^{0}$, com a temperatura para a formação de óxido por mol de $\mathrm{O}_{2}$ consumido.

Eletrodo padrão de hidrogênio = consiste numa barra de platina platinizada imersa numa solução ácida padrão $1,2 \mathrm{M} \mathrm{HCl}$, na qual a atividade do $\mathrm{H}_{2}$ é unitária e através da qual se borbulha hidrogênio purificado a $1 \mathrm{~atm}$ ou $\sim 0,1 \mathrm{MPa}$ de pressão.

Ensaio de Taxa de Deformação Lenta = Ensaio de Taxa de deformação lenta e constante que permite causar em laboratório o surgimento de trinca por CST. Corresponde aos acrônimos em inglês CERT ("Constant Extension Rate Test") ou

SSRT (“Slow Strain Rate Test”).

Falha $=$ Ver Defeito 
Falha de Empilhamento ("Stacking-Fault")= Situação de desordenação de empilhamento de planos de deslizamento numa determinada estrutura cristalina, que pode provocar movimento de discordâncias que causarão início de fratura e/ou os defeitos no material.

Fator de Intensidade de Tensão $(\mathrm{K})$ =Fator correlacionando tensão e geometria de um componente sujeito a um carregamento que exprime adequadamente sua resistência à fratura. Sua unidade é [K]=[FORÇA]. [COMPRIMENTO] ${ }^{1 / 2}$.

Força motriz $=$ Expressão utilizada em ciência dos materiais para designar uma grandeza ativa num determinado processo (pode não ser necessariamente uma força).

Inconel $600=$ Nome comercial às vezes dado à liga 600 .

Laminação e Recozimento= Tratamento termomecânico sofrido pela Liga 600 para se obter recristalização e uma alta resistência relativa no material. Essa condição torna esse material altamente susceptível à CSTAP e CSTIG cáustica. Corresponde ao inglês "Mill Annealing". A laminação e recozimento à baixa temperatura (LTMA=“Low Temperature Mill Annealing”) é feita a cerca de $980^{\circ} \mathrm{C}-$ utilizada pela Westinghouse: produz alta resistência mas alta susceptibilidade à CST. A laminação e recozimento à alta temperatura (HTMA="High Temperature Mill Annealing") é feita a cerca de $1040^{\circ} \mathrm{C}$ ou mais - utilizada pela Babcock \& Wilcox e Combustion Engineering: produz resistência mecânica menor do que a LTMA mas também menor susceptibilidade à CST.

Modelo=Descrição de um mecanismo ou processo que leva a uma determinada falha, como CSTAP na Liga 600 à alta temperatura, neste texto.

Modelagem = Descrição matemática de um determinado modelo, de modo que permita quantificar os seus efeitos, como tamanho da trinca, velocidade de propagação da trinca, tempo de iniciação, tempo de falha, etc. 
$\mathrm{pH}=$ É a medida da concentração do cátion hidrogênio que controla a acidez e alcalinidade. Matematicamente, $\mathrm{pH}=\operatorname{colog}[\mathrm{H}]^{+}$. $\mathrm{pH}<7$ corresponde a uma solução ácida; $\mathrm{pH}=7$ a uma solução neutra e $\mathrm{pH}>7$ a uma solução básica. $\mathrm{O}$ pH de uma solução normalmente varia quando sua temperatura varia: por exemplo, a água pura que tem um pH de 7,0 na temperatura ambiente, tem um pH de cerca de 5,6 nas temperaturas típicas do gerador de vapor.

Potencial de eletrodo padrão $=$ Potencial de equilíbrio numa reação eletroquímica quando as atividades de seus reagentes e produtos são unitárias $\left(E^{0}\right)$.

ppm $=$ Partes por milhão em peso de uma determinada substância. 10000 ppm corresponde a $1 \%$.

Sensitização = Condição dos aços inoxidáveis e Ligas do tipo Inconel na qual os materiais tornam-se mais sensíveis ou susceptíveis à corrosão em meios ácidos oxidantes como resultado de seu tratamento térmico. A sensitização é o resultado de uma redução localizada na concentração de cromo nos contornos de grão do metal causada pela precipitação de carbonetos de cromo que ocorrem durante o tratamento térmico.

Submodos $=$ Regiões definidas para uma combinação material-meio sobre um diagrama eletroquímico (como potencial $\mathrm{x} p \mathrm{pH}$ ou potencial $\mathrm{x}$ densidade de corrente), susceptível a certos tipos de corrosão ou imunidade à corrosão. Assim, há submodos de corrosão sob tensão, pite, corrosão generalizada ou passividade.

Tempo de Iniciação= Refere-se ao tempo de iniciação de um defeito, como trinca, num determinado material: às vezes chamado de tempo de incubação ou tempo que esse defeito demora para aparecer no material.

Tempo de Falha $=$ Tempo decorrido para aparecer no material uma determinada falha. Por exemplo, o tempo de falha de um determinado tubo pode ser definido como o tempo de iniciação da falha (às vezes chamado de tempo de incubação ou tempo que essa falha demora para aparecer no material) mais o tempo de propagação dessa falha através de uma espessura pré-determinada, por 
exemplo, $40 \%$ da espessura de parede: normalmente a partir dessa espessura $\circ$ tubo precisa sofrer uma intervenção de manutenção.

Taxa de Deformação= Variação da deformação com o tempo. No SI sua unidade é s ${ }^{-1}$.

Tensão= Tensão é uma medida da força em uma determinada área que tende a deformar um determinado material. Sua medida em unidades SI é Pascal (Pa) ou força em Newtons $(\mathrm{N})$ dividida pela área $\left(\mathrm{m}^{2}\right)$.

Tensão de escoamento = Valor da tensão além da qual o material não mais se comporta elasticamente e se torna plasticamente deformável.

Tensão de fluxo = média da tensão em que se inicia o regime plástico e da última tensão (antes da ruptura) em que domina o regime plástico.

Tensões aplicadas $=$ tensões devidas a cargas aplicadas ou condições como gradientes de pressão ou temperatura; as tensões aplicadas desaparecem quando suas forças-causa são removidas.

Tensões residuais = tensões intrínsecas ao material e não desaparecem quando suas condições de aplicação são removidas. As tensões residuais são freqüentemente resultado das deformações plásticas do material.

Trinca assistida pelo ambiente $=$ Corresponde ao acrônimo inglês EAC ("Environment assisted crack") e se refere aos tipos de trinca que recebem influência do ambiente: corrosão sob tensão, corrosão sob fadiga, fragilização por hidrogênio.

USNRC = Comissão Regulatória Nuclear dos Estados Unidos ou "United States National Regulatory Comission": órgão governamental norte americano com jurisdição concedida por seu estatuto, sobre a operação segura das usinas nuclearesnorteamericanas 


\section{INTRODUÇÃO}

A degradação de alguns materiais estruturais durante a operação de reatores nucleares com água pressurizada (RAP), representa um dos principais fatores técnicos que podem limitar a eficiência e viabilidade das plantas de energia nuclear. A experiência acumulada com reatores comerciais mostra a necessidade de melhorar o entendimento dos fenômenos relativos aos materiais principalmente à corrosão e irradiação - e procedimentos analíticos para o uso das informações obtidas nos testes que permitam estimar a sua vida útil [ROBERTS, 1981].

Dentre os principais modos de degradação que atingem os RAP, destacase a fratura por corrosão sob tensão pela água do circuito primário (CSTAP), onde são predominantes tensões de tração, altas temperaturas de operação e microestruturas susceptíveis a esse tipo de trinca. As trincas podem produzir acidentes decorrentes de falhas que provocam seccionamento de componentes estruturais, dos bocais do mecanismo de acionamento das barras de controle (MAB) [USNRC, 2001] ou perda de refrigerante [SHAH et al, 1994].

A maior parte dos reatores nucleares tipo RAP construídos e em operação no mundo ocidental, têm os bocais de penetração do mecanismo de acionamento das barras de controle do reator de água pressurizada (MAB) feitos de aço inoxidável, liga 600 (ASME-SB-166 [ASME, 1998]) e outros materiais cujas composições estão indicadas na Tabela 1.1.

A liga 600 é uma superliga austenítica $75 \mathrm{Ni} 15 \mathrm{Cr}$-Fe, com alta resistência mecânica, resistência à corrosão e à oxidação, em temperaturas elevadas. $\mathrm{O}$ material tem estrutura cristalina cúbica de face centrada (CFC). É utilizada principalmente em indústrias de processamento, química, energética e nuclear. As principais aplicações nucleares são: tubos trocadores de calor, geradores de vapor, luvas e bocais de vasos de RAP [BUSO, 2001].

Os principais marcos históricos para a obtenção da liga 600 foram:

1751- Descoberta do níquel por Cronstedt (Suécia).

1803- Primeiro refino do níquel (Richter). 
1889- Processo de extração do níquel (Mond Carbonyl Process). Fundação da International Nickel Company. Descoberta das Ligas Inconel.

1932- O Inconel 600 aparece para uso na indústria de processamento de alimentos/laticínios [BUSO, 2001].

Normalmente esses bocais são laminados e recozidos ("mill annealed"), para haver uma recristalização que dê uniformização na estrutura cristalina do material após fabricação. Por exemplo, uma placa de espessura 50,8mm, é aquecida a $9820 \mathrm{C}$ por 1 hora e resfriada ao ar.

Na Figura 1.1 é mostrada uma microestrutura típica para uma amostra dessa liga de um tubo gerador de vapor laminado e recozido por 2 minutos e 30s à $930^{\circ} \mathrm{C} \pm 15^{\circ} \mathrm{C}$, tamanho de grão 6-10 G (ASTM), d 11-45 $\mu \mathrm{m}$ e tipo de estrutura com precipitados principalmente intragranulares formando uma rede envelhecida de contornos de grãos [FOCT, 1999].

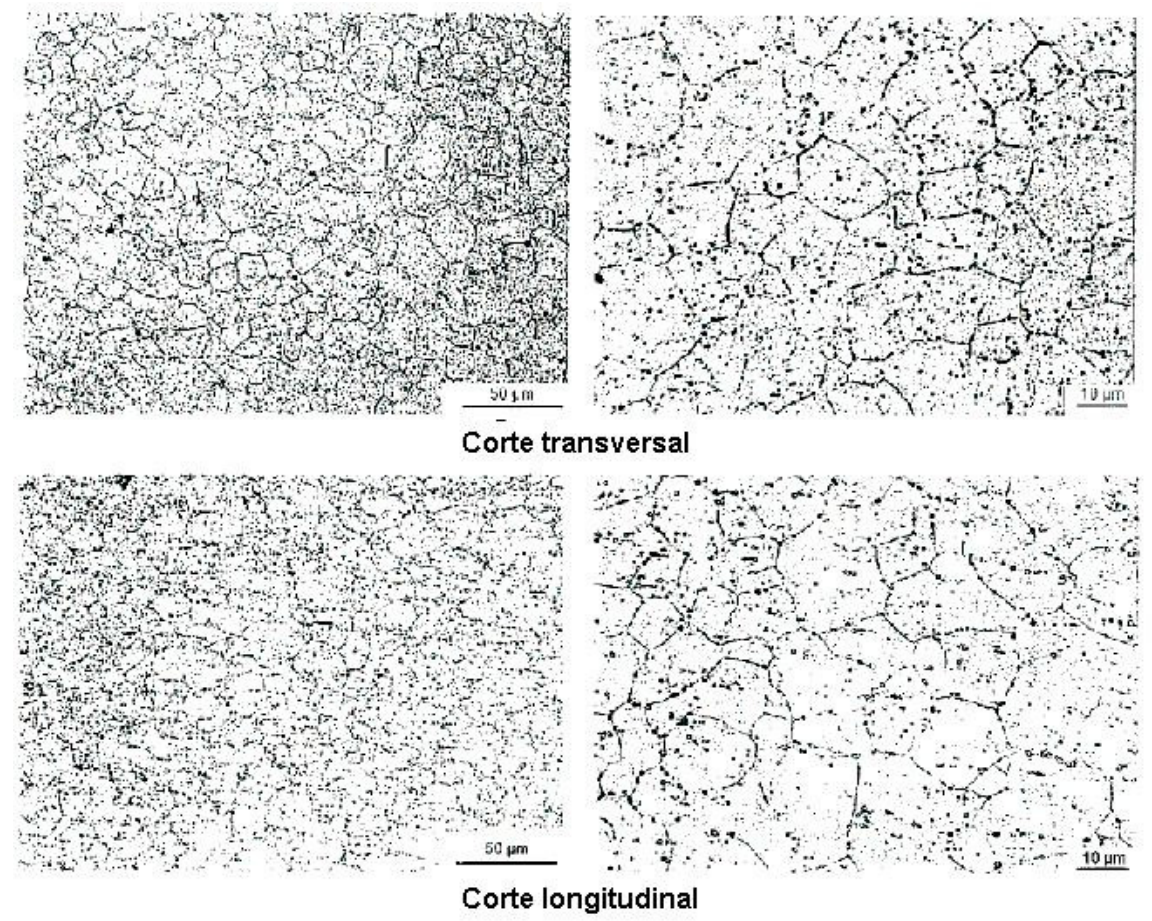

Figura 1.1. Estrutura metalográfica da liga 600 de tubo gerador de vapor, com ataque eletrolítico no ácido ortofosfórico a 10\% [FOCT, 1999]. 
Tabela 1.1. Composição química dos materiais envolvidos na construção dos bocais do MAB [ASME, 1998], [CHIAVERINI, 1982], [RINCKEL, 1998], [SHAH et al, 1994], [STAEHLE, 2001].

\begin{tabular}{ccccccccc}
\hline \hline $\begin{array}{c}\text { Compo- } \\
\text { sição } \\
(\%)\end{array}$ & $\begin{array}{c}\mathrm{Ni} \\
(\mathrm{min})\end{array}$ & $\mathrm{Cr}$ & $\mathrm{Fe}$ & $\begin{array}{c}\mathrm{Mn} \\
(\mathrm{max})\end{array}$ & $\begin{array}{c}\mathrm{C} \\
(\mathrm{max})\end{array}$ & $\begin{array}{c}\mathrm{Si} \\
(\max )\end{array}$ & $\begin{array}{c}\mathrm{S} \\
(\max )\end{array}$ & $\mathrm{Nb}+\mathrm{Ta}$ \\
\hline liga 600 & 72,0 & $\begin{array}{r}14,0- \\
17,0\end{array}$ & $\begin{array}{c}6,0- \\
10,0\end{array}$ & 1,0 & 0,15 & 0,5 & 0,015 & - \\
\hline liga 182 & 59,0 & $\begin{array}{c}13,0- \\
17,0\end{array}$ & 10,0 & - & 0,10 & - & - & $1,0-2,5$ \\
\hline liga 82 & $\begin{array}{c}67,0 \\
(\mathrm{Ni}+\mathrm{Co})\end{array}$ & $\begin{array}{c}18,0- \\
22,0\end{array}$ & 3,0 & - & 0,10 & - & - & $2,0-3,0$ \\
\hline $\begin{array}{c}\text { aço } \\
\text { inoxidável } \\
\text { A 316 }\end{array}$ & $\begin{array}{c}10,0- \\
14,0\end{array}$ & $\begin{array}{c}16,0- \\
18,0\end{array}$ & balanço & 2,0 & 0,10 & 1,0 & & $\begin{array}{c}(2,0-3,0 \\
\text { de Mo) }\end{array}$ \\
\hline
\end{tabular}

A liga 600 tem excelente resistência à corrosão, tanto em ambientes oxidantes como em redutores, bem como resistência ao ácido bórico. Na Tabela 1.2 é mostrada uma comparação entre as principais propriedades dessa liga e as do aço inoxidável 304.

Tabela 1.2. Comparação entre propriedades mecânicas da liga 600 e do aço inoxidável 304 [SPECIAL METALS, 2004], [SCHVARTZMAN et al., 2005].

\begin{tabular}{ccc}
\hline \hline & liga 600 & AISI 304 \\
\hline Composição & $75 \mathrm{Ni} 15 \mathrm{Cr} 9 \mathrm{Fe}$ & $10 \mathrm{Ni} \mathrm{18} \mathrm{Cr} \mathrm{Fe}$ \\
\hline Dureza (Brinell) & 170 & $160-190$ \\
\hline $\begin{array}{c}\text { Limite de Resistência } \\
(\mathrm{MPa})\end{array}$ & 655 & 755 \\
\hline $\begin{array}{c}\text { Limite de escoamento } \\
(\mathrm{MPa})\end{array}$ & 310 & 266 \\
\hline $\begin{array}{c}\text { Alongamento em 50mm } \\
(\%)\end{array}$ & 40 & $50-60$ \\
\hline
\end{tabular}

Na Figura 1.2 é mostrada uma comparação entre as perdas de massa resultantes de oxidação à alta temperatura das liga 600 e do aço inoxidável 304 [SPECIAL METALS, 2004], 


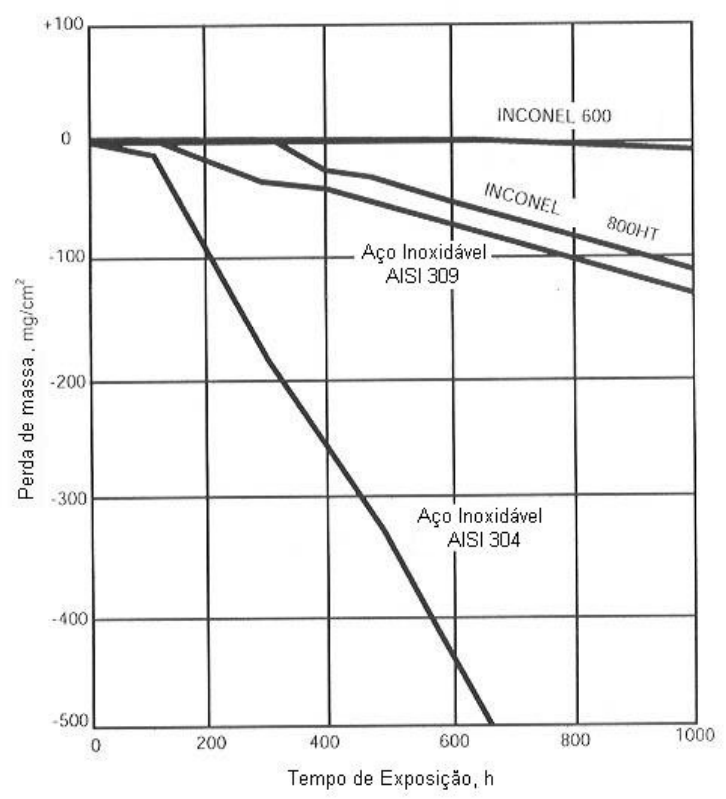

Figura 1.2. Perda de massa a $980^{\circ} \mathrm{C}$ da liga 600 comparativamente ao AISI 304 [SPECIAL METALS, 2004].

Nota-se nessa Figura que a liga 600 praticamente não perde massa com a exposição à temperatura, quando comparada com os aços inoxidável ou com a liga $800 \mathrm{HT}$.

Porém, o principal defeito significativo que se manifestou durante a vida útil da liga 600 foi a iniciação e crescimento de trincas por corrosão sob tensão.

Esse tipo de fratura também é conhecida como fratura por efeito Coriou pois foi este pesquisador o primeiro a detectá-la no Inconel 600 em água pura a alta temperatura no final dos anos 1950. Na Figura 1.3 é mostrado um corpo de prova de Inconel $600 \mathrm{com}$ fratura do tipo CSTAP após 3 e 6 meses de ensaio em água pura a $350^{\circ} \mathrm{C}$ [CORIOU et al., 1966]. É esse exatamente o tipo de trinca por CSTAP que surge nos bocais do mecanismo de acionamento das barras de controle dos reatores de água pressurizada [HALL et al., 1992]. 


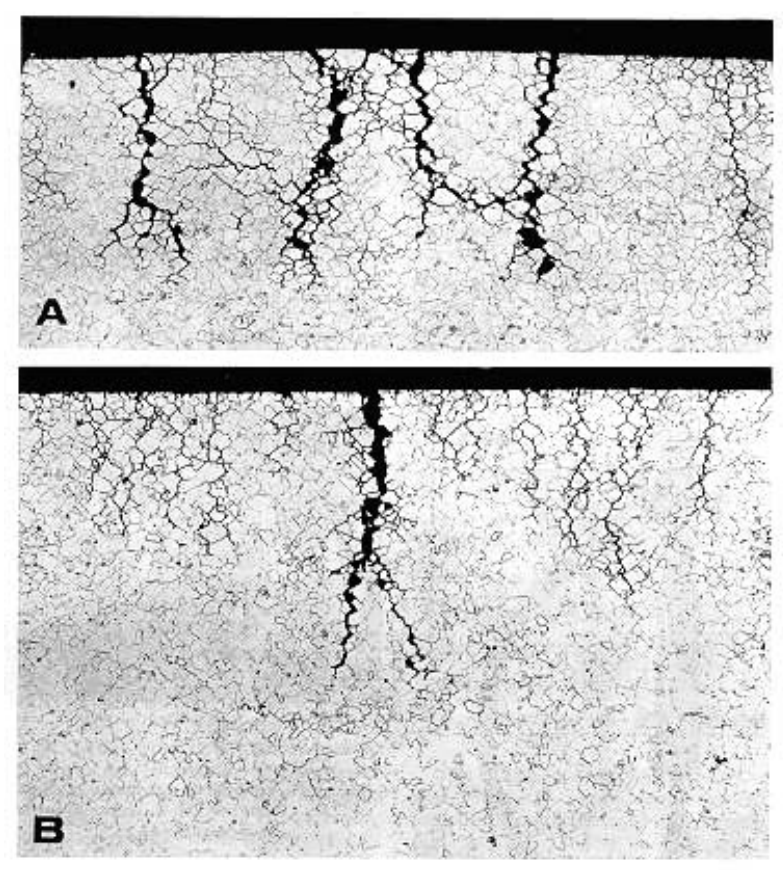

Figura 1.3. Seção de corpo de prova de Inconel 600 pré-tensionado, triađallanapós ensaios de tensão em água pura a $350^{\circ} \mathrm{C}$ : (A) após 3 meses- tensão de 460,9 MPa; (B) após 6 meses tensão de 323,6 MPa; Nota: Os corpos de prova foram tensionados em carga constante, um pouco acima do limite de escoamento do material, de modo que ficaram um pouco deformados; assim, o valor relativo da tensão aplicada foi uniforme em todos os casos e corresponderam a uma deformação constante e permanente de 0,5\%; aumento de 75 vezes [CORIOU et al., 1966].

A CSTAP em liga 600 foi observada em tubos geradores de vapor de RAP no início de 1974 numa revisão publicada por van Rooyen. Não apareceu porém esse tipo de falha nos RAP fabricados na Alemanha que utilizaram a liga 800 ao invés da liga 600 [SERRA, 1981]. Foi porém nos últimos 25 anos de operação em reatores nucleares, que foi notada a CSTAP nos componentes de bocais dos MAB dos RAP feitos de liga 600. A parte inferior de cada bocal é feita de liga 600 , ajustada à superfície interna do tampo do vaso e selada com solda de penetração parcial. A solda e a parede do bocal acima dela são partes integradas à barreira de pressão do sistema. Cada bocal de penetração é fabricado em aço inoxidável, conectado ao tubo de liga 600 por solda metálica dissimilar (isto é, solda que une materiais diferentes) e sua parte superior é conectada à carcaça do MAB com um arranjo parafusado e selado com solda, conforme apresentado na Figura 1.4. 
Esse projeto do sistema de penetração bem como seus materiais são essencialmente os mesmos em quase todos os RAP, inclusive alguns da Alemanha. Assim estão sendo consideradas as plantas na África do Sul, Bélgica, Brasil, Coréia, China, Espanha, EUA, França, Japão, Suécia, Suíça, Taiwan e as plantas de Obrigheim e Muelheim - Kaerlich, na Alemanha. Existem tipicamente entre 40 a 90 desses sistemas de penetração por vaso de pressão do tipo RAP [IAEA, 1997].

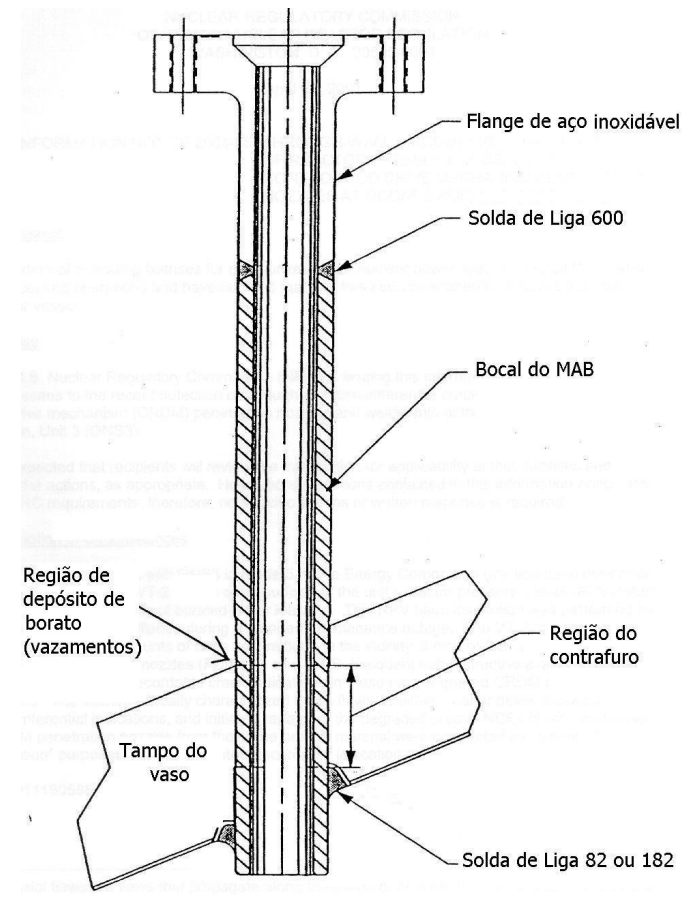

Figura 1.4. Esquema de bocal do mecanismo de acionamento das barras de controle num reator tipo RAP fabricado pela Westinghouse. Nota: para principais dimensões ver Figura 7.1 [SHAH et al, 1994].

\subsection{Estratégias e métodos de inspeção}

A detecção de trincas é obtida por inspeções que exigem remoção do isolamento do tampo do vaso PWR, sendo isso de difícil execução; no procedimento de inspeção da empresa Eletricité de France (EDF N.13), recomenda-se um sistema de monitoração para detectar vazamentos no período de 1 hora da ordem de 0,2 l/h. A inspeção dos bocais do MAB seguem os procedimentos ASME sec. XI, EPRI, Westinghouse. Quanto aos critérios para 
reparo das trincas nesses bocais, a USNRC aceita a operação com trincas em bocais menores ou iguais a $75 \%$ da espessura da parede (trincas axiais) e comprimento da trinca circunferencial menor do que $10 \%$ do perímetro do bocal desde que seja reinspecionada em períodos de manutenção subsequentes [ASME, 1998]. A estratégia de inspeção e manutenção dos componentes de liga 600 sujeitos a CSTAP deve ser elaborada pela integração da estimativa da propagação de trinca e considerações sobre vazamento antes da quebra (LBB, "leak before break") [BHANDARI \& PELLISSIER TANON, 1998],[FAIDY et al, 1994], [SCOTT, 1996]. Por exemplo, para a Usina Nuclear de Palisades (EUA), foi elaborada uma estratégia de inspeção desses bocais baseada em índices de susceptibilidade à CSTAP, obtidos através de ponderações introduzidas nos fatores material, ambiente e tensão, chegando-se a duas conclusões interessantes: o material deve ter uma rede contínua de carboneto de cromo intergranular; se isso não acontecer, a susceptibilidade à CSTAP aumenta, combinada com condições de tratamento térmico e teor de carbono; os bocais do MAB com ângulos de ajuste mecânico com o tampo, menor do que $22,5^{\circ}$ são menos susceptíveis à CSTAP do que aqueles com ângulo de ajuste entre $22,5^{\circ}$ e $45^{\circ}$ [HOANG et al, 1998]. Em geral a maioria das plantas nucleares adota estratégias de inspeção [HOANG et al, 1998],[HONG et al, 1997].

\subsection{Histórico das inspeções realizadas}

Em setembro de 1991, ocorreu um vazamento por um bocal periférico do MAB durante um teste hidrostático após 10 anos de operação, em Bugey 3, uma planta do tipo RAP na França, que tinha operado por cerca de $84000 \mathrm{~h}(72000 \mathrm{~h}$ de potência efetiva à plena carga) desde 1979. A pressão de teste hidrostático foi de 20,7 MPa. O vazamento, detectado na monitoração por emissão acústica, foi em torno de $0,70 \mathrm{l} / \mathrm{h}$. O exame visual revelou que a trinca era orientada axialmente e localizada na depressão inferior correspondente à porção inferior da solda de penetração parcial. Os exames destrutivos do bocal danificado revelaram que a trinca através da parede iniciou-se na superfície interior do bocal e foi causada pela CSTAP e não por fadiga, o tipo de defeito mais comum detectado nesse tipo de bocal. A trinca estava presente antes do teste 
hidrostático, mas não ocorriam vazamentos significativos durante a operação. O exame destrutivo também revelou a presença de uma pequena trinca circunferencial no metal base na superfície externa do bocal. A trinca circunferencial foi conectada à trinca axial através da parede. Admitiram-se duas hipóteses: ela poderia ser parte daquela trinca axial passante ou o refrigerante primário que vazou pela trinca passante da parede poderia ter causado a trinca circunferencial [SHAH et al, 1994].

No início de 1994, foram encontradas trincas nos bocais do MAB da planta de Zorita, na Espanha; a maioria dessas trincas eram axiais e localizadas na extensão livre dos bocais, embora com algumas trincas circunferenciais localizadas próximas às soldas de penetração parcial. Essas trincas foram causadas por ataque químico pela intrusão de resinas da água desmineralizada no refrigerante primário e não por CSTAP; no entanto a CSTAP pode ter tido algum papel nas trincas circunferenciais próximas à solda [SHAH et al, 1994].

Até 1994, foram inspecionados 4181 bocais do MAB em 79 plantas do tipo RAP distribuídas por todos os continentes, sendo constatada a existência de trincas do tipo CSTAP em 101 deles. As trincas foram encontradas em 35 plantas na Europa, sendo 30 na França, 2 na Suécia, 2 na Bélgica e 1 na Suíça [SHAH et al, 1994].

Mais recentemente foram feitas três inspeções na Usina de Oconee, EUA. $\mathrm{Na}$ primeira, em novembro de 2000, na unidade 1, foram detectadas trincas passantes nas ranhuras em forma de "J" nas soldas entre os bocais e o vaso, em um bocal do MAB além de outras em quatro bocais para instalação de termopares. Na segunda, em fevereiro de 2001, na unidade 1, foi descoberta mais uma trinca em bocal do MAB, do mesmo tipo descrito acima. Na terceira, em março de 2001, na unidade 3 detectaram-se nove trincas axiais em bocais do $M A B$, além de trincas circunferenciais passantes em dois bocais. Deve-se ressaltar que as trincas encontradas nessas três últimas inspeções ocorreram na região dos passes de enchimento das soldas de material liga 82 ou liga $182 \mathrm{em}$ zonas termicamente afetadas entre as paredes dos bocais feitos de liga 600 e 0 material do vaso RAP feito de aço baixa liga [USNRC, 2001].

O resultado dessas três últimas inspeções levou a uma revisão no processo de licenciamento das usinas nucleares nos EUA com novas exigências de inspeção dos vasos dos reatores RAP, como por exemplo, da obrigatoriedade 
de total remoção do isolamento térmico do tampo do vaso para inspeção adequada dos componentes susceptíveis à fratura, conforme é ilustrado pela Figura 1.5 [USNRC, 2004].

(a)

(b)
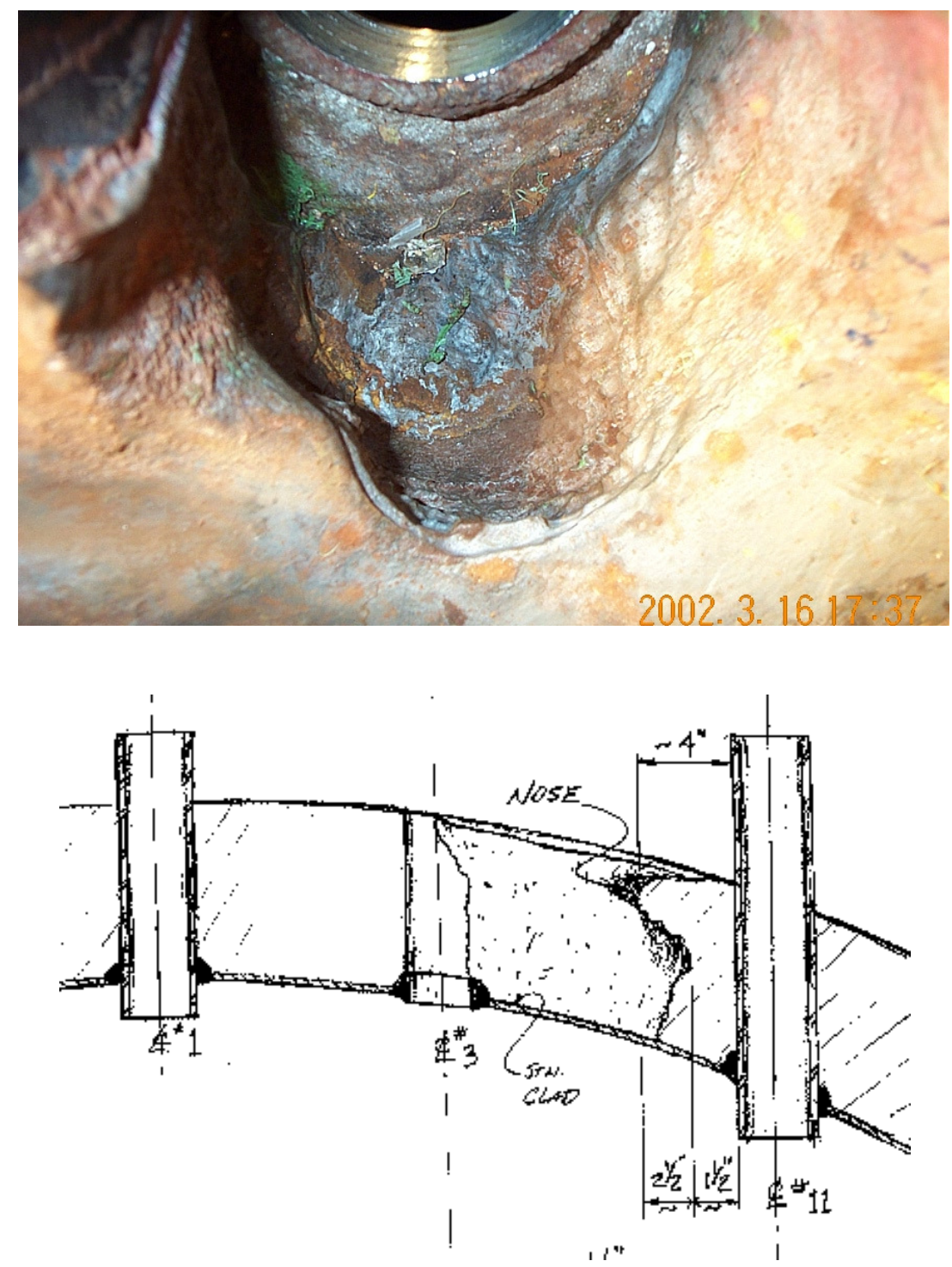

Figura 1.5. Dano por corrosão generalizada, causado pelo ácido bórico depositado através de vazamento por CSTAP através de bocal do MAB da Usina Davis Besse, unidade $n^{\circ}$. 3, em março de 2002. (a) Vista de topo com isolamento térmico removido, dimensões aproximadas de $4 \times 5$ $\mathrm{pol}^{2}$. (b)Vista esquemática da área degradada espessura do revestimento=3/8 pol [USNRC, 2004]. 


\subsection{Melhoria da resistência a trincas: materiais e projetos}

A melhoria de resistência a trincas pode ser feita pela deposição de níquel ao filme passivo; pelo jateamento com esferas ("shot peening") que faz as altas tensões residuais de tração serem compensadas pelo aumento do limite de escoamento do material; pela minimização das temperaturas operacionais e pela adição de zinco—na forma de acetato de zinco que tem alta solubilidade em água do circuito primário na temperatura de operação - ao refrigerante do RAP, que reage com o cromo do filme passivo da liga 600 e forma um filme protetor mais estável à CSTAP [ASME, 1998], [IAEA, 1997]. Outra possibilidade é a substituição da liga 600 pela liga 690, que tem um teor mais elevado de cromo e é termicamente tratado para resultar numa tensão de escoamento suficientemente baixa que evita alta tensão residual, impedindo a sensitização com 0 conseqüente empobrecimento de cromo dos contornos de grão. As unidades onde foram feitas essas substituições operam há pouco tempo, necessitando assim de monitoração de desempenho para se determinar sua integridade a longo prazo [EYRE, 1997].

Constata-se, portanto a grande importância da inspeção e o acompanhamento da vida útil de um reator deste tipo.

Um instrumento importante para auxiliar e orientar essa inspeção é o acompanhamento através de um modelo estabelecido e quantificado por sua respectiva modelagem. É na proposta de modelos e suas respectivas modelagens que se insere a contribuição pretendida por este trabalho.

\subsection{Objetivos}

Nesta Tese de Doutorado tem-se por objetivo um estudo de modelos e proposta de modelagem para corrosão sob tensão em liga 600 em água de circuito primário de reator de água pressurizada, superpondo modelos pertinentes ao estudo e quantificação do fenômeno e os validando com dados obtidos em experimentos e na literatura. Poderá ser um trabalho que tenha aplicação direta e na indústria nuclear e de vasos de pressão.

Para que o leitor possa compreender como se alcançou o objetivo desta Tese, é necessário que ele trilhe ainda que de modo resumido, o longo caminho que percorremos durante os cinco anos de trabalho sobre o assunto: corrosão sob tensão, modelos e modelagem. Para se compreender a modelagem, é 
preciso ter-se inteirado do amplo conjunto de modelos existentes para explicar o fenômeno "corrosão sob tensão"; antes é preciso entender os vários mecanismos individuais ou em atuação simultânea que provocam esse fenômeno, resultante de uma interação complexa entre causas que são objetos de estudo da eletroquímica, mecânica da fratura e ciência dos materiais; depois disso é necessário dissecar-se as principais modelagens, isto é como se quantificam os efeitos do fenômeno de acordo com alguns dos modelos existentes aceitos para explicá-lo. Cumpre aqui observar que nem todos os modelos existentes dispõem de modelagens para quantificá-los: é o caso da grande maioria dos modelos em que o hidrogênio exerce papel fundamental na operação de seus mecanismos. Finalmente se chega ao que se entendeu pela busca de um caminho pouco explorado onde se pode dar uma contribuição original. Ë necessário então dar se uma visão da parte experimental na qual se baseou este trabalho. A partir daí mostram-se como foram obtidos os resultados, suas limitações, uma discussão, conclusões e recomendações para trabalhos futuros no assunto.

Assim, fez-se uma introdução ao fenômeno "corrosão sob tensão em liga 600 em água do circuito primário à alta temperatura" e sua contextualização no panorama da ciência e da tecnologia nuclear (no corrente Capítulo 1); no Capítulo 2 procurou-se conceituar amplamente o fenômeno "corrosão sob tensão" e mostra-se sua complexidade de abordagem no campo da tecnologia: daí procurou-se falar da abordagem de engenharia estabelecida por R.W. Staehle (EUA) para tratar as falhas de corrosão sob tensão em tubos geradores de vapor de liga 600 em água do circuito primário a alta temperatura: pode-se em princípio estender essa metodologia ao mesmo fenômeno nos bocais do mecanismo de acionamento das barras de controle do reator de água pressurizada, objeto desta Tese; no Capitulo 3 procurou-se mostrar a morfologia da fratura e a composição do filme passivo sobre o material, uma vez que é através da ruptura desse filme que protege sua superfície que se dá a iniciação do fenômeno. A abordagem foi principalmente do ponto de vista científico dos materiais e se baseou fortemente nas pesquisas dos franceses D. Caron e F. Foct - a França parece estar na vanguarda desta abordagem; o Capítulo 4 é dedicado a se entender a contribuição do meio ambiente e da temperatura ao fenômeno. Essa contribuição provêm de diversos pesquisadores em laboratórios espalhados pelo mundo, mormente nos EUA, no Japão, no Reino Unido e Canadá: Staehle soube compilar 
muito bem essas informações experimentais; o Capítulo 5 foi elaborado para ressaltar a importância do papel do hidrogênio na corrosão sob tensão e na fragilização da liga 600, um fenômeno que apareceu na revisão bibliográfica, relativamente pouco estudado: novamente a França (Foct) pareceu estar na vanguarda dessa pesquisa, seguida bem atrás pelo Japão; o Capítulo 6 aborda a influência do material liga 600 no fenômeno, ressaltando o papel do teor de cromo na microestrutura do material - elemento responsável pela proteção contra esse tipo de corrosão, através da formação de segmentos de precipitados de carbonetos de cromo nos contornos de grão do material base e como elemento dissolvido nas bordas dos grãos: a sua falta, no caso de sensitização, é responsável pela maior vulnerabilidade à corrosão sob tensão; 0 capítulo 7 aborda a influência dos parâmetros mecânicos, tensão de tração e taxa de deformação como agentes ativos na corrosão sob tensão. A fluência e o escorregamento intergranular são fatores importantes no caso da liga 600. O encruamento é um tratamento mecânico que também influi no fenômeno. $O$ fechamento de trinca é importante no caso de tensões cíclicas quando pode haver também a ocorrência de fadiga; o Capítulo 8 é o mais longo e é dedicado a levantar uma genealogia de mecanismos e modelos existentes e no final compara os principais modelos quanto à sua aplicabilidade: é ressaltada a importância da taxa de deformação e da fluência na quebra do filme passivo, bem como o papel importante do hidrogênio para assistir à fratura por corrosão sob tensão; o papel da oxidação interna também é ressaltado, principalmente no caso da iniciação da fratura por corrosão sob tensão à alta temperatura em água primária em liga 600: foram fundamentais no caso, as pesquisas de R. Rebak e Smialowska (EUA), P.M.Scott (Reino Unido e França), além de D.Caron (França); o Capítulo 9 trata da superposição dos modos de corrosão com o ambiente, definidos pelos diagramas de Pourbaix - potencial versus $\mathrm{pH}$ - e que definem em seu espectro as condições termodinâmicas de ocorrência de diversas formas de corrosão (e passivação) de um determinado material num determinado meio e numa determinada temperatura: são fornecidos os princípios de construção desses diagramas em temperaturas diferentes da ambiente, problema da Termoquímica. Também é abordada a construção do diagrama tridimensional de fração de resistência à corrosão sob tensão com base topográfica sobre esse diagrama, uma contribuição importante de Staehle, para a compreensão do fenômeno; o 
Capítulo 10 é dedicado à revisão das principais técnicas de modelagem, sejam elas determinísticas, probabilísticas ou mistas: cumpre ressaltar o papel importante do pesquisador Y. Garud (EUA) no estabelecimento dessas técnicas, seja utilizando taxa de deformação lenta e constante (os equipamentos de ensaio denominados ETDL: ensaios por taxa de deformação lenta, traduzindo os acrônimos SSRT: "slow strain rate testing" ou CERT: "constant extension rate load") , seja utilizando carga constante (CL: "constant load "); no Capítulo 11 propõe-se a construção do modelos propostos, que são quatro, todos baseados na superposição do modo com o ambiente: um semelhante ao original de Staehle (que ele não detalhou como foi construído). Os outros compostos com três modelos revisados no Capítulo 8 e com suas modelagens revisadas no Capítulo 10; o Capítulo 12 descreve a parte experimental que foi realizada no CDTN por sua equipe, utilizando o equipamento de ETDL recentemente lá instalado. Essa parte inclui também os ensaios eletroquímicos pelo CDTN e o cálculo estimativo do potencial medido em relação ao padrão de hidrogênio; o Capítulo 13 detalha os resultados obtidos na validação dos quatro modelos propostos, utilizando dados da parte experimental do Capítulo 12 e algum da literatura. Discute os resultados obtidos; os Capítulos 14, Conclusões e 15, Recomendações, fecham e apontam para o futuro prosseguimento desta pesquisa.

\subsubsection{Contribuições originais}

Staehle propôs um diagrama que exprime a condição termodinâmica de ocorrerem diversos modos de CSTAP na liga 600 (Figura 1.6) [STAEHLE, 1992a].

Para construí-lo, partiu-se de diagramas de potencial $x \mathrm{pH}$, conhecidos como diagramas de Pourbaix, para a liga 600 imersa em água primária a alta temperatura $\left(300\right.$ a $350^{\circ} \mathrm{C}$ ). Sobre ele, determinaram-se os submodos de corrosão, utilizando dados experimentais da literatura de diversos pesquisadores. Em seguida acrescentou-se uma dimensão adicional a esse diagrama, tornando-o tridimensional, correlacionando-se através do eixo adicional, um parâmetro denominado "fração de resistência à CST".

Partiu-se da conceituação desse autor e utilizando-se os dados experimentais do CDTN fez-se o seguinte:

a) Proposta de uma modelagem empírico-comparativa semelhante a de Staehle, com a fração de resistência à CST quantificada como a razão de tempo 
de iniciação no meio de interesse/ meio neutro: esse é um dos parâmetros obtidos através de ensaios CERT/SSRT ("Constant Extension Rate Testing" ou "Slow Strain Rate Testing") ou Ensaio de Taxa de Deformação Lenta (ETDL);

b) Proposta de três modelagens distintas através da superposição no diagrama de Pourbaix marcado com submodos de CSTAP, com três outros modelos: 1) Modelo semi-empírico-probabilístico de Staehle [GORMAN et al, 1994]; 2) Modelo simplificado de tempo de iniciação de Garud [GARUD, 1997]; 3) Modelo de dano por taxa de deformação de Boursier [BOURSIER et al, 1995]. 

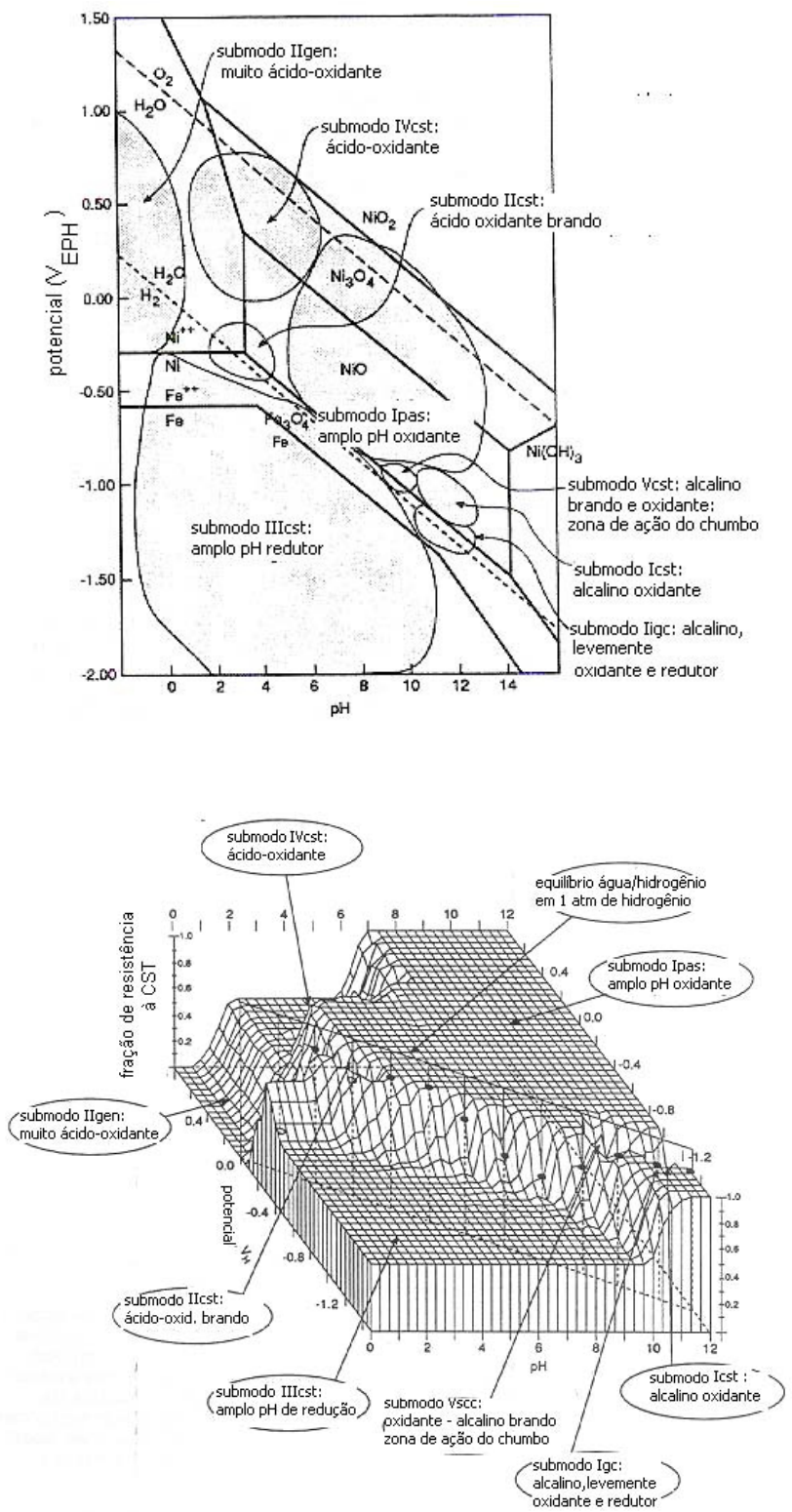

Figura 1.6. Diagramas potencial $\mathrm{xpH}$ para a liga 600 na faixa de $300^{\circ} \mathrm{C}$ para a condição de tratamento laminado e recozido ("mill annealed"). Abaixo, o diagrama tridimensional para correlação com fração de resistência à CSTAP; acima, o esquema bidimensional representa a base da figura tridimensional, potencial $\times \mathrm{pH}$, com as áreas de submodos de corrosão assinaladas. Submodos ocorrem repetindo os modos de corrosão intergranular, pite, CST e corrosão generalizada - de acordo com suas condições termodinâmicas de ocorrência, representáveis ao longo de diagramas potencial x densidade de corrente e nos acima mostrados [STAEHLE, 1992a]. 


\section{O FENÔMENO dA CORROSÃO SOB TENSÃO E A ABORDAGEM DE ENGENHARIA}

\subsection{Conceituação do fenômeno de CST}

A taxa de corrosão de um material metálico depende do meio em que se encontra, da temperatura, da sua microestrutura metalúrgica e composição química. Heterogeneidades na microestrutura bem como a deformação plástica contribuem para ocorrência de corrosão localizada. Se as tensões são suficientemente grandes e um pouco abaixo da tensão de escoamento, os processos anódicos são acelerados e a taxa de corrosão aumenta localmente. A corrosão acelerada pela tensão é conhecida como corrosão sob tensão sendo resultante da interação entre tensão, microestrutura e o meio em que ele se encontra [HEMPEL, 1964]. A Figura 2.1 ilustra essa conceituação.

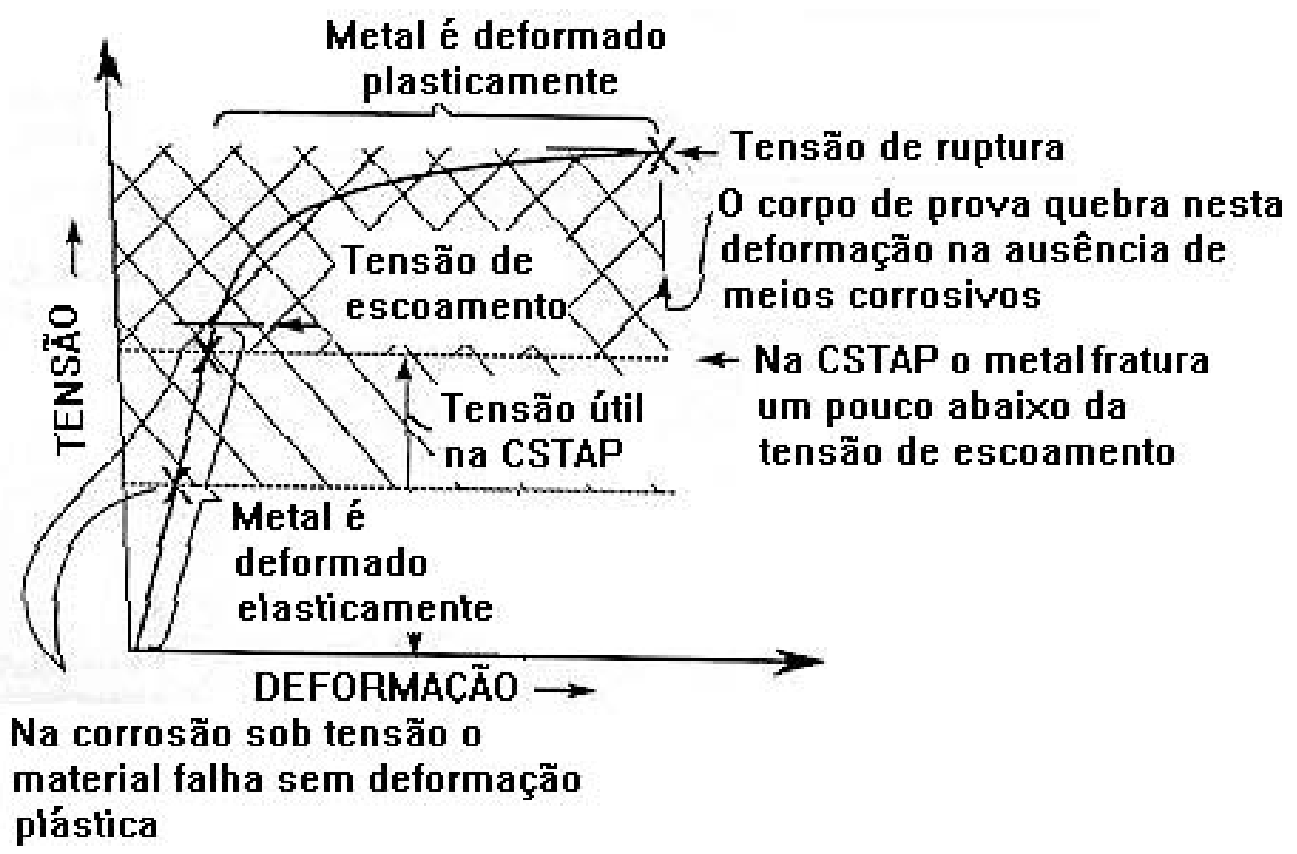

Figura 2.1. Esquema indicando no diagrama tensão $x$ deformação, a região de CSTAP, para o Inconel 600 [GORMAN \& STAEHLE, 1989].

A CST se distingue da corrosão sob fadiga pela natureza das tensões e pela importância de um determinado meio. A CST necessita de uma tensão estática de tração, seja aplicada ou residual de fabricação, mas relativamente poucos meios são capazes de causá-la, já que esses têm que agir sobre uma superfície necessariamente protegida por um filme passivo. Por outro lado, 
qualquer meio capaz de algum ataque localizado é provavelmente suficiente para acelerar um defeito de fadiga, gerando um defeito de corrosão sob fadiga (CSF). O esquema da Figura 2.2. ilustra a região preferencial de CSF.

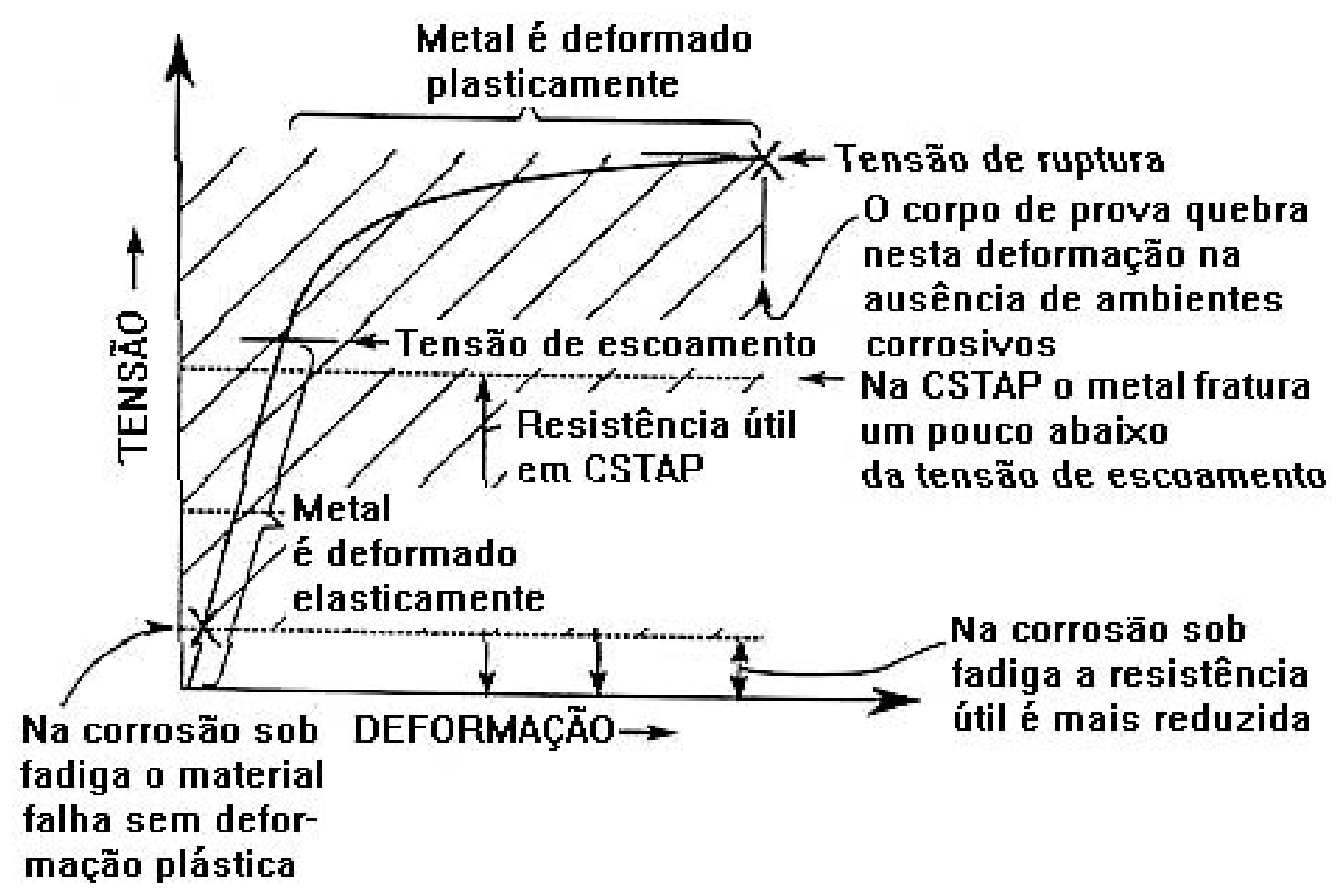

Figura 2.2. Esquema indicando no diagrama tensão $x$ deformação, a região de CSF [GORMAN \& STAEHLE, 1989].

Praticamente todas as classes de ligas são susceptíveis à CST. Aços inoxidáveis em cloretos e em meios fortemente cáusticos. Ligas de cobre em amônia e aminas; ligas de ouro em cloreto férrico; ligas de alumínio em cloretos, e assim por diante. Vide Tabela 2.1. 
Tabela 2.1. Íons específicos e substâncias que causam CST sobre diversas ligas, quando presentes em baixa concentração e como impurezas, adaptado de [ASM, 2002].

\begin{tabular}{|c|c|c|}
\hline 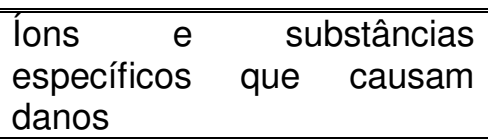 & Ligas susceptíveis à CST & Temperatura $\left({ }^{0} \mathrm{C}\right)$ \\
\hline \multicolumn{3}{|l|}{ Grupo halogênio } \\
\hline Ílons fluoreto & $\begin{array}{l}\text { Aços } \quad \text { inoxidáveis } \\
\text { austeníticos sensitizados }\end{array}$ & ambiente \\
\hline Cloro gasoso & $\begin{array}{l}\text { Aços de baixa liga e alta } \\
\text { resistência }\end{array}$ & ambiente \\
\hline lodetos gasosos & Ligas de zircônio & 300 \\
\hline $\begin{array}{l}\text { lons e } \\
\text { específicos questâncias } \\
\text { danos }\end{array}$ & Ligas susceptíveis à CST & Temperatura $\left({ }^{0} \mathrm{C}\right)$ \\
\hline \multicolumn{3}{|c|}{ Grupo do oxigênio (sistemas $\mathrm{H}_{2} \mathrm{O}-\mathrm{O}_{2}-\mathrm{H}_{2}$ ) } \\
\hline $\mathrm{O}_{2}$ dissolvido em $\mathrm{H}_{2} \mathrm{O}$ líquida & $\begin{array}{l}\text { Aços } \\
\text { sensitizados }\end{array}$ & 300 \\
\hline $\begin{array}{lc}\text { Hidrogênio gasoso } & \text { à } \\
\text { temperatura ambiente } & \end{array}$ & $\begin{array}{l}\text { Aços de baixa liga e alta } \\
\text { resistência }\end{array}$ & Ambiente \\
\hline $\begin{array}{l}\text { Hidrogênio gasoso a altas } \\
\text { temperatura e pressão }\end{array}$ & $\begin{array}{l}\text { Aços de baixa e média } \\
\text { resistência }\end{array}$ & $>200$ \\
\hline $\begin{array}{l}\text { Hidróxidos }(\mathrm{LiOH}, \mathrm{NaOH}, \\
\mathrm{KOH})\end{array}$ & $\begin{array}{l}\text { Aços carbono, ligas de Fe- } \\
\text { Cr-Ni (trincamento cáustico) }\end{array}$ & $>100$ \\
\hline \multicolumn{3}{|c|}{ Grupo do oxigênio (sistemas S, Se, Te) } \\
\hline Ácidos politiônicos $\left(\mathrm{H}_{2} \mathrm{~S}_{\mathrm{n}} \mathrm{O}_{6}\right)$ & 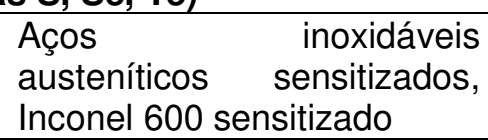 & Ambiente \\
\hline Gás sulfídrico $\left(\mathrm{H}_{2} \mathrm{~S}\right)$ & $\begin{array}{l}\text { Aços de baixa liga e alta } \\
\text { resistência }\end{array}$ & Ambiente \\
\hline $\begin{array}{l}\text { Impurezas de sulfetos em } \\
\text { solução aquosa }\end{array}$ & $\begin{array}{l}\text { Aços de alta resistência } \\
\text { (trincamento induzido por } \\
\text { hidrogênio acelerado) }\end{array}$ & Ambiente \\
\hline \multicolumn{3}{|l|}{ Grupo do nitrogênio } \\
\hline $\mathrm{N}_{2} \mathrm{O}_{4}$ líquido & $\begin{array}{l}\text { Ligas de titânio de } \text { alta } \\
\text { resistência }\end{array}$ & \\
\hline $\begin{array}{l}\mathrm{N}, \mathrm{P}, \mathrm{As}, \mathrm{Sb}, \mathrm{Bi} \text { ligados no } \\
\text { metal }\end{array}$ & $\begin{array}{ll}\text { Aços inoxidáveis } & \text { (na } \\
\text { presença de } & \left.\mathrm{Cl}^{-}\right) \text {: } \\
\text { trincamento acelerado } & \end{array}$ & Ambiente \\
\hline $\begin{array}{l}\text { As, } \mathrm{Sb} \text { e } \mathrm{Bi} \text { como íons em } \\
\text { solução aquosa }\end{array}$ & $\begin{array}{l}\text { Aços de alta resistência, } \\
\text { entrada acelerada de } \\
\text { hidrogênio e trincamento } \\
\text { induzido por hidrogênio }\end{array}$ & Ambiente \\
\hline \multicolumn{3}{|c|}{ Grupo do carbono (C, Si, Ge, Sn, Pb) } \\
\hline $\begin{array}{l}\text { Íons carbonato em soluções } \\
\text { aquosas }\end{array}$ & Aço carbono & 100 \\
\hline Gases $\mathrm{CO}-\mathrm{CO}_{2}-\mathrm{H}_{2} \mathrm{O}$ & Aço carbono & ............ \\
\hline $\begin{array}{l}\text { İons de chumbo em solução } \\
\text { aquosa }\end{array}$ & Ligas de alto teor de níquel & \\
\hline
\end{tabular}


Há diversos mecanismos para explicar a CST. De fato, é duvidoso que somente um mecanismo, mesmo excluindo o efeito do hidrogênio numa primeira instância, se aplique: porque é fácil citar no mínimo um caso onde nenhuma teoria consegue abranger os fatos correlatos do fenômeno e observações [HEMPEL, 1964]. As maiores diferenças entre teorias concernem ao modo de iniciação e propagação. Acredita-se que as trincas podem iniciar e propagar por meios puramente eletroquímicos, por uma combinação de processos eletroquímicos e mecânicos ou por processos puramente mecânicos como é ilustrado na Figura 2.3 [STAEHLE, 1992a].

A razão para a dificuldade na concordância do desenvolvimento da trinca por CST - em contraste com a trinca por fadiga onde há muito menos controvérsia - vem de observações bem documentadas onde já a menos de $20 \%$ da tensão de escoamento do material pode haver o surgimento de trincas por CST. Assim se é forçado a imaginar uma teoria que possa explicar como a tensão é intensificada, como a tenacidade à fratura do material é diminuída ou como o processo de dissolução eletroquímica é acelerado localmente. As teorias correntes tentam suprir respostas para uma ou mais dessas importantes questões [HEMPEL, 1964].

Alguns pesquisadores acreditam que a trinca será originada pela ruptura do filme passivo depois que ele atinge uma espessura definida sob tensão. Outros, sabendo que em alguns sistemas não há filmes, sugerem dissolução seletiva de elementos de liga, muito semelhante à conhecida dezincificação do latão- $\alpha$ que é causa do ataque por pite. A intensificação de tensões da base de um pite ou na ponta de uma trinca é supostamente suficiente para causar escoamento e fratura frágil. Outra teoria sugere que a intensificação adicional de tensão vem do efeito cunha causado pela formação crescente de produtos de corrosão ao longo dos flancos das trincas, atrás de sua ponta. Desde que seja conhecida a relação entre energia de superfície e tenacidade à fratura, uma teoria corrente assume que a iniciação e a fratura frágil são ambas resultantes de uma diminuição da energia de superfície. É postulado que uma adsorção iônica de uma espécie particular da solução reduz a energia de superfície e também a resistência à fratura, de modo suficiente para que as microtrincas apareçam na superfície. A superfície assim exposta fica sendo uma área ativa para rápida adsorção e catalisa então a propagação da trinca. 


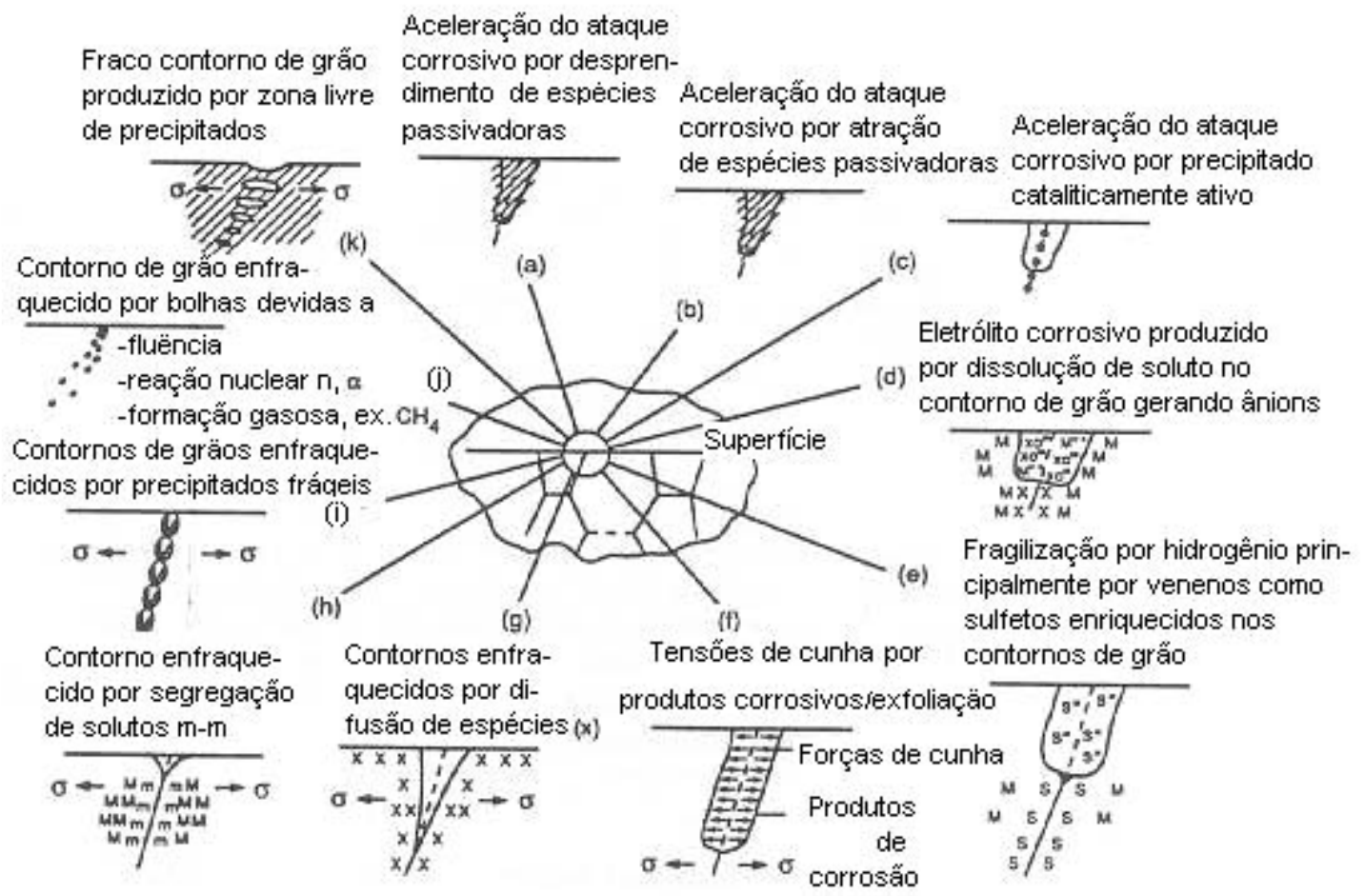

Figura 2.3. llustração dos processos de CST, do mais químico (a) ao mais mecânico(k) [STAEHLE, 1992a].

A maior parte do trabalho experimental existente gira em torno da eletroquímica do fenômeno. Há muitas curvas na literatura mostrando a relação entre potencial e tempo para espécimes sob tensão de tração num meio corrosivo. Utilizando essas curvas e dados ordinários de polarização, pode-se prever a natureza e a quantidade de corrente aplicada necessária para prevenir ou acelerar o defeito. A polarização a um desejado potencial por meio de um potenciostato pode eliminar o período de incubação ou tempo para a iniciação da trinca e causar a falha imediata por CST. Do mesmo modo, usando-se a mesma técnica com uma corrente oposta, pode-se conseguir uma proteção efetiva contra esse tipo de falha. Assim, a CST é pelo menos parcialmente eletroquímica. É muito difícil, no entanto, entender a dissolução anódica muito rápida somente através de um caminho estreito. Uma teoria prefere explicar isso como um efeito eletromecânico e descrever o processo de dissolução como uma dissolução ativada de um material em escoamento e sem filme passivo protetor. Em outras palavras, essa teoria assume que o máximo efeito da CST acelerada acontece ao longo de um caminho estreito em ligas imersas em ambientes muito específicos. 
Uma teoria mais unificada do fenômeno da CST utiliza a estrutura defeituosa do material para explicar a reatividade química em certos sítios da estrutura e também para mostrar como os defeitos podem intensificar a tensão durante a deformação. Uma conseqüência muito importante é a de uma aparente dependência da susceptibilidade à CST com a energia de falha de empilhamento ("stacking -fault"). Esse fato por si só pode explicar o porque de metais puros não serem susceptíveis à CST: energias de empilhamento-deslocamento muito elevadas. E também o porque de certos elementos de liga ou impurezas aumentarem a susceptibilidade de fratura. Outro resultado obtido pela consideração de empilhamentos - deslocamentos durante deformação é uma pressuposição sobre o motivo pelo qual as trincas podem ser intergranulares ou transgranulares, mas raramente de ambos os tipos simultaneamente .

Através de experimentos utilizando a técnica de microscopia eletrônica por transmissão, salientou-se a resistência superior à CST transgranular (CSTT) de ligas cujos filmes passivos deformados mostravam arranjo celular de emaranhados ("tangles") de discordâncias. As ligas mais susceptíveis parecem ter uma rede de discordâncias plana após uma superfície delgada sofrer deformação. Embora se saiba que a distribuição de discordâncias é dependente da energia de falha de empilhamento, também infelizmente é fato que o parâmetro de energia de falha de empilhamento, $Y$, é muito difícil de se medir experimentalmente. Para complicar esse quadro, há ainda certos elementos intersticiais que aparentemente não alteram $\mathrm{y}$ mas têm um efeito decisivo no arranjo de discordâncias. De qualquer modo, acha-se que a causa da iniciação de trincas em aços inoxidáveis austeníticos são discordâncias que chegam na superfície em planos de deslizamento ativos durante a deformação plástica.

Há uma corrente de pensamento que considera o tipo de fratura por CST por descarga catódica de hidrogênio como sendo um caso especial de CST. Esse fenômeno é usualmente chamado de "fragilização por hidrogênio" (FPH) ou "trincamento por hidrogênio" e é melhor entendido se não for incluído como pertencente à CST. A fratura aparentemente ocorre somente após o hidrogênio penetrar na liga e somente aquelas com baixa solubilidade relativa para o hidrogênio são susceptíveis. A trinca é acelerada por correntes catódicas, uma vez que essas aumentam a taxa de desprendimento de hidrogênio, e pela presença de venenos ou filmes interferindo com a evolução do hidrogênio 
molecular na superfície. Venenos são efetivos para a recombinação de hidrogênio atômico em molecular e assim são capazes de forçar o hidrogênio para dentro do metal: por exemplo, o arsênico, o enxofre, o selênio e o fósforo. Um caso típico muito susceptível a essa forma de fragilização são as estruturas martensíticas, devido à baixa solubilidade ao hidrogênio [HEMPEL, 1964].

Para fechar essa conceituação deve-se ressaltar que CST, CSF e FPH, embora sejam fenômenos distintos, são superpostos, pois apresentam uma região de muitas características comuns, especialmente na morfologia de defeito, conforme é ilustrado na Figura 2.4 (Staehle e outros colaboradores ressaltam isso no caso da CST-CSF da liga 600 [STAEHLE et al., 1981]). Mecanisticamente são fenômenos semelhantes que exigem condições ambientais, metalúrgicas e mecânicas suficientes para que possam ocorrer [HEMPEL, 1964], [HERTZBERG, 1989], [VAN DER SLUYS et al., 1990]. Por exemplo, no caso da CST, com relação ao fator tensão (condições quase-estáticas), a trinca é mais difícil de prever que no caso da CSF (condições de cargas cíclicas) [VAN DER SLUYS et al., 1990]. Por essa razão os três fenômenos acima são inter-relacionados e muitas vezes são referidos na literatura como sendo trincas assistidas pelo ambiente - "environmental assisted cracking" (EAC). 


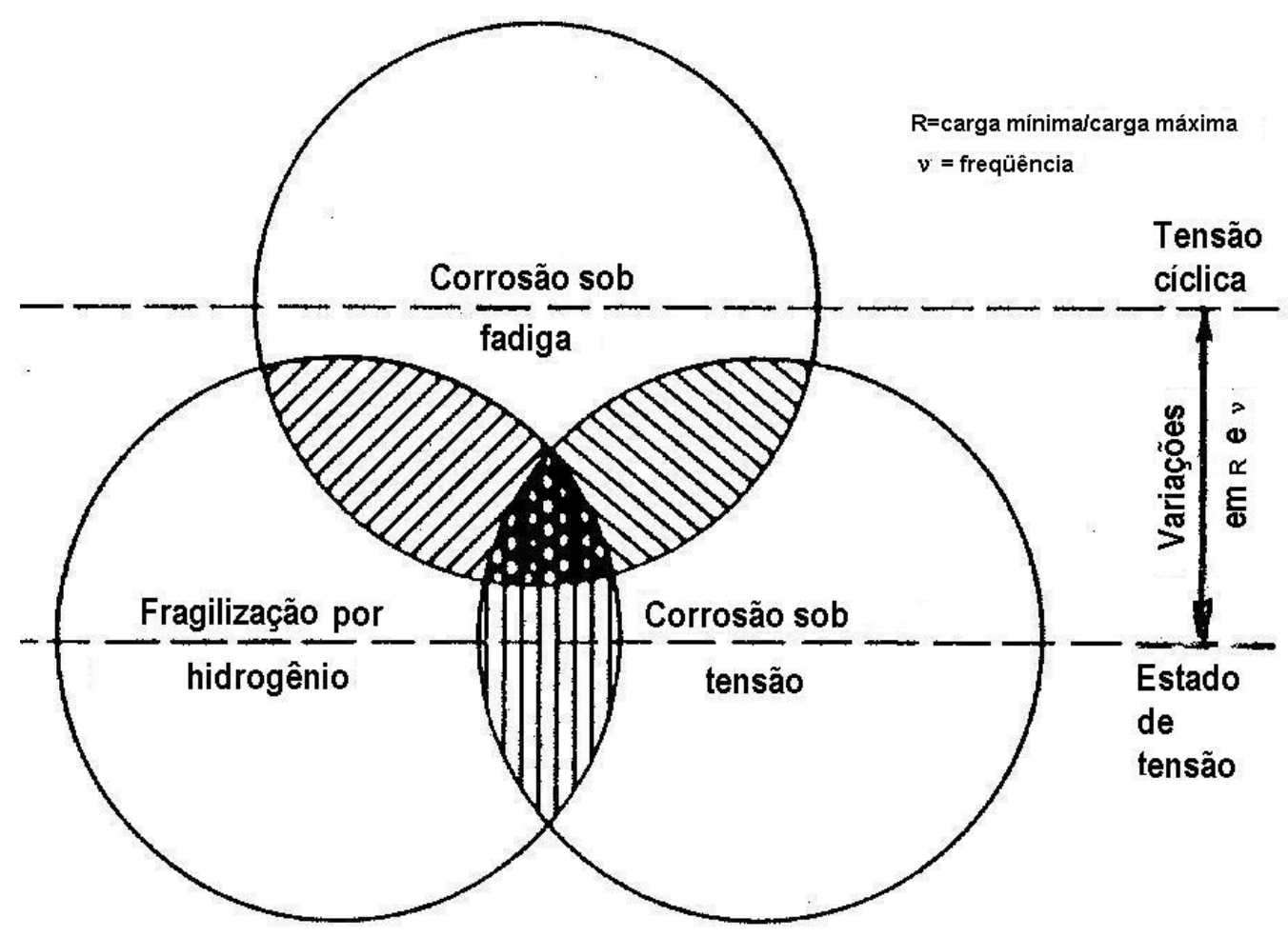

Figura 2.4. Esquema ilustrativo da relação entre CST, CSF e FPH. Quando a freqüência $v$ é inferior a cerca de $0,1 \mathrm{~Hz}$, a fratura é por CST; acima desse valor é por CSF [FOCT, 1999], [HERTZBERG, 1989].

\subsection{Morfologia da fratura por CST}

A morfologia da fratura por CST em metais é outro aspecto de difícil predição no processo: as ligas homogêneas podem trincar inter ou transgranularmente, raramente de modo simultâneo, como já afirmado anteriormente. Na Figura 2.5 sugere-se, além da explicação metalúrgica eletroquímica exposta no item anterior, uma explicação mecanística para esse fenômeno.

Há necessidade, no entanto, de explicações mais profundas porque os fatores meio e estrutura metalográfica também estão envolvidos na gênese da CST. 


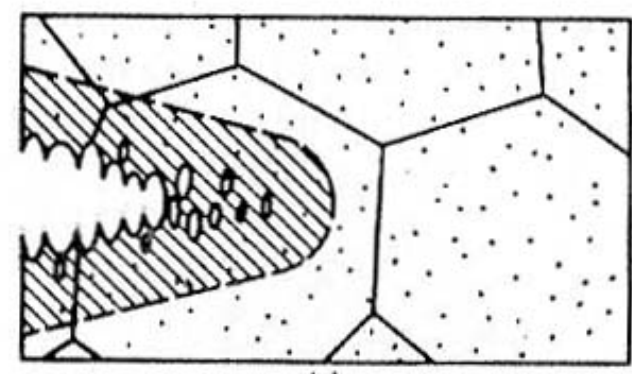

(a)

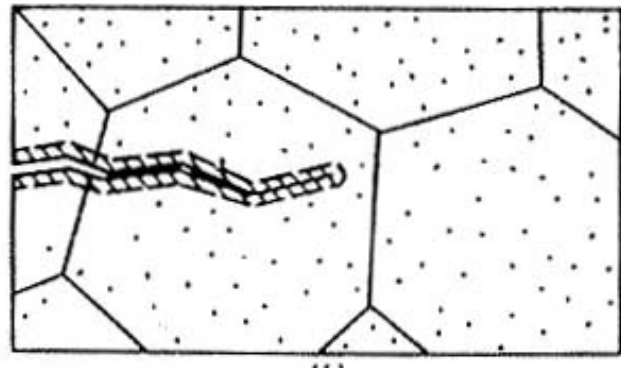

(b)

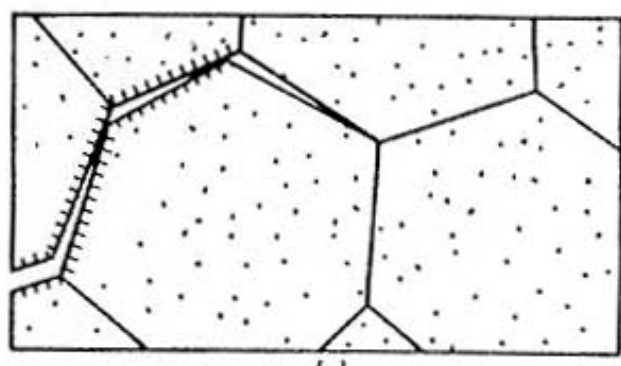

(c)

Figura 2.5. Diagrama de diferentes caminhos de trinca como função do nível de tensões: (a) Alto fator de intensidade de tensões (K) gera coalescência de microvazios; (b) níveis médios de K geram fratura transgranular por mecanismo de quasiclivagem; (c) baixos K levam a trincas intergranulares [HERTZBERG, 1989].

Para explicar trincas intergranulares há duas teorias: segundo Logan, para iniciar a trinca pode haver na região susceptível, os chamados caminhos ativos pré-existentes formados por segregados/precipitados nos contornos de grãos da microestrutura do material; assim as trincas se originam em contornos de grãos de alta energia e a concentração de tensões na ponta da trinca leva ao rompimento/retardamento da restauração da película passiva na ponta da trinca; o metal livre da ponta da trinca é mais anódico do que o metal coberto com película sobre os flancos da trinca e a área anódica muito pequena da ponta quando comparada com a área dos flancos que é catódica, dá origem a densidades de corrente muito elevadas levando à rápida dissolução da ponta da trinca. Alternativamente, Robertson e Tatelman [Robertson e Tatelman apud RAMANATHAN, 1992] supõem que a trinca se forma por um mecanismo químicomecânico formado de processos descontínuos e sucessivos que ocorrem em etapas sucessivas de corrosão e fratura: a trinca propaga-se livremente, as discordâncias dirigem-se para a trinca aliviando a tensão, o meio corrosivo difunde-se na trinca reagindo com o metal danificado sendo o acúmulo de discordâncias suficiente para continuar a fratura. 
Para explicar trincas transgranulares há as seguintes teorias: na ausência de caminhos ativos pré-existentes, os ataques iniciais podem ser submicroscópicos de acordo com diferenças locais na composição do metal, espessura da película passiva protetora, continuidade da película, concentração do meio corrosivo. Segundo Parr e Straub [Parr e Straub apud RAMANATHAN, 1992], a quebra da película ocorre devido a deformações existentes no metal base, resultando em exposição da superfície do metal; o caminho da trinca é gerado ciclicamente por ruptura alternada da película (aumento da deformação provoca a sua ruptura): este seria um mecanismo do caminho ativo gerado pela deformação. Para Logan [Logan apud RAMANATHAN, 1992] as tensões destroem a película em regiões pequenas da superfície metálica expondo-as anodicamente enquanto as regiões cobertas com película são catódicas, resultando em rápido ataque eletroquímico nas regiões anódicas.

Para uma explicação mais genérica, Keating [Keating apud RAMANATHAN, 1992] propôs que as trincas se iniciam por um processo químico ou eletroquímico, progredindo mecanicamente até serem retidas por um contorno de grão, inclusões (metálicas ou não metálicas) ou grãos orientados desfavoravelmente. A trinca progride por um processo químico mais lento, até que a concentração de tensões aumente novamente em sua ponta, quando progredirá a seguir de modo mecânico. Neste caso, a velocidade de crescimento de trinca é praticamente independente do fator de intensidade de tensões instantâneo, como mostra Knott [KNOTT, 1976] num exemplo para uma liga Al-Zn-Mg resfriada ao ar antes do envelhecimento, ao passo que para a mesma liga temperada em água, o crescimento da trinca é proporcional ao fator de intensidade de tensões: isto se explica porque no primeiro caso os precipitados nos contornos de grão estão bem espaçados numa zona susceptível de deformação plástica (> $1 \mu \mathrm{m}$ ) ao passo que no segundo caso essa zona é pequena $(<1 \mu \mathrm{m})$. Vide Figura 2.6. 


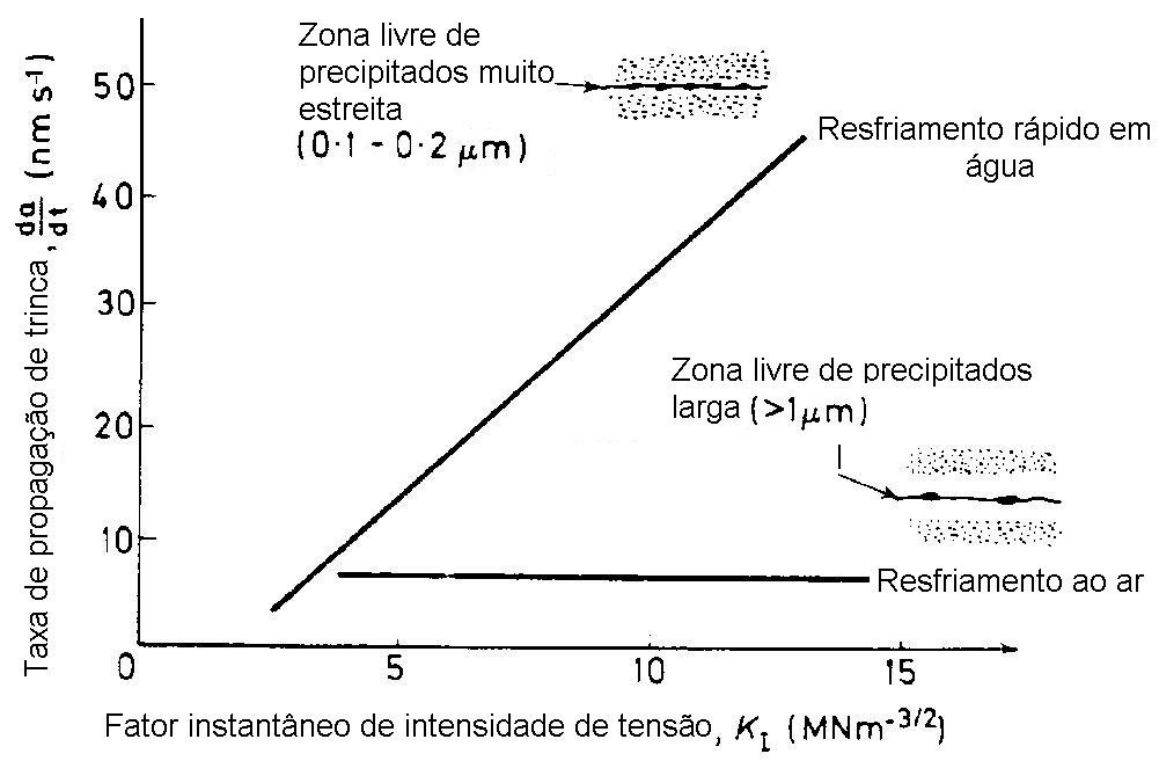

Figura 2.6. Variação na velocidade de crescimento de trinca por CST com o fator de intensidade de tensões [KNOTT, 1976].

\subsubsection{Modos e submodos de corrosão}

Um conceito útil para se compreender a morfologia da CST é o definido por Staehle [STAEHLE, 1995], que considera cinco morfologias ou modos de corrosão para quaisquer materiais, conforme ilustrado na Figura 2.7. São modos que ocorrem independentemente do tipo de material: corrosão generalizada, corrosão intergranular, pite, corrosão sob tensão e fadiga assistida pelo ambiente.

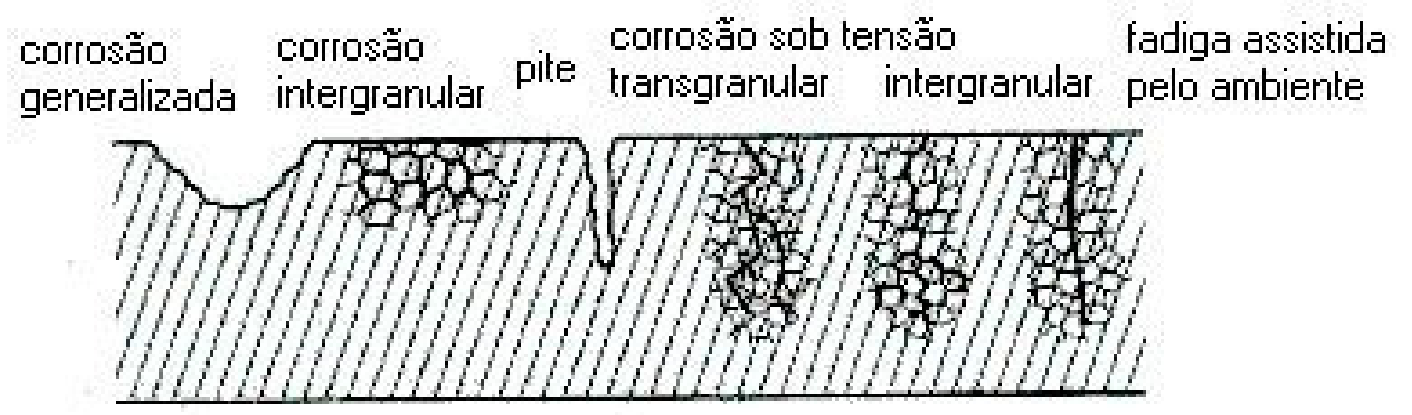

Figura 2.7. Esquema de cinco modos intrínsecos de corrosão: corrosão generalizada, corrosão intergranular, pite, corrosão sob tensão e fadiga assistida pelo ambiente; de CST são mostradas as duas morfologias, intergranular e transgranular [STAEHLE, 1995]. 
Staehle observa que autores como Fontana, Uhlig e Revie [Fontana; Uhlig e Revie apud STAEHLE, 1995] consideram as formas de corrosão como sendo: galvânica, diferencial, erosão-corrosão, microbiológica e outras; porém essas não são realmente formas de corrosão e sim definem diferentes ambientes que afetam os modos mostrados na Figura 2.7.

Por outro lado, o conceito de "submodo" de corrosão, vem do fato de que se pode ter para cada um dos modos na Figura 2.7, ocorrendo segundo diferentes combinações de material-ambiente, muitas dependências diferentes com a tensão, ambiente, temperatura e material. Esses submodos ocorrem assim de maneira discreta, definindo um domínio de ocorrência sobre um diagrama que possa exprimir o universo de combinações que definem o ambiente, como é o caso do diagrama de Pourbaix - potencial versus pH. Na Figura 2.8 eles são exemplificados num diagrama potencial versus densidade de corrente como: de pite, passividade, corrosão generalizada e corrosão sob tensão; notar que pode existir mais de um submodo para alguns tipos de corrosão, como neste caso de corrosão sob tensão onde estão apontados três diferentes submodos I, II e III [STAEHLE, 1992a]. 


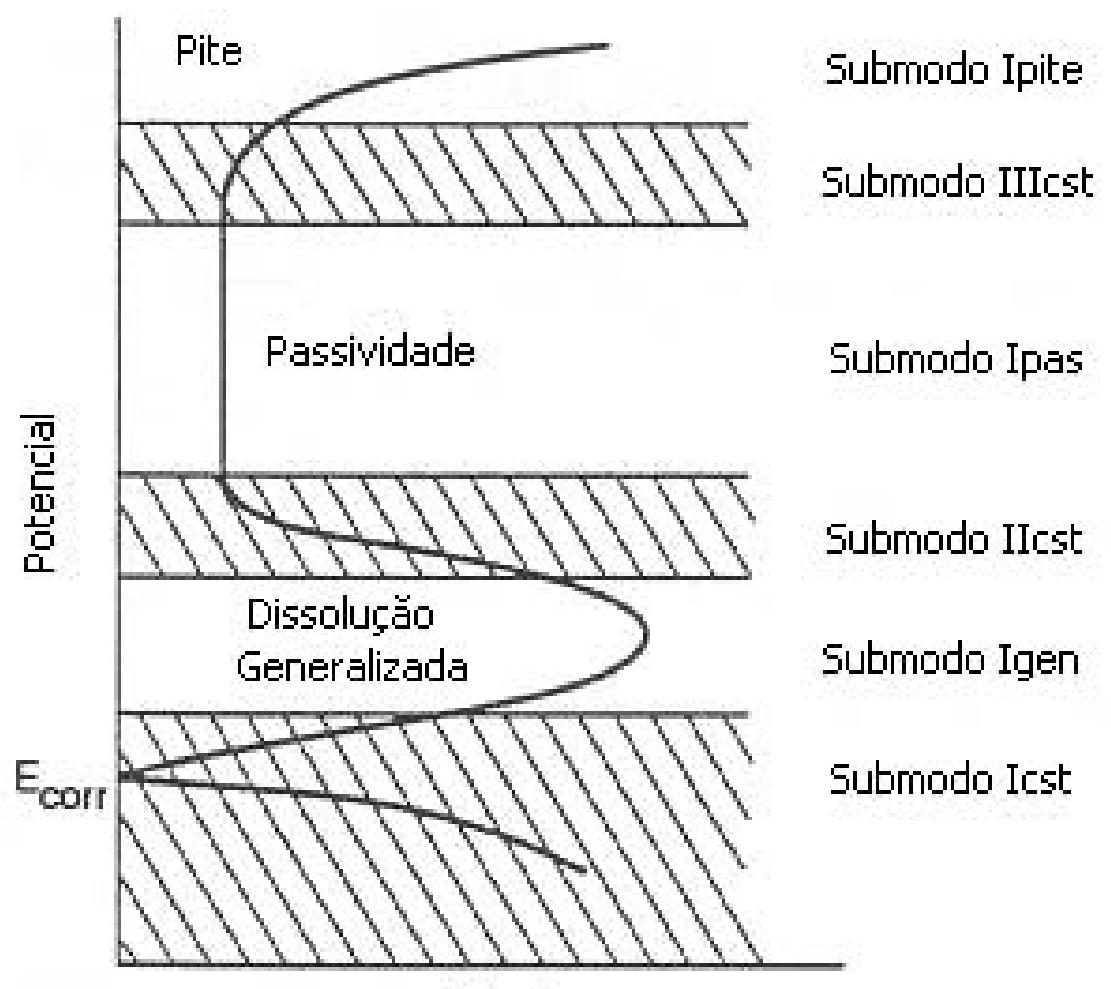

Densidade de Corrente

Figura 2.8. Esquema das regiões de CST em função do potencial relacionado com uma curva de polarização ativa-passiva. Os submodos são designados em termos de corrosão sob tensão (cst), dissolução ou corrosão generalizada (gen), pite (pite) e passividade (pas); o diagrama é aplicado a um pH arbitrário [STAEHLE, 1992a].

\subsection{Definição da influência ambiental}

A CST depende do meio adequado para se desenvolver, daí a grande importância que tem a definição exata do ambiente onde está se desenvolvendo a trinca. A fim de se predizer a possível ocorrência dos vários modos e submodos de corrosão, é necessário se determinar a relação entre as condições nas quais os vários modos de corrosão acontecem e as condições produzidas pelos diferentes meios. Uma maneira simples de relacionar as condições ambientais com as possíveis atividades dos modos de corrosão é ilustrada na Figura 2.9. Nessa é mostrada a relação entre as condições ambientais (Figura 2.9.b) e as condições nas quais o modo de corrosão ocorre (Figura 2.9.a). Essas condições estão mostradas em coordenadas potencial versus $\mathrm{pH}$, mas poderiam ter sido utilizadas outras. Na Figura 2.9.c é mostrada a superposição dessas condições; na sobreposição (dupla hachura) é mostrada onde a falha por um modo 
específico num meio especifico é provável de ocorrer, embora nada mostre sobre a evolução, a cinética de progressão da mesma [STAEHLE, 1995].

(a) Definiçăo de modo

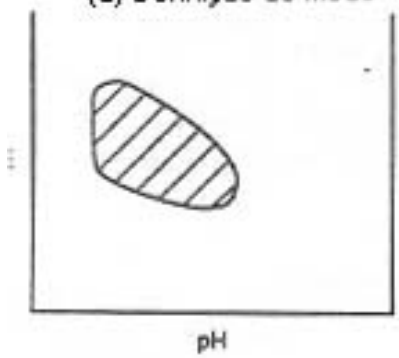

(b) Definiçăo do meio

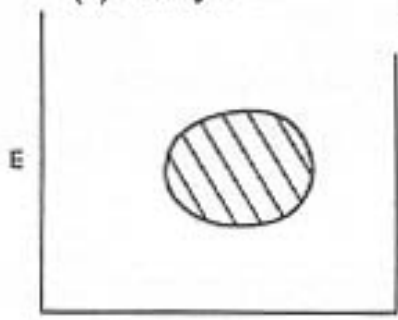

pH (c)

Definiçăo de modo Definiçăo do meio

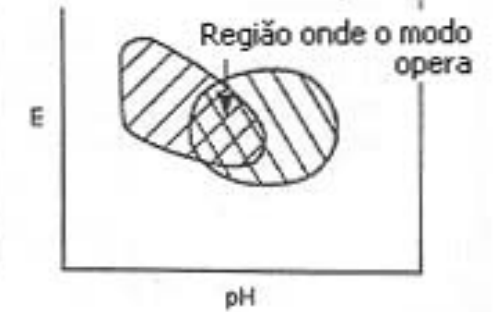

Figura 2.9. Esquema do (a)diagrama de modo de corrosão; (b) diagrama da definição do meio; (c) sobreposição de (a) e (b) [STAEHLE, 1995].

Por outro lado, esse é um diagrama termodinâmico de probabilidade de ocorrência de trincas. Essa definição é fundamental na modelagem de iniciação de trincas que se fará neste trabalho: esse diagrama neste caso, é para a Liga 600 em água pura a alta temperatura e está mostrado na Figura 1.6. O mesmo diagrama, no entanto pode resumir informações sobre a cinética do processo de CST, potencial e $\mathrm{pH}$ sendo ambas variáveis termodinâmicas e cinéticas. Ou seja, o domínio da cinética é definido pelos domínios termodinâmicos. A relação entre termodinâmica e cinética é ilustrada na Figura 2.10 que compara os diagramas termodinâmicos para fases da água e do metal com os respectivos diagramas de cinética eletroquímica e transformações metalúrgicas. Nota-se que em ambos os casos, os diagramas termodinâmicos proporcionam as condições de contorno para os respectivos diagramas cinéticos [STAEHLE, 1992a]. 

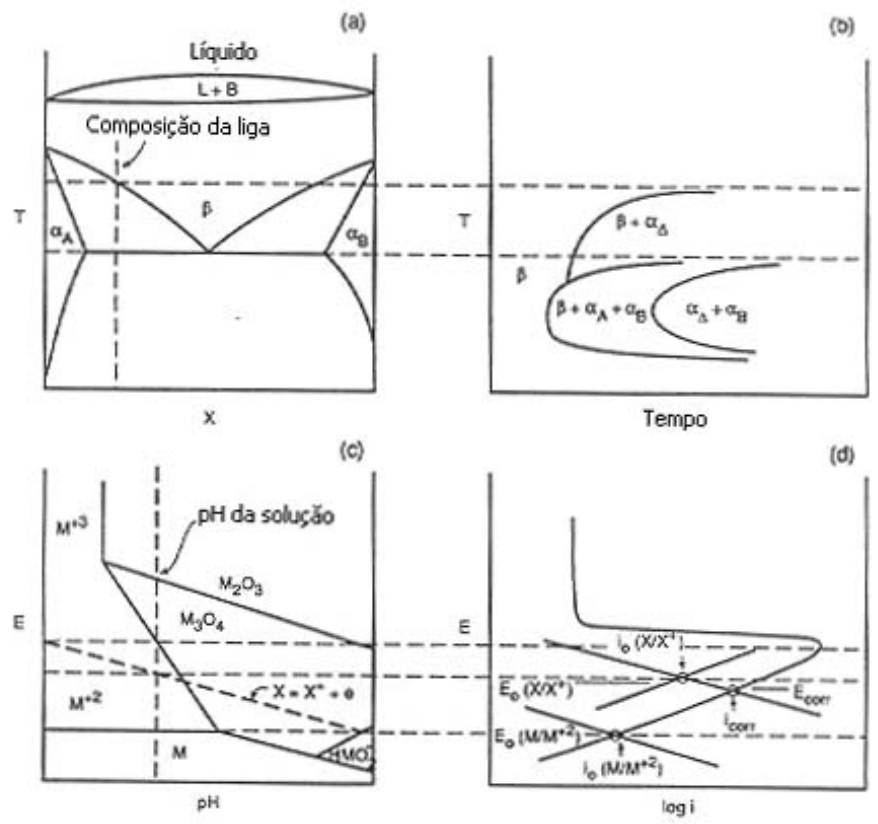

Figura 2.10. Nos diagramas (a) e (b) são ilustrados, respectivamente, o diagrama de fase baseado termodinamicamente e as curvas TTT baseadas cineticamente. Em (c) e (d) são mostrados respectivamente, o o diagrama de Pourbaix, potencial-pH e as curvas de polarização que são baseadas cineticamente [STAEHLE, 1992a].

Cumpre ressaltar a relevância desse ponto na modelagem proposta neste trabalho, pois pretendeu-se associar as regiões de ocorrência de trinca por CST com a cinética de evolução dessas trincas.

Os ambientes que podem ocorrer adjacentes às superfícies onde haverá CST podem ser divididos em quatro categorias, para um melhor entendimento do alcance de sua ação, segundo Staehle [STAEHLE, 1995]:
1) Nominal geral;
2) Nominal característico;
3) Nominal local;
4) Nominal característico ou acidental.

Esse autor classifica todos os ambientes como "nominais" para sugerir que eles são partes implícitas do projeto e precisam ser explicitamente considerados pelos projetistas dos equipamentos onde podem ocorrer CSTAP. É 
portanto, importante que esses perguntem aos especialistas em corrosão qual é o significado de cada uma dessas categorias de ambiente. Seguem abaixo exemplos do que se quer dizer [STAEHLE, 1992a], [STAEHLE, 1995]:

- No caso de materiais eletrônicos imersos em ar úmido, esse é o ambiente "nominal geral";

- No entanto, dentro dessa categoria geral há variações na corrosividade; por exemplo, abaixo de $50 \%$ de umidade relativa não há corrosão: essa só inicia acima de 50\%; essa condição define, portanto o "nominal característico" para um determinado processo corrosivo que está sendo estudado;

- Como exemplo de "nominal local" pode-se citar se há formação local de células galvânicas ou de frestas ("crevices"): especialmente em CST deve-se considerar que pode ocorrer aumento de concentração local em frestas que são associadas com a transferência de calor e efeitos de molhamento e secamento: Warren, por exemplo, utilizou um teste que provocava esse efeito e que acelerou a CST como resultado da crescente concentração de cloreto na superfície de aços inoxidáveis, conforme [STAEHLE, 1992a];

- Como exemplo de "nominal característico ou acidental", pode-se citar produtos que vazam no vapor provenientes de tubos perfurados do condensador.

Ainda com relação ao ambiente, deve ser considerada sua mudança no tempo, segundo as diferentes condições encontráveis em relação aos seguintes fatores: fabricação; armazenamento; transporte; instalação; partida; regimes de operação; parada; operação contínua por longos períodos.

Deve ser considerado também se o ambiente não provoca alteração nas tensões residuais que irão provocar CST: em estruturas de pequenas dimensões importantes acréscimos de tensão residual podem ser provocados pela expansão dos produtos de corrosão.

Há também o efeito de projeto, em que o componente pode falhar por mais de um processo. Cada um dos processos pelos quais a corrosão pode produzir falha pode ser chamado de um caso de corrosão de "modo-localização". Assim um componente pode ter o mesmo submodo de corrosão em diferentes localizações; pode também apresentar falhas por diferentes submodos na mesma localização. É importante considerar que a falha pode ocorrer dos dois lados de um componente de um certo material: é o caso de tubos de trocadores de calor. 
Podem ocorrer falhas também geradas por impurezas de ambientes externos, por exemplo, de isolamento térmico, de depósitos externos, entre outros. Há projetos que exacerbam a corrosão, como superfícies de transferência de calor onde há superaquecimento e concentração de impurezas; quando se formam depósitos superficiais; ou ainda formação de pares galvânicos indesejáveis; estagnação de fluxo que produz depósitos .

Finalmente deve-se ressaltar o papel dos efeitos de controle ambiental em que a corrosão pode ser minimizada pelo controle do meio: esses controles devem ser feitos quando se conclui que as condições naturais não têm capacidade de minimizar a corrosão adequadamente. Por exemplo, selagem hermética de equipamentos, inibidores da fase vapor, captadores de oxigênio, ajustes de $\mathrm{pH}$ utilizando adições sólidas ou voláteis e inibidores específicos anódicos ou catódicos. Deve-se atentar para o aparecimento de efeitos colaterais como o que ocorre quando se usam produtos cáusticos para aumentar o pH: a adição de fosfato, hidróxido de sódio e hidróxido de lítio pode ajustar o pH mas é possível que esses produtos concentrados possam causar CST [STAEHLE, 1995].

\subsection{Definição da influência do material}

Os seguintes aspectos dos materiais precisam ser definidos com relação à corrosão: composição média; composição de múltiplas fases; espécies e concentrações de impurezas; composição do contorno de grão; anisotropia dos grãos; resistência; tenacidade; trabalho a frio; condições superficiais [STAEHLE, 1995].

A definição da composição do contorno de grão é talvez a mais importante delas, uma vez que muitos modos de aceleração de falhas ocorrem nesses locais. Se os contornos de grãos têm composições que são mais susceptíveis de degradação do que o material em si, a corrosão geralmente irá ocorrer nesses. Na Figura 2.3 são mostrados onze diferentes caminhos que levam a defeitos prematuros, portanto toda essa gama de possibilidades deve ser considerada. Na Figura 2.11, são mostrados os possíveis perfis de composição associada com adsorção de espécies em contornos de grão e com precipitação para formar segundas fases. Nesse último caso, a mudança de composição é 
relativamente pequena, mas a magnitude da diferença entre a composição média de impurezas e a composição no contorno de grão pode ser de cinco a seis ordens de grandeza. Os precipitados se formam nas regiões indicadas na Figura 2.11(b). A extensão de mudança de composição é ampla, havendo três regiões de mudança: na região adjacente à zona sem precipitados, na região de composição do precipitado e na interface entre o precipitado e a zona livre dele [STAEHLE, 1995].
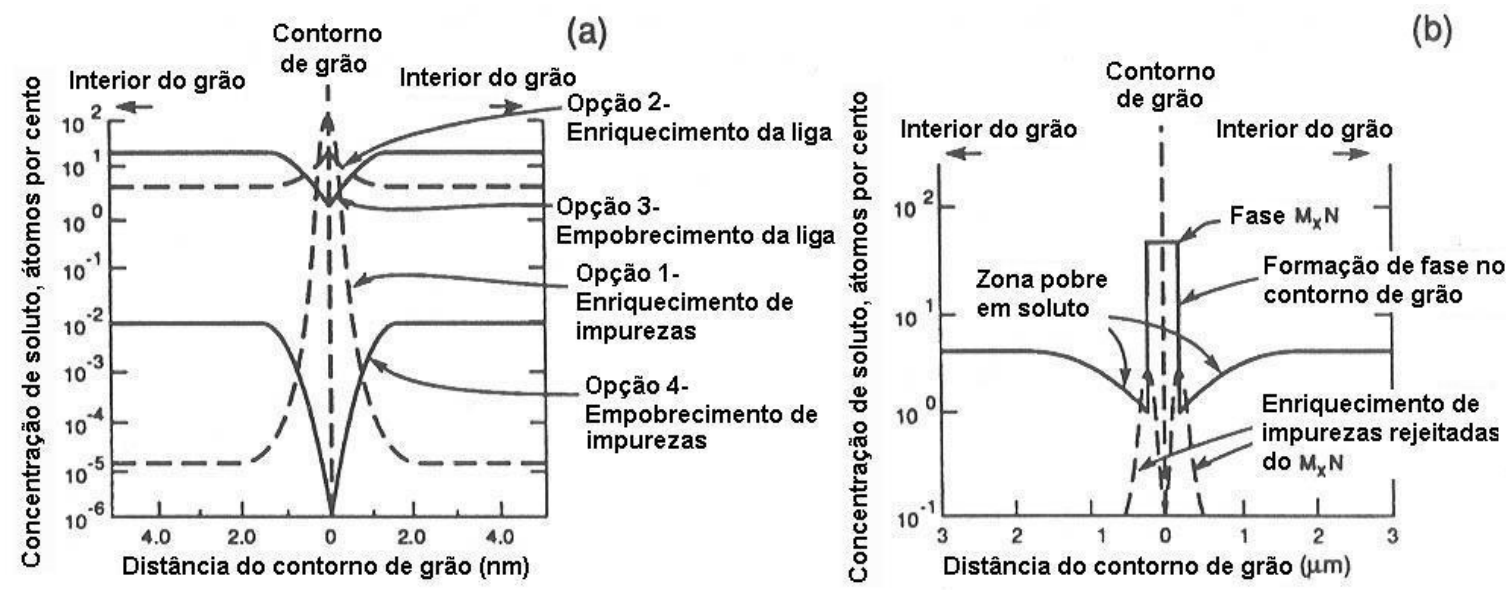

Figura 2.11. Esquema da concentração versus distância dos contornos de grão, para circunstâncias onde os precipitados são formados e onde as espécies atômicas são adsorvidas.

(a) Quatro opções para concentração versus distância onde os átomos são adsorvidos ou rejeitados nos contornos de grão; (b) Principais perfis de composição versus distância para o caso onde os precipitados são formados nos contornos de grão [STAEHLE, 1995]. 


\subsection{Superposição de modo de corrosão com ambiente}

Na Figura 2.9 é mostrada a superposição entre modo e meio ambiente, resultando na região desse meio onde o modo opera. Para o caso da liga $600 \mathrm{em}$ água primária a alta temperatura, esse diagrama esquemático, mostrado na Figura 2.9, resultou na Figura 1.6 superior. Note-se que na prática há vários submodos de corrosão, como estão identificados nessa Figura [STAEHLE, 1995]. Esse diagrama tem diversas vantagens expostas por Staehle em diversos artigos: [STAEHLE\&GORMAN, 1989]; [STAEHLE, 1991]; [STAEHLE, 1992a]; [STAEHLE, 1992b]; [STAEHLE, 1995], [STAEHLE, 2001].

Essa superposição é importante na modelagem proposta nesta Tese, motivo pelo qual será tratada individualmente num capíitulo à parte dentro da aplicação em estudo (capítulo 9).

\subsection{Definição de falha}

Normalmente são consideradas falhas de corrosão quando há perfuração de barreiras mecânicas (por exemplo: tubos, cascos) num determinado tempo menor do que a vida de projeto. No entanto, de forma geral, essa definição pode ser diferente, dependendo dos diferentes materiais e aplicações. Seguem alguns exemplos [STAEHLE, 1995]:

1. Diminuição na qualidade da aparência visual;

2. Falha de uma fração de componentes, como em quadros de circuitos eletrônicos;

3. Falha de uma fração de tubos de um trocador de calor;

4. Penetração parcial da corrosão;

5. Emanação de produto para o meio ambiente. 


\subsection{Definição estatística}

Devido ao grande número de fatores que influenciam o aparecimento de falhas, especialmente no caso de CST, há necessidade de se introduzir um tratamento estatístico para abordar esse fenômeno complexo, dos múltiplos fatores que contribuem para o aparecimento da falha. Esses possuem variabilidades implícitas no material e no meio onde se dá a falha [STAEHLE, 1995].

A própria iniciação de uma trinca por CST é uma mistura de processos determinísticos e estocásticos, conforme é ilustrado na Figura 2.12.

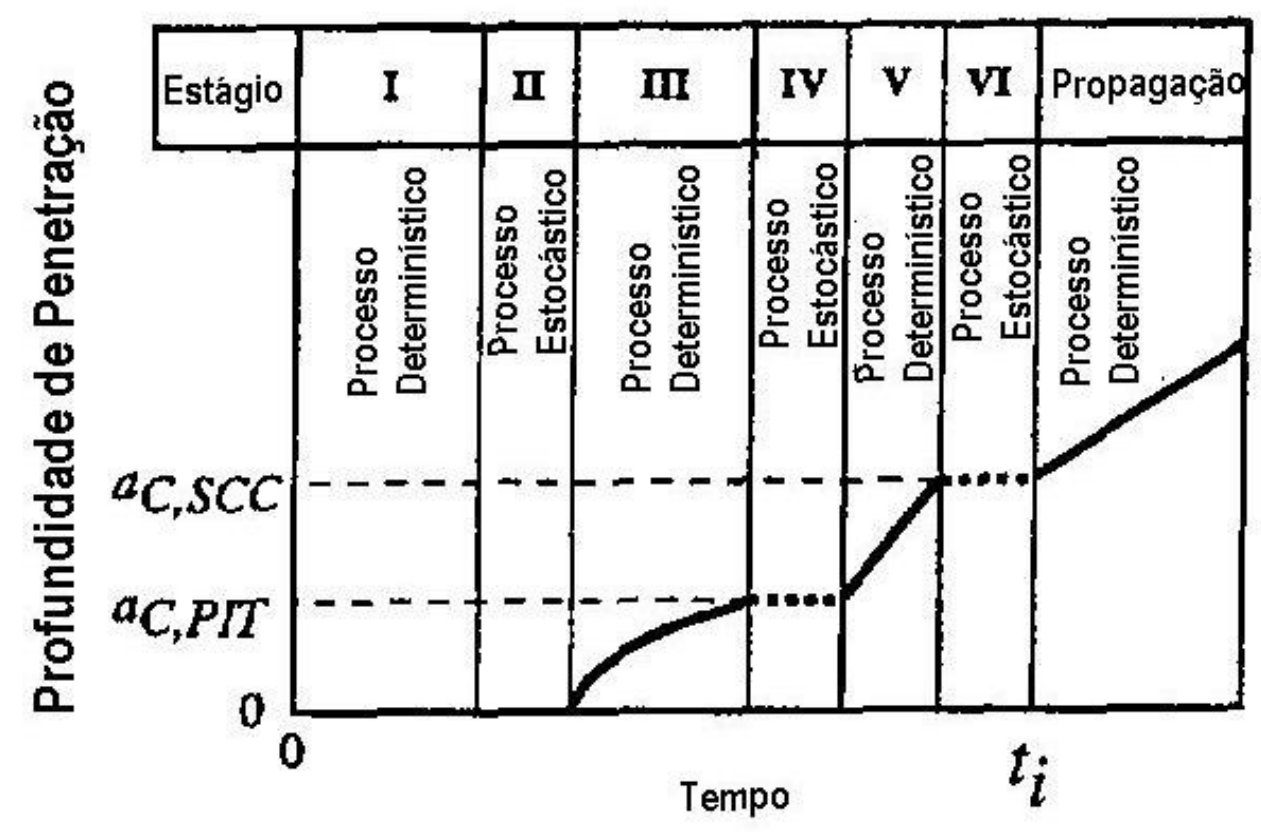

Figura 2.12. Esquema mostrando a profundidade de uma trinca por CST como uma mistura de processos determinísticos e estocásticos, da pesquisa de Akashi e Nakayama [STAEHLE, 2001].

A natureza estatística da falha por CST é extensivamente discutida em [STAEHLE, 2001]. Independente do tipo de abordagem estatística utilizada é necessário um quadro básico dentro do qual a falha pode ser definida e predita. Pode ser utilizado, por exemplo, um diagrama de profundidade de falha (ou trinca) versus tempo (ou tempo ${ }^{-1}$ ). Esse método estatístico tem limitações porque sempre carrega uma margem de risco; no entanto, pode ser usado para fins práticos como por exemplo, quando há poucos recursos para estudos ou pesquisas mais 
aprofundadas ou quando os tempos de falha são bem conhecidos e maiores do que o tempo de vida útil do equipamento [STAEHLE, 1995].

No desenvolvimento de uma forma estatística como base para um modelo quantitativo de falha, podem ser utilizadas diversas distribuições [STAEHLE, 2001]. A distribuição de Weibull é uma das mais utilizadas porque ela descreve de maneira muito ampla o fenômeno de falha (Apêndice 1). A função densidade de probabilidade descrevendo o tempo de falha é dada na equação (2.7.1) e exemplos dessas funções são mostrados na Figura 2.13. A distribuição acumulativa de falha é mostrada na equação (2.7.2) e sua versão linear na equação (2.7.3) e exemplos dessa função são mostrados na Figura 2.14, onde são mostradas as frações de itens com falha versus tempo [STAEHLE, 1995].

$$
\begin{gathered}
f(t)=\left\{b / \theta\left[\left(t-t_{0}\right) / \theta\right]^{b-1}\right\} \cdot \exp \left\{\left[-\left(t-t_{0}\right) / \theta\right]^{b}\right\} \\
F(t)=1-\exp \left[\left(t-t_{0}\right) / \theta\right]^{b} \\
\log \{\log [1 /(1-F(t))]\}=A+b \cdot \log \left(t-t_{0}\right)
\end{gathered}
$$

com: $f(t)=$ função densidade de probabilidade; $b=$ inclinação de Weibull; $t=t e m p o$; $\mathrm{t}_{0}=$ tempo de iniciação; $\theta$ =tempo característico de Weibull; $\mathrm{F}(\mathrm{t})=$ =fração cumulativa de falha. 
(a) Com a mesma inclinação

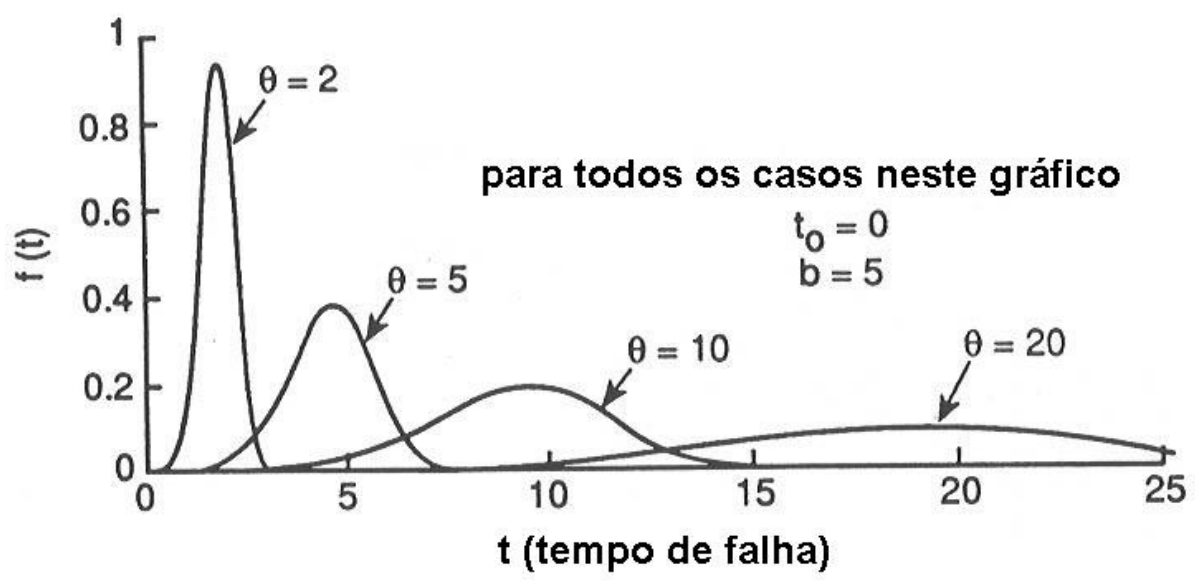

(b) Com o mesmo parâmetro característico

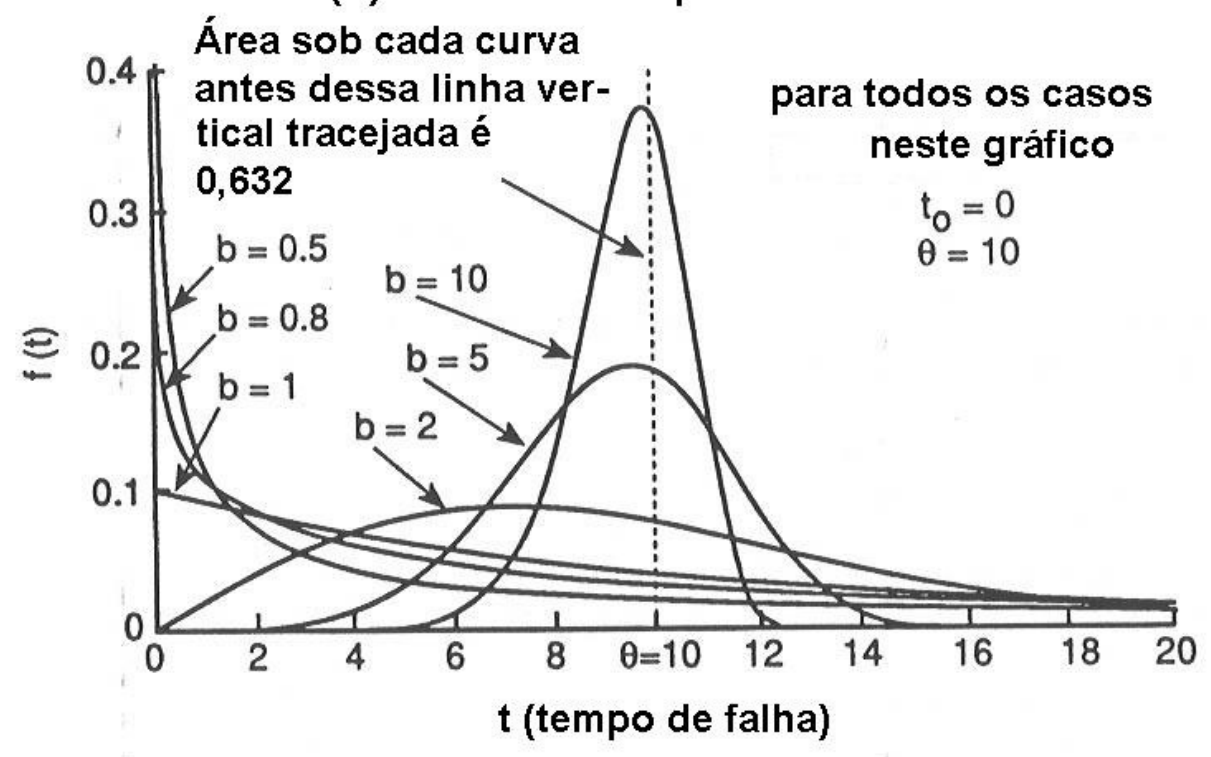

Figura 2.13. Função densidade de probabilidade para a distribuição de Weibull (a) parâmetro $b=5$ $\operatorname{com} \theta=2,5,10,20$; (b) $\theta=10$ com $b=0,5 ; 0,8 ; 1,0 ; 10$. O tempo de iniciação $t_{0}=0$ em ambos os casos. Tempo de falha está em unidade arbitrária [STAEHLE, 1995]. 


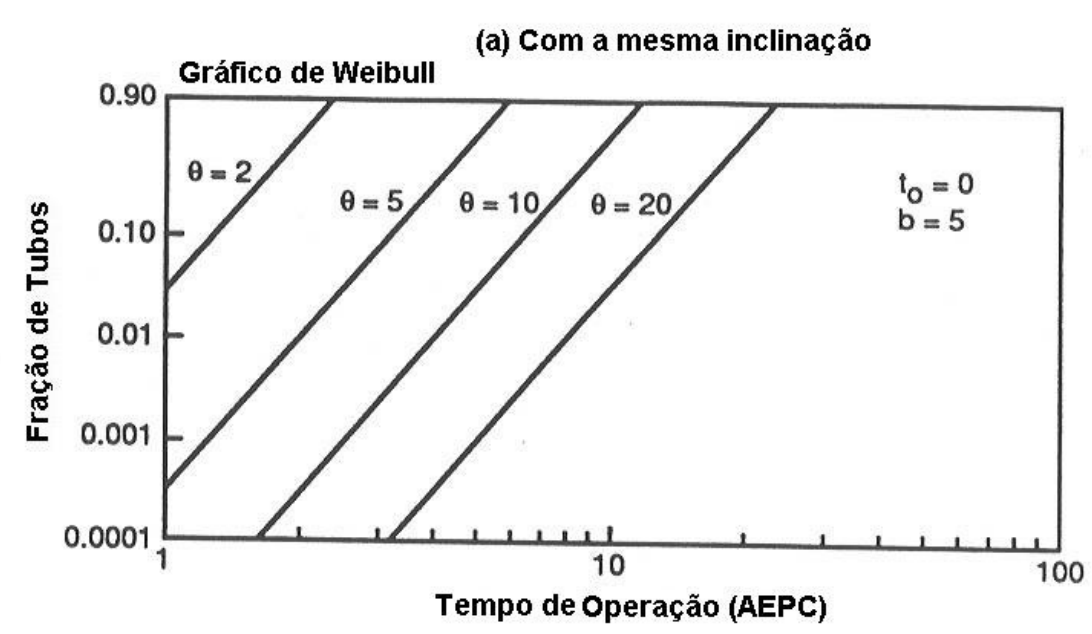

(b) Com o mesmo tempo característico

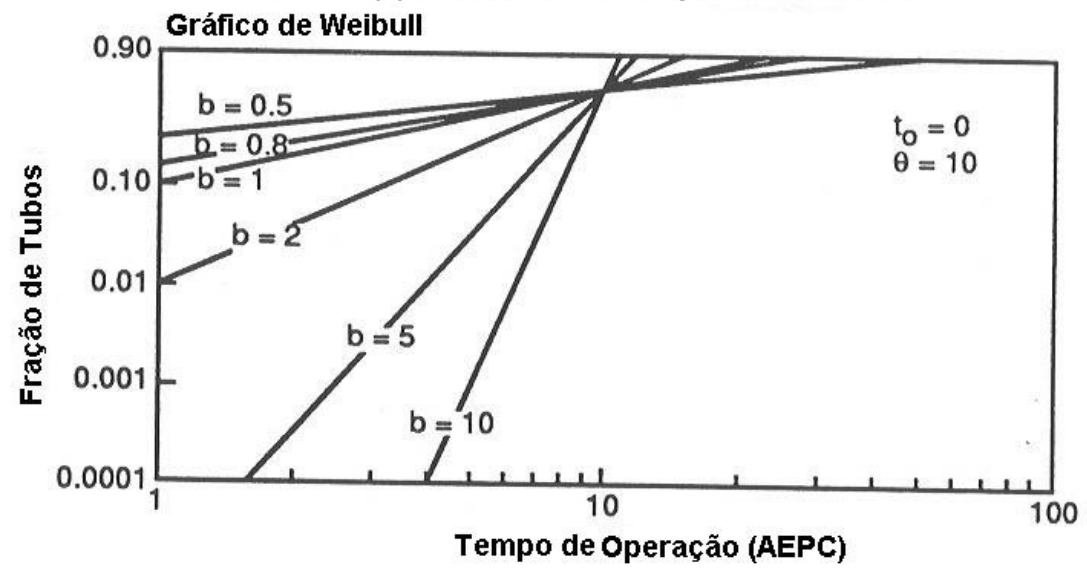

Figura 2.14. Distribuição acumulativa linearizada de Weibull (a) $b=5 \operatorname{com} \theta=2,5,10,20$; (b) $\theta=10$ com $b=0,5 ; 0,8 ; 1,0 ; 10$. $O$ tempo de iniciação $t_{0}=0$ em ambos os casos. Tempo de falha está em unidade arbitrária; AEPC=Anos Efetivos a Plena Carga (ver Glossário) [STAEHLE, 1995].

Os parâmetros das equações de Weibull (2.7.1) a (2.7.3) podem ser determinados em função de variáveis ambientais, como sugere a dependência desses parâmetros com a tensão, conforme mostrado na Figura 2.15. Após feito isso, é possível utilizar a equação (2.7.3) para predizer o desempenho em outras circunstâncias, como mostrado na Figura 2.16. Também é possível predizer como a fração de falha varia quando as variáveis ambientais variam no tempo [STAEHLE, 1995]. 

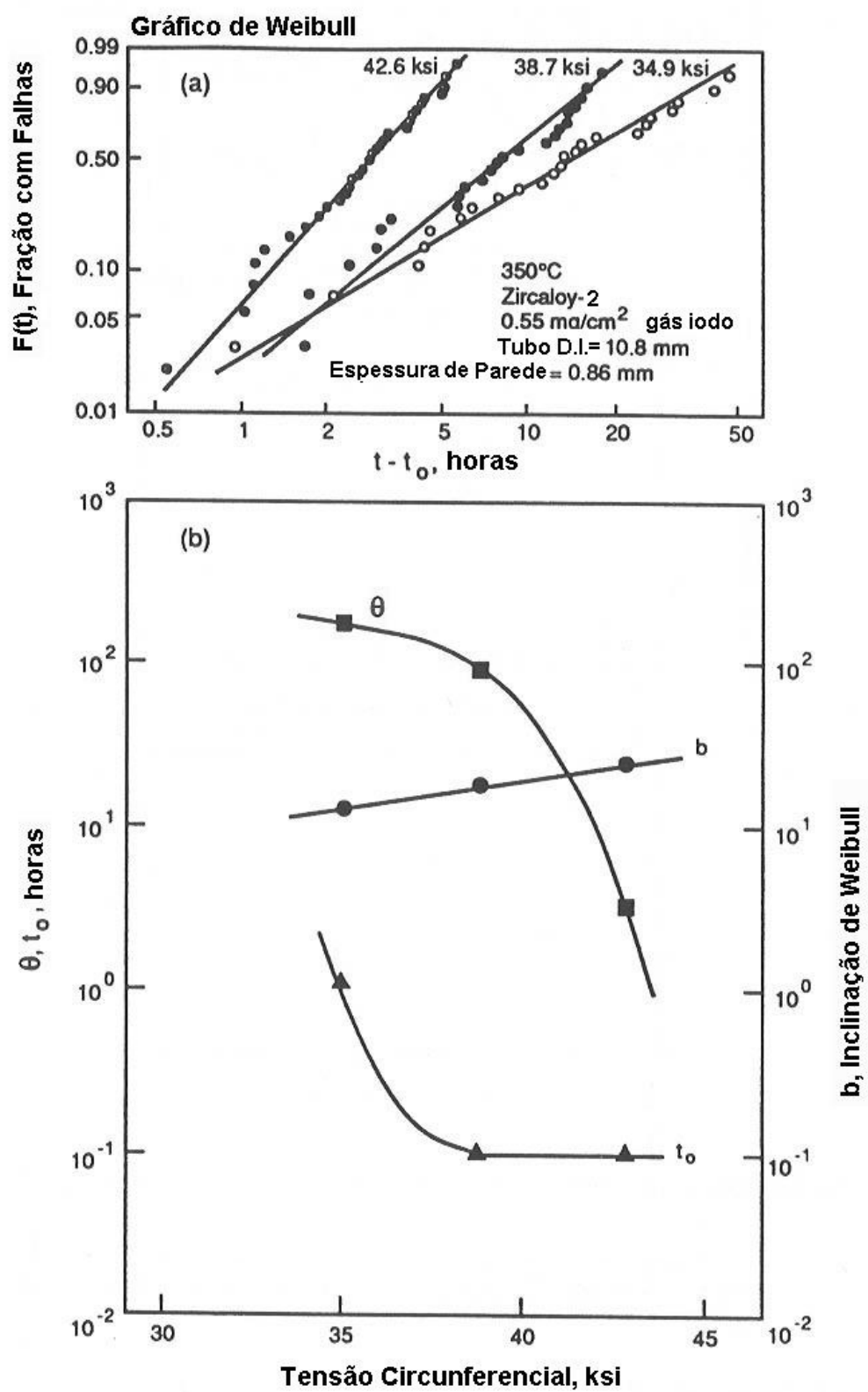

Figura 2.15. Efeito da tensão na taxa de falha cumulativa do Zircaloy-2 em iodo gasoso (a) Distribuições acumulativas para três tensões; (b) Efeito da tensão no tempo característico, inclinação e tempo de iniciação. Adaptado de S.Shimada e M.Nagai [STAEHLE, 1995]. 
(a) Gráfico de Probabilidade

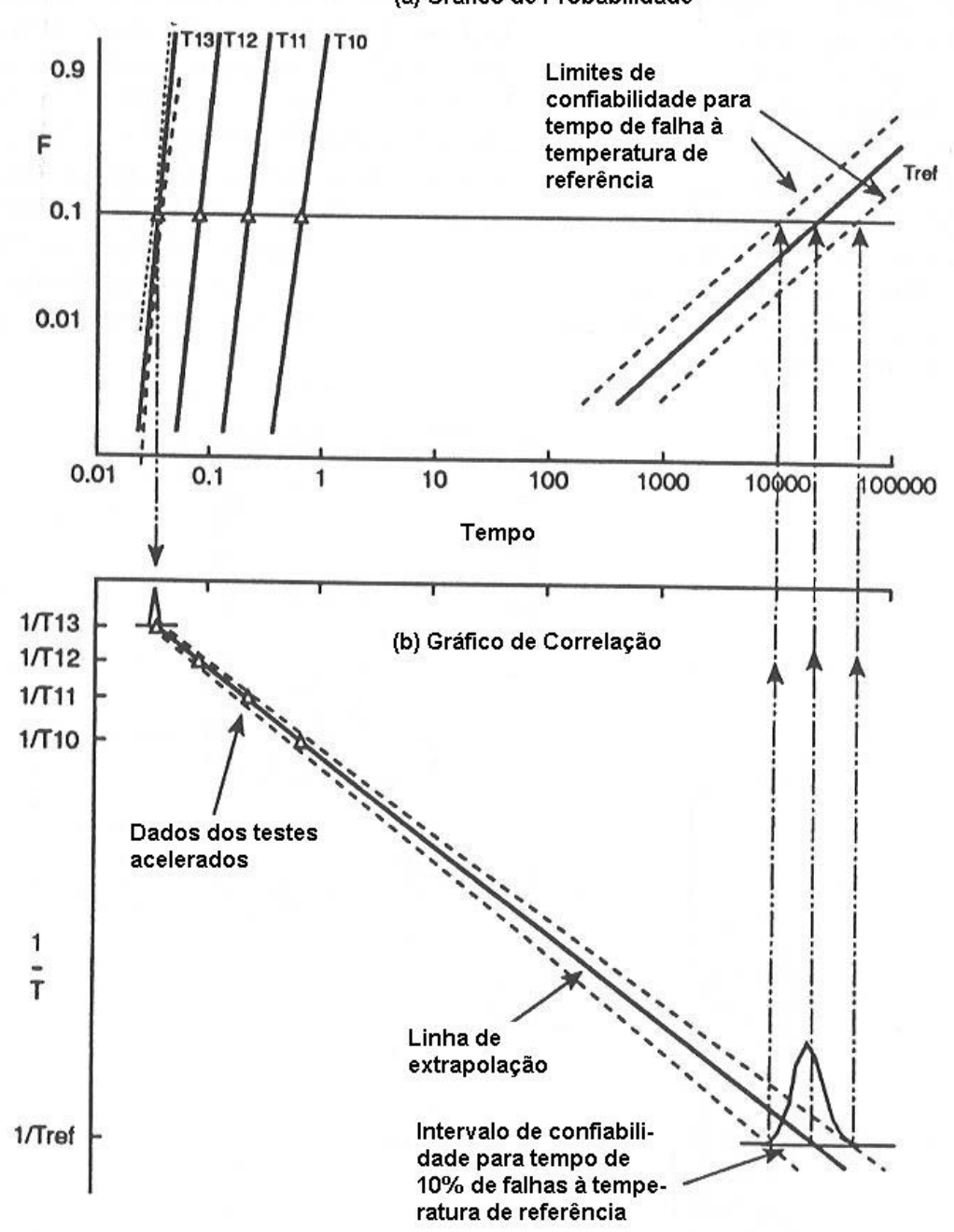

Figura 2.16. (a) Gráfico esquemático da probabilidade acumulativa mostrando curvas para altas temperaturas e para temperatura de referência. Os limites de confiabilidade também são mostrados; (b) $1 / T$ versus tempo mostrando as funções densidade de probabilidade correspondentes aos gráficos de probabilidade acumulativa. De Staehle e Stavropoulos [STAEHLE, 1995].

Ressalte-se finalmente, que a abordagem estatística exposta neste item é a base da técnica de modelagem aplicada ao modelo empírico [GORMAN et al., 1994], que será exposta no item 2.13.1. 


\subsection{Testes acelerados}

Para se obter a informação necessária para avaliar os parâmetros estatísticos das equações (2.7.1), (2.7.2) e (2.7.3), pode-se executar testes acelerados, que são feitos em tempos mais curtos, porém em condições mais agressivas em relação às condições normais onde o componente opera. Esse processo está mostrado na Figura 2.16, onde os resultados dos testes acelerados são extrapolados para as condições reais de operação. Há várias considerações críticas a serem feitas para realizar esses testes com critério: a principal delas é que os testes acelerados sejam realizados considerando os mesmos modos e submodos existentes nas condições operacionais originais de operação; também, deve ser ressaltado que há vários caminhos para se obter a aceleração dos testes, seja por exemplo, via temperatura, tensão e concentração de produtos no meio: é desejável se obter a referida aceleração por vários desses caminhos para maximizar a confiabilidade da predição. Outros detalhes e restantes considerações críticas sobre testes acelerados são dadas em [STAEHLE, 1995].

\subsection{Previsão}

Para previsão do desempenho, os dados devem aparecer como na Figura 2.13. No entanto, é possível que um ou outro componente possa apresentar mais do que um submodo de falha. Nesse caso, a fração total de falha é um menos a produtória dos complementos das frações de falha em cada submodo aplicável, como é mostrado na equação (2.9.1) e na Figura 2.17.

$$
F_{\mathrm{T}}=1-\left(1-F_{1}\right) \cdot\left(1-F_{2}\right) \ldots\left(1-F_{3}\right)
$$




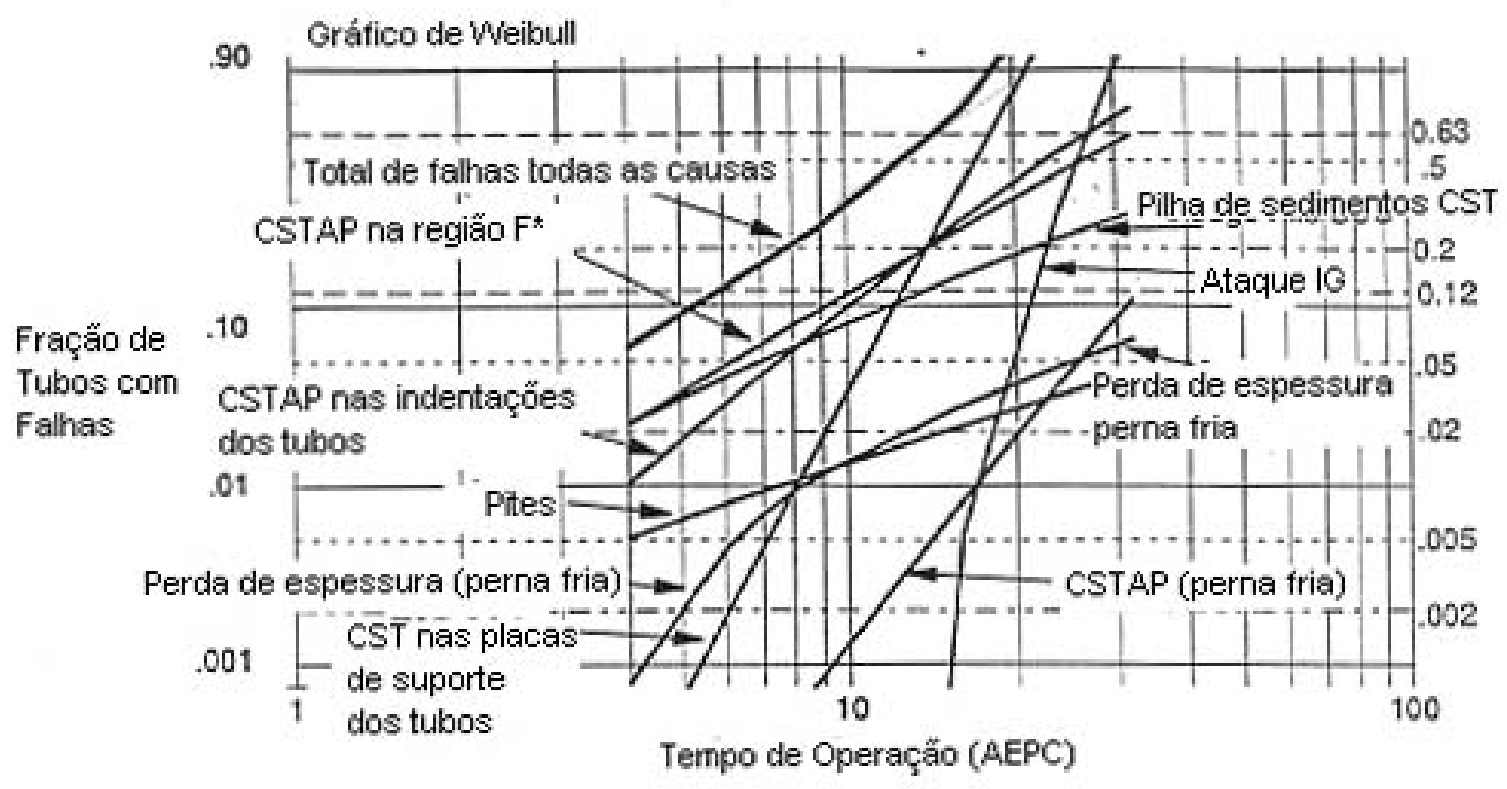

Figura 2.17. Exemplo de adição de distribuições acumulativas para casos distintos de falhas por corrosão ou perda de espessura em função da localização numa usina nuclear, produzindo uma distribuição combinada do total das falhas dessa usina [GORMAN \& STAEHLE, 1989].

\subsection{Modificações e otimização: projeto, materiais, ambientes e operação}

As previsões desenvolvidas no item anterior deverão demonstrar se o projeto é satisfatório ou não. Se ele for inadequado em algum aspecto, esses resultados acarretarão modificações no projeto, materiais, ambientes e modo de operação: podem ser necessárias várias iterações neste processo [STAEHLE, 1995]. 


\subsection{Realimentação de informações e correção}

Quando o equipamento opera, podem ocorrer problemas inesperados: essa informação é útil para modificar o projeto, material, ambiente e modo de operação. Para proporcionar essa realimentação de informações, é normalmente necessária instrumentação adequada e medições periódicas do equipamento em operação. Para isso deve-se proceder ao levantamento de existência e propagação de trincas, o que pode ser obtido através de vários métodos de ensaios não destrutivos ou ainda equipamentos especiais de inspeção como o mostrado na Figura 2.18.
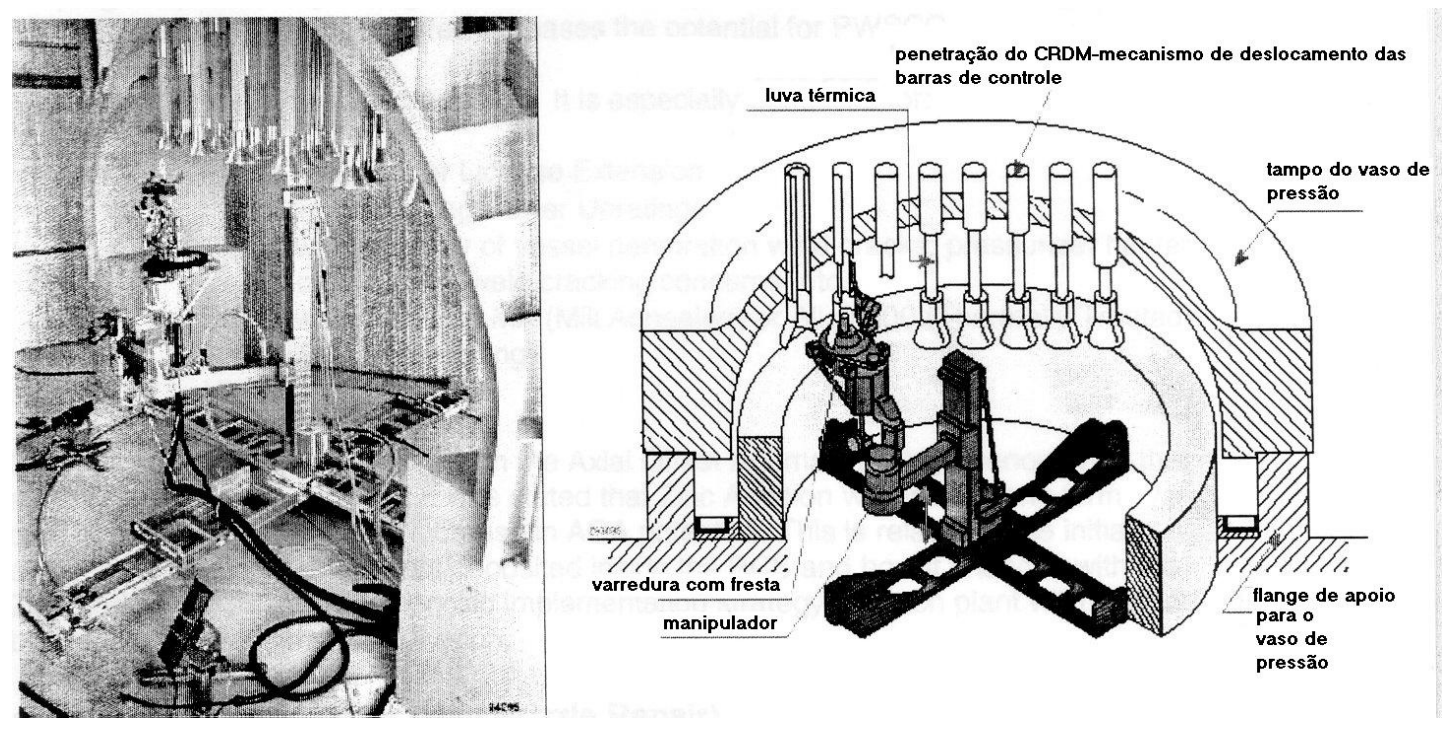

Figura 2.18. Equipamento especial de inspeção para os bocais do mecanismo de acionamento das barras de controle de reator de água pressurizada [IAEA, 1997].

Há casos de alguns sistemas que não podem ser facilmente monitorados e inspecionados, como os recipientes de lixo radioativo: nesse caso, são necessários níveis mais altos de considerações iniciais de projeto [STAEHLE, 1992a]. 


\subsection{Abordagem do projeto baseada em corrosão}

As etapas descritas entre os itens 2.2.1 e 2.11 consistem em um método proposto por Staehle, nomeado de "Abordagem de Projeto Baseada na Corrosão" ("Corrosion-based design approach"). Este método de engenharia tem por objetivo determinar e assegurar o desempenho dos materiais com base na corrosão. Resumindo o que foi escrito nos itens anteriores, pode-se estruturar esquematicamente nos seguintes dez passos [STAEHLE, 1995]:

1. Definição do meio ambiente.

2. Definição do material.

3. Definição dos modos e submodos.

4. Superposição do ambiente com as definições de modo/submodo.

5. Definição de falha.

6. Definição estatística.

7. Testes acelerados.

8. Previsão.

9. Realimentação.

10. Modificação e otimização do projeto, material, meio ambiente, operação.

Note-se que essa metodologia, aqui aplicada à CST, pode ser estendida a qualquer tipo de corrosão, tendo em vista que os processos de outros tipos de corrosão em geral são de análise bem mais simples.

Essas idéias também não são particularmente novas, mas o método permite uma codificação de "bom senso comum da engenharia de corrosão": os textos sobre corrosão raramente visam estratégias estruturadas para a predição de falhas e em sua maioria discutem os modos de corrosão sem uma abordagem integrada com conexão aos projetos ou previsões [STAEHLE, 1992a]. 


\section{A CORROSÃO SOB TENSÃO NA LIGA 600 EM ÁGUA dO CIRCUITO PRIMÁRIO}

A CSTAP é uma das mais comuns e perigosas formas de corrosão conjunta com a aplicação de tensão de tração estática. Ela ocorre freqüentemente sem indicação macroscópica de uma fratura iminente, já que muitas trincas desenvolvem-se com poucas evidências de produtos de corrosão, sem deformação plástica macroscópica do material e com características de fratura frágil, embora com muito menor velocidade de propagação do que essas [RAMANATHAN, 1992].

A CSTAP requer a presença simultânea de altas tensões, ambiente corrosivo (neste caso também alta temperatura da água) e uma microestrutura susceptível a trincas [ROBERTS, 1981], [SHAH et al, 1994].

A CSTAP afeta principalmente os tubos geradores de vapor, tanto do lado da água do circuito primário, quanto do lado do circuito secundário. $O$ outro conjunto de componentes afetados pela CSTAP é formado pelos bocais do MAB, que também estão em contacto com a água do circuito primário, cuja temperatura é em torno de $315^{\circ} \mathrm{C}$ e pressão em torno de $16 \mathrm{MPa}$. Essa região está localizada em torno das ranhuras do tipo "J", que recebem solda de fixação e selagem dos bocais, da parte que atravessa o tampo do vaso do RAP, conforme é ilustrado na Figura 3.1.

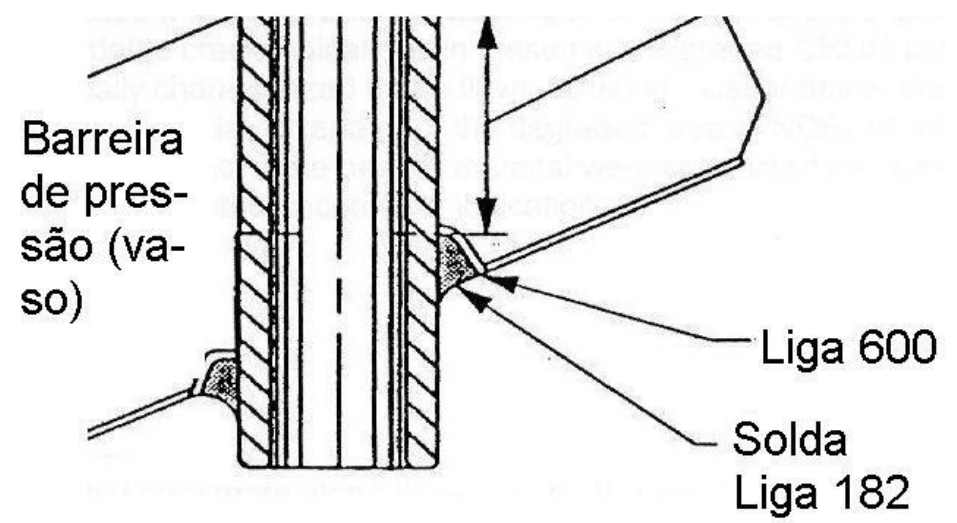

Figura 3.1. Região da solda dissimilar tipo "J", entre os bocais do MAB e a carcaça do tampo do vaso tipo RAP [MEDOFF, 2001]. 
Essa solda dissimilar com a Liga 600 é executada no material Liga $182=$ 59,0 min $\%$ Ni; $13,0-17,0 \% \mathrm{Cr} ; 10,0 \% \mathrm{Fe} ; 0,10 \% \mathrm{C} ; \mathrm{Nb}+\mathrm{Ta}=1,0-2,5 \%$ ou Liga $82=$ 67, 0 min\% ( $\mathrm{Ni}+\mathrm{Co}$ ); 18,0-22,0\% Cr; 0,10\%C; 3,0\% Fe; Nb+Ta=2,0-3,0\% [STAEHLE, 2001]. Esse último caso é objeto de estudo desta Tese, com a seguinte simplificação importante: está-se considerando apenas as trincas iniciadas na liga 600 e não na junção da liga 600 com as ligas 182 ou 82: isto porque esse é um caso bem mais complexo, onde há outras interações mecânicas a serem consideradas, como novas tensões residuais introduzidas pela aplicação da solda e outras estruturas cristalinas como as dendríticas, novos precipitados decorrentes de novos elementos de liga, variações na estrutura cristalina devido a ações de temperaturas que influenciam no tratamento térmico, entre outros fatores. Um bom ponto de partida para detalhamento dessas variações está em [BUSO, 2001].

\subsection{Descrição morfológica}

A CSTAP da liga 600 caracteriza-se por um número limitado de trincas localizadas em pontos precisos dos componentes, como as zonas de mandrilamento dos tubos de geradores de vapor, ou no caso em estudo, em regiões próximas à solda de fixação dos bocais do MAB dessa Liga, com o tampo do vaso do RAP. Elas, no entanto, são bem mais numerosas em ensaios de laboratório, em regime de deformação lenta, e repartidas ao longo do corpo de prova. As ramificações dessas trincas são raramente profundas e seu aspecto geralmente intergranular de aparência frágil, ainda que o material tenha um comportamento mecânico dúctil [FOCT, 1999].

A fratura frágil em si ocorre em baixa temperatura quando as impurezas segregadas nos contornos de grãos abaixam sua energia de coesão [LEMAITRE \& CHABOCHE, 1990].

No caso da liga 600 a CSTAP apresenta predominantemente a morfologia de fratura intergranular, devida principalmente ao fenômeno de fluência ("creep") à alta temperatura.

A fratura intergranular devida à fluência é observada principalmente a médias e altas temperaturas - superiores a um terço da temperatura absoluta de fusão do material - e pode apresentar-se com ou sem deformação viscoplástica 
total: nesse último caso, justifica-se o termo "frágil". Os defeitos que levam a esse modo de fratura são inicialmente na forma de cavidades nos contornos de grãos onde as discordâncias estão empilhadas e que subseqüentemente aumentam de volume e se auto-reproduzem. Também podem estar na forma de decoesões chamadas de pontos triplos que resultam da intersecção de três cristais que seguem planos de deslizamento intercristalinos. Essas decoesões intergranulares ocorrem durante um determinado período de tempo e podem ser causadas pela fluência. Quando ocorrem as decoesões em vários contornos de grão adjacentes, diz-se que se iniciou uma fratura cristalina [LEMAITRE \& CHABOCHE, 1990].

No entanto, também foi observada a presença de trincas pseudo intergranulares, conforme ilustrado na Figura 3.2(c), que são formadas de pequenos degraus, em torno de $1 \mu \mathrm{m}$, ao longo dos grãos cujas juntas são inferiores a $45^{\circ}$ em relação ao eixo de solicitação das tensões [FOCT, 1999]. 

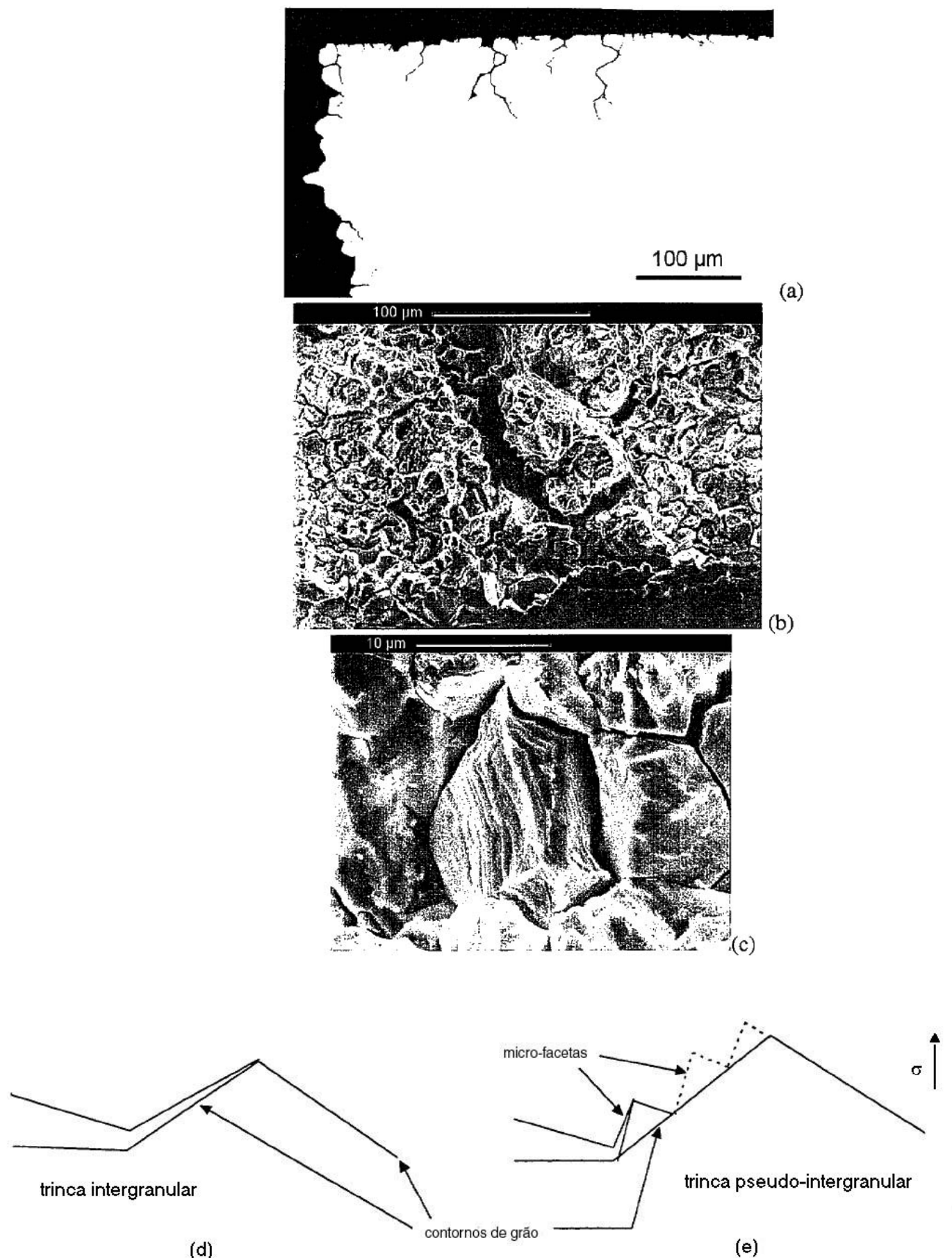

Figura 3.2. Trincas de CSTAP da liga $600,360^{\circ} \mathrm{C}$, tração lenta: (a) corte longitudinal do corpo de prova; (b) superfície de ruptura de aspecto intergranular; (c) e pseudo-intergranular; (d) esquema de trinca intergranular; (e) trinca pseudo-intergranular [FOCT, 1999].

A fratura transgranular é extremamente rara, mas já foi observada em proporções significativas em casos particulares de solicitações, sendo que 
aumenta para velocidades de deformação mais elevadas e menores temperaturas [FOCT, 1999].

Do ponto de vista teórico, a CST pode ser dividida em nove estágios [STAEHLE, 1992], como é mostrado na Figura 3.3:

1. O filme passivo, película de proteção, adapta-se ao meio ambiente.

2. Há perfuração química ou mecânica do filme passivo.

3. Inicia-se a trinca por pite, corrosão intergranular ou quebra do filme passivo através de camadas inter deslizantes devidas às tensões de cisalhamento, túneis, dissolução seletiva e fragilização por hidrogênio.

4. Surge prematuramente a CST.

5. Há coalescência de algumas trincas por CST.

6. Propagação de CST coalescida até atingir o coeficiente de intensificação de tensão crítico de CST (K ICST).

7. Propagação no estágio I.

8. Propagação no estágio II.

9. Propagação no estágio III.

Do ponto de vista prático, a CST pode ser dividida em três estágios sucessivos: (a) iniciação: tempo necessário para que uma trinca atinja a detecção óptica de trincas, 1 a $2 \mu \mathrm{m}$. Esse pode corresponder à duração de instauração de condições eletroquímicas e mecânicas necessárias à aparição de uma trinca e pode variar de uma centena a vários milhares de horas de acordo com a sensibilidade do material à CST e o tipo de ensaio utilizado para caracterização; (b) propagação lenta; (c) propagação rápida: uma vez atingido um tamanho crítico, sua velocidade de propagação aumenta bruscamente, de um fator cerca de 10. Esse estágio não é sistematicamente observado; assim, o período de iniciação constitui a maior parte da duração da vida de um corpo de prova solicitado em deformação imposta e a propagação lenta representa o essencial da duração da vida do corpo de prova num ensaio à deformação imposta [FOCT, 1999].

Santarini propôs uma caracterização morfológica da CST com a ajuda de uma função descrevendo a evolução no tempo da repartição das profundidades 
de trincas de CST: esse modelo morfológico permite estimar por extrapolação os tempos de iniciação verdadeiros [CARON, 2001].

Há ainda a possibilidade prática de se considerar iniciação e propagação como uma única fase, cujo resultado é o parâmetro de dano mecânico: nesse caso, é preciso utilizar um modelo de iniciação e propagação de trincas como o de Gerber e Garud [BEGLEY, 1990], [GORMAN et al, 1994].

\subsection{Composição química e estrutura do filme passivo}

A maioria dos modelos atribui importância fundamental ao filme passivo no processo de CST. Esse terá um papel direto no caso de mecanismos de fratura por dissolução ou ruptura desse filme ou indireto agindo como barreira à absorção de hidrogênio. Assim torna-se necessário conhecer a composição química, a estrutura da camada de óxido formado em meio primário na superfície da liga 600, bem como sua evolução na presença de hidrogênio [FOCT, 1999].

Antes de tudo é necessário identificar as espécies termodinamicamente estáveis susceptíveis de se formar na superfície da liga 600 nessas condições de oxidação. Os valores do potencial de circuito aberto da Liga em meio primário são vizinhos próximos a algumas dezenas de milivolts do potencial de equilíbrio $\mathrm{H}^{+} / \mathrm{H}_{2}$ [FOCT, 1999]. Muitos diagramas de Pourbaix, potencial-pH, foram levantados em água a $300^{\circ} \mathrm{C}$, para o níquel, ferro e cromo [CHEN, 1983]. Sabendo-se que o hidrogênio em solução causa diminuição do potencial, pode-se esperar que um pequeno aumento da pressão parcial de hidrogênio seja suficiente para desestabilizar o $\mathrm{NiO}$ presente à superfície da liga 600 (o níquel pode contudo entrar na composição de óxidos $\mathrm{NiFe}_{2} \mathrm{O}_{4}$ e $\mathrm{NiCr}_{2} \mathrm{O}_{4}$ ). No que concerne ao ferro e ao cromo, as espécies estáveis são respectivamente $\mathrm{Fe}_{3} \mathrm{O}_{4}$ e $\mathrm{Cr}_{2} \mathrm{O}_{3}(\mathrm{CrOOH}$ também é possível) [FOCT, 1999]. 


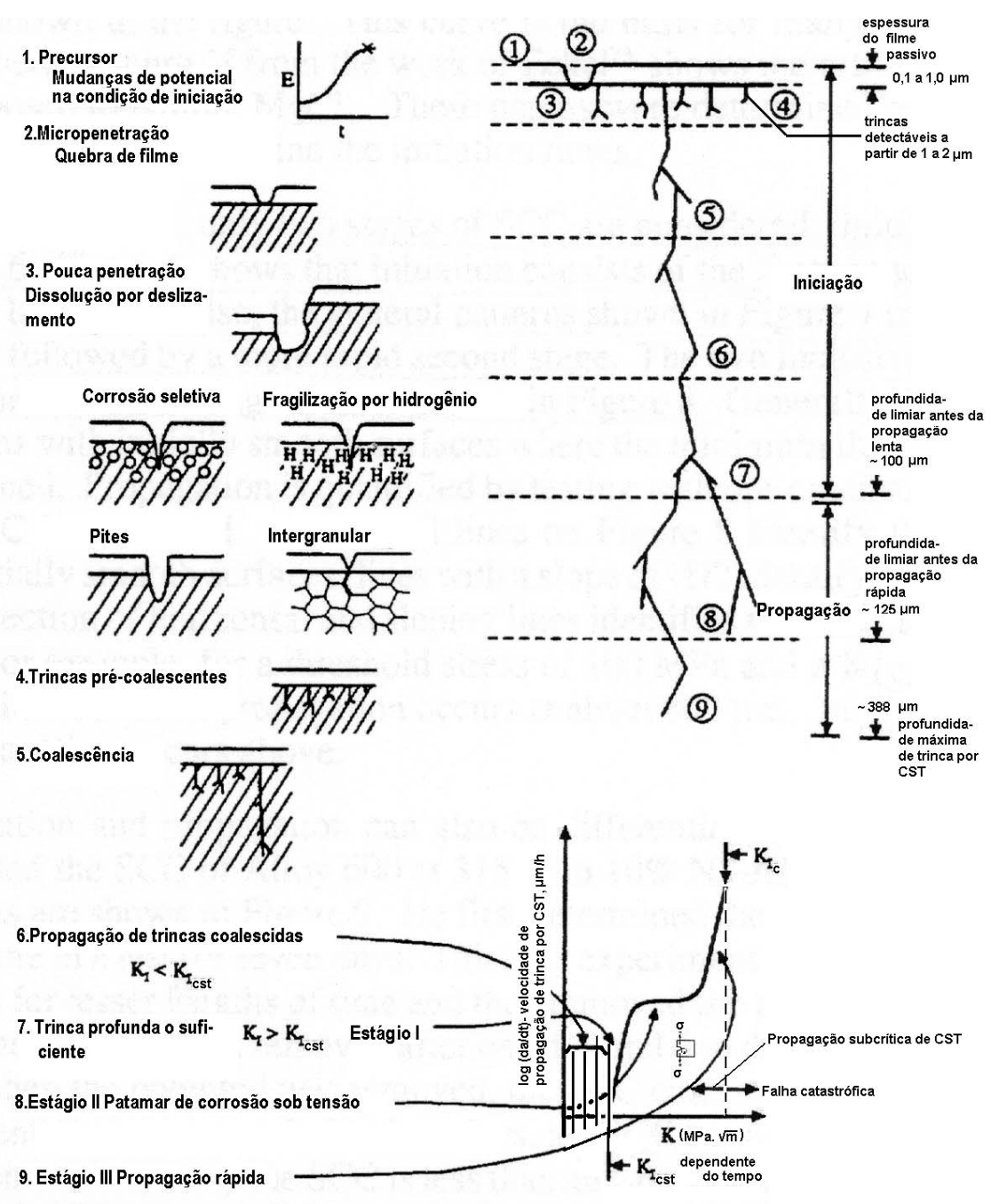

Figura 3.3. Evolução em etapas discretas na iniciação e propagação da CST de [STAEHLE, 1992]. As espessuras das trincas foram estimadas para experimentos de espécimes de liga $600 \mathrm{em}$ condição de $\operatorname{CSTAP}\left(360^{\circ} \mathrm{C}\right)$, ensaiados em SSRT com taxa de deformação $=10^{-7} \mathrm{~s}^{-1}, \mathrm{~K}_{\text {ICST }} \sim 10$

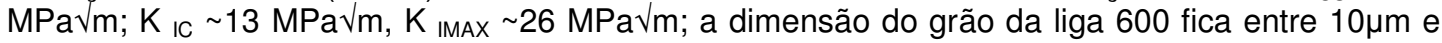
$50 \mu \mathrm{m}$; velocidades de propagação de trincas típicas para propagação lenta $\sim 0,36 \mu \mathrm{m} / \mathrm{h}$ e para propagação rápida 4,6 $\mu \mathrm{m} / \mathrm{h}$ : essas informações foram baseadas em experimentos de Foct em [FOCT, 1999] e em consideração de Andresen [ANDRESEN, 2005].

As análises de espectroscopia por descarga luminescente (EDL) realizadas sobre amostras de tubos oxidados durante muitas centenas de horas em meio primário indicam qualitativamente a composição atômica do óxido em $\mathrm{Fe}, \mathrm{Ni}, \mathrm{Cr}$, mas também de Al muitas vezes presente por causa dos tratamentos de superfície ligados ao processo de fabricação (jateamento por alumina). Combrade e outros [COMBRADE et al., apud FOCT 1999] mostraram que o filme é constituído por óxidos espinéis de fórmula genérica ( $\mathrm{Fe}, \mathrm{Ni})(\mathrm{Cr}, \mathrm{Fe})_{2} \mathrm{O}_{4}$ enriquecidos em cromo em relação à matriz. Outros autores efetuaram análises para precisar em função da temperatura, a composição do óxido indicada por 
Combrade. A $325^{\circ} \mathrm{C}$ em meio de água primária, o óxido apresenta uma estrutura de camada dupla cuja parte externa é constituída por cristalitos associadas à estrutura espinel $\mathrm{Ni}_{x} \mathrm{Fe}_{2-\mathrm{x}} \mathrm{O}_{4}$, conforme ilustrado na Figura 3.4. Por outro lado, a $350^{\circ} \mathrm{C}-360^{\circ} \mathrm{C}$, Gardey [GARDEY apud FOCT 1999] coloca em evidência uma parte externa caracterizada pela presença de palhetas micrométricas ricas em níquel, conforme mostrado na Figura 3.4. O autor supõe com base em resultados obtidos por outros pesquisadores, que essa camada externa é composta de $\mathrm{NiO}$ e $\mathrm{Ni}(\mathrm{OH})_{2}$. Para as duas condições de temperatura, a camada compacta interna tem teores em ferro, níquel e cromo próximos daqueles da matriz metalográfica com um enriquecimento eventual de cromo que pode ser bastante marcado e que depende do estado inicial da superfície do material. A partir de estudos de corrosão generalizada, foi demonstrada uma forte dependência da resistência à corrosão com o teor de cromo. Assim, Gardey mostrou que a liga 600 cujo óxido é enriquecido com cromo por um tratamento de superfície de polimento eletrolítico, apresenta uma oxidação bem menor (filme mais fino e com relaxação reduzida). Esses óxidos apresentam uma estrutura em camada dupla onde a camada interna é fortemente enriquecida em cromo [FOCT, 1999].

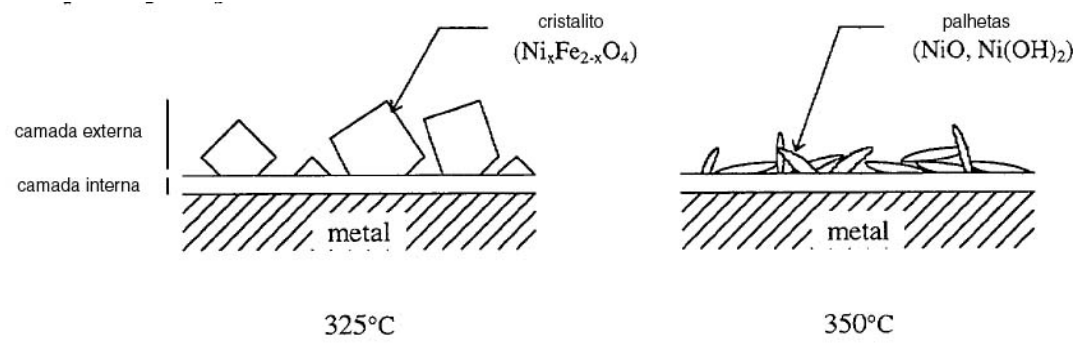

Figura 3.4. Esquema de Gardey da morfologia dos óxidos da liga 600 em água primária a $325^{\circ} \mathrm{C}$ e $350^{\circ} \mathrm{C}$. A camada interna é composta de teores de $\mathrm{Fe}, \mathrm{Ni}$ e Cr próximos dos da matriz metálica. Pode haver nessa camada um forte enriquecimento de $\mathrm{Cr}$ dependente do estado superficial inicial do material [FOCT, 1999].

\subsection{Composição química e estrutura dos óxidos sobre as superfícies de ruptura}

Convém se comentar também como é a distribuição dos diferentes tipos de óxidos na região de fratura. Em análises microscópicas efetuadas por meio de microscópio eletrônico de transmissão (MET) mostrou-se que há formação de zonas porosas oxidadas sobre várias micra ao longo dos contornos de grãos na vizinhança de trincas por CST, assim como a formação de uma zona porosa mais curta, entre 50 e $100 \mathrm{~nm}$, na frente da ponta da mesma. As penetrações intergranulares não trincadas são constituídas de um óxido poroso de estrutura 
similar àquela de $\mathrm{NiO}$ mas enriquecida em cromo. Ao longo dos flancos e na ponta da trinca, o óxido também tem a mesma estrutura do $\mathrm{NiO}$, junto com $\mathrm{Cr}_{2} \mathrm{O}_{3}$. Finalmente foi observada a 100nm da ponta da trinca, uma zona porosa com presença de óxidos. Essas observações podem ser sintetizadas na Figura 3.5 e foram feitas sobre uma lâmina fina retirada de uma amostra de um tubo em "U" em liga 600 após ensaio em água primária a $330^{\circ} \mathrm{C}$ e concentração de hidrogênio na água, $40 \mathrm{ml}$ CNTP. $\mathrm{kg}^{-1} \mathrm{H}_{2} \mathrm{O}$ (23kPa) [CARON, 2001].

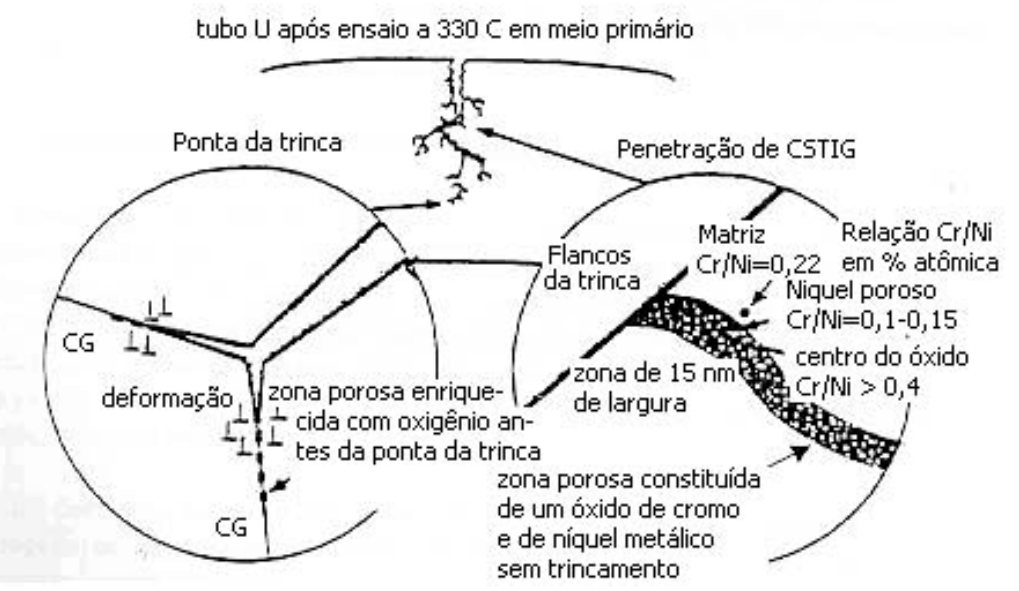

Figura 3.5. Esquema representativo dos resultados de observações através de MET numa trinca por CST na liga 600 [CARON, 2001].

Fish e outros autores estudaram através de difração de elétrons e espectroscopia por raio-X de energia dispersa (EDX), a composição de óxidos depositados em superfícies de trincas por CSTAP na liga 600 e obtiveram: a) na superfície adjacente à trinca, uma camada dupla formada externamente por um óxido espinel de NiCrFe e internamente por um espinel rico em $\mathrm{Cr}$ composto com um óxido hexagonal na forma de $\mathrm{Cr}_{2} \mathrm{O}_{3}$ com $\mathrm{Fe}$ e $\mathrm{Ni}$; b) na superfície interna da trinca um óxido composto (Ni, Cr, Fe)O [FISH et al., 1997]. 


\section{INFLUÊNCIA DO MEIO NA CST EM LIGA 600}

\subsection{Temperatura}

A CSTAP da liga 600 é um fenômeno termicamente ativado, com o efeito da temperatura descrito por uma energia de ativação aparente [FOCT, 1999]: o aumento da temperatura acelera a taxa de reações químicas e geralmente acelera a taxa de reações de corrosão [STAEHLE, 1992a]. Também as altas energias de ativação permitem o transporte de íons ou vacâncias através do filme passivo [SCOTT\&COMBRADE, 1996].

Esse aumento segue a lei de Arrehnius descrita pela equação (4.1.1) [STAEHLE, 1992a].

$$
R_{c}=A \exp [-Q / R T]
$$

com: $R_{c}=$ taxa de reações de corrosão; $A=$ constante; $Q=$ energia de ativação; $\mathrm{R}=$ constante universal dos gases; $\mathrm{T}=$ temperatura absoluta.

Em 1889 Arrehnius observou que existe um "estado de ativação" intermediário entre reagentes e produtos, sugerindo que a taxa de reação é controlada por uma expressão da forma (4.1.1). Essa equação é baseada na equação de van't Hoff que descreve o efeito da temperatura nas constantes de equilíbrio para reações. A prova rigorosa para essa equação utiliza os conceitos da Mecânica Estatística especialmente da estatística de Boltzmann: assim para ocorrer a movimentação de discordâncias, há necessidade que seja ultrapassada uma barreira através do referido "estado de ativação". São necessárias considerações de mecânica quântica para calcular a forma exata dessas barreiras de energia potencial face às discordâncias e foram propostas muitas dessas formas. O presente modelo utiliza a forma que apresenta o melhor ajuste às propriedades mecânicas macroscópicas. A lei de Boltzmann de distribuição de energia é a equação mais importante da Mecânica Estatística e sua premissa básica é a de que a energia é quantizada em pacotes mínimos de energia hvcom $\mathrm{h}$ a constante de Planck $\mathrm{e} v$ a freqüência de vibração do oscilador. Considera-se que $\mathrm{N}$ discordâncias são capturadas pelos obstáculos e que cada discordância seja um oscilador: essas discordâncias têm diferentes níveis de energia que podem ser quantizados em pacotes discretos. Cada um desses 
níveis é então preenchido com um número especifico de discordâncias $R_{c}$ e pode ser mostrado que a distribuição de $R_{c}$ discordâncias em níveis de energia proporcionais a $\mathrm{Q} / \mathrm{RT}$, é uma função exponencial da forma (4.1.1), que é a forma da distribuição de Boltzmann [MEYERS et al., 2002].

Em reações eletroquímicas, a forma dessa equação inclui o potencial eletroquímico E [STAEHLE, 1992a].

$$
\mathrm{R}_{\mathrm{c}}=\mathrm{Bexp}\left[-\left(\mathrm{Q}^{*} \pm \mathrm{zFaE}\right) / \mathrm{RT}\right]
$$

com: $B=$ constante da reação eletroquímica; $Q^{*}=$ energia de ativação química na reação eletroquímica; $\mathrm{z}=$ carga nas espécies ativadas; $\mathrm{F}=$ constante de Faraday; $\alpha=$ coeficiente de transferência; $Q^{*} \pm z F a E=$ energia eletroquímica de ativação: o sinalı significa que a equação se aplica genericamente a reações anódicas ou catódicas, sendo + para anódicas e - para catódicas.

$\mathrm{Na}$ equação (4.1.2) é mostrado que pode haver várias contribuições à energia de ativação global. Além do potencial eletroquímico, a tensão mecânica pode também entrar na energia de ativação em alguns processos cuja taxa é com ela relacionada [STAEHLE, 1992a].

O processo de fratura desaparece para temperaturas menores do que cerca de $280^{\circ} \mathrm{C}$ e atinge o máximo por volta de $360^{\circ} \mathrm{C}$ em ensaios de laboratório [FOCT, 1999]. Os dados disponíveis desses ensaios são numerosos e dispersos numa faixa relativamente grande, de $Q=80$ a $220 \mathrm{~kJ} / \mathrm{mol}$ [CARON, 2001]. São valores de referência para a iniciação, $Q$ entre $180-185 \mathrm{~kJ} / \mathrm{mol}$ e para a propagação rápida, $\mathrm{Q}=130 \mathrm{~kJ} / \mathrm{mol}$. Isso significa que o fenômeno é amplificado em oito vezes entre $320^{\circ} \mathrm{C}$ e $360^{\circ} \mathrm{C}$ [FOCT, 1999]. Alguns resultados sugerem que a energia de ativação aparente diminui quando o material é ligeiramente encruado, mas isto não está comprovado [CARON, 2001].

Outras estimativas para a energia de ativação $Q$, para materiais de liga 600, foram deduzidas de estudos de laboratório e de experiências de campo: sua faixa varia de 163 a $227 \mathrm{~kJ} / \mathrm{mol}$ (39 a $65 \mathrm{kcal} / \mathrm{mol}$ ), com um valor mais precisamente estimado de $209 \mathrm{~kJ} / \mathrm{mol}(50 \mathrm{kcal} / \mathrm{mol})$. As estimativas para a energia de ativação para os componentes dessa Liga fabricados a partir de barras podem ser diferentes daquelas dos fabricados de material a partir de tubos. Tanto a iniciação quanto o crescimento da CSTAP são muito sensíveis à temperatura. Por 
exemplo, o tempo de iniciação da CSTAP será tipicamente reduzido pela metade para um acréscimo de $10^{\circ} \mathrm{C}$ numa temperatura de operação de $315^{\circ} \mathrm{C}$, a trinca se iniciando mais prematuramente [IAEA, 1997].

\subsection{Composição química}

Entre as variáveis que influenciam a CSTAP, o efeito da composição química da água é particularmente forte, inclusive nos fatores que criam um ambiente diferente no ambiente da ponta da trinca em relação ao ambiente geral do meio [ANDRESEN, 2005]: esses fatores são da mais alta significação conforme se detalhará no item 11.1 .

O ensaio por taxa de deformação lenta (ETDL, correspondente ao "constant extension rate loading test", ou CERT) proporciona uma maneira simples para assegurar que a fase de iniciação é ultrapassada e que a susceptibilidade inerente da CST possa ser determinada para uma condição meio-material. Esse ensaio é amplamente utilizado para a determinação das dependências químicas da CST [STAEHLE, 1992a]. No entanto, não são todos coerentes os resultados obtidos em diversos laboratórios que efetuaram experiências sobre esse tipo de influência, variando a composição química do meio primário (ácido bórico e hidróxido de lítio) e em conseqüência do $\mathrm{pH}$, sendo assim difícil de se deduzir uma tendência firme. Pode-se, contudo observar que a CST é mais importante em meio primário do que em água pura, talvez devido à importância decisiva da dissolução nesse fenômeno [FOCT, 1999]. 


\subsubsection{Espécies oxidantes}

As reações de corrosão são normalmente aceleradas pela adição de espécies oxidantes, incluindo oxigênio, nitratos, íons férricos, cromatos, peróxido de hidrogênio, cloratos. Na Figura 4.1 são mostrados os potenciais de equilíbrio para essas espécies e as respectivas espécies reduzidas, comparadas aos equilíbrios oxigênio/água e água/hidrogênio. Esses efeitos têm sido utilizados em testes de filtragem para a efetividade de adições de cromo e de molibdênio em aços, bem como para outros materiais que se pretendem utilizar à alta temperatura [STAEHLE, 1992a].

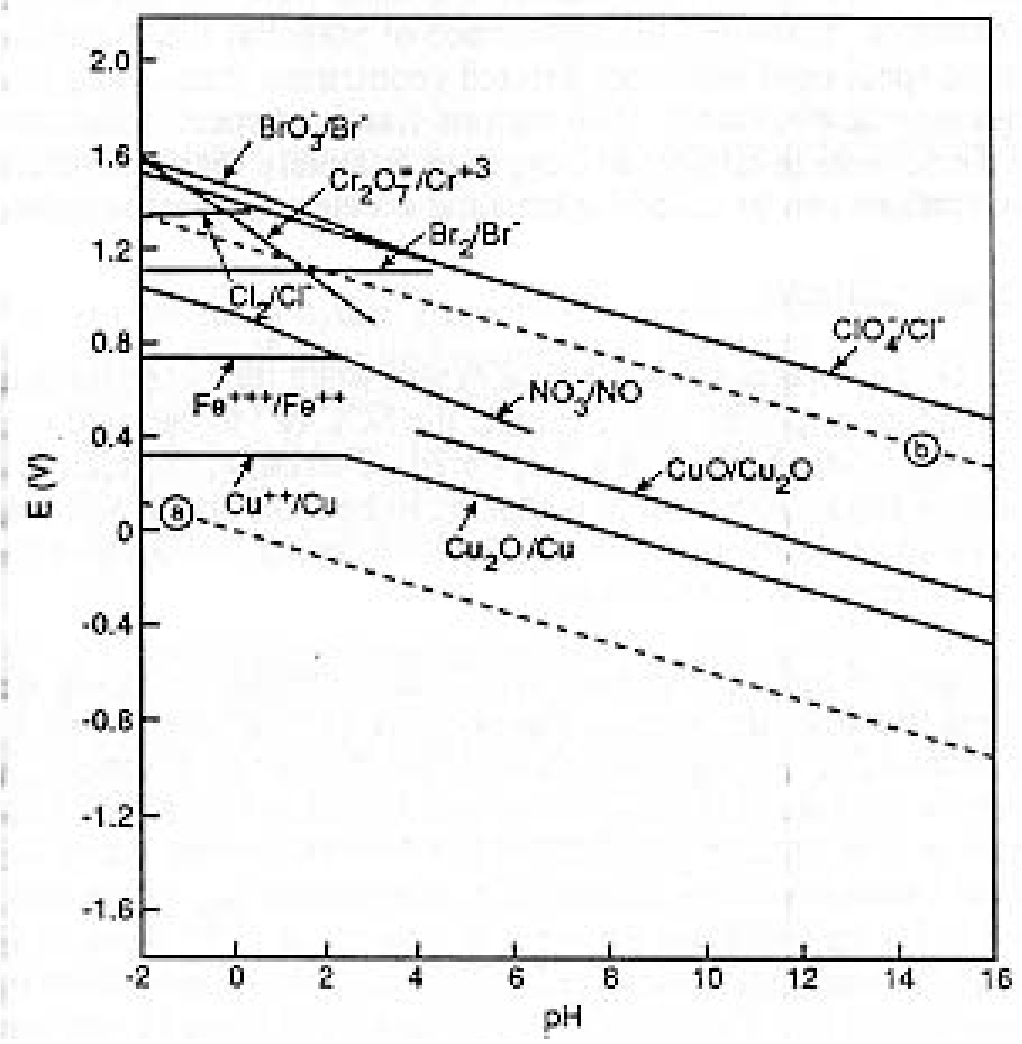

Figura 4.1. Gráfico da dependência potencial-pH de casos de equilíbrio de oxidação comparados a $25^{\circ} \mathrm{C}$ : adaptado do Atlas de Pourbaix [STAEHLE, 1992a].

A adição de oxigênio/espécies oxidantes eleva também o potencial do material-meio a uma condição que pode atingir o potencial de pite, provocando esse tipo de corrosão que pode ser a iniciação de CST. Nesse tipo de corrosão o meio perfura pequenos poços no metal (pites): buracos não largos porém 
profundos. Os formatos desses pites são geralmente hemisféricos, cônicos ou cilíndricos, conforme ilustrado na Figura 4.2 [GORMAN \& STAEHLE, 1989].

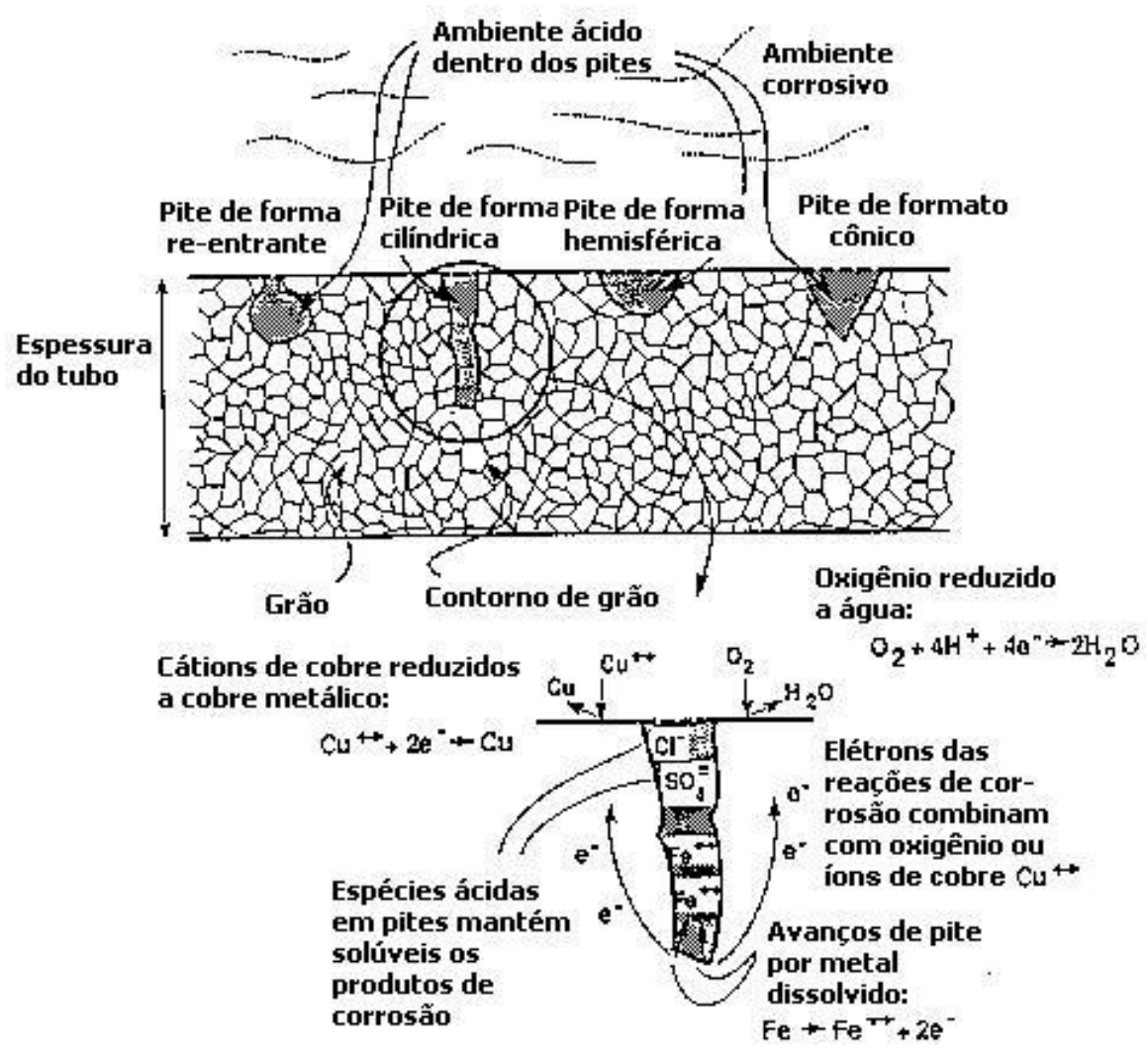

Figura 4.2. Esquema de corrosão por pite [GORMAN \& STAEHLE, 1989].

O pite normalmente se inicia em contornos de grão ou em precipitados de impurezas como sulfetos ou carbonetos. Também pode iniciar numa superfície homogênea. A maior parte da superfície não corrói significativamente, mas quando inicia num determinado local da superfície, ele tende a se localizar nesse local. Esse tipo de defeito é acelerado ou por compostos formadores de ácidos como sulfatos e cloretos ou espécies oxidantes. Essas espécies oxidantes aceleram a reação de pite pela absorção de elétrons dos átomos de metal dissolvido [GORMAN \& STAEHLE, 1989].

O processo de pite é bem estudado através do levantamento de curvas de polarização potenciodinâmicas e de outros procedimentos padronizados como os aplicados por Singh: nesse trabalho o autor mostra como é o comportamento ao pite da liga 600 à temperatura ambiente em solução diluída 0,1M de ácido sulfúrico variando a concentração de $\mathrm{NaCl}$. Entre outras conclusões o autor 
mostra que há um aumento da corrosão por pite com o aumento da concentração de $\mathrm{NaCl}$ e que a liga 601, com teor de cromo mais alto do que a liga 600 , não se comporta melhor ao pite nessas condições [SINGH, 2001].

Ryan e outros pesquisadores mostraram através de ensaios utilizando espectroscopia de massa de íons secundários de escala nanométrica, como é o mecanismo de iniciação do pite no aço inoxidável 316: esse se dá adjacente a partículas secundárias na matriz metalográfica, no caso inclusões de MnS e como existe uma significativa redução na razão Cr:Fe em volta dessas partículas tornando essas zonas empobrecidas em $\mathrm{Cr}$, susceptíveis a altas taxas de dissolução que nucleiam os pites [RYAN et al., 2002].

O processo de fratura da liga 600 na presença de oxigênio com 20 ppm de cloreto é muito acelerado, cerca de dez vezes em relação ao mesmo meio sem cloretos, e a superfície de ruptura intergranular apresenta um aspecto alveolar, evidenciando o papel da dissolução localizada nos contornos de grão [FOCT, 1999].

\subsubsection{Espécies redutoras}

Nem todos os processos de corrosão são acelerados apenas quando o potencial é aumentado por causa das espécies oxidantes: a CST da liga 600 em água pura é acelerada também quando o potencial é abaixado. A adição de espécies redutoras, causando esse abaixamento de potencial, pode provocar a CST [STAEHLE, 1992a]. Entre as espécies redutoras, é fundamental o efeito provocado pelo hidrogênio, que merece uma seção à parte. 


\section{INFLUÊNCIA DO HIDROGÊNIO NA CST EM LIGA 600}

A fratura assistida por hidrogênio é causada pela acumulação de concentração crítica de $\mathrm{H}_{2}$ em regiões altamente tensionadas do material. Para ocorrer a fratura, o $\mathrm{H}_{2}$ dissociado $\left(\mathrm{H}_{2(\mathrm{~g})} \rightarrow \mathrm{H}^{+}{ }_{(\mathrm{g})}+\mathrm{H}^{+}{ }_{(\mathrm{g})}\right)$ precisa estar disponível na superfície do material e precisa estar apto a difundir rapidamente nas regiões de alta tensão mantendo uma concentração crítica de $\mathrm{H}_{2}$ nessas regiões. $\mathrm{O}$ hidrogênio que se difunde através do meio em volta da trinca, é fisicamente adsorvido na proximidade da ponta da trinca (adsorção química dissociativa), penetrando no material e difundindo para a região de alta concentração de tensões onde participa da reação de fragilização através de vários processos como interação com discordâncias [FOCT, 1999] ou formação de produto frágil como o hidreto de ferro no caso de ligas ferrosas (Figura 5.1).

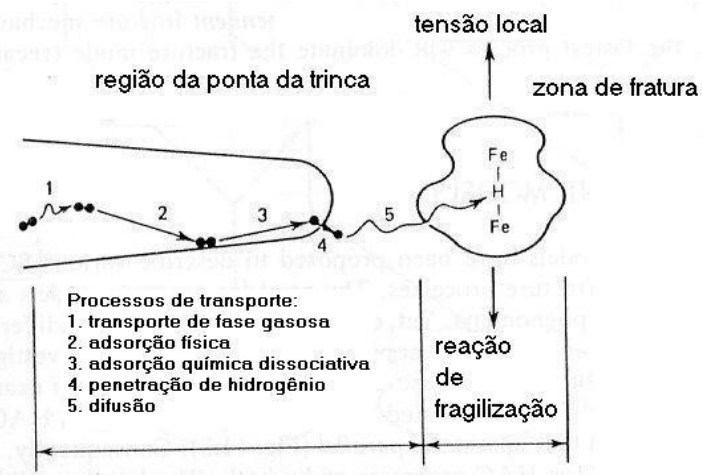

Figura 5.1. Vários processos envolvidos na fragilização por hidrogênio de ligas ferrosas [FONTANA \& GREENE, 1978].

Fontana e Greene distinguem o processo de CST assistida por hidrogênio como sendo anódico, com liberação de cátions metálicos da ponta da trinca, ou seja há formação de corrente anódica, na forma $\mathrm{M} \rightarrow \mathrm{M}^{++}+2 \mathrm{e}^{--}$e a fragilização por hidrogênio um processo catódico, com formação da corrente catódica do tipo $2 \mathrm{H}^{+}+2 \mathrm{e}^{-} \rightarrow 2 \mathrm{H}$ (Figura 5.2). 


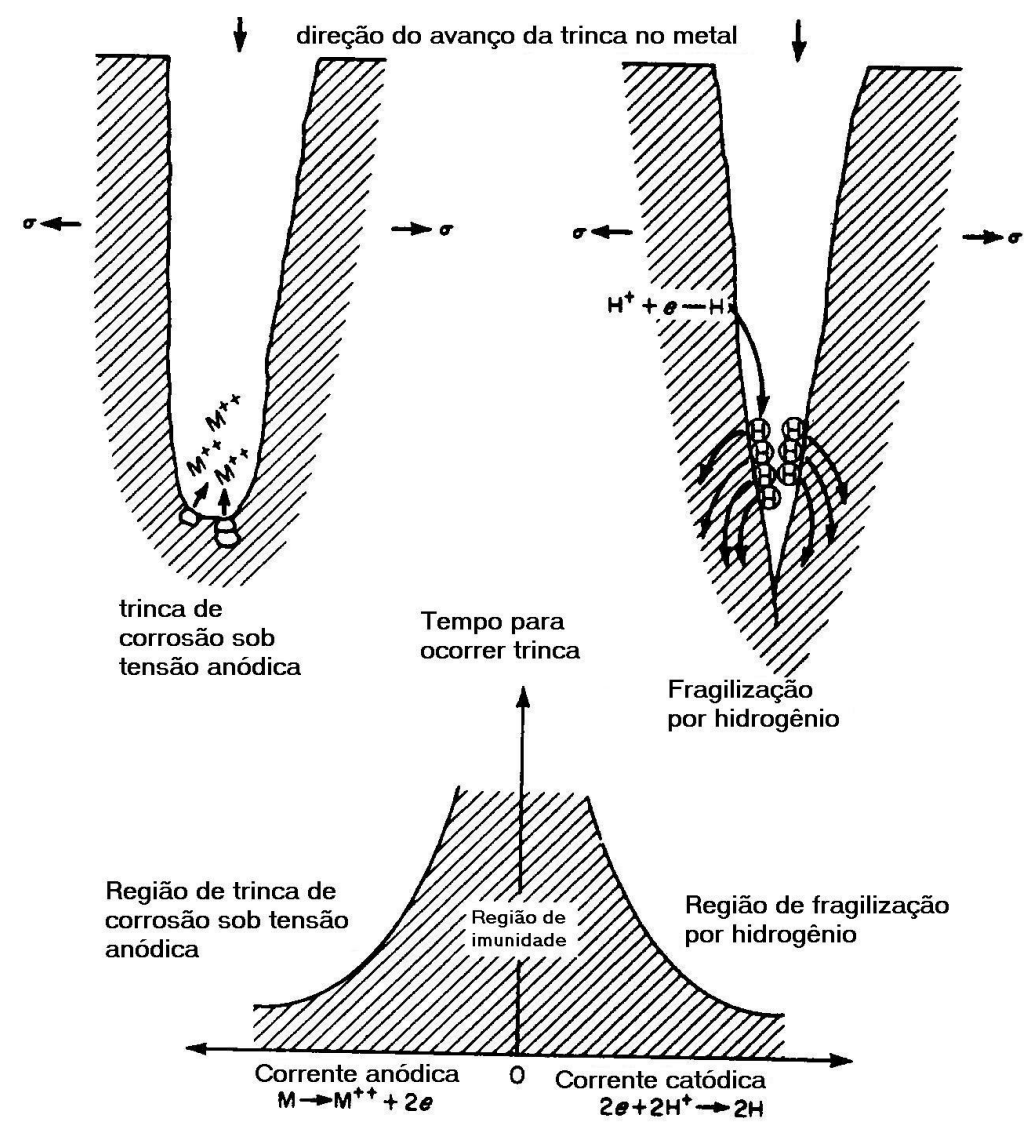

Figura 5.2. Esquema mostrando a diferença de trinca de corrosão sob tensão anódica e fragilização por hidrogênio catódica [FONTANA \& GREENE, 1978].

O hidrogênio provoca uma aceleração da CST na liga 600 até um determinado ponto a partir do qual essa passa a diminuir, conforme é ilustrado na

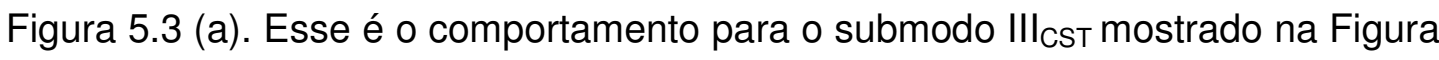
1.5. Para outro submodo como o I CST ou submodo de CST cáustica, esse comportamento é diferente: adicionando-se hidrogênio, há uma diminuição da CST, conforme é ilustrado na Figura 5.3 (b). Após isso, segue o comportamento da Figura 5.3 (a). A corrosão sob tensão cáustica é um processo anódico: acrescentando-se hidrogênio, há diminuição do potencial e pára-se o efeito contrário à CST ilustrado na Figura 5.3 (b). 
(a)

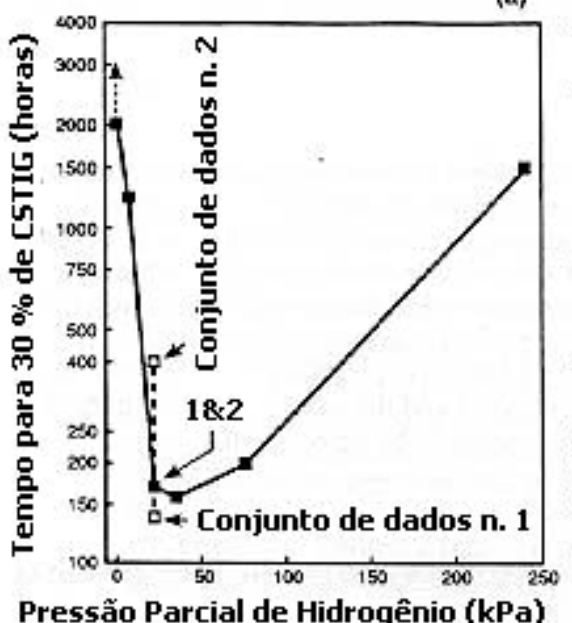

(b)

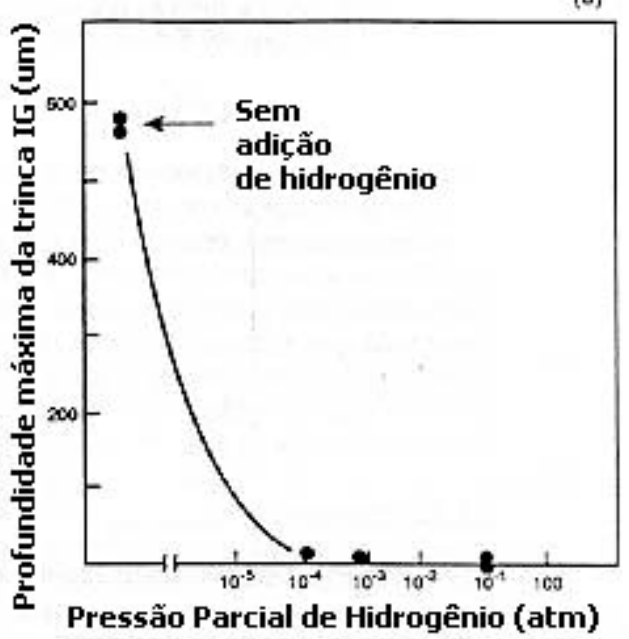

Figura 5.3. (a) Efeito da pressão parcial de hidrogênio sobre o tempo de indução de corrosão sob tensão intergranular (CSTIG) no Inconel $60030 \%$ laminado e recozido a $400{ }^{8} \mathrm{C}$ e $20,8 \mathrm{MPa}$. (b) Efeito da pressão de hidrogênio na CSTIG do Inconel 600 laminado e recozido numa solução de $40 \% \mathrm{NaOH}+\mathrm{Fe}_{3} \mathrm{O}_{4}+\mathrm{Cu}+\mathrm{CuO}$ a $325^{\circ} \mathrm{C}$ testado por 200horas, utilizando-se espécimes do tipo anel-C tensionados a 294,2 MPa [STAEHLE, 1992a].

A $360^{\circ} \mathrm{C}$, constatou-se que a velocidade de propagação passa por um máximo para concentrações de hidrogênio próximas àquelas correspondentes à fronteira de estabilidade termodinâmica do $\mathrm{NiO}$ e do Ni metálico, conforme é mostrado na Figura 5.4. Para o resultado dessa, provavelmente o valor de $K_{l}$ foi superestimado, ou seja os ensaios foram efetuados com valores de $\mathrm{K}_{\mathrm{l}}$ inferiores

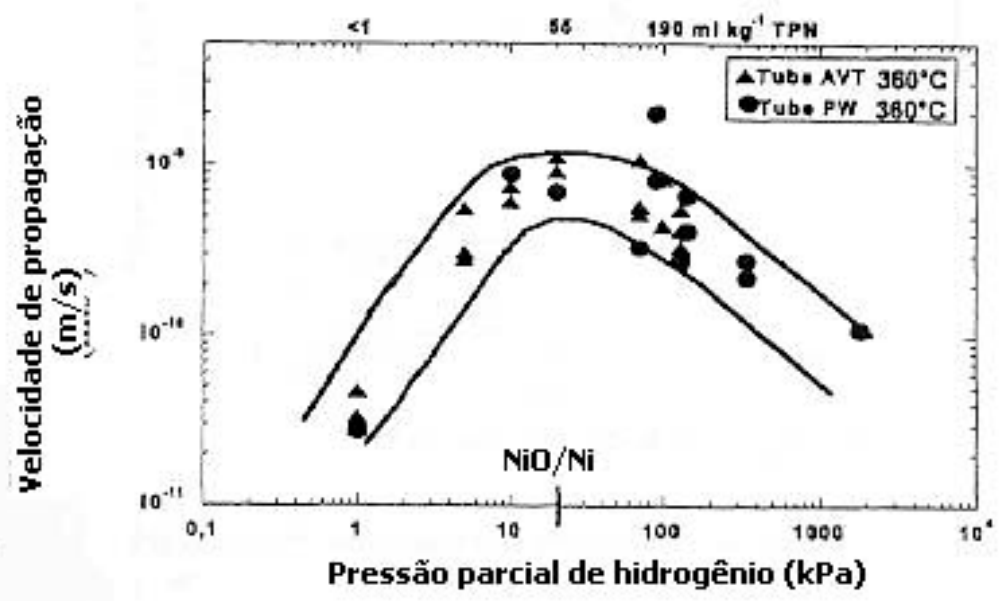

Figura 5.4. Influência do hidrogênio sobre a velocidade de propagação da CST na liga 600: tubos pré- trincados a $360^{\circ} \mathrm{C}$ [CARON, 2001]. 
aos do patamar de velocidade de propagação, pois não se constatou o efeito do hidrogênio para valores de $K_{I}$ pertencentes ao patamar de propagação, mas somente uma diminuição do $\mathrm{K}_{\mathrm{ICST}}$ quando é aumentada a concentração de hidrogênio: por isso concluiu-se que o hidrogênio dissolvido age somente sobre a iniciação da CST.

Quando a temperatura do meio é diminuída para $338^{\circ} \mathrm{C}$, não se observa mais uma diminuição da velocidade de propagação de trincas de CST quando se aumenta a concentração de hidrogênio. Entre $320{ }^{\circ} \mathrm{C}$ e $330^{\circ} \mathrm{C}$, os dados são insuficientes para permitir concluir sobre a existência de um máximo eventual. $A$ $290^{\circ} \mathrm{C}$, a velocidade de propagação parece passar por um máximo e a $288^{\circ} \mathrm{C}$, não se observa mais um máximo na evolução de velocidades de propagação: assim, o comportamento da CST com adição de hidrogênio entre $290^{\circ} \mathrm{C}$ e $330^{\circ} \mathrm{C}$ (faixa de temperaturas de operação de um RAP), além de escassos, são aparentemente contraditórios em alguns casos [CARON, 2001].

Os resultados concernentes à aplicação de sobre tensão catódica na CST da liga 600 são poucos. $\mathrm{A} 350^{\circ} \mathrm{C}$, durante o ensaio de taxa de deformação lenta de $5.10^{-7} \mathrm{~s}^{-1}$, Totsuka mostrou que a aplicação de um potencial catódico aumenta a superfície intergranular trincada, conforme é ilustrado na Figura 5.5. Mas além de uma certa sobre tensão, esse autor constata um efeito de saturação, cuja explicação pode ser uma provável sobre estimativa dos potenciais locais realmente aplicados em virtude da queda ôhmica devido à fraca condutividade da água pura. Por outro lado, Foct observa a $360^{\circ} \mathrm{C}$, ao longo de um ensaio de taxa de deformação lenta de $10^{-7} \mathrm{~s}^{-1}$, que a velocidade de propagação da CST aumenta com uma sobre tensão catódica de $-350 \mathrm{mV}$ em relação ao potencial de corrosão. A aplicação de um potencial catódico aumenta a quantidade de hidrogênio atômico formado e assim a quantidade de hidrogênio que pode ser absorvido pelo material. Pode-se assim postular uma participação do hidrogênio absorvido no processo de CST da liga 600 [FOCT, 1999], [CARON, 2001]. 


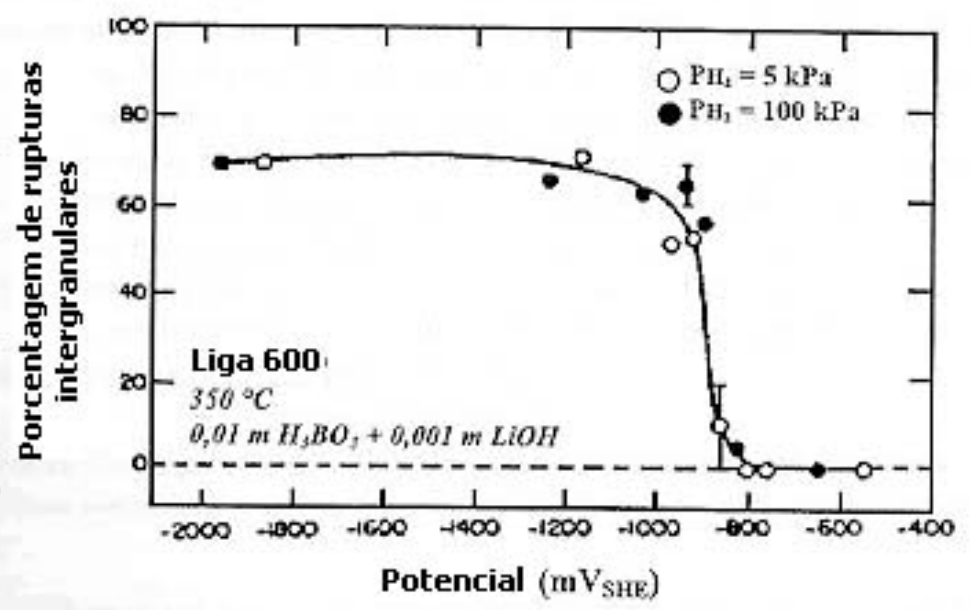

Figura 5.5. Influência de sobre tensão catódica sobre a CST da Liga 600 em água primária a $350^{\circ} \mathrm{C}$, para pressões parciais de hidrogênio de $5 \mathrm{kPa}$ e de $100 \mathrm{kPa}$ [CARON, 2001].

Para que o hidrogênio fragilize o material, é necessário que ele seja preso por uma falha da rede cristalina. Essas falhas podem ser de baixa energia, principalmente discordâncias ou de caráter irreversível, como superfícies internas com micro trincas ou poros. Nas ligas que podem sofrer oxidação interna, como a liga 600, o hidrogênio pode ficar preso sobre as interfaces metal-óxidos, que formam armadilhas irreversíveis. Essa prisão do hidrogênio se deve à formação de ligações com o ânion hidroxila $\left(\mathrm{OH}^{-}\right)$na interface da trinca e induzirá um aumento de volume nas fronteiras das fases [CARON, 2001].

A fragilização por hidrogênio que atinge as ligas Ni-Cr-Fe cujo teor de cromo é inferior a 18\%, são sensíveis ao hidrogênio, desde que seu teor em níquel seja inferior a $15 \%$ ou superior a $35 \%$, conforme demonstrou Lagneborg na faixa de temperatura entre $-100^{\circ} \mathrm{C}$ e $20{ }^{\circ} \mathrm{C}$. Como a liga 600 tem $75 \%$ em níquel, ela é potencialmente fragilizável pelo hidrogênio à baixa temperatura. Essa hipótese foi confirmada por Lecoester e Foct através de corpos de prova précarregados com hidrogênio. A fragilização por hidrogênio nas ligas de níquel existe na faixa de $-50^{\circ} \mathrm{C}$ a $100^{\circ} \mathrm{C}$ e diminui à medida que a temperatura aumenta, até desaparecer. Para a liga 600 esse efeito persiste até $250^{\circ} \mathrm{C}$. Foct não observa esse efeito além de $200^{\circ} \mathrm{C}$ [FOCT, 1999], [CARON, 2001].

Apesar da fragilização, o hidrogênio apresenta um efeito benéfico: sob sua presença há uma aparente melhoria das propriedades de passivação do 
óxido que se enriquece em cromo e se afina quando a pressão de hidrogênio aumenta [FOCT, 1999].

\subsection{Influência do hidrogênio sobre a oxidação da liga 600}

Na água desaerada à alta temperatura, a atividade do hidrogênio no meio impõe o valor do potencial de eletrodo do material. Esse se comporta como um eletrodo de hidrogênio, sendo que a composição e as propriedades dos óxidos superficiais dependem deste potencial. Assim a composição desses óxidos é variável não só em relação à concentração de hidrogênio e temperatura do meio, como também em função da espessura do próprio filme formado.

Para exposições de curta duração, inferiores a 48 horas e para uma concentração em hidrogênio de $40 \mathrm{ml} \mathrm{CNTP.} \mathrm{kg}^{-1} \mathrm{H}_{2} \mathrm{O}$ à $\mathrm{T}=325^{\circ} \mathrm{C}$, os produtos de oxidação são constituídos de óxidos simples e/ou hidróxidos dos principais elementos de liga Ni-Fe-Cr. Após 163 horas de oxidação nas mesmas condições experimentais, análises por espectroscopia de descarga luminescente (EDL) indicaram que o filme de óxido se enriqueceu em ferro na lâmina mais superficial e em cromo na interface entre o material e o óxido. Para a duração intermediária de 100 horas, a análise por espectroscopia fotoeletrônica por raio-X (EFX) de superficies de ligas $\mathrm{Ni}_{(1-x)^{-}} \mathrm{Cr} x$ - Fe com uma menor concentração de hidrogênio, $16 \mathrm{ml}$ CNTP. $\mathrm{kg}^{-1} \mathrm{H}_{2} \mathrm{O}$, sugeriu que as fases presentes sejam principalmente $\mathrm{Ni}(\mathrm{OH})_{2}$ e/ou $\mathrm{Cr}_{2} \mathrm{O}_{3}$, embora Caron afirme que a formação de $\mathrm{Ni}(\mathrm{OH})_{2}$ não seja possível a $360^{\circ} \mathrm{C}$, sugerindo que essa fase possa ser a transformação de uma outra forma de níquel presente a essa temperatura durante o resfriamento. A partir de 250 horas a $360^{\circ} \mathrm{C}$ e concentração de hidrogênio $=42 \mathrm{ml} \mathrm{CNTP.} \mathrm{kg}^{-1} \mathrm{H}_{2} \mathrm{O}$, o filme superficial é do tipo $\mathrm{M}_{3} \mathrm{O}_{4}$ com $\mathrm{M}=53 \% \mathrm{Cr}+15 \% \mathrm{Fe}+33 \% \mathrm{Ni}$ e com um enriquecimento relativo em ferro da lâmina mais superficial. Além disso, os resultados de análises complementares por EFX indicaram que os estados químicos do níquel, do cromo e do ferro são coerentes com a formação de um óxido do tipo espinel de fórmula geral $(\mathrm{Fe}, \mathrm{Ni})(\mathrm{Cr}, \mathrm{Fe})_{2} \mathrm{O}_{4}$. Para durações superiores a 8500 horas, forma-se um óxido do tipo MO, M sendo na sua maior parte de níquel além de $\mathrm{M}_{3} \mathrm{O}_{4}$.

Foram efetuadas na superfície de mais de 100 lâminas finas oxidadas em meios em concentrações de hidrogênio dissolvido compreendidas entre 40 e 60 
ml CNTP. $\mathrm{kg}^{-1} \mathrm{H}_{2} \mathrm{O}$, a temperaturas de $325^{\circ} \mathrm{C}$ e $360^{\circ} \mathrm{C}$, análises em relação à composição na espessura do óxido formado. Nessas foi mostrado que o óxido presente na superfície externa é rico em ferro tendo uma estrutura espinel, ou de $\mathrm{FeCr}_{2} \mathrm{O}_{4}, \mathrm{Fe}_{3} \mathrm{O}_{4}$ e $\mathrm{NiFe}_{2} \mathrm{O}_{4}$, propostas por Fish. A $325^{\circ} \mathrm{C}$ e concentração de hidrogênio de $40 \mathrm{ml} C N T P$. $\mathrm{kg}^{-1} \mathrm{H}_{2} \mathrm{O}$, Gardey confirmou a presença de agregados de $\mathrm{NiFe}_{2} \mathrm{O}_{4} \mathrm{sob}$ forma de cristalitas de grande porte de 2 a $3 \mu \mathrm{m}$. Abaixo dessa camada, o óxido é mais rico em cromo: $\mathrm{NiCr}_{2} \mathrm{O}_{4}, \mathrm{FeCr}_{2} \mathrm{O}_{4}$ e $\mathrm{Cr}_{2} \mathrm{O}_{3}$, conforme Fish. Por outro lado, nos ensaios por meio de raios $\mathrm{X}$ superficiais em amostras de Liga 600 testadas em um ciclo com recirculação à temperatura de $330^{\circ} \mathrm{C}$ e concentração de hidrogênio de 25 a $50 \mathrm{ml}$ CNTP. g $^{-1} \mathrm{H}_{2} \mathrm{O}$, sugeriu-se que o óxido superficial tinha uma estrutura do tipo espinel, conforme item 2.3.2. Esses resultados foram confirmados em outros referentes a tubos geradores de vapor em Liga 600 de unidades nucleares de Lovisaa e por isso considerados representativos nessa condição [CARON, 2001].

\subsection{Propriedades eletroquímicas do óxido da liga 600}

Vários autores levantaram a curva de polarização da liga 600 em água à alta temperatura: Totsuka e outros traçaram as curvas de polarização para a Liga e para o Ni-Cr-Fe na água e Angeliu e outros para a liga 600 (Figura 5.6), concluindo que há um aumento do valor da corrente anódica sobre ela quando aumenta a concentração do hidrogênio [FOCT, 1999].

Totsuka associa essa variação a uma diminuição da proteção do filme passivo sobre a superfície da Liga, para concentrações intermediárias de

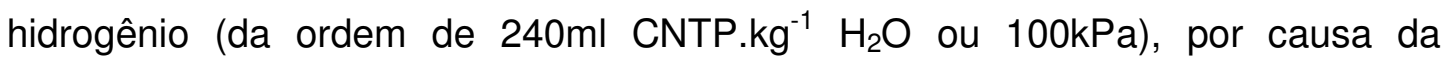
desestabilização do $\mathrm{NiO}$ no óxido, em favor do níquel metálico. No entanto, não foi quantificada a parte da corrente devida à oxidação do hidrogênio e nem verificado se a intensidade de correntes anódica diminui para concentrações de hidrogênio mais elevadas, condição na qual a sensibilidade à CST é menor, não sendo possível concluir que o aumento de corrente foi devido apenas às modificações de propriedade do filme passivo [FOCT, 1999],[CARON, 2001].

Caron mostrou através de resultados de ensaios de cronoamperometria efetuados por Foct, que após a depassivação catódica, o aumento na concentração de hidrogênio dissolvido diminui sensivelmente o valor da corrente 
anódica de repassivação. Isto está de acordo com os diagramas de potencial-pH que indicam uma estabilização do óxido metálico na presença de hidrogênio e assim correntes de oxidação mais fracas.

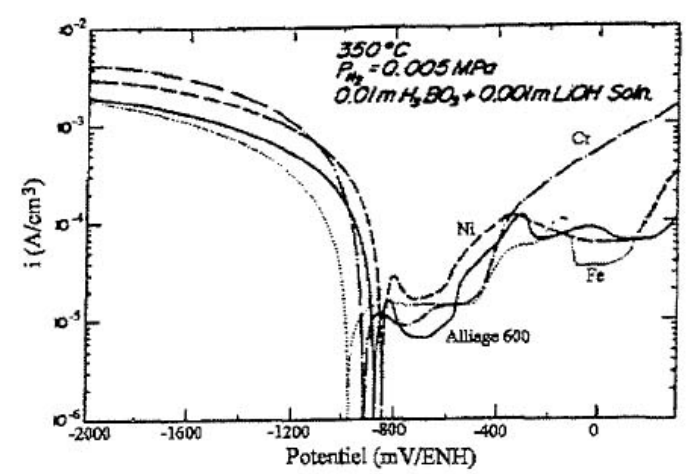

(a)

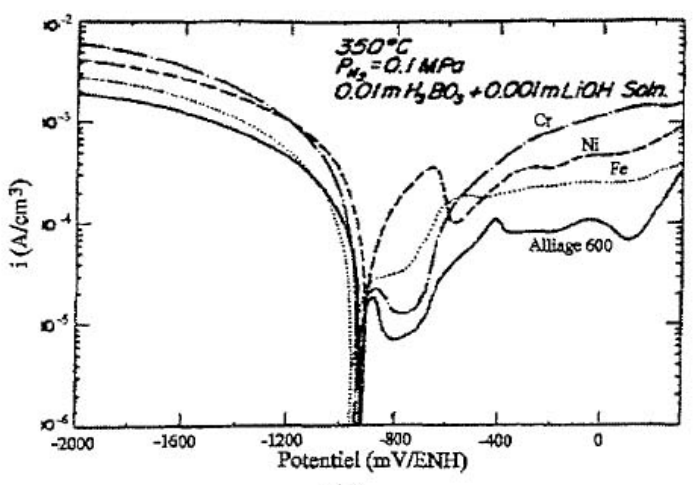

(b)

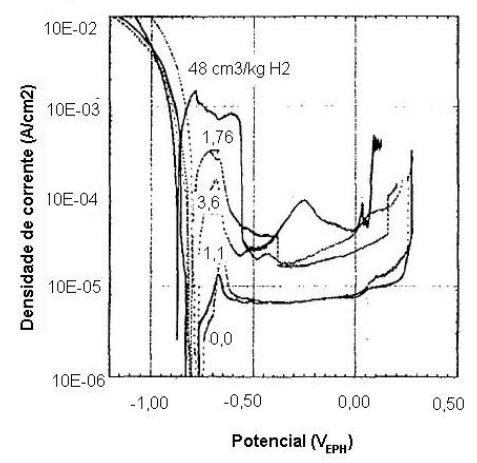

Figura 5.6. Curvas de polarização do $\mathrm{Ni}$, do $\mathrm{Cr}$ e do $\mathrm{Fe}$ e da Liga 600 em água primária com ácido bórico $0,01 \mathrm{M} \mathrm{e} \mathrm{T}=350^{\circ} \mathrm{C}$ sob: (a) pressão parcial de hidrogênio de 0,05 bar (12 ml CNTP.kg ${ }^{-1}$ $\mathrm{H}_{2} \mathrm{O}$; b) 1 bar (240ml CNTP. $\mathrm{kg}^{-1} \mathrm{H}_{2} \mathrm{O}$ ), de SMIALOWSKA e outros e (c) Liga 600 em água primária com ácido bórico $0,1 \mathrm{M}$ e pressão parcial de hidrogênio de 0 a 0,2 bar (48 ml CNTP. $\mathrm{kg}^{-1}$ $\mathrm{H}_{2} \mathrm{O}$ ): de Angeliu e outros [FOCT, 1999].

Através da comparação de curvas de repassivação, mostrou-se que a corrente de repassivação decresce no tempo de modo similar em diversos meios hidrogenados. Isso sugere que a cinética de repassivação não depende da concentração em hidrogênio no meio e por conseqüência da natureza do óxido superficial, o que parece surpreendente.

Porém Caron coloca restrições sobre esses resultados, pois o potencial aplicado é insuficiente para depassivar inteiramente a superfície e reduzir o óxido de cromo $\mathrm{Cr}_{2} \mathrm{O}_{3}$, sendo assim apenas uma depassivação parcial concernente às formas oxidadas do níquel, como o $\mathrm{NiO}$. 
O mesmo autor mostra através de ensaios realizados a $288^{\circ} \mathrm{C}$ entre concentrações de hidrogênio compreendidas entre 0 e $48 \mathrm{ml} \mathrm{CNTP.} \mathrm{kg}^{-1} \mathrm{H}_{2} \mathrm{O}$ que quando a depassivação resulta de uma tração rápida que coloca uma parte da superfície do corpo de prova em contacto direto com o meio sem nenhuma camada protetora de óxido, há uma diminuição de corrente; quando a concentração de hidrogênio é maior ou igual a $17,6 \mathrm{ml} C N T P . \mathrm{kg}^{-1} \mathrm{H}_{2} \mathrm{O}$ ou seja, quando o Ni é estável, a corrente decresce mais lentamente que a concentrações de hidrogênio compreendidas entre 0 e 4 ml CNTP. $\mathrm{kg}^{-1} \mathrm{H}_{2} \mathrm{O}$ (Figura 5.7). Essa diferença de comportamento é atribuída à oxidação do hidrogênio ou à formação de um óxido menos protetor para concentrações de hidrogênio dissolvido para as quais o níquel é estável. Mayer deduz que as propriedades e a composição do filme de superfície são modificadas conforme a concentração de hidrogênio: quando essa aumenta, a permeabilidade da liga 600 ao hidrogênio também aumenta. Hecker mostra que os filmes de óxido na superfície do tipo espinel ( $\mathrm{Ni})(\mathrm{Fe}) \mathrm{Cr}_{2} \mathrm{O}_{3}$ são mais permeáveis ao hidrogênio do que um filme constituído exclusivamente de $\mathrm{Cr}_{2} \mathrm{O}_{3}$. 


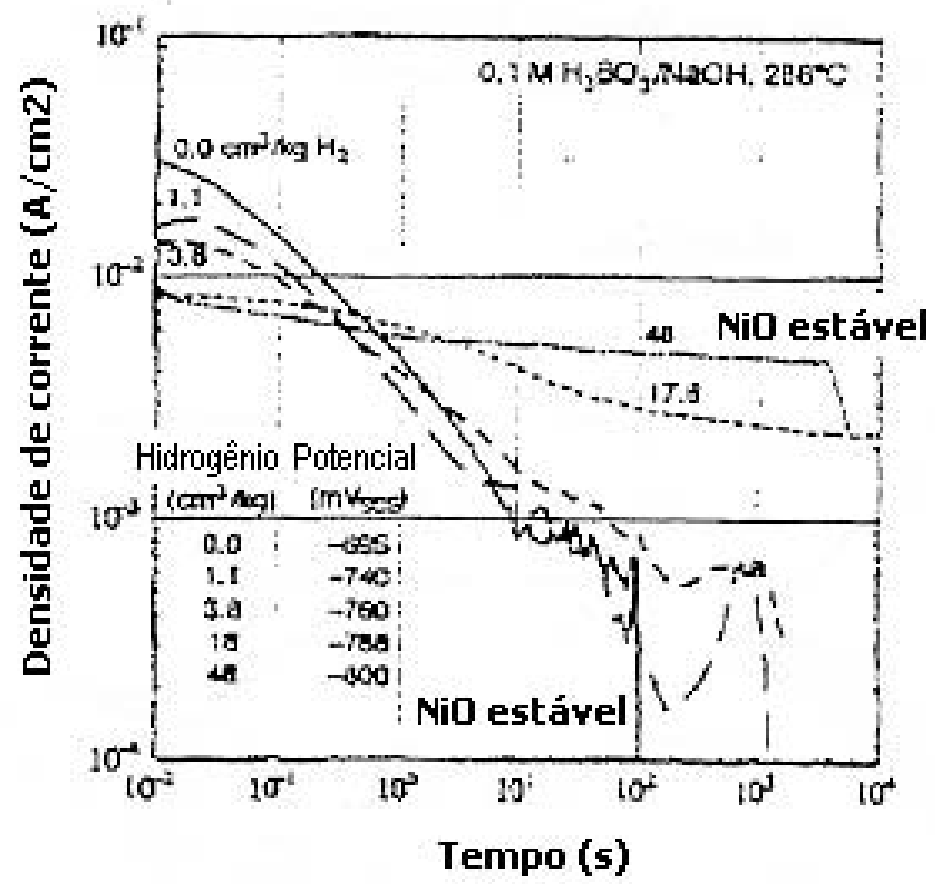

Figura 5.7. Transitórios de corrente de repassivação da liga 600 em meio primário a $288^{\circ} \mathrm{C}$ após depassivação por tração rápida [CARON, 2001].

Em resumo, nos ensaios realizados de corrente de dissolução em função de diferentes concentrações de hidrogênio, é mostrado que a dissolução diminui quando a concentração de hidrogênio aumenta [CARON, 2001].

Por outro lado, Nakagawa e outros autores mostraram em ensaios com liga 600 em água primária a $360^{\circ} \mathrm{C}$, através do levantamento das curvas de polarização anódica, que o pico da densidade de corrente aumenta quando o

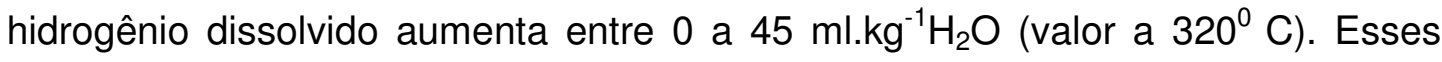
picos atingem o máximo entre 11 e $30 \mathrm{ml}^{\mathrm{kg}}{ }^{-1} \mathrm{H}_{2} \mathrm{O}$ (valor a $350^{\circ} \mathrm{C}-360{ }^{\circ} \mathrm{C}$ ). Através da análise dos filmes de óxido, verificou-se que esses são relativamente espessos e ricos em Ni, abaixo de $11 \mathrm{ml}^{\mathrm{kg}} \mathrm{kg}^{-1} \mathrm{H}_{2} \mathrm{O}$, mas acima dessa concentração de hidrogênio eles se tornam mais finos e ricos em $\mathrm{Cr}$ e Fe. A susceptibilidade da Liga é máxima a $11 \mathrm{ml} . \mathrm{kg}^{-1} \mathrm{H}_{2} \mathrm{O}$, revelando que as propriedades do filme passivo de óxidos têm um importante papel na CSTAP da liga 600 [NAKAGAWA et al., 2003]. 


\subsection{Hidrogênio absorvido e fragilização das ligas de níquel}

Sob efeito de uma solicitação mecânica, o filme da ponta da trinca pode romper-se e o hidrogênio entrar localmente com maior facilidade no material e exercer nas superfícies expostas da trinca, um papel fragilizante. Assim os pequenos átomos de hidrogênio podem ser capturados nos numerosos espaços intersticiais. Além disso, a capacidade de transferir uma parte de sua carga eletrônica aos átomos vizinhos mais próximos, favorece a fragilização da ligação metal-metal. Finalmente, seu volume parcial muito elevado pode contribuir para deformar a rede metálica do ambiente. A noção de fragilização por hidrogênio faz aparecer os fenômenos de geração, absorção e adsorção de átomos de hidrogênio. Rios provou que o hidrogênio proveniente do hidrogênio molecular é mínimo, não havendo correlação entre a quantidade de hidrogênio absorvido e a supressão do hidrogênio de cobertura, mesmo na presença de superfícies expostas; no segundo caso, o hidrogênio é diretamente disponível sob forma mono atômica provindo das reações de corrosão. Ou ele é absorvido no material, ou ele se recombina na forma de di-hidrogênio. No caso do níquel, a descarga de hidrogênio catódico é rápida e sua recombinação lenta: assim a probabilidade que eles penetrem através da ponta da trinca é alta.

Quanto ao transporte, ele pode ser por difusão intersticial, curto circuitos de difusão ou transporte associado à deformação plástica: no primeiro caso, o hidrogênio se difunde nos espaços vazios tetraédricos e octaédricos da estrutura cristalina cúbica de face centrada (CFC). Esse tipo de difusão é caracterizado pelo coeficiente de difusão e permeabilidade do material ao hidrogênio: a velocidade de difusão é muito pequena à temperatura ambiente, assim o hidrogênio não penetra em tempos curtos a grandes distâncias da ponta da trinca (coeficiente de difusão aparente $D_{a p}=6.10^{-11} \mathrm{~cm}^{2} . \mathrm{s}^{-1}$ a $25^{\circ} \mathrm{C}$ ). Em compensação, a temperaturas na faixa $290-330^{\circ} \mathrm{C}$, a penetração do hidrogênio é muito maior, pois o coeficiente aparente de difusão é também muito maior, da ordem de 4 ordens de grandeza $\left(D_{a p}=6.10^{-7} \mathrm{~cm}^{2} . \mathrm{s}^{-1}\right.$ a $\left.330^{\circ} \mathrm{C}\right)$; no segundo caso, curtos circuitos de difusão, esses são modos de transporte de hidrogênio associados à presença de defeitos da rede cristalina como discordâncias e contornos de grãos. Fenômenos de difusão preferencial ao longo dos contornos de grãos do níquel foram observados à temperatura ambiente por diversos autores, mas não acima 
de $150^{\circ} \mathrm{C}$; no terceiro caso, o transporte associado à deformação plástica está associado com o movimento de discordâncias, que constituem em certas condições espécies de armadilhas móveis. Quando há uma deformação plástica, as discordâncias são colocadas em movimento com a atmosfera de hidrogênio, sob a condição da velocidade de difusão do hidrogênio ser compatível com a velocidade de deslocamento dessas.

Para o hidrogênio fragilizar o material, é necessário que ele seja capturado por um defeito da rede cristalina. Através de estudos de dessorção do hidrogênio após a deformação por ruptura de corpos de prova em liga $600 \mathrm{em}$ água a $350^{\circ} \mathrm{C}$, colocou-se em evidência dois tipos de captura: a de baixa energia e a de caráter irreversível. A de baixa energia é constituída de discordâncias, que é compatível com os resultados de Rios que mostrou que a quantidade de hidrogênio absorvida na liga 600 está diretamente ligada à tensão imposta ao material e também com os resultados de Totsuka que mostrou que a quantidade de hidrogênio absorvida na Liga é máxima na zona de ruptura. A de caráter irreversível é atribuída por Shewmon como sendo devida a defeitos das superfícies internas-microtrincas ou poros. Viu-se no item 3.3, que foram observados óxidos na frente da ponta da trinca por CST na liga 600: Huang relata que essa Liga sofre oxidação interna e que o hidrogênio é capturado através das interfaces metal/óxido que constituem armadilhas de caráter irreversível. Essas resultariam da formação de ligações hidroxilas $\left(\mathrm{OH}^{-}\right)$na interface e induzem um aumento de volume na fronteira das fases. Também Myers evidenciou a interação entre óxidos internos e hidrogênio em $\mathrm{Al}_{2} \mathrm{O}_{3} / \mathrm{Al}$ : o hidrogênio seria capturado nos poros da interface precipitado/metal e nos vazios do óxido [CARON, 2001]..

Os parâmetros que influenciam o efeito fragilizante do hidrogênio são a composição da liga e a temperatura: Lagneborg mostrou que as ligas $\mathrm{Ni}-\mathrm{Fe}-\mathrm{Cr}$ na faixa entre -100 e $20{ }^{\circ} \mathrm{C}$, cujo teor em cromo é inferior a $18 \%$ são sensíveis ao efeito fragilizante do hidrogênio, para teores em níquel inferiores a $15 \%$ ou superiores a $35 \%$. Com $75 \%$ em Ni, a liga 600 é então potencialmente fragilizável pelo hidrogênio à baixa temperatura. Isso também foi confirmado por Lecoester e Foct em corpos de prova pré-carregados em hidrogênio; quanto à temperatura, o efeito fragilizante do hidrogênio para as ligas de níquel existe entre $-50^{\circ} \mathrm{C}$ e $100^{\circ} \mathrm{C}$, diminuindo quando aumenta a temperatura até desaparecer. Lecoester mostrou que o efeito fragilizante do hidrogênio persiste até $250{ }^{\circ} \mathrm{C}$ para a liga 600 
e também Lagneborg e Foct [FOCT, 1999] não observaram esse efeito além de $200^{\circ} \mathrm{C}$ [CARON, 2001].

Cabe ainda uma última observação importante: 0 tamanho e o crescimento da trinca normalmente são medidos através de monitoramento do potencial elétrico por corrente contínua, quando essa passa através do espécime e o potencial elétrico através da ponta da trinca é medido. Um instrumento monitora o conjunto de acionamento, normalmente num SSRT-máquina de tração que causa uma taxa de deformação lenta sobre o espécime (v. item 2.15.1.11.1). Thompson e outros ressaltaram os cuidados que se deve ter ao interpretar a queda de potencial em corrente contínua da liga 600 em água primária a $315^{\circ} \mathrm{C}$, quando se estuda o efeito do hidrogênio, porque embora essa seja uma técnica amplamente utilizada e de boa sensibilidade - podendo medir mudanças no tamanho de trinca de até $0,002 \mathrm{~mm}$ em espécimes de tração compacta 1T (CT) o crescimento da resistividade da Liga 600 acima dessa temperatura causado pelo $\mathrm{H}_{2}$, pode mascarar os resultados: assim, num gráfico crescimento de trinca por CST versus tempo de ensaio, há a indicação de um crescimento parabólico de 0 a 0,45 $\mathrm{mm}$ em aproximadamente 1500 horas que não corresponde a um real crescimento de trinca e sim ao aumento da resistividade da liga 600. Para solucionar isso os autores sugerem que se façam sempre ensaios adicionais como o de medição do deslocamento da abertura da trinca junto com a variação do carregamento para medição da compliância e também ensaios destrutivos de inspeção metalográfica [THOMPSON et al., 1997]. 


\section{INFLUÊNCIA DO MATERIAL NA CST EM LIGA 600}

\subsection{Parâmetros metalúrgicos}

A liga 600, para efeito de aplicação na confecção dos bocais do MAB de RAP, sofre tratamento térmico na faixa de 870 a $980^{\circ} \mathrm{C}$ por 90 minutos ou mais, exceto os fabricados na França que são tratados na faixa de 710 a $860^{\circ} \mathrm{C}$ se a tensão de escoamento exceder $343 \mathrm{MPa}$. Na fabricação, o processo de usinagem introduz tensões residuais e torna a tensão de escoamento maior do que a do material original. A solda de penetração e o processo de montagem dos bocais também introduzem tensões residuais e deformações, a interferência entre o bocal e o tampo introduz pequenas tensões circunferenciais ("hoop stresses") que tendem a relaxar durante a soldagem [SHAH et al., 1994].

O material para fabricação dos bocais mais susceptível à CSTAP é aquele que recebeu um recozimento final com uma temperatura relativamente baixa re-cristalizando os grãos trabalhados a frio, mas que não causou dissolução dos precipitados de carbonetos. Esses carbonetos não dissolvidos restringem o crescimento de grãos resultando numa estrutura de grão fino com carbonetos intragranulares e poucos precipitados de carbonetos intergranulares; durante 0 resfriamento do recozimento final, os carbonetos não precipitam nos novos contornos de grãos por causa da falta de carbono na solução disponível para precipitação: esse é o caso, por exemplo, da caracterização do material dos bocais da unidade 2 de Calvert -Cliffs [HALL et al., 1992].

\subsection{Microestrutura}

A microestrutura é um dos parâmetros preponderantes na CST. A liga 600 é constituída de uma matriz austenítica de precipitados - carbonetos de cromo, carbonitretos e nitretos. A distribuição de carbonetos em contornos de grãos depende da temperatura $\mathrm{T}_{\mathrm{A}}$ do tratamento de laminação e recozimento ("mill annealing"). Geralmente se obtém três tipos de estrutura. Se a temperatura do tratamento é superior à de re-dissolução de carbonetos $T_{S}$, a recristalização acompanha uma precipitação nos contornos de grãos durante o resfriamento. Isso conduz à estrutura do tipo I (Figura 6.1.a), cujo tamanho de grão está entre $20 \mu \mathrm{m}$ 
e $50 \mu \mathrm{m}$. Por outro lado, se $T_{A}$ é inferior a $T_{S}$, a dissolução dos carbonetos é parcial e a precipitação se fará no resfriamento principalmente sobre os carbonetos e numa menor medida sobre os contornos de grão. Obter-se-á a estrutura do tipo II (Figura 6.1.b), caracterizada por uma repartição dos carbonetos intragranulares sobre os contornos de grão da rede antiga de grãos. $O$ tamanho dos grãos varia entre $10 \mu \mathrm{m}$ e $20 \mu \mathrm{m}$. Observar-se-á a estrutura III (Figura 6.1.c) nas mesmas condições uma vez que a precipitação antes do tratamento é intragranular. A repartição de carbonetos é assim aleatória.

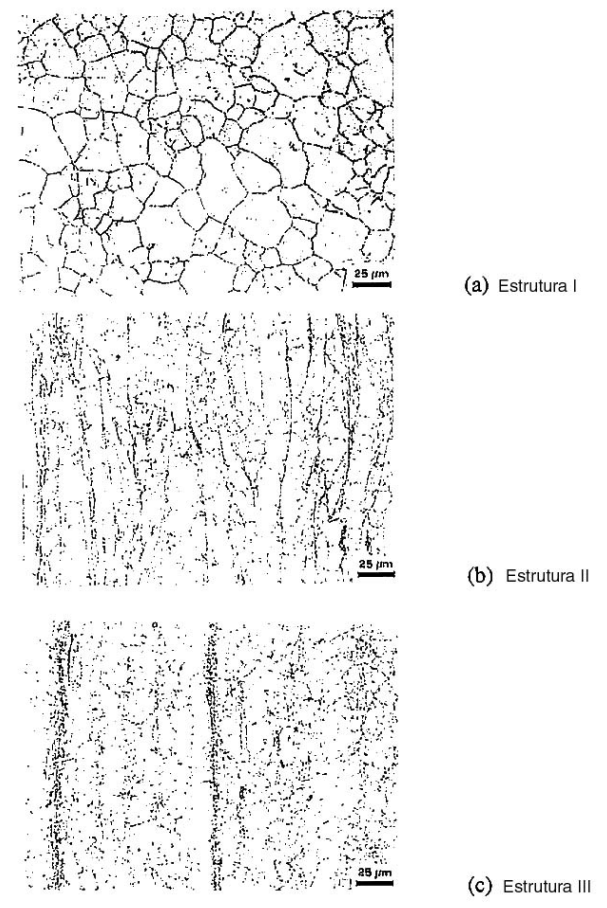

Figura 6.1. Diferentes tipos de microestrutura da liga 600 segundo o tratamento térmico. Ataque efetuado com ácido ortofosfórico [FOCT, 1999].

Estudos concluíram que aumenta na razão direta a susceptibilidade`a CST, quando se passa da estrutura metalográfica do tipo I ao tipo III. Essa influência da microestrutura é atribuída à distribuição de carbonetos nos contornos de grão. $\mathrm{O}$ tratamento térmico suplementar de normalização a $700^{\circ} \mathrm{C}$ permite também que os carbonetos precipitem nos contornos de grão, o que melhora a resistência à CST, exceto no caso particular de um pré - encruamento à medida que os carbonetos precipitam nas bandas de deformação [FOCT, 1999].

Symons e outros pesquisadores estudaram amostras de liga 600 em água a alta temperatura hidrogenada com vapor e em três condições microestruturais 
diferentes - material como recebido, recozido, recozido e deformado- através de metalografia óptica (MO) e microscopia eletrônica analítica (MEA): obtiveram diversas estruturas principalmente de grãos e seus contornos: nas amostras tratadas termicamente houve eliminação da subestrutura de discordâncias e aumento da precipitação da forma $\mathrm{M}_{7} \mathrm{C}_{3}$ em contornos de grãos de carbonetos intergranulares, havendo um diminuição da susceptibilidade à CST do material; o trabalho a frio produziu aumento dessa susceptibilidade entre outras conclusões [SYMONS et al., 1997].

As precipitações de carboneto de cromo ocorrem prematuramente na liga 600 devido à solubilidade do carbono ser baixa mesmo a temperaturas muito altas, por exemplo $0,03 \%$ em peso a $1000^{\circ} \mathrm{C}$. Os precipitados nessa liga incluem o $\mathrm{M}_{7} \mathrm{C}_{3}$ e o $\mathrm{M}_{23} \mathrm{C}_{6}$, além de nitretos de titânio e carbonitretos. Após tratamentos de processo e subseqüentes tratamentos térmicos, a estrutura predominante é o $\mathrm{M}_{7} \mathrm{C}_{3}(\mathrm{M}>95 \% \mathrm{Cr})$, com a chamada estrutura cristalina pseudo-hexagonal. Com temperaturas de envelhecimento mais altas ou depois de tempos maiores em baixas temperaturas quando a atividade do carbono é menor, o $\mathrm{M}_{23} \mathrm{C}_{6}$ pode precipitar. Esse carboneto tem estrutura dendrítica (ramificada) e tem uma relação cubo-sobre-cubo com a matriz: seu conteúdo metálico é mais de $90 \% \mathrm{Cr}$ e os precipitados intergranulares podem ser produzidos variando de pequenas ou grandes partículas discretas a porções semi-contínuas dessas partículas [BRUEMMER \& WAS, 1994].

Embora o mecanismo pelo qual essa precipitação de carbonetos nos contornos de grãos não seja perfeitamente conhecido [BRUEMMER \& WAS, 1994], foi proposta uma explicação para sua ação sobre a CST, com base nos efeitos sobre a plasticidade do material: observações através de microscopia eletrônica de transmissão demonstraram que os carbonetos intergranulares favorecem a emissão de discordâncias do contorno ao interior do grão, o que relaxa as tensões no contorno e assim diminui o aparecimento de trincas intergranulares, conforme é ilustrado na Figura 6.2. O efeito inverso é obtido para os carbonetos intragranulares que bloqueiam as discordâncias emitidas pelo contorno e reemitem essas para o contorno. Esse processo aumenta por conseqüência as tensões no contorno e acelera o aparecimento de trincas. Nesse caso, o efeito dos carbonetos intragranulares não é preponderante, face à sua baixa densidade volumétrica [FOCT, 1999]. 


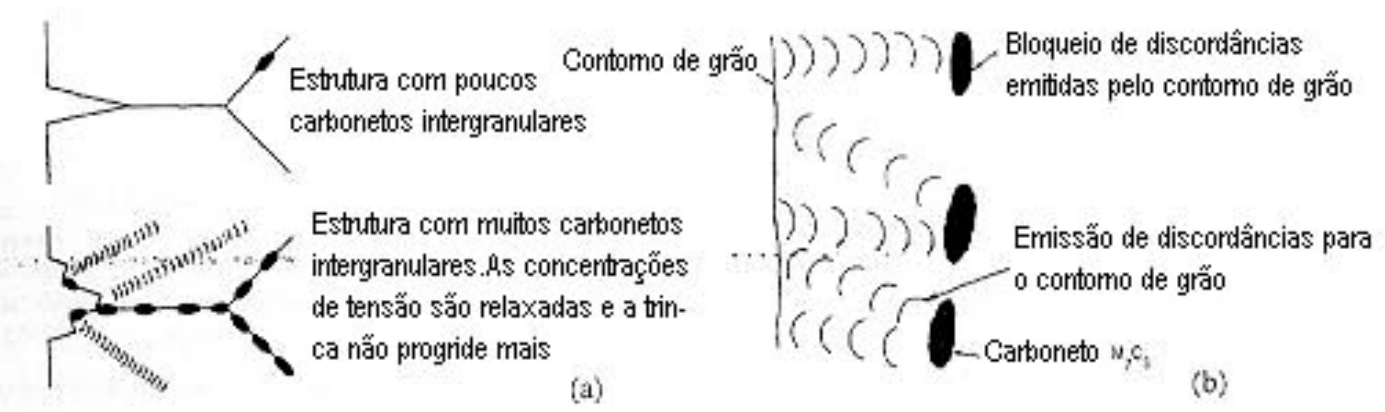

Figura 6.2. Efeito dos carbonetos (a) intergranulares e (b) intragranulares sobre as discordâncias, [FOCT, 1999].

Shah e outros autores [BRUEMMER \& WAS, 1994], [HALL et al., 1992], [SHAH et al., 1994] afirmam que a experiência de campo e as pesquisas mostram que a resistência à CSTAP da liga 600 é máxima quando os contornos de grãos são recobertos com carbonetos contínuos ou semi - contínuos. A resistência à CSTAP é mínima quando os contornos de grão são recobertos com carbonetos discretos e bastante espaçados (isto é, uma zona livre de precipitados ou PFZ- "precipitate free zone"). O tempo de iniciação da trinca por CSTAP cresce cinco vezes quando a cobertura de carbonetos nos contornos de grão cresce de 0 a $100 \%$. O contorno de carbonetos cresce para maior tamanho de grão e quando a temperatura do tratamento térmico é suficientemente alta para dissolver todo os carbonetos depositados antes do tratamento, resulta numa microestrutura mais resistente à CSTAP [SHAH et al., 1994].

Bruemmer também observa a partir de experimentos que a influência das porções semi-contínuas de carbonetos sobre a CSTIG depende bastante do meio em que a liga está imersa [BRUEMMER \& WAS, 1994].

Gras resume o duplo papel que pode ter a precipitação de carbonetos: se a precipitação for intergranular, ela pode retardar significativamente 0 deslizamento intergranular e conseqüentemente a velocidade de propagação de trincas por CST; por outro lado, se a precipitação for intragranular, ela pode aumentar o deslizamento intergranular, através de deformação por fluência ("creep") nos contornos de grãos, aumentando assim a velocidade de propagação de trincas por CST [GRAS, 1993]. 


\subsection{Sensitização}

Sendo a sensitização um fenômeno que atinge os aços inoxidáveis, pode afetar as juntas soldadas típicas da construção mecânica dos bocais do MAB, de liga 600 com liga 182 ou a liga 82. A sensitização provoca um aumento de precipitados intergranulares ricos em cromo e ao mesmo tempo exaure esse elemento das regiões das bordas dos grãos onde o cromo dissolvido os protegia conforme ilustrado na Figura 6.3.

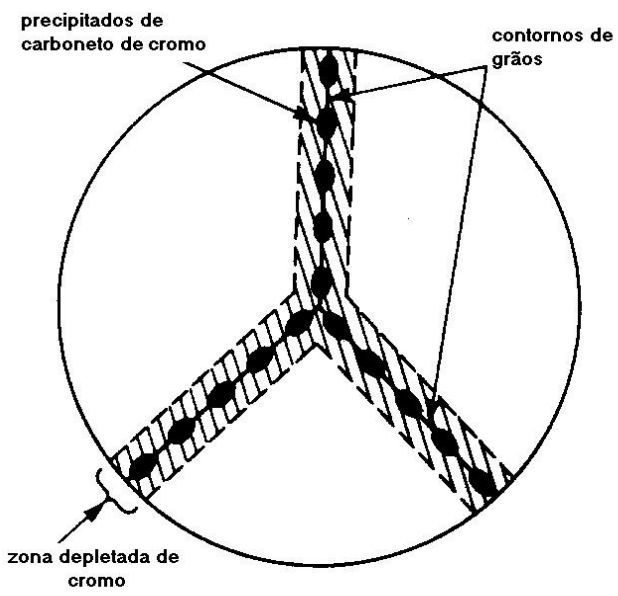

Figura 6.3. Esquema representando a sensitização para um aço inoxidável 304 [FONTANA \& GREENE, 1978].

A sensitização de aços inoxidáveis aumenta a taxa de corrosão intergranular e CST intergranular. Assim as juntas soldadas ficam mais susceptíveis à CST e deve ser estudada uma mudança na concentração de cromo para compensar esse efeito, conforme é ilustrado na Figura 6.4 [BRUEMMER \& WAS, 1994],[STAEHLE, 1992a]. 


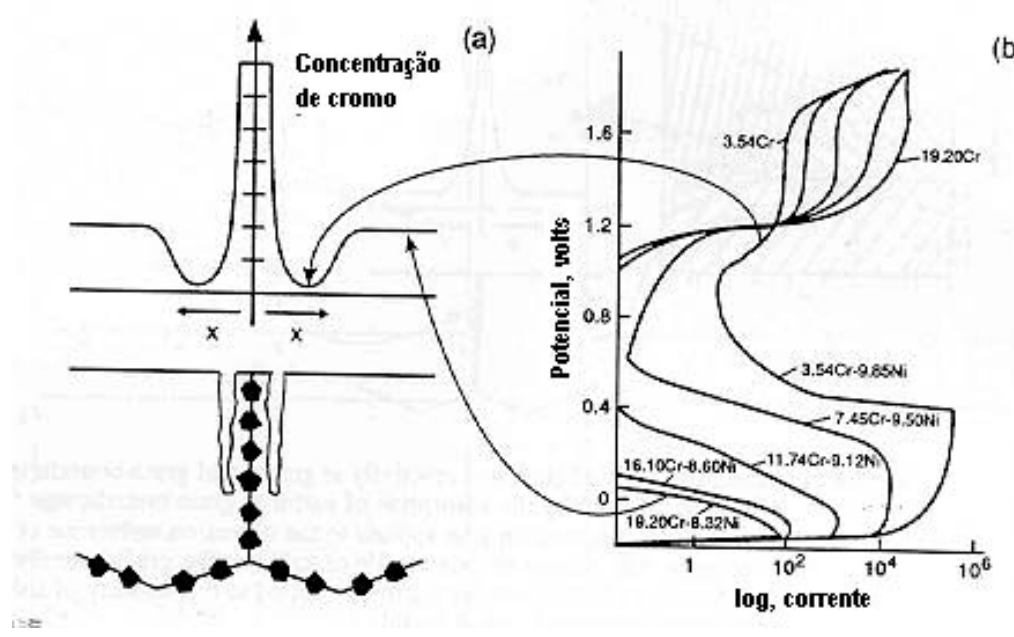

Figura 6.4. Esquema da reatividade química nos grãos e seus contornos de um aço inoxidável quando afetado pela diminuição de cromo da região adjacente aos precipitados de carboneto de cromo. (a) perfil de concentração de cromo quando afetado pela formação de carboneto de cromo. (b) Taxa de reação das ligas em função da concentração de cromo a $25^{\circ} \mathrm{C}$ como mostrado nas curvas de polarização do trabalho de Osozawa, Bohnekamp e Engel [STAEHLE, 1992a].

\subsection{Conteúdo de cromo}

Quando o teor de cromo das ligas à base de níquel-cromo-ferro aumenta de 0 até $20 \%$, o tempo de falha aumenta sensivelmente, de cerca de 50 horas a mais de 5000 horas (material com $\sigma_{R}=2,4 \sigma_{e}$ em água primária a $360^{\circ} \mathrm{C}$ ), conforme [FOCT, 1999].

Em meio primário oxigenado há um efeito prejudicial da diminuição de cromo dos contornos de grãos - antes por causa do papel do cromo ligado à fluência do que por causa da influência sobre a passivação - mas o mesmo não ocorre em meio hidrogenado [FOCT, 1999]. A diminuição de cromo intergranular na liga 600 ocorre quando esse material é tratado termicamente a $700^{\circ} \mathrm{C}$ por $100 \mathrm{~h}$, como é ilustrado no gráfico da distância dos contornos de grão versus concentração de cromo. A CSTIG é observada nessa liga quando a depleção de $\mathrm{Cr}$ nos contornos de grão caem abaixo de aproximadamente $8 \%$ em peso [BRUEMMER \& WAS, 1994].

A influência dos filmes de óxido sobre a resistência à CST das ligas $600 \mathrm{e}$ 690 permanece ainda mal conhecida. Parece não haver influência do teor de cromo sobre a velocidade de propagação lenta para os dois materiais, mas não foi investigada a influência do teor de cromo sobre as velocidades de propagação rápida nas duas ligas, o que parece ser uma diferença notável entre elas. Pode ser também que a melhoria do comportamento à CST na liga 690 esteja ligada a 
outros parâmetros como a precipitação intergranular ou ao teor de carbono solúvel [FOCT, 1999].

Was também investigou o efeito da composição dos contornos de grãos nos processos de deformação relativos à CST das ligas de níquel em água de alta temperatura: com aumento nos teores de cromo e carbono, são fortemente afetados os processos locais de fluência nesses contornos, trazendo um efeito benéfico de proteção à CST [STAEHLE, 1992a].

\subsection{Carbono dissolvido}

Ainda pouco estudado, este parâmetro chamou a atenção de Smialowska que tentou explicar o efeito benéfico dos carbonetos intergranulares sobre a resistência à CST com base nas curvas de polarização. Estas indicam uma diminuição de corrente de passivação na presença de precipitados nos contornos de grão e supõe-se que o carbono dissolvido nos contornos (cujo teor é diminuído por precipitação intergranular) torna a passivação mais difícil. Assim aumenta a dissolução da liga, favorecendo o processo de fratura por CST. Was obteve, no entanto resultados divergentes. Ele observou uma melhoria na resistência à CST, quando o teor de carbono dissolvido aumenta de 0 a 0,03\%. Em trabalhos mais recentes indica-se mais uma influência do carbono dissolvido sobre a plasticidade, que diminui muito a velocidade de fluência secundária na ponta da trinca, melhorando assim a resistência à CST [FOCT, 1999]. 


\title{
7. INFLUÊNCIA DE PARÂMETROS MECÂNICOS NA CST EM LIGA 600
}

\author{
7.1. Tensão
}

As trincas por CSTAP dos componentes de liga 600 são principalmente resultantes de altas tensões residuais. As tensões aplicadas provenientes da operação do reator são normalmente baixas. As tensões mais altas são produzidas durante a fabricação e instalação [BHANDARI \& PELLISSIER TANON, 1998]. As tensões são maiores na localização de $0^{0}$ no sentido da periferia do tampo (Figura 2.38), sendo que as tensões circunferenciais excedem as tensões axiais por um fator de 1,6 . As tensões a $180^{\circ}$ na periferia dos bocais são mais baixas, mas a tensão circunferencial é ainda maior do que a tensão axial. Na Figura 7.1, é apresentada a localização das trincas num arranjo típico de bocal do MAB de um vaso de RAP. Quando o ângulo de ajuste decresce, a magnitude das tensões medidas, circunferenciais e axiais e a diferença entre elas, também são reduzidas. As tensões axiais e circunferenciais na superfície interna do bocal central são aproximadamente iguais e de menor magnitude; assim, aí não foram detectadas trincas. A análise pelo método dos elementos finitos praticamente coincide com as medições em campo. A magnitude das tensões residuais induzidas por soldagem depende da tensão de escoamento do material do bocal, do seu diâmetro, da espessura da parede, do ângulo de ajuste do bocal e do comprimento da solda. As maiores tensões residuais são associadas com as maiores tensões de escoamento, menores diâmetros, paredes mais espessas, maiores ângulos de ajuste e maiores tamanhos de solda. O teste hidrostático realizado em fábrica alivia essas tensões residuais de pico no bocal. As forças de aperto do flange, teste hidrostático no campo e cargas operacionais em regime permanente ("steady state") reduzem essas tensões residuais de pico na superfície interna do bocal [SHAH et al, 1994].

A taxa de dano ou velocidade de propagação cresce de acordo com a expressão (7.1.1). 
Taxa de dano $=$ B. $\sigma^{\mathrm{a}}$

com B uma constante de proporcionalidade, $4 \leq \mathrm{a} \leq 7$ e $\sigma$ a máxima tensão principal de tração, que inclui a tensão aplicada e a residual. Essa correlação sugere que uma redução de 50 \% na tensão efetiva resultará num decréscimo de no mínimo 16 vezes (para o expoente da equação acima igual a 4) na razão de dano. O correspondente tempo de iniciação da CSTAP também aumenta [SHAH et al, 1994].

\section{Secção longitudinal}

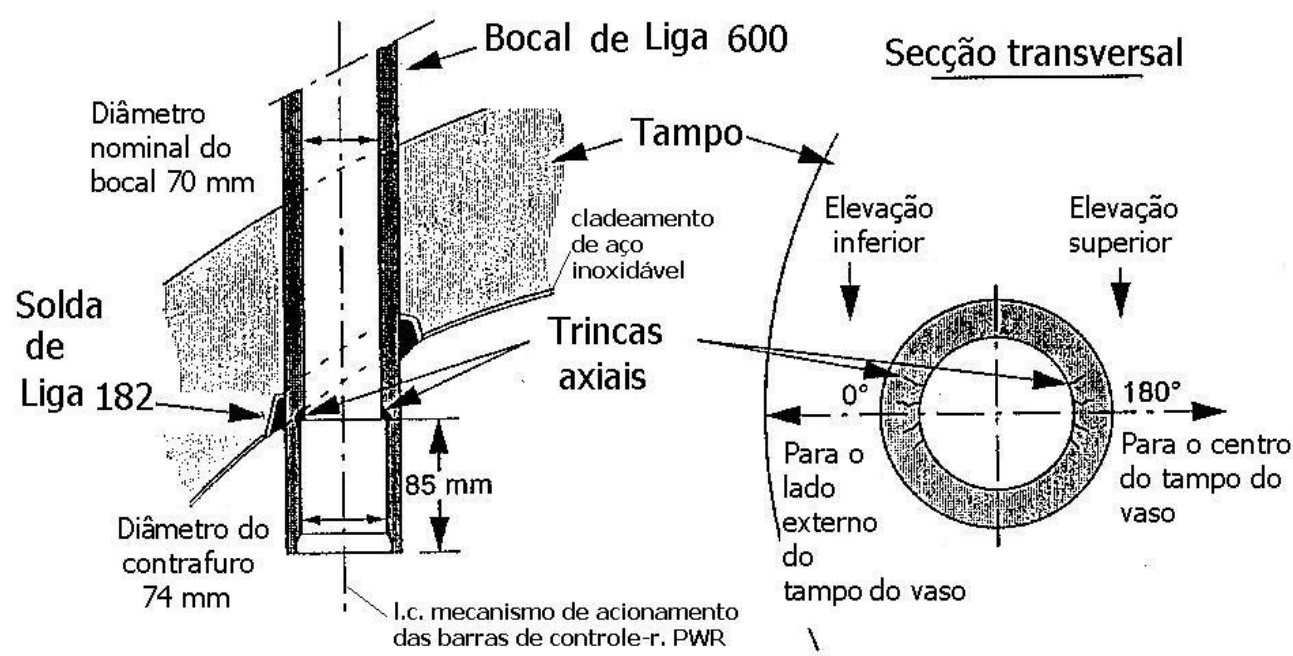

Figura 7.1. Localização de trincas em bocal do MAB da Usina de Bugey 3 [SHAH et al., 1994].

Em estudos realizados através de ensaios de carga constante, nas empresas EDF e Westinghouse, foi mostrado que o tempo de falha no caso de ruptura $t_{r}$ e a tensão $\sigma$ são relacionados por (7.1.2).

$$
\mathrm{t}_{\mathrm{r}}=\mathrm{k} \cdot \sigma^{-4}
$$

com k uma constante que pode variar com 0 material e tratamento termomecânico, a temperatura e o meio ensaiado. Não ocorre fratura a tensões inferiores ao limite elástico [FOCT, 1999]. 


\subsection{Taxa de deformação}

Em alguns estudos foi mostrado que a taxa de deformação é um parâmetro mais pertinente do que a tensão para descrever a fratura. Boursier [BOURSIER apud FOCT, 1999] obteve a partir de ensaios de CST em tração lenta e sob carga constante uma expressão para a velocidade de crescimento de trincas da forma (7.2.1).

$$
\mathrm{da} / \mathrm{dt}=\mathrm{A} \cdot \dot{e}^{0,58}
$$

com è a taxa de deformação aparente.

Abadie [ABADIE apud FOCT, 1999] confirmou essa correlação pela análise da fratura múltipla observada sobre corpos de prova submetidos à deformação lenta. Nessa foi mostrado que a velocidade de propagação lenta é proporcional à taxa de deformação elevada `a potência 0,6 , o que concordou com o resultado de Boursier: pode-se assim considerar que a fratura por CST é regida pela tensão local que por sua vez é comandada pela taxa de deformação.

Bosch [BOSCH apud FOCT, 1999] no entanto, não constatou essa dependência quando realizou ensaios no regime de solicitação cíclica: ele mostrou que o crescimento de trinca por ciclo é comparável ao comprimento da trinca por CST em propagação rápida durante o mesmo período independente da freqüência, quando essa é inferior a $0,1 \mathrm{~Hz}$, que conforme se viu na Figura 2.4, corresponde aproximadamente ao limite CST/CSF. Esses resultados porém são relativos, uma vez que ele utilizou nos ensaios corpos de prova entalhados do tipo CT nos quais as velocidades de propagação de trincas eram rápidas, ao passo que Boursier e Abadie utilizaram-nos lisos, em que as velocidades de propagação eram lentas.

De qualquer modo a importância da taxa de deformação e o fato de que a fratura não aparece abaixo do limite de elasticidade, sublinham o papel primordial da plasticidade no fenômeno da CST. Isso se aplica diretamente aos mecanismos e respectivos modelos, de dissolução localizada pela ruptura do filme passivo - a taxa de deformação controlando a freqüência de ruptura do filme, no modelo de Ford \& Andresen - e nos modelos de interação corrosão -deformação, como no modelo semi empírico de dano por taxa de deformação de Garud e Gerber (item 8.4). Esse modelo se baseia justamente sobre o importante papel da taxa de 
deformação lenta que proporciona tempo suficiente para a ação do meio sobre o material, através da perturbação da interface de proteção do filme passivo, no caso da CSTAP em alta temperatura na liga 600 [GARUD, 1996].

A taxa de deformação influi na fluência (que ocorre a uma temperatura do material superior a um terço da sua temperatura absoluta de fusão) e no deslizamento intergranular que pode vir a provocar a quebra do filme passivo. Por isso, esses fenômenos terão tratamento à parte nos dois itens seguintes.

\subsubsection{Fluência}

Vários resultados experimentais indicam que a fluência global e intergranular está correlacionada com a CST. Assim é necessário se apresentar as principais relações empíricas do envolvimento da fluência global ou intergranular no processo de CST da liga 600 em meio primário.

$\mathrm{Na}$ faixa de temperatura em torno de $360^{\circ} \mathrm{C}$, as velocidades de fluência da liga 600 são muito pequenas e normalmente é necessário esperar mais de 1000 horas a tensões muito elevadas, cerca de 450 a $650 \mathrm{MPa}$, para se atingir a fluência secundária. Essas tensões são próximas do limite de ruptura da liga 600 que gira em torno de 600 a $700 \mathrm{MPa}$ a $350^{\circ} \mathrm{C}$. Vários autores mostraram que a resistência à fluência da liga 600 apresenta, na maioria dos casos, uma boa correlação com a CST.

Três fatores podem influir no comportamento da fluência à CST: teor de cromo na Liga; teor de carbono dissolvido e microestrutura [FOCT, 1999].

Was [WAS apud FOCT, 1999] mostrou que há diminuição da susceptibilidade à CST com o aumento do teor de cromo por um aumento da resistência à fluência -- esse fator parece ser uma das bases da substituição da liga 600 pela liga 690 que contém teor de cromo mais elevado [EYRE, 1997]. Esse pesquisador também mostrou que a velocidade da fluência secundária diminui sensivelmente quando o teor de cromo das ligas Ni-Cr-Fe sintéticas varia de 5 a $30 \%$. A explicação para esse fato é que o cromo desacelera as discordâncias e abranda o material. No entanto, Mithieux [MITHIIEUX apud FOCT, 1999] observou efeitos relativamente pequenos do teor em cromo sobre a diminuição da velocidade de fluência. Quanto à influência do carbono dissolvido, Sung e outros autores [SUNG et al. apud FOCT, 1999] mostraram que em liga 600 de alta pureza 
para ensaios, um aumento na concentração de carbono em solução sólidas de 20 a 320 ppm, produz uma diminuição da velocidade de fluência secundária de um fator de cerca de 2000 vezes. Eles constataram que o comportamento em fluência é correlacionado com o da CST, principalmente em função do teor em carbono dissolvido. Quando esse aumenta, limitando o movimento das discordâncias, diminui a fluência e conseqüentemente aumenta a resistência (diminui a susceptibilidade) à CST [FOCT, 1999]; quanto à microestrutura, Mithieux constatou que a precipitação intergranular que diminui a susceptibilidade à CST [BRUEMMER \& WAS, 1994], reduz também a velocidade de fluência. Boursier constatou o efeito contrário, para uma série de tubos em liga 600 MA ("mill annealed", laminada e recozida), onde se atingiram velocidades de fluência as mais elevadas para estruturas com precipitações intragranulares, estruturas essas pouco resistentes à CST .

\subsubsection{Deslizamento intergranular}

Para Mithieux, mais importante do que essa correlação entre fluência global e CST, é o papel desempenhado pelo deslizamento intergranular e a sensibilidade à CST. Ele exprime essa relação através de um parâmetro que faz a analogia do material com um fluido, a "viscosidade intergranular": para isso ele partiu de numerosos ensaios de fluência em ar nas ligas 600 e 690. Esse parâmetro é uma função crescente da densidade de carbonetos nos contornos de grãos, decrescente com a susceptibilidade à fluência do material e que depende do tipo de liga e do contorno de grão. Ele mostrou assim que a velocidade de propagação de trinca dessas ligas é uma função (ajustada linearmente) decrescente da viscosidade intergranular do material. Isso permite inclusive, estabelecer um método preditivo da propagação de trinca, em meio de água primária, a partir da função de variação de viscosidade intergranular na microestrutura do material. No entanto, Angeliu e outros pesquisadores [ANGELIU et al. apud FOCT, 1999] chegaram a resultados não coerentes com Mithieux, através do mesmo tipo de ensaio realizado em liga níquel-ferro-cromo em atmosfera de argônio e água primária a $360^{\circ} \mathrm{C}$ : apesar das velocidades de deslizamento intergranular serem praticamente idênticas em argônio e em água primária, a taxa de deformação macroscópica aumenta de uma ordem de grandeza na água 
primária, sendo essa que causa a CSTAP. Ou melhor, a fração de taxa de deformação devida ao deslizamento intergranular diminui muito em água primária em relação ao argônio. Isso mostra que nesse meio o deslizamento intergranular não tem relação com a susceptibilidade à CST.

\subsection{Encruamento}

O efeito do encruamento sobre a resistência à fratura por CST varia de acordo com o tipo de solicitação aplicada. Ao longo de um ensaio de carga constante, o encruamento aumenta o limite elástico (tensão de escoamento) do material e conseqüentemente a tensão limite de fratura (não existe fratura abaixo do limite elástico). Em compensação no domínio plástico, Boursier mostrou que a velocidade de propagação das trincas é multiplicada por seis na presença de uma camada encruada no material, conforme é mostrado na Figura 7.2.

Esse fenômeno foi observado tanto em deformação lenta quanto em carga constante. Pode-se, contudo observar que se a velocidade de propagação de trincas é fortemente acelerada, o número total de trincas iniciadas é sensivelmente idêntico com ou sem camada encruada. O efeito negativo do encruamento foi evidenciado por outros autores que constataram um aumento de uma ordem de grandeza na velocidade de propagação de trincas [FOCT, 1999]. 


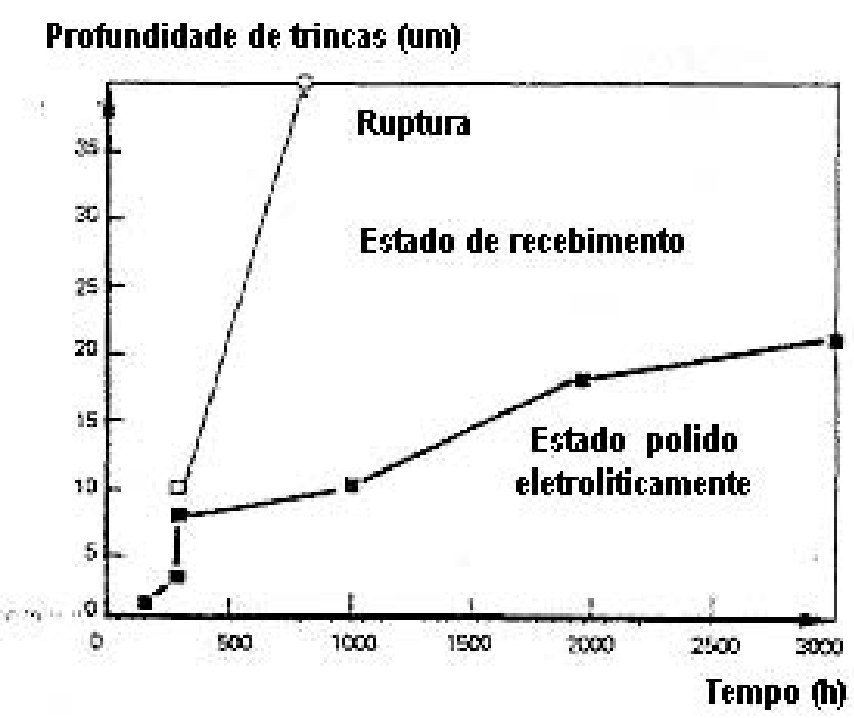

Figura 7.2. Influência do encruamento superficial sobre a profundidade máxima das trincas da Liga 600 em ensaio à carga constante a $360^{\circ} \mathrm{C}$ em água primária hidrogenada [FOCT, 1999].

Matematicamente o efeito do encruamento é representado através da equação (7.3.1), onde são atribuídos diferentes valores a $\sigma$ dependendo da taxa de encruamento.

$$
t_{f}=A \sigma^{n}
$$

com $t_{f}=$ tempo de falha; $\sigma=$ tensão, $A=$ constante; $n=$ expoente de tensão, variando de -4 a $-5,3$.

Quanto maior o encruamento, maior o $\sigma$, menor o tempo de falha, isto é, um material de alta resistência trabalhado a frio carregando altas tensões será mais susceptível à CST [HALL et. al, 1992].

Porém, o caso acima descrito pode não servir como lei geral, pois há casos observados onde o comportamento do material encruado é diferente:

a) Chambreuil-Paret [CHAMBREUIL-PARET apud FOCT, 1999] observou um efeito benéfico do pré - encruamento cíclico em fadiga sobre materiais como o aço inoxidável 316L, em que houve um aumento no tempo de iniciação de fratura por CST. O autor explica esse comportamento, em primeiro lugar porque os locais de iniciação como as linhas de deslizamento são multiplicadas, a dissolução 
sendo distribuída sobre uma superfície bem maior e sobre linhas de deslizamento mais finas que retardam a iniciação; em segundo, baseado na explicação do Modelo de Corrosão Assistida pela Plasticidade $(\mathrm{MCAP}=\mathrm{CEPM}=$ "Corrosion Enhanced Plasticity Model”), porque a propagação de trincas é retardada pela estrutura de discordâncias de baixa energia, gerada pela ciclagem em fadiga.

b) Staehle observa que o encruamento produz efeitos diferentes em altas e baixas tensões: em baixas tensões o aumento do encruamento reduz 0 tempo de falha significativamente. Em altas tensões, o efeito é inverso [STAEHLE, 1992].

c) Moshier e Brown fizeram um estudo bastante interessante e detalhado sobre o efeito do encruamento no comportamento à CSTAP da liga 600 , entre $252^{\circ} \mathrm{C}$ e $360^{\circ} \mathrm{C}$. Os autores estudaram, além do efeito do encruamento, os efeitos da variação do fator de intensidade de tensões e da orientação dos grãos do material. Para o encruamento, chegaram à equação (7.3.2) que relaciona a velocidade de crescimento de trinca $\left(\mathrm{v}_{\mathrm{CST}}\right)$ com a velocidade de crescimento de trinca no material não encruado $\left(\mathrm{V}_{\mathrm{CST}}{ }^{0}\right)$ e a tensão de escoamento $\sigma_{Y}$ através de um fator $\alpha$, que fica entre 0,0040 e 0,0047 $\mathrm{MPa}^{-1}$ :

$$
\mathrm{v}_{\mathrm{CST}}=\mathrm{v}_{\mathrm{CST}}{ }^{0} \cdot \exp \left[\alpha \cdot \sigma_{\mathrm{Y}}\right]
$$

Também a energia de ativação $Q$ decresce sistematicamente de 138 e $158 \mathrm{~kJ} / \mathrm{mol}$ para $126 \mathrm{~kJ} / \mathrm{mol}$, conforme aumenta o encruamento e a tensão de escoamento das amostras de liga 600 [MOSHIER \& BROWN, 1999]. 


\subsection{Fechamento de trinca}

Pode ocorrer nos processos de fratura ambientalmente assistidos, que envolvam tensões cíclicas, que as trincas nem se propaguem (ou se propaguem com velocidade menor que o esperado) se sofrerem fechamento devido a processos físico-químicos como: crescimento de óxidos, plasticidade induzida ao longo da trinca, rugosidade induzida ao longo da trinca, transformação de fase induzida na trinca e viscosidade induzida no fluido contido na trinca. Andresen e Campbell efetuaram ensaios de propagação de trincas em espécimes do tipo CT (1T) com as ligas 82 e 600 e aços inoxidáveis 304 e 316, em água a alta temperatura e carga cíclica regida pela razão de carga $R=K_{\min } / K_{\max }$ e freqüência $f$. Obtiveram diversos casos de interesse onde houve fechamento de trinca, ilustrado pela Figura 7.3 [ANDRESEN \& CAMPBELL, 1989].

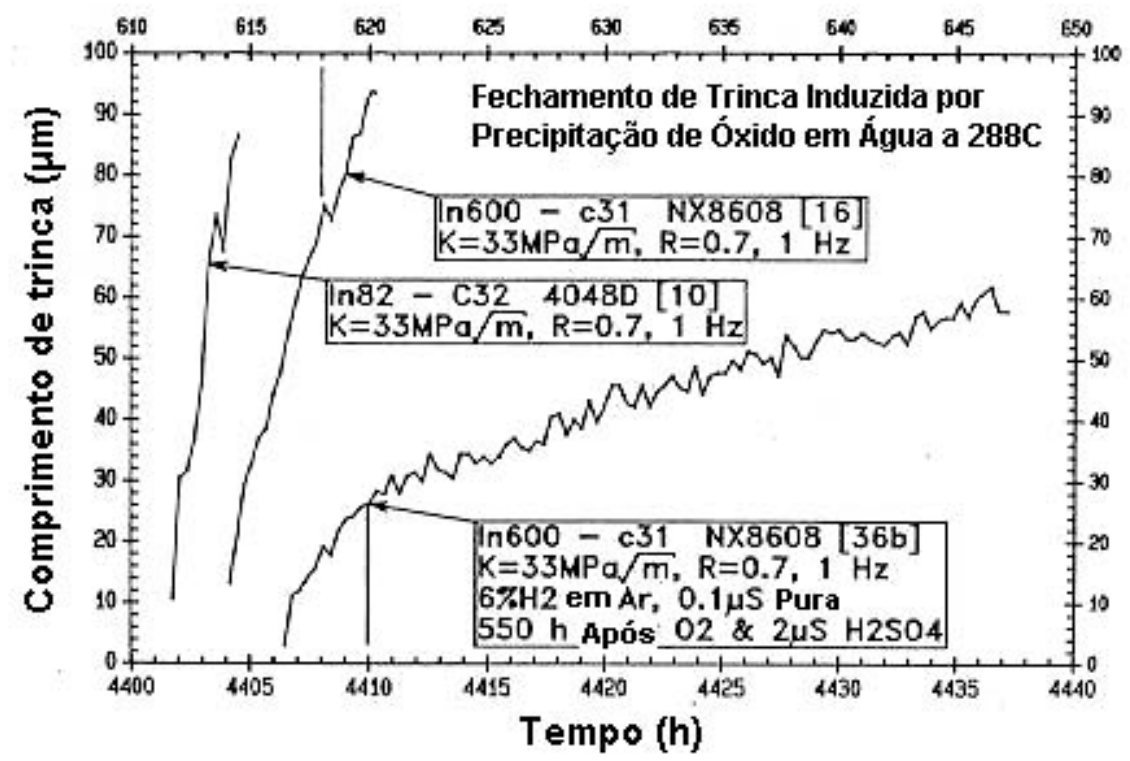

Figura 7.3. Dados de velocidade de propagação de trinca de espécimes de liga 82 e 600 ensaiados com razão de carga $\mathrm{R}=0,7$ e $1 \mathrm{~Hz}$. Foram observadas altas velocidades de propagação de trinca em duas partes dos ensaios, com resultados equivalentes à propagação obtida em aço inoxidável. Numa terceira parte do ensaio a velocidade de propagação de trinca era inicialmente alta, depois decaiu lentamente até um valor intermediário ( 10 vezes acima da velocidade obtida em ensaio de carga constante, mas 10 vezes abaixo dos outros dados) [ANDRESEN\&CAMPBELL, 1989]. 


\section{MECANISMOS E MODELOS NA CST EM LIGA 600}

A CSTAP requer a presença simultânea de tensões de tração, ambiente corrosivo à alta temperatura e uma microestrutura susceptível a trincas [SHAH et al., 1994], [RINCKEL, 1998].

Dentre alguns dos modelos de iniciação e propagação das trincas por CSTAP, é considerado o estado eletroquímico do material em torno da ponta da trinca, seguido da cinética de iniciação e propagação da trinca, que se dá após a quebra de película passiva (camada de óxido protetor) na ponta da trinca, criando uma zona anódica que forma uma pilha com a zona catódica ainda protegida pela película passiva (bordas da trinca), provocando um processo rápido de corrosão [FONTANA \& GREENE, 1976], [PANASIUK, 1997]. A movimentação e o acúmulo de discordâncias na matriz metalográfica, pode gerar degraus na superfície susceptível, provocando o rompimento da película passiva, com o conseqüente início da trinca por CST.

O hidrogênio do meio também pode influir na iniciação e na propagação da trinca, através de seu transporte, adsorção à parede da trinca e posterior absorção e difusão através do material, provocando fragilização por hidrogênio [KNOTT, 1976], [HERTZBERG, 1989], [FOCT, 1999], [CARON, 2001], [MILLS \& BROWN, 2001]: há modelos que explicam a ação do hidrogênio adsorvido através da ponta da trinca difundindo pela rede cristalina, agindo sobre as regiões de alta tensão triaxial adiante da ponta da trinca, provocando alterações na plasticidade do material e iniciando-se trincas através da ação de discordâncias sobre obstáculos. Esses modelos de interação entre a corrosão e a deformação são denominados de MCAP (Modelo de Corrosão Assistida pela Plasticidade) ou CEPM (Corrosion Enhanced Plasticity Model) e PLAH (Plasticidade Localizada Assistida por Hidrogênio) ou HELP (Hydrogen Enhanced Localised Plasticity) (item 8.9.2). Nas referências [FOCT, 1999] e [CARON, 2001], tem-se uma revisão completa e aprofundada desses mecanismos.

O oxigênio dissolvido na água também é um fator de susceptibilidade à CSTAP [ROBERTS, 1981] devendo ficar numa faixa adequada para formação da película passiva no aço mas também não muito alta para alimentar por exemplo a formação de pite, mecanismo de corrosão localizada que como já se viu, pode 
iniciar a trinca por CSTAP. Uma revisão bastante completa e aprofundada desses mecanismos é dada por Hertzberg [HERTZBERG, 1989].

A velocidade de propagação da trinca de CST ( $\left.\mathrm{V}_{\mathrm{CST}}\right)$ pode ser expressa e quantificada como uma função de fatores metalúrgicos como tratamento térmico (TT), tamanho de grão (TG), trabalho a frio (TF), fatores ambientais como temperatura $(\mathrm{T}), \mathrm{pH}$, potencial eletroquímico $(\mathrm{E})$, pressão parcial de hidrogênio $\left(\mathrm{p}_{\mathrm{H} 2}\right)$ e fatores mecânicos como fator de intensidade de tensão aplicada $\left(\mathrm{K}_{\mathrm{I}}\right)$, deformação (e), evoluindo de acordo com a expressão funcional (8.1) [REBAK \& SMIALOWSKA, 1995].

$$
V_{C S T}=f\left(K_{1}, e, T T, T G, T F, T, p H, E, p_{H 2}\right)
$$

Para se alcançar o objetivo de modelar a fratura por CST na liga 600 é preciso estudar antes quais são os mecanismos e modelos aplicáveis ao caso, dos quais foram dadas considerações gerais no item anterior. Esses podem ser divididos em famílias segundo os parâmetros que governam o fenômeno, além dos empíricos e numéricos, de acordo com a classificação adaptada de [FOCT, 1999]:

a) Mecanismos de dano por fluência;

a.1) Fluência global;

a.2) Deslizamento intergranular;

b) Mecanismos de dissolução assistida por ruptura do filme passivo;

b.1) Modelo semi-empírico de dano por taxa de deformação de Garud e Gerber;

b.2) Modelo de fratura acoplada ao ambiente de Macdonald e UrquidiMacdonald;

c) Mecanismos de fratura assistida pelo hidrogênio;

d) Mecanismo de oxidação interna;

e) Mecanismos de interação entre o ambiente e a deformação.

f) Modelos empíricos e numéricos. 


\subsection{Mecanismo de dano por fluência}

Was [WAS apud FOCT, 1999] propôs um mecanismo permitindo justificar tanto a ruptura da liga 600 em água do circuito primário como em meio inerte. Nele, a fratura intergranular por CST é resultante de um dano do material por fluência. Logo que esse material flui, formam-se vazios nos contornos de grão que coalescem, dando origem a cavidades. A ruptura é conseqüência dessa cavitação intergranular e da sobrecarga dúctil dos ligamentos que separam esses vazios. Assim, logo que a liga 600 que flui rapidamente é testada em deformação lenta, os efeitos da fluência têm tempo de se manifestar e danificá-la. Esse fato é confirmado por diversos outros pesquisadores e nesse mecanismo a água primária e o hidrogênio acrescem susceptibilidade à CST aumentando a mobilidade das discordâncias e assim da velocidade de fluência. Was justificou esse modelo observando certas semelhanças entre as rupturas provocadas na fluência em argônio e na CST em água primária: ambas têm planos de fratura parcialmente intergranulares frágeis e cavidades. A grande limitação desse modelo é que ele foi deduzido com base em experimentos com liga 600 de alta pureza e com baixo teor em carbono e não com ligas 600 industriais.

Hall [HALL apud REBAK \& SMIALOWSKA, 1996] desenvolveu uma modelagem para a CSTIG da liga $600 \mathrm{em}$ alta temperatura, baseado no fato de que a fluência é ambientalmente assistida. Para a fluência utilizou um mecanismo de discordâncias termicamente ativadas. A velocidade de propagação da trinca é assumida como sendo controlada por um processo de fratura por fluência expresso pela equação (8.1.1).

$$
\mathrm{v}_{\mathrm{CST}}=\left[2 \mathrm{r}_{\mathrm{C}} \varepsilon_{\mathrm{S}} / \varepsilon_{\mathrm{C}}\right] \cdot \exp \left\{-\Delta \mathrm{H}_{0} / \mathrm{RT}^{*} \cdot\left[1-\mathrm{b}\left(\mathrm{K}-\mathrm{K}_{\mathrm{th}} / \mathrm{K}_{\mathrm{S}}-\mathrm{K}_{\mathrm{th}}\right)^{\mathrm{p}}\right]\right\}
$$

com $r_{C} \circ$ raio da ponta da trinca, $\varepsilon_{S} \circ$ parâmetro de material proporcional à densidade de discordâncias móveis e à energia térmica de ativação, $\varepsilon_{C}$ a deformação crítica de fluência necessária para a fratura, $\Delta \mathrm{H}_{0}$ a entalpia de ativação independente da temperatura, $\mathrm{R}$ a constante universal dos gases, $T^{*}$ uma temperatura equivalente tal que $1 / T^{*}=1 / T-1 / T_{0}$, sendo $T_{0}$ uma temperatura de referência, $b$ uma constante, $K$ é um fator de intensidade de tensão aplicado, $K_{\text {th }} O$ fator de intensidade de tensão limite, $K_{S}$ é um fator de intensidade de tensão de saturação e $p$ o expoente de tensão. 
Essa modelagem no entanto é limitada: por exemplo, no modelo de corrosão assistida pela plasticidade (MCAP, CEPM, item 8.9.2), que é o modelo mais aperfeiçoado para explicação do efeito do hidrogênio, a equação (8.1.1) não pode ser utilizada sem muitas pressuposições como para os valores de $r_{C}, \varepsilon_{C}, b, p$ e $T_{0}$ que são desconhecidos. Enfim, a fluência parece ter um papel importante na CSTIG da liga 600, mas é improvável que o processo de fluência controlada por difusão seja o único fator responsável pela propagação desse tipo de trinca.

Boursier e outros propuseram um modelo de dano por taxa de deformação [BOURSIER et al, 1995]: é um modelo que considera como parâmetro fundamental na CSTAP da liga 600 à alta temperatura, a taxa de deformação na ponta da trinca (ao invés da tensão) e conseqüentemente a fluência na mesma, como fator que rege sua iniciação e a propagação. Os autores se basearam em dados experimentais obtidos através do método desenvolvido por Santarini [SANTARINI, 1989] e obtiveram relações empíricas para a taxa de fluência na ponta da trinca, para ensaios do tipo carga constante ("constant load", CL) e SSRT/CERT. A seguir, a relação (8.1.2) obtida para o último caso:

$$
\dot{e}_{p t}=C \dot{e}_{a p p}+D(d a / d t) / x^{*}
$$

com: $\dot{e}_{\mathrm{pt}}=$ fluência na ponta da trinca, e $\dot{e}_{\mathrm{app}}=$ taxa de deformação macroscópica, $\mathrm{da} / \mathrm{dt}=$ velocidade de propagação da trinca, $\mathrm{x}^{*}=$ comprimento de calibração, $\mathrm{C}, \mathrm{D}=$ constantes.

De acordo com Gras, a taxa de deformação aparente mínima para ocorrer CSTAP na liga 600 é menor que é ${ }_{\mathrm{app}} \sim 2.10^{-7} \mathrm{~s}^{-1}$, podendo essa atingir $10^{-6} \mathrm{~s}^{-1}$ se as condições forem muito severas e o material particularmente susceptível à CSTAP [GRAS,1993].

Com base em diagrama desenvolvido pelos autores, pode-se unificar os resultados para os tempos de iniciação e propagação lenta, para alcançar uma profundidade de trinca da ordem de 80-90 $\mu \mathrm{m}$, de acordo com (8.1.3).

$$
t_{f}=K \cdot \dot{e}_{p t}^{-0,67}
$$




\subsection{Mecanismo de dano por deslizamento intergranular}

Um segundo mecanismo de CST induzida pela deformação por fluência foi proposto por Kergavarat [KERGAVARAT apud FOCT, 1999], mas não é deflagrado pela deformação devida à fluência global e sim pela parte da fluência local ligada ao deslizamento intergranular. Isto porque 0 pesquisador baseou sua interpretação sobre a correlação observada entre a propensão dos contornos de grão ao deslizamento e a susceptibilidade do material à CST: o deslizamento intergranular provoca tensões elevadas nos contornos que são necessárias à propagação de trincas. Os contornos orientados a $45^{\circ}$ da tensão macroscópica têm uma forte tendência a deslizar, o que induz incompatibilidades nos contornos adjacentes, perpendiculares ao eixo de tração, gerando assim tensões importantes. Essas tensões estão na origem de um mecanismo de dano segundo Stroh (item 8.9.2). Esse mecanismo é também assistido pelo hidrogênio e os eventos do mesmo seriam os seguintes, conforme Figura 8.1:

1- Após a ruptura do filme de óxido, o hidrogênio penetra no material e se difunde nos contornos de grãos para se concentrar nas zonas apresentando elevadas concentrações de tensão tais como as junções triplas;

2- A concentração de tensão causada pelo deslizamento dos contornos a $45^{0}$, associada com um efeito de fragilização por hidrogênio conduz a uma decoesão, separação, na junta tripla;

3- O fator de intensidade de corrosão sob tensão, $K_{\text {ICST }}$ é atingido e a microtrinca se propaga ao longo do contorno perpendicular ao eixo da solicitação macroscópica de tensão. 


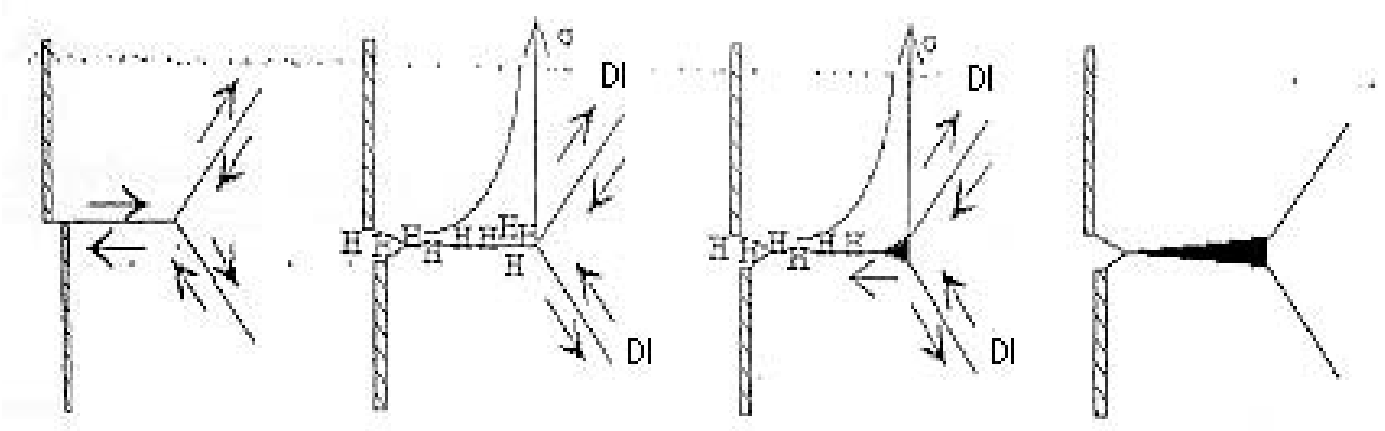

Dl=deslizmento intergranular $\mathrm{H}=$ hidrogênio

Figura 8.1. Esquema ilustrativo das diferentes etapas do mecanismo de CST induzido por deslizamento intergranular [FOCT, 1999].

A limitação desse modelo é que ele não explica no final da etapa 3 como a trinca continua a se propagar , uma vez que a tensão é relaxada e as condições mecânicas na ponta da trinca não permitem que ela continue a se propagar, retomando novamente a etapa 1 [FOCT, 1999].

\subsection{Modelo de dissolução localizada pela ruptura do filme passivo}

O modelo de dissolução localizada pela ruptura do filme passivo, um dos mais importantes, foi proposto em 1952 por Logan e depois retomado por Ford em 1982 [FOCT, 1999].

Esse modelo foi formulado para explicar o crescimento de trincas em aços carbono, aços inoxidáveis e aços ligados com níquel a altas temperaturas: o avanço da trinca é relacionado com as reações de oxidação que ocorrem na ponta da trinca quando a película passiva de proteção é rompida pela deformação crescente na matriz subjacente. A extensão do avanço da trinca é relacionada pela lei de Faraday à densidade de carga de oxidação associada com a dissolução e repassivação na superfície exposta do metal onde a película foi rompida [REBAK \& SMIALOWSKA, 1995].

O mecanismo é constituído das seguintes etapas do processo sobre o filme passivo existente na superfície do material, no qual a trinca por CST se propaga de maneira periódica [ANDRESEN \& FORD, 1988], [ANDRESEN \& FORD, 1996], [MACDONALD, 1996], [REBAK \& SMIALOWSKA, 1995], [FOCT, 1999]:

1- ruptura do filme passivo; 
2- dissolução do material, no caso a liga exposta ao meio, caracterizando propagação da trinca;

3- repassivação da superfície exposta.

A ruptura do filme passivo acontece por deformação plástica localizada, permitindo a propagação da trinca por dissolução anódica do metal exposto (Figura 8.2).

A propagação da trinca segundo esse modelo é possível somente se a razão de passivação não é nem muito rápida, nem muito lenta. Entre esses dois extremos, isto é, passivação perfeita e corrosão generalizada, respectivamente, cada evento de ruptura causa um incremento da extensão da trinca não excessivamente brusco [ROBERTS, 1981]. Essas trincas podem ser transgranulares ou intergranulares, conforme ilustra a Figura 2.5. 


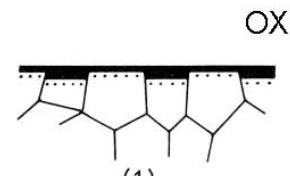

(1)

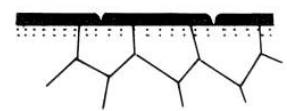

(3)

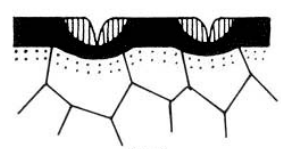

(5)

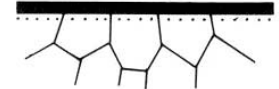

(2)

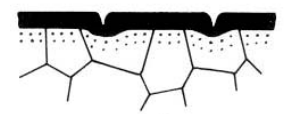

(4)

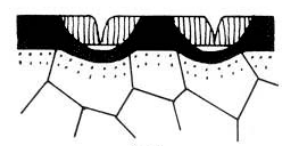

(6)
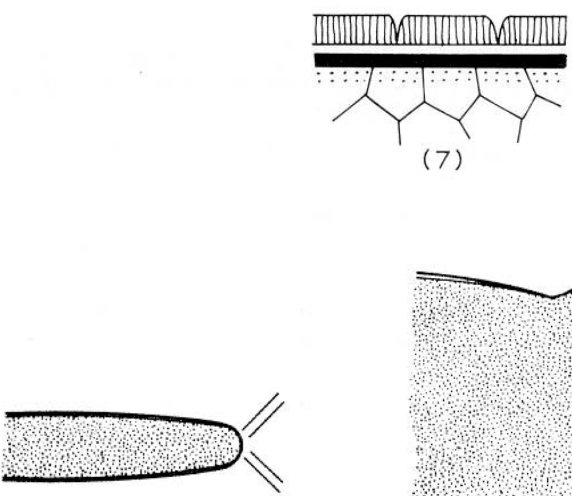

(7)

(a)

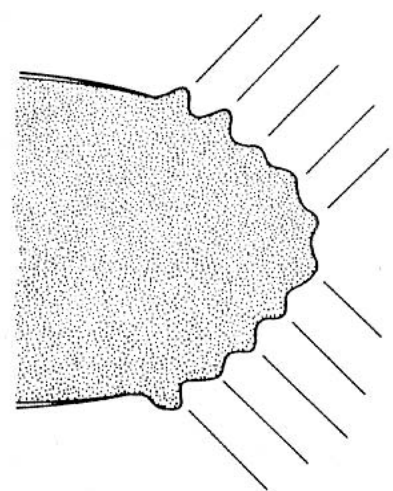

$\langle b|$

Figura 8.2. Esquema de ruptura de filme passivo em 7 etapas, mostrando em (1) a (3) a ação mecânica sobre o filme passivo, em (4) a (6) uma ação do meio sobre ele, resultando em um afinamento excessivo em (7); no detalhe abaixo, da quebra do filme passivo na ponta da trinca, a deformação plástica na trinca (a) resulta em um número de eventos de ruptura do filme associado com a dissolução transiente anódica em (b) [ROBERTS, 1981], [HERTZBERG, 1989].

A velocidade de propagação da trinca está relacionada com a corrosão da liga e depende de dois parâmetros: a freqüência de ruptura do filme passivo governada pela taxa de deformação do material e a propagação da trinca cujo incremento é governado pela cinética de dissolução, através da lei de Faraday. Existe assim uma competição entre a velocidade de deformação da ponta da trinca e a velocidade de repassivação. Se a repassivação for muito rápida, a 
propagação torna-se desprezível e se a repassivação for muito lenta a corrosão generalizada a dilui, conforme é ilustrado na Figura 8.3 [FOCT, 1999].

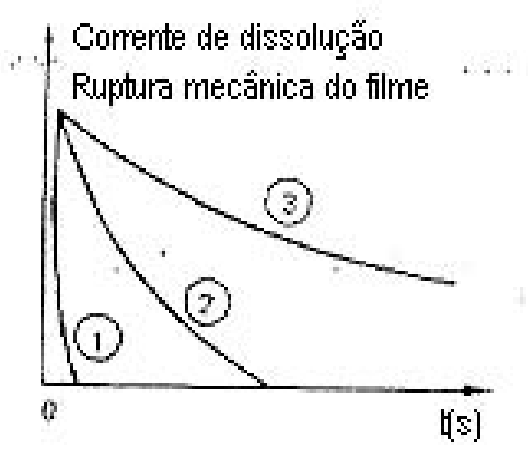

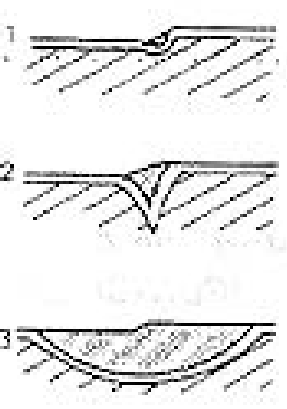

comosấo generalizada

Figura 8.3. Influência da cinética de repassivação de acordo com Staehle [FOCT, 1999].

Como a propagação da trinca se faz por dissolução do metal, é possível através da aplicação da lei de Faraday, relacionar-se a velocidade de propagação da trinca $v_{\text {CST }}$ com a quantidade de corrente (carga) $Q_{T}$ consumida entre duas rupturas sucessivas do filme passivo, de acordo com a expressão (8.3.1).

$$
v_{C S T}=M . Q_{T} / \rho . z . F . t_{R}
$$

com $M=$ massa atômica do metal; $\rho=$ densidade volumétrica; $z=$ carga de oxidação, ou seja, número de elétrons trocados durante a oxidação de um átomo de metal; $\mathrm{F}=$ constante de Faraday; $\mathrm{t}_{\mathrm{R}}=$ período de ruptura do filme passivo [FOCT, 1999].

Como

$$
1 / t_{R}=\dot{e}_{P T} / e_{R}
$$

com $\dot{e}_{\mathrm{PT}}=$ taxa de deformação na ponta da trinca; $\mathrm{e}_{\mathrm{R}}=$ deformação de ruptura do filme passivo. E ainda considerando que a lei de passivação geralmente quantificada sobre os transitórios de corrente obtidos durante os ensaios de passivação é da forma (8.3.3).

$$
i=i_{0} \cdot t^{-n}
$$


com $\mathrm{i}=$ densidade de corrente, $\mathrm{i}_{0}=$ densidade inicial de corrente na ponta da trinca no tempo de início da repassivação to e $n$ é um parâmetro que representa os efeitos do meio ambiente e do material. E também que

$$
\mathrm{Q}_{\mathrm{T}}=\int_{0}^{\mathrm{tr}} \mathrm{i} . \mathrm{dt}
$$

Obtém-se então de (8.3.1), (8.3.2), (8.3.3) e (8.3.4), uma expressão relacionando a velocidade de propagação da trinca e a taxa de deformação na ponta da trinca (8.3.5) [REBAK \& SMIALOWSKA, 1995], [FOCT, 1999].

$$
v_{C S T}=f(n) \cdot \dot{e}_{P T}^{n}
$$

com

$$
f(n)=M \cdot i_{0} \cdot t_{0}{ }^{n} / z \cdot F \cdot \rho \cdot(1-n) \cdot e_{R}^{n}
$$

Shoji obteve a expressão (8.3.7), considerando a dissolução governada pela difusão em fase líquida.

$$
i=i_{0} \cdot t^{-0,5}
$$

Essa expressão leva à velocidade de propagação de trinca conforme (8.3.8).

$$
v_{\mathrm{CST}}=\mathrm{A} \cdot \dot{\mathrm{e}}_{\mathrm{PT}}{ }^{0,5}
$$

Combrade através de experiências de repassivação, achou a lei regida da forma (8.3.9) [FOCT, 1999].

$$
i=i_{0} \cdot t^{-0,68}
$$

Deve-se ressaltar que para chegar à essa modelagem, Andresen e Ford supuseram que existe um alto grau de independência das contribuições química e mecânica à velocidade de propagação da trinca [ANDRESEN \& FORD, 1988].

A principal vantagem desse modelo é que ele permite uma quantificação da velocidade de propagação, difícil em outros mecanismos, mas é insuficiente para descrever todo o dano por CST, conforme Rios [RIOS apud FOCT, 1999]. 
Ford e Andresen obtiveram através de dados experimentais, uma modelagem para a velocidade de propagação de trinca em aço inoxidável 304 e ligas à base de níquel em água a alta temperatura em reatores do tipo RAF (reator de água fervente ou BWR, boiled water reactor). $O$ valor de $n=0,65$ parece representar bem as condições da água a temperatura de $330^{\circ} \mathrm{C}$ no potencial de circuito aberto [REBAK \& SMIALOWSKA, 1996]:

$$
V_{\text {CST }}=\left(7,8 \cdot 10^{-3} n^{3,6}\right)\left(4,1 \cdot 10^{-14} K^{4}\right)^{n}
$$

Na Figura 8.4 é mostrado o gráfico $v_{C S T}$ versus $K_{l}$ e o conjunto de dados recolhidos para sua elaboração. 


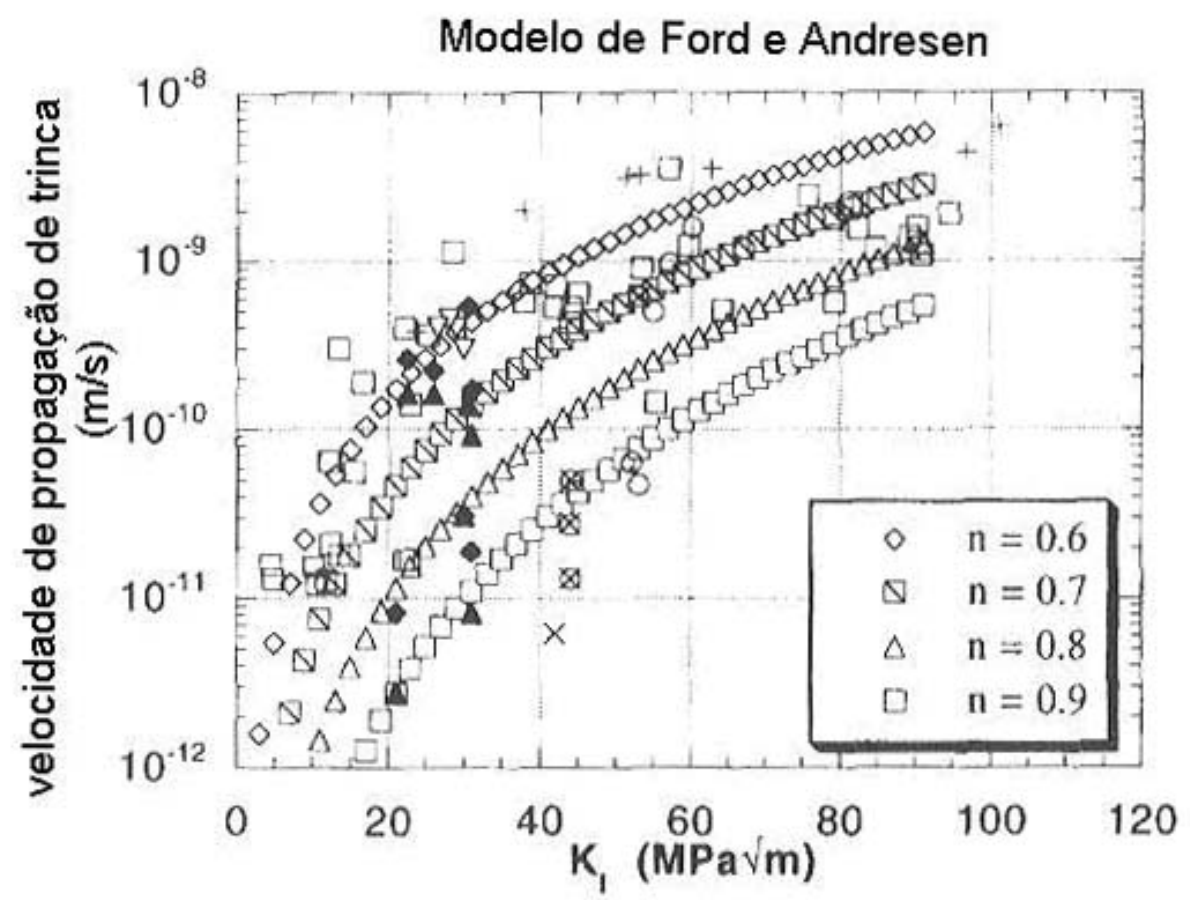

Figura 8.4. Comparação entre valores de velocidade de propagação de trinca preditos pelo modelo de Ford e Andresen e os dados experimentais [REBAK \& SMIALOWSKA, 1996].

Macdonald aponta as seguintes deficiências nesse modelo [MACDONALD, 1996]:

a) No modelo embora seja seguida a lei de Faraday, não está pressuposta explicitamente a conservação de carga;

b) No modelo não é postulada uma forte interação com as condições ambientais, sugerindo que a reação de dissolução do metal não é fortemente catalisada pelo $\mathrm{H}^{+}$ou por ânions presentes na solução;

c) O parâmetro n da equação (8.3.3) nem sempre é o mesmo da equação (8.3.5);

d) Andresen e Ford continuam o desenvolvimento de seu modelo assumindo que $A=f(n)$ e $n$ na equação (8.3.5) são funções contínuas do potencial de corrosão, da condutividade, de um parâmetro que caracteriza o grau de sensitização do material, etc. Macdonald prova que a dependência com a 
condutividade tinha sido considerada apenas com relação à temperatura ambiente e não com relação à alta temperatura do meio.

Andresen e Ford refutaram as críticas de Macdonald nos seguintes pontos [ANDRESEN\&FORD, 1996]:

a) A diferença de condutividade atribuída à temperatura ambiente e à alta temperatura é apenas uma observação formal, pois esse não é um parâmetro fundamental no crescimento da trinca;

b) Os pesquisadores afirmam que a conservação de carga está implícita em seu modelo que considerou a lei de Faraday e as correntes catódicas tanto na modelagem analítica quanto na experimental, na química do meio na trinca e a cinética de passivação;

c) O modelo de Andresen e Ford realmente depende de medidas da cinética de passivação em água à alta temperatura, como função da química do meio da ponta da trinca e da química da solução do meio, que vão refletir no parâmetro n. Isto não é um problema teórico e sim de variação experimental;

d) Andresen e Ford refutam outras observações de Macdonald como sendo apenas formais e admitem para seu modelo a principal restrição de ser dependente da taxa de deformação que é um parâmetro com poucos dados experimentais e carente de uma expressão matemática absoluta que possa tornála mais útil do ponto de vista determinístico.

e) Andresen [ANDRESEN, 2005] admite que o modelo precisa ainda ser aperfeiçoado nos seguintes pontos: formulações validadas que representem corretamente a redistribuição de deformações resultantes do avanço da trinca; formulações validadas que representem o espectro das condições de carga cíclica à carga com taxa de deformação lenta constante e carga constante; validações experimentais de materiais com diferentes características, inclusive quanto ao comportamento à fluência (caso da liga 600) e predições de taxa de deformação na ponta da trinca de trincas incipientes. 


\subsection{Modelo semi-empírico de dano por taxa de deformação, de Garud e Gerber}

Esse modelo se baseia na observação de que o processo de deformação local repetidamente interrompe as qualidades de proteção da interface entre o material subjacente e o ambiente. Também o fato de que a interação significativa entre o meio e a deformação afeta o desenvolvimento local do dano, através de mecanismos como formação e migração de vacâncias, microtrincas, entre outros, incluindo os efeitos do hidrogênio catodicamente gerado, foi levado em consideração para a formulação do modelo que utiliza a taxa de deformação e a mecânica de dano num sentido de engenharia. Essa importância da mecânica de deformação, especificamente da taxa de deformação foi geralmente reconhecida nos últimos anos pelos pesquisadores do assunto.

Esse modelo parte portanto, de uma teoria semi-empírica da CST, em que se considera a taxa de deformação ao invés da tensão como a principal variável mecânica. Os seus autores formalizaram o conceito de taxa de deformação como fator motriz num modelo de dano que permite predições quantitativas na vida útil dependente da CST. Uma função de dano é definida de modo vinculado a um componente submetido a um histórico de taxa de deformação. Quando essa função de dano atinge um valor crítico, prediz-se a CST. O valor crítico da função de dano depende do material e do ambiente de interesse.

$$
\mathrm{D}=\int_{0}^{\mathrm{t}} \mathrm{A}[\dot{\mathrm{e}}(\mathrm{t})]^{\mathrm{p}} \mathrm{dt}
$$

com $\mathrm{t}=$ tempo; $\dot{e}(\mathrm{t})=$ taxa de deformação total em função do tempo; $\mathrm{A}$ e $\mathrm{p}=$ parâmetros que dependem da combinação material-ambiente [BEGLEY, 1990].

A validação experimental foi feita por Sung e Was em 1991, que mostraram [GARUD, 1996]:

a- A ocorrência de fluência na liga 600 por volta de $360^{\circ} \mathrm{C}$;

b- o importante papel da deformação por fluência na fratura intergranular no meio de água pura.

Nos ensaios de Boursier e outros em 1992, foi demonstrado que a fluência da liga 600 em tubos era responsável pela CSTAP e que a taxa de deformação era mais importante do que a tensão nesse processo. Essa 
conclusão foi baseada em três ensaios comparativos com os seguintes resultados:

a- Dois espécimes foram sujeitos à mesma taxa de deformação aplicada por 300 horas no meio água, após pré-tensão, com uma única diferença: um espécime foi pré- tensionado rapidamente em meio inerte e descarregado antes de deformar no meio, a uma tensão mais baixa de 360MPa e outro a uma tensão mais alta de 740MPa. O último espécime durante a deformação foi carregado a $850 \mathrm{MPa}$, contrastando com o outro que foi carregado a 510MPa, tensão mais baixa. No entanto, o espécime com carga mais alta apresentou CST menos severa do que o com carga mais baixa;

b- Um terceiro espécime foi exposto durante 300 horas em água sob carga constante de 850MPa, com evidente decréscimo da taxa de deformação em oposição a uma taxa de deformação constante aplicada e não apareceu nenhuma CST mensurável.

É um modelo concebido para a aplicação em CSTAP da liga 600, mas não somente a esse material, conforme ressalta Jones: por exemplo, nos seguintes casos:

a- aços austeníticos de tubulações em reatores de água leve;

b- aços inoxidáveis duplex numa variedade de meios contendo $\mathrm{H}_{2} \mathrm{~S}, \mathrm{CO}_{2}$ e $\mathrm{Cl}^{-}$;

c-aço ferrítico de tubulações API $5 \mathrm{LX60}$ em meio com carbonatos e bicarbonatos;

d- aços inoxidáveis austeníticos em solução de cloreto de cálcio.

É importante sublinhar os seguintes pontos na aplicação do modelo [GARUD, 1996]:

1- a importância da taxa de deformação lenta aplicada a muitos componentes sujeitos à CST para se dar tempo suficiente para ocorrer a ação do meio ambiente inclusive a quebra do filme passivo;

2- As fontes de taxas de deformação podem ser permanentes ou cíclicas, incluindo as tensões residuais e as desenvolvidas no processo de CST em si;

3- os materiais usuais metálicos normalmente estão sujeitos à fluência, mesmo a baixas temperaturas; 
4- mesmo que essa fluência seja pequena, o que é importante no processo de CST é o longo tempo de aplicação da taxa de deformação, condição em que há tempo suficiente para agirem a dissolução local e os efeitos da plasticidade ou fragilização que permitem a ação do hidrogênio.

O modelo embora sendo determinístico, tem uma boa concordância com modelos probabilísticos aplicados à avaliação de vida residual por CST em tubos geradores de vapor, como foi mostrado por Garud e Mcllree em 1995: nesse particular, foi demonstrado que a maior parte do espalhamento pode ser atribuído simplesmente à variação esperada no nível de tensão nesses tubos e as predições foram consistentes com a inclinação estimada do gráfico da distribuição de Weibull desse modelo probabilístico.

Entre as limitações desse modelo são apontadas as seguintes [GARUD, 1996]:

1- É possível que a cinética do desenvolvimento da fratura por CST mude significativamente durante o processo, com o tamanho da trinca e seu fator de intensidade de tensões associado. No entanto, o modelo existente não prevê essa possibilidade;

2- É provável que a cinética de crescimento de uma trinca que acontece no campo, em serviço, seja significativamente diferente de uma trinca artificialmente introduzida, como no início da trinca do espécime de mecânica da fratura utilizado: dificilmente as condições no campo e no laboratório serão equivalentes, por exemplo, quanto ao campo de tensões, geometria e outros fatores;

3- A introdução de um fator dependente do tempo em aspectos relacionados com a deformação, incluindo a fluência, requer fatores adicionais como o tamanho absoluto da trinca ou tensão líquida da seção considerada e a velocidade instantânea de propagação da trinca, fatores não considerados no modelo existente.

Finalmente, ressalta-se a vantagem de nesse modelo não haver necessidade de distinção entre iniciação e propagação, pois sua modelagem se centra em torno do parâmetro de dano $D$, que engloba essas duas fases.

Uma modelagem adequada para esse modelo está desenvolvida no item 10.2 . 
O crescimento de trinca é suposto que ocorra pelo mecanismo de deslizamento/ ruptura do filme passivado, mas o processo é governado pela conservação de carga que pode ser expressa pela equação (8.5.1).

$$
i_{\text {trinca }} \cdot A_{\text {trinca }}+\int_{S} i_{c}{ }^{N} d S=0
$$

em que $\mathrm{i}_{\text {trinca }}$ é a densidade de corrente saindo da trinca, $A_{\text {trinca }}$ é a área da boca da trinca, $\mathrm{i}_{c}{ }^{\mathrm{N}}$ é a densidade de corrente catódica líquida devida à transferência de carga na superfície externa, que resulta da soma das densidades parciais de corrente para a oxidação do hidrogênio, redução do oxigênio, redução do peróxido de hidrogênio e dissolução do metal; dS é um incremento de superfície. O crescimento de trinca é calculado utilizando-se a lei de Faraday,

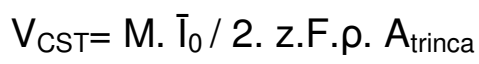

em que

$$
\bar{T}_{0}=2 \cdot i_{0}^{0} \cdot A_{t}^{0} \cdot\left(t_{0} / t_{f}\right)^{1 / 2} \cdot \exp \left[-\left(\varphi_{s}{ }^{L}-\varphi_{s}{ }^{0} / b_{a}\right]\right.
$$

sendo $\bar{I}_{0}$ a corrente total que sai da trinca, $\mathrm{i}_{0}{ }^{0}$ a densidade de corrente padrão de troca para a reação de dissolução, $A_{t}{ }^{0} a$ área da ponta da trinca, $b_{a}$ a constante de Tafel, $t_{f}$ é o período da fratura cíclica do filme passivado na ponta da trinca, to é uma constante determinada do transiente de repassivação, $\varphi_{s}{ }^{0} \circ$ potencial padrão e $\varphi_{s}{ }^{L}$ o potencial na solução adjacente à ponta da trinca, dado por (8.5.4).

$$
\varphi_{s}{ }^{L}=\varphi_{s}{ }^{0}+\ln \left[\left(1,282 \cdot 10^{-5} \cdot A_{t}^{0} \cdot t_{0}^{1 / 2} \cdot K_{l}^{2}\right) / \bar{I}_{0}\right]
$$

em que $\mathrm{K}_{\mathrm{I}}$ é o fator de intensidade de tensão no modo I [MACDONALD\&URQUIDIMACDONALD,1989],[REBAK \& SMIALOWSKA, 1995].

Há ainda outros modelos desse tipo, teóricos de iniciação e propagação das CSTAP, considerando os esforços cíclicos e efeito do meio corrosivo, como 
alguns desenvolvidos na Ucrânia, onde são considerados simultaneamente os estados de tensão - deformação e o estado eletroquímico do material em torno da ponta da trinca. Essas condições são caracterizadas pelo fator de intensidade de tensões $K_{\max }$, o potencial eletrolítico $\varphi_{\mathrm{t}}$, e o índice de hidrogênio do fluido-meio e o $\mathrm{pH}_{\mathrm{t}}$ na ponta da trinca. Assim, a velocidade de crescimento da trinca, $\mathrm{V}$, é uma função $V=f\left(K_{\max }, \varphi_{t}, \mathrm{pH}_{t}\right)$. Nessas condições, os diagramas de velocidade de crescimento de trinca são invariantes com $\varphi_{t}$ e $\mathrm{pH}_{\mathrm{t}}$, dependendo apenas de $\mathrm{K}_{\max }$, já que $\mathrm{pH}_{\mathrm{t}}=$ constante e $\varphi_{\mathrm{t}}=$ constante: eles podem ser levantados experimentalmente e utilizados na predição da vida de componentes sujeitos à CSTAP [PANASIUK, 1997].

Andresen e Ford criticaram o modelo de fratura acoplada com o ambiente, principalmente nos seguintes pontos [ANDRESEN, 2005], [ANDRESEN\&FORD, 1996]:

a) O modelo não considera muitas dependências importantes da CSTAP como a tensão ou a condutividade da solução;

b) No modelo não há reconhecimento da natureza desaerada do meio na maior parte das reações que se dão na trinca. Não foi considerada a redução do oxigênio nas paredes da trinca. Essa anomalia cria uma oportunidade irreal para que toda a corrente iônica se acople entre a ponta e a boca da trinca;

c) As concentrações iônicas consideradas no modelo são improváveis e ir -realistas;

d) A hipótese fundamental do gradiente de potencial como origem da trinca não explica vários tipos de trinca em água muito desaerada com pequenas adições, por exemplo, de ácido sulfúrico ou água do circuito primário de RAP com pequenas quantidades de sulfeto;

e) O modelo não dá subsídios para uma distinção entre materiais sensitizados ou não;

f) O modelo não permite distinguir entre íons específicos presentes com a mesma condutividade;

g) O modelo não permite distinguir os materiais bem como seus tratamentos e condições (ex. material irradiado). 


\subsection{Mecanismo e modelo de oxidação interna}

Um modelo foi proposto por Scott para a CST das ligas à base de níquel e provém da extrapolação do mecanismo de oxidação ao ar à alta temperatura. $\mathrm{O}$ mecanismo proposto se baseia sobre a difusão intergranular de átomos de oxigênio oriundos da dissociação da água [FOCT, 1999]. Está detalhado para a liga 600 no artigo de Scott e Le Calvar [SCOTT\& LE CALVAR, 1993].

O mecanismo de dano resulta da oxidação seletiva de certas espécies presentes nos contornos de grão - como o carbono e o cromo - por esses átomos de oxigênio provocando uma nova fase fragilizante - bolhas gasosas de $\mathrm{CO}_{2}$ e $\mathrm{CO}$ no caso do carbono, $\mathrm{Cr}_{2} \mathrm{O}_{3}$ no caso do cromo [FOCT, 1999]. O mecanismo se inicia por fragilização/corrosão intergranular da liga 600 , originada pela difusão do oxigênio na rede cristalina, formando uma camada absorvida no estado atômico [FOCT, 1999] ou adsorvida de oxigênio nos contornos de grãos, ou óxido interno do tipo $\mathrm{Cr}_{2} \mathrm{O}_{3}$ ou ainda pela formação de bolhas de gases $\mathrm{CO} / \mathrm{CO}_{2}$. A equação baseada na formação interna de gases é (8.6.1).

$$
v_{C S T}=\left(81 \cdot k \cdot T \cdot D_{0} / 512 \gamma^{3} \cdot a^{2}\right) \cdot\left(\delta \cdot N_{S} / 6 \pi \cdot z\right)^{1 / 2} \cdot \sigma_{p} \cdot K_{I}
$$

em que $\mathrm{k}$ é a constante de Boltzmann $\left(1,38 \cdot 10^{-23} \mathrm{~J} / \mathrm{K}\right), \mathrm{D}_{0}$ coeficiente de difusão no contorno de grão para o oxigênio $\left(8,25.10^{-11} \mathrm{~cm}^{2} / \mathrm{s}\right)$, $\mathrm{Y}$ a energia de superfície no contorno de grão $\left(1,75 \mathrm{~J} / \mathrm{m}^{2}\right)$, a a distância interatômica $\left(2,5.10^{-10} \mathrm{~m}\right), \delta$ a espessura do contorno de grão $\left(1.10^{-9} \mathrm{~m}\right), \mathrm{N}_{\mathrm{s}}$ a solubilidade de superfície do oxigênio $\left(3.10^{-6}\right.$ frações de mol), z o número de locais ocupados por salto do átomo de gás, $\sigma$ a tensão de escoamento do material (para a liga 600 a $330^{\circ} \mathrm{C}=160$ $\mathrm{MPa}$ ) e $\mathrm{K}_{\mathrm{l}}$ é o fator de intensidade de tensão na ponta da trinca [SCOTT\& LE CALVAR, 1993],[REBAK \& SMIALOWSKA, 1995],[REBAK \& SMIALOWSKA, 1996].

A $330^{\circ} \mathrm{C}(603 \mathrm{~K})$, a equação (8.6.1) se torna (8.6.2).

$$
\mathrm{V}_{\mathrm{CST}}=2,6719 \cdot 10^{-11} \cdot \mathrm{K}_{\mathrm{I}}
$$

sendo $v_{\text {CST }}$ em $\mathrm{m} / \mathrm{s}$ e $\mathrm{K}_{\mathrm{l}}$ em $\mathrm{MPa} \sqrt{\mathrm{m}}$. As predições por este modelo estão mostradas na Figura 8.5. 


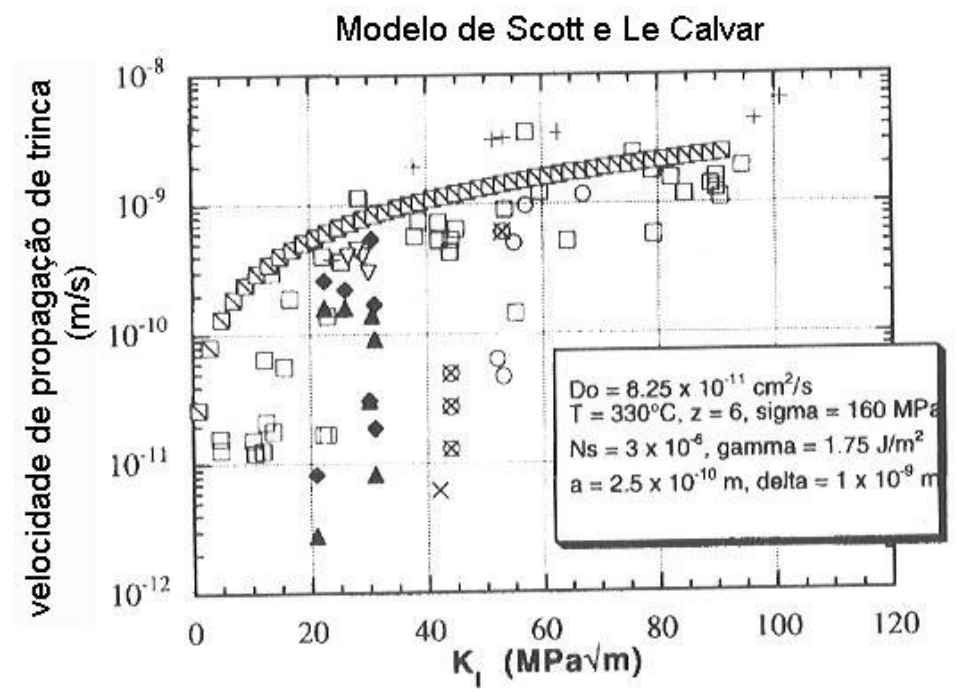

Figura 8.5. Comparação entre valores de velocidade de propagação de trinca preditos pelo modelo da oxidação interna e os dados experimentais [REBAK \& SMIALOWSKA, 1996].

Notar que na região de $K_{l} \geq 30 \mathrm{MPa} \sqrt{\mathrm{m}}$, a velocidade de propagação de trinca segundo o modelo de oxidação interna é pouco maior do que os valores experimentais. No entanto, na região em que $\mathrm{K}_{\mathrm{l}}<30 \mathrm{MPa} \sqrt{\mathrm{m}}$, o que é previsto por esse modelo é muito maior do que o obtido experimentalmente e a dependência entre a velocidade de propagação e $\mathrm{K}_{\mathrm{I}}$ é menor do que em relação aos dados experimentais. Mesmo que o mecanismo de oxidação interna tenha um desenvolvimento determinístico e dê uma razoável predição da velocidade de propagação na região de $K_{1} \geq 30 \mathrm{MPa} \sqrt{\mathrm{m}}$, é improvável que essa velocidade seja controlada por processos de difusão conforme a equação (8.6.1). Além do mais, não há evidência de formação de bolhas de gás nos contornos de grão à frente da ponta da trinca [REBAK \& SMIALOWSKA, 1996].

A oxidação interna afeta uma zona pouco profunda antes do início de trincas por CST e não pela difusão do oxigênio em longas distâncias.As limitações do modelo estão justamente relacionadas com a difusão e atividade do oxigênio [FOCT, 1999]: a velocidade daquela rege a profundidade afetada pela fragilização pelo oxigênio e conseqüentemente $o$ avanço da trinca a cada incremento do seu tamanho; a atividade determina se haverá oxidação interna. Portanto, nesse modelo há uma forte dependência da trinca em função do potencial eletroquímico. Explica, portanto os potenciais mais anódicos do que os do equilíbrio $\mathrm{Ni} / \mathrm{NiO}$, quando a liga se oxida e se forma um filme de óxido que age como barreira à absorção do oxigênio. Por outro lado, para potenciais mais catódicos, a atividade 
do oxigênio é fortemente reduzida, embora ainda possa ocorrer um pouco da oxidação interna. Nesses casos, a trinca pára ou desacelera. Esses fenômenos estão de acordo com diversos resultados experimentais já conhecidos conforme 0 item 4.2.1 onde se constata que a CST da liga 600 se produz dentro de um estreito domínio de pressões de hidrogênio correspondente a uma estreita zona de potencial centrada em torno do potencial de equilíbrio $\mathrm{Ni} / \mathrm{NiO}$.

Gourgues [GOURGUES apud FOCT, 1999] fez estudos para validar esse modelo e salientou a fragilização intergranular numa profundidade de $10 \mu \mathrm{m}$ em corpos de prova em água primária a $360^{\circ} \mathrm{C}$ sem tensão. Gendron e outros [GENDRON et al. apud FOCT, 1999] constataram em vapor d'água a $400^{\circ} \mathrm{C}$, uma leve oxidação fragilizante numa profundidade de $1 \mu \mathrm{m}$ e análises de espectrometria de massa por íons secundários (EMIS) mostraram que há uma formação localizada de $\mathrm{Cr}_{2} \mathrm{O}_{3}$ nos contornos de grãos à profundidade idêntica à da trinca, de $1 \mu \mathrm{m}$ : esses pesquisadores acham que somente a oxidação interna não explica a CST da liga 600 em água primária, mas certamente tem um papel nela, seja pela fragilização direta dos contornos de grão, seja pela formação de um filme de óxido incompleto que favorece a entrada de hidrogênio no material: o hidrogênio e o oxigênio com um papel complementar no mecanismo de dano da liga 600 em água primária a alta temperatura.

Um outro mecanismo análogo, não de oxidação interna, mas de fragilização por hidrogênio foi proposto por Shen e Shewmon (item 8.8) para explicar a corrosão intergranular da liga 600, baseado na iniciação de uma alta densidade de bolhas de hidrogênio nos contornos de grão [SHEN \& SHEWMON apud REBAK \& SMIALOWSKA, 1996].

Um terceiro mecanismo é a formação de bolhas de $\mathrm{CO} / \mathrm{CO}_{2}$, (embora se aplique mais a regiões de oxidação) proposto por Scott e Le Calvar [SCOTT \& LE CALVAR, 1993]: também localizadas nos contornos de grão, essas bolhas exerceriam pressões internas suficientemente elevadas para fragilizar os grãos do material; esse mecanismo também tem o problema do anterior, para as bolhas de metano, em que é pouca a comprovação experimental [CARON, 2001].

Há ainda um quarto mecanismo que é baseado na segregação de átomos de oxigênio nos contornos de grão. Segundo Losch [LOSCH apud CARON, 2001], a adsorção seguida da formação de ligações nos contornos de grão entre átomos metálicos e oxigênio, produziria um enfraquecimento das ligações metálicas dos 
átomos próximos e vizinhos devidos à transferência de carga entre os átomos metálicos e o oxigênio. A ruptura intergranular se produziria no nível de ligações metálicas fragilizadas. Cotrell [COTRELL apud CARON, 2001], mostrou por meio de considerações de balanço de cargas, que a segregação do oxigênio e/ou do hidrogênio nos contornos de grão, pode favorecer a decoesão desses contornos. Isso pode explicar o resultado obtido por Ogino [OGINO \& YAMAZAKI apud CARON, 2001], que mostrou que uma penetração de oxigênio nos contornos de grão do níquel aumenta o efeito fragilizante do hidrogênio e conduziu a um modo de fratura intergranular. Haveria assim um efeito sinergético entre o oxigênio e o hidrogênio, com a fragilização dos contornos sendo intensificada pelo efeito fragilizante do oxigênio. $O$ pesquisador postulou que o hidrogênio se associaria com o oxigênio presente nos contornos de grão para formar ligações hidroxilas.

Um resultado interessante é que os valores de velocidade de propagação calculados por Scott e Le Calvar, no caso de uma segregação de átomos de oxigênio nos contornos de grão, são da mesma ordem de grandeza que aquelas normalmente medidas para a liga 600 [SCOTT \& LE CALVAR, 1993], [CARON, 2001].

Uma característica importante da oxidação interna é que ela pode explicar junto com o mecanismo de fluência (item 8.1), a iniciação de fratura na liga 600 na água do circuito primário a alta temperatura, conforme ilustrado na Figura 8.6. 

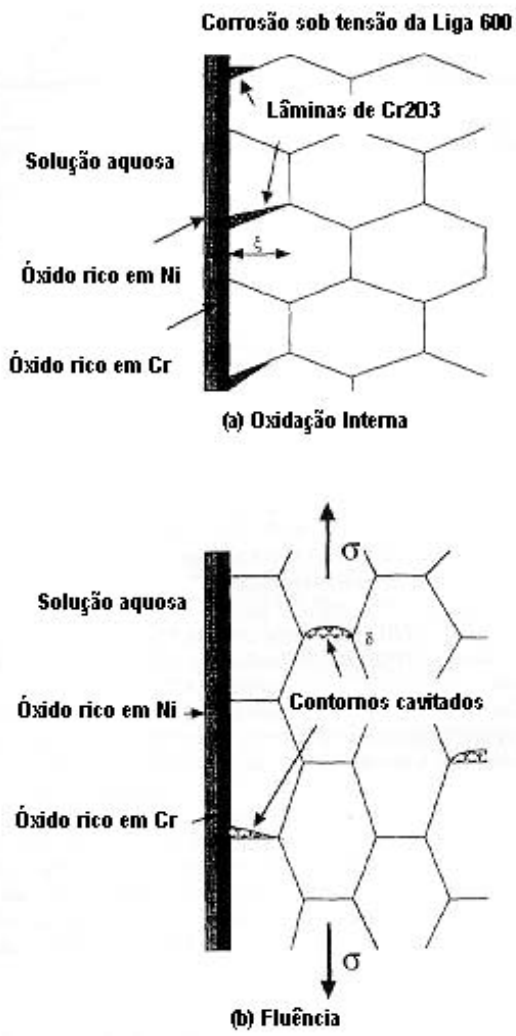

Figura 8.6. Representação esquemática dos mecanismos propostos para o tempo de iniciação à trinca de CST na liga 600 em água primária em alta temperatura [REBAK \& SMIALOWSKA, 1996].

Para explicar a iniciação, Rebak e Smialowska distinguem as seguintes etapas [REBAK \& SMIALOWSKA, 1996]:

1) Formação de um defeito ou falha na superfície recoberta com o filme passivo. Esse defeito pode ser formado tanto por deslizamento intergranular, coalescência de lacunas por fluência, quebra do filme devido à acumulação de lacunas, oxidação interna dos contornos de grão e outros. O tempo de falha depende dos mecanismos considerados. Como esse tempo é longo, da ordem de 15 anos (para tubos geradores de vapor de liga 600 em água primária), isto sugere que esse tempo é determinado por processos controlados por difusão. Assim são considerados dois mecanismos:

1a) Antes de se formar um filme passivo permanente sobre a superfície em serviço, forma-se um filme transitório dependente do tamanho de grão, trabalho a frio, acabamento superficial e outras. O diagrama de Ellingham (ver 
Glossário) prediz que o cromo é mais reativo do que o ferro e o níquel. Nas temperaturas de trabalho a difusão do oxigênio é mais rápida nos contornos de grão do que na estrutura do material. Assim, ocorre oxidação preferencial nos contornos de grão, formando $\mathrm{Cr}_{2} \mathrm{O}_{3}$ numa profundidade dada por:

$$
\xi^{2}=2 .\left(D_{0} \cdot c_{0} / v \cdot c_{C r}\right) . t
$$

com: $\mathrm{D}_{0}=$ coeficiente de difusão, $\mathrm{c}_{0}=$ solubilidade do $\mathrm{O}$ em fração molar e equilíbrio com o $\mathrm{NiO}$ na liga 600 a alta temperatura, $\mathrm{v}=$ coeficiente estequiométrico, $\mathrm{c}_{\mathrm{Cr}}=$ fração molar do $\mathrm{Cr}$ na Liga e $\mathrm{t}=$ tempo. Os pesquisadores obtiveram a solução numérica da equação (8.6.3), para temperatura da água $330^{\circ} \mathrm{C}$ e obtiveram $\mathrm{t}=17,3$ anos para uma camada de profundidade $\xi=10 \mu \mathrm{m}$ (aproximadamente um tamanho de grão). Essa camada oxidada pode trincar sob tensão e abrir uma entrada para a água do meio ou agir como intensificador de tensão.

1b) O dano total da cavitação produzida nos contornos de grão pode ser calculado assumindo que a fluência exerce um papel fundamental. A taxa de fluência da liga 600 exposta em água primária é três vezes maior do que a taxa de fluência nas mesmas condições em ar. A explicação postulada para isso é que a injeção de hidrogênio atômico ou vacâncias na liga pode auxiliar na emissão das discordâncias. Quando ocorre a fluência, a deformação total resultante não é distribuída uniformemente, mas concentra-se em contornos de grão mais susceptíveis. Anderson e Rice [ANDERSON \& RICE apud REBAK \& SMIALOWSKA, 1996] desenvolveram um modelo para calcular a cavitação nos contornos de grão causada pela fluência. Para zonas superficiais de cavitação bem separadas, não interagentes entre si, a taxa de separação de contornos de grãos dర/dt é dada por:

$$
\mathrm{d} \delta / \mathrm{dt} \leq 1,8 . \dot{e} . \mathrm{g}
$$

com è=taxa de fluência e g=tamanho de grão. 
Fazendo o cálculo, os autores obtiveram, para valores de dס/dt entre 1,5 e $120 \mu \mathrm{m}$, um tempo de 15 anos para tamanho de grão $10 \mu \mathrm{m}$. Isso sugere que a fluência pode ser responsável para eventos de iniciação de trincas .

2) Formado o defeito de superfície, o aumento da trinca se dá pelo acúmulo de impurezas, concentração de tensões (dissolução por deslizamento), entrada de hidrogênio na liga e outros mecanismos.

As explicações dadas acima para os dois processos que são postulados ocorrerem durante o tempo de iniciação de CST está de pleno acordo com as variáveis que influenciam a CST (equação 8.1): (a) a temperatura governa a formação de óxidos e ativa os processos de difusão; (b) as tensões assistem o processo de fluência, fragmentam os contornos de grão oxidados, abrem a trinca permitindo ingresso do meio corrosivo e sustém a exposição do metal sem película de óxido na ponta da trinca; (c) o pH da solução controla a estabilidade solubilidade versus capacidade de proteção dos óxidos; (d) o trabalho a frio aumenta a atividade do metal em certos pontos que ficarão menos protegidos pelo óxido e concentra a tensão devida à redução da plasticidade local do material; (e) os carbonetos nos contornos de grãos diminuem a reatividade do cromo com difusão de oxigênio e diminuem a taxa de fluência por meio de mecanismos que impedem a emissão de discordâncias; (f) 0 potencial eletroquímico, o hidrogênio gasoso e a presença de espécies como o $\mathrm{ZnO}$ controlam a compactação do filme passivo na superfície. As propriedades do filme passivo podem controlar processos externos como a dissolução anódica ou os processos internos como movimentação de discordâncias através da inibição da descarga de hidrogênio atômico ou pela difusão de lacunas através do filme passivo [REBAK \& SMIALOWSKA, 1996].

Cumpre ressaltar que em trabalho dos pesquisadores Gourgues, Scott e Andrieu, foi apresentada micrografia óptica obtida através de microscópio eletrônico de transmissão, mostrando a oxidação preferencial dos contornos de grão de zona fragilizada de liga 600 [GOURGUES et al., 1995]. 


\subsection{Mecanismos e modelos de fratura assistidos pelo hidrogênio}

Embora a liga 600 seja susceptível à fragilização por hidrogênio $(\mathrm{FPH})$ à baixa temperatura e esse fenômeno pareça desaparecer a altas temperaturas, é útil que possamos compreender um pouco mais desses mecanismos e como agem sobre esse material. Alguns modelos, descritos em detalhe por Rios, combinam a ação do hidrogênio com outros fenômenos como plasticidade, corrosão, que provocam a fratura por ação conjunta ou sucessiva [FOCT, 1999].

A fragilização induzida pelo hidrogênio se dá basicamente por três mecanismos [CARON, 2001]:

1) Formação de pressão interna - Provocada pelo hidrogênio absorvido que se recombina no nível de falhas estruturais como cavidades, contornos de grão, interfaces, para formar bolhas de di-hidrogênio gasoso.

Para penetrar no material, o hidrogênio deve de início se adsorver sobre sua superfície. Para o hidrogênio gasoso, essa etapa se faz mediante dissociação da molécula de $\mathrm{H}_{2}$. No meio aquoso, a adsorção de hidrogênio é associada a uma descarga catódica e se produz segundo a seguinte reação [FOCT, 1999]:

$$
\mathrm{H}^{+}+\mathrm{e}^{-}+\mathrm{M} \leftrightarrow \mathrm{MH}_{\mathrm{ads}}
$$

A existência da camada de óxido passivo torna a dissociação da molécula de hidrogênio mais difícil diminuindo a quantidade de hidrogênio adsorvido e conseqüentemente o absorvido. O filme passivo parece também ter uma influência nociva sobre a adsorção de hidrogênio em meio aquoso, onde é necessária uma imposição de uma sobretensão catódica para sua penetração intersticial. Também a difusão de hidrogênio é dificultada pelo óxido em relação ao material. Uma vez absorvido o hidrogênio vai se alojar nos sítios intersticiais da rede cristalina - sítios octaédricos para os metais CFC—e sob carga catódica, é possível de se atingir concentrações superiores a 50 ppm na liga 600. Por seu pequeno tamanho $-0,53 \AA$ de raio - o hidrogênio tem uma mobilidade claramente mais importante que outros compostos intersticiais. No entanto, ela é 
bem menor nas ligas CFC como a liga 600 do que nos metais CCC com empilhamento de discordâncias menos compacto.

Lecoester [LECOESTER apud FOCT, 1999], estudou a influência da temperatura sobre a difusão do hidrogênio na liga 600 e obteve a equação (8.7.2) que expressa a difusão do hidrogênio na liga 600 em função da temperatura.

$$
\mathrm{D}=2,4.10^{-3} \exp [-42300 / \mathrm{RT}]
$$

com $\mathrm{D}=$ coeficiente de difusão que varia a $20^{\circ} \mathrm{C}$ entre $1,6.10^{-11} \mathrm{~cm}^{2} \mathrm{~s}^{-1}$ e $7,8.10^{-10}$ $\mathrm{cm}^{2} \mathrm{~s}^{-1}$ e aumenta até $5,5.10^{-8} \mathrm{~cm}^{2} \mathrm{~s}^{-1}$ a $210^{\circ} \mathrm{C}$. Utilizando essa equação a $360^{\circ} \mathrm{C}$, obtém-se um coeficiente de difusão aparente do hidrogênio $7,75 \cdot 10^{-7} \mathrm{~cm}^{2} \mathrm{~s}^{-1}$.

A pressão dessas bolhas é suficiente para produzir uma extensão volumétrica de defeitos de empolamento ("blistering") e que conduz à ruptura local do material. Na liga 600, de acordo com Shewmon, o gás formado é o metano: o que contraria essa hipótese é que não há formação de microcavidade sobre os planos de ruptura [CARON, 2001].

2) Formação de fase frágil - No caso, resultante da presença de hidrogênio e da tensão aplicada, resultando, no caso do níquel, na formação de hidretos do tipo $\mathrm{NiH}_{\mathrm{x}}$ : no caso da liga 600 é improvável a formação desse produto, em virtude das condições de temperatura e fugacidade do hidrogênio em meio água do circuito primário. Em temperaturas elevadas, esses hidretos são termodinamicamente instáveis e não podem ser formados;

3) Enfraquecimento das ligações interatômicas:

a) Diminuição da energia de superfície;

b) Modificação da densidade eletrônica dos átomos metálicos Provoca a fragilização por decoesão e a fragilização por hidrogênio (FPH). No caso do níquel, o hidrogênio cede seus elétrons à órbita $3 \mathrm{~d}$ incompleta dos átomos de $\mathrm{Ni}$. $\mathrm{O}$ aumento da densidade eletrônica dessa órbita se traduz por um aumento das forças de repulsão entre os átomos, uma vez que essas condicionam a distância interatômica entre dois átomos. A condição necessária para observar uma fratura por esse mecanismo é que a tensão 
aplicada seja suficientemente elevada para ser superior ou igual à força de coesão local enfraquecida pela presença do hidrogênio.

\subsubsection{Fragilização por diminuição da energia de superfície}

A FPH é explicada por Petch [PETCH apud FOCT, 1999] como sendo uma conseqüência da adsorção dos átomos do mesmo sobre as paredes da ponta da trinca. As equações (8.7.3) e (8.7.4) representam esse mecanismo.

$$
d y=-\Gamma k T d l n P
$$

com $\gamma=$ =energia de superfície do material, $\Gamma=$ número de moléculas adsorvidas, $\mathrm{k}=$ coeficiente específico da molécula adsorvida, $\mathrm{P}=$ pressão e $\mathrm{T}=$ temperatura. Por outro lado, a tensão crítica de ruptura de um material frágil é diretamente ligada à energia de superfície pelo critério de Griffith, de acordo com (8.7.4).

$$
\sigma=\sqrt{ }(2 \gamma E / \pi a)
$$

com E=módulo de Young do material e a=profundidade da trinca.

Portanto, resulta que uma diminuição da energia de superfície abaixa a possibilidade de propagação de trincas.

Esse mecanismo explica como a ruptura por clivagem de um material frágil é favorecida pela adsorção de hidrogênio, mas não como um material dúctil do tipo CFC, sem transição dúctil - frágil, como a liga 600 , pode trincar. Além disso, a energia de superfície que caracteriza a ruptura é normalmente muito maior do que a energia de superfície termodinâmica, embora apenas essa seja afetada pela adsorção de hidrogênio. Por último, esse mecanismo não explica porque outras substâncias com energia de adsorção mais significativas não causam (ou causam menor) efeito fragilizante: $\mathrm{O}_{2}, \mathrm{~N}_{2}, \mathrm{H}_{2} \mathrm{O}$. Mesmo porque traços de oxigênio ou de vapor d'água no hidrogênio, diminuem seu efeito de fragilização [FOCT, 1999]. 


\subsubsection{Fragilização por decoesão}

A teoria da decoesão é baseada nesse efeito causado pelo hidrogênio, quando ele se acumula criticamente em zonas de fortes tensões triaxiais. $O$ hidrogênio se difunde sob efeito da tensão através de uma zona plástica situada na ponta da trinca onde as tensões triaxiais são mais altas e abaixa as forças de coesão da rede. Quando a energia de coesão é suficientemente baixa, a tensão na ponta da trinca fica maior que a tensão de decoesão e a trinca se propaga. Contudo esse mecanismo só é válido para tensões muito altas na ponta da trinca, para que a concentração em hidrogênio seja suficientemente importante para abaixar sensivelmente a energia de decoesão do material. O mecanismo foi proposto por Troiano [TROIANO apud FOCT, 1999],e retomado por Oriani [ORIANI apud FOCT, 1999], que formulou a hipótese da tensão na ponta da trinca poder atingir valores muito elevados e capazes de romper as ligações interatômicas. Por isso as concentrações de hidrogênio precisariam ser muito elevadas. Segundo esse pesquisador, a energia de coesão da rede $E_{c}$ decresce linearmente com 0 aumento da concentração em hidrogênio $\mathrm{C}_{\mathrm{H}}$, segundo a equação (8.7.5).

$$
\mathrm{E}_{\mathrm{c}}=\mathrm{E}_{\mathrm{c}}^{0}-\alpha \mathrm{C}_{\mathrm{H}}
$$

com $E_{c}^{0}$ a energia de coesão da rede na ausência de hidrogênio e a uma constante. Vê-se a partir dessa relação, que a tensão de coesão diminui na presença do hidrogênio e a trinca se propaga quando a tensão local atinge a tensão de decoesão. 


\subsubsection{Fragilização por hidrogênio}

A FPH pode estar fortemente ligada aos fenômenos de transporte do hidrogênio pelas discordâncias. De acordo com Tien [TIEN et al. apud FOCT, 1999], diversas observações validam esse fato:

- Os sítios de iniciação de trinca são localizados nas zonas de deformação plástica.

- As cinéticas de dano/dissolução são mais rápidas do que a difusão do hidrogênio na rede cristalina, o que pode indicar que as discordâncias carregam o hidrogênio quando se deslocam: Tien observou ainda o desaparecimento da FPH a velocidades de solicitação elevadas e temperaturas altas ou baixas.

- Os materiais são mais sensíveis à FPH, à medida que os deslizamentos são mais planos: isso pode ser explicado por uma penetração mais profunda do hidrogênio transportado pelas discordâncias e um enriquecimento localizado mais significativo.

O autor não explica porém os mecanismos pelos quais essas interações geram a FPH: Stroh [STROH apud FOCT, 1999] o faz supondo que o hidrogênio nos contornos de grãos tem um papel semelhante ao dos carbonetos, servindo de barreira, ancoragem contra o movimento das discordâncias, aumentando assim sua energia necessária para colocá-las em movimento. Esse crescimento da tensão de escoamento causa um endurecimento do material que favorece a trinca por clivagem em relação à ruptura dúctil. Essa interpretação reforça a de Tien para temperaturas elevadas quando a mobilidade do hidrogênio é significativa: nesse caso o hidrogênio não mais serve de barreira ou de ancoragem das discordâncias.

Muitos outros pesquisadores reforçam o efeito inverso do hidrogênio sobre a mobilidade das discordâncias em relação ao descrito por Tien: por exemplo, Beachem [BEACHEM apud FOCT, 1999] sugere que o enriquecimento em hidrogênio na ponta da trinca facilita a deformação plástica. Segundo esse pesquisador, a emissão e a mobilidade das discordâncias acontece para tensões relativamente baixas, desenvolvendo-se assim plasticidade muito localizada em escala microscópica antes da ponta da trinca, dando lugar a uma ruptura localmente dúctil, mas de aspecto frágil. 
O mecanismo intitulado "Plasticidade Local Assistida pelo Hidrogênio" (PLAH ou HELP, "Hydrogen Enhanced Localised Plasticity") é o desenvolvimento da proposta de Beachem por Birnbaum [BIRNBAUM et al. apud FOCT, 1999]: O hidrogênio abaixa localmente a tensão de escoamento do material que determina a deformação. Produz-se ruptura dúctil por cisalhamento nessas pequenas zonas amolecidas situadas na ponta da trinca enquanto a deformação global permanece pequena. Isso confere um aspecto macroscópico frágil à ruptura. As trincas transgranulares podem se propagar por uma sucessão de pequenos cisalhamentos ao longo dos planos de deslizamento, enquanto que as trincas intergranulares são produzidas pela segregação do hidrogênio nos contornos de grão. Assim a deformação plástica se concentra em torno do contorno e a trinca se propaga por pequenos eventos de ruptura transgranular dúctil num plano médio intergranular. Isso explica a morfologia pseudo intergranular desse tipo de trinca, conforme ilustrado na Figura 3.2. Esse modelo foi validado por observações de diversos autores: a) macroscópicas, onde se constatou que o hidrogênio pode aumentar localmente a velocidade de fluência comparável às observadas através de MET para aumento da velocidade de discordância, causando um amolecimento localizado e b) microscópicas por MET sobre amostras de materiais onde puderam ser observados os comportamentos de discordâncias em função da presença de hidrogênio: o hidrogênio pode aumentar a densidade de discordâncias sobre empilhamentos sendo que essas podem coalescer gerando uma microtrinca pelo mecanismo de Stroh. Há pelo menos um ponto desse modelo que precisa ser melhor esclarecido: qual é o mecanismo exato da ruptura decorrente da localização da plasticidade, pois só é visualizada uma única ruptura dúctil por cisalhamento nos planos $\{111\}$. 


\subsection{Mecanismo de formação de pressão interna de hidrogênio}

Shen e Shewmon propuseram um mecanismo para explicar a CSTIG na liga 600 baseado na nucleação de alta densidade de bolhas de metano nos contornos de grãos do material. As bolhas são geradas pelo efeito de interação das tensões e da pressão gerada por metano formado na reação entre o carbono existente nos contornos de grãos e o hidrogênio injetado na liga em conseqüência do processo corrosivo. Esses pesquisadores afirmaram que a dissolução anódica tem um efeito indireto no controle da quantidade de hidrogênio injetada na liga e que a velocidade de propagação da trinca é controlada pela difusão nos contornos de grão. Esse modelo é suportado por algumas evidências experimentais como a de que a susceptibilidade à trinca por CSTIG é máxima quando as atividades do carbono e do hidrogênio são máximas, sugerindo um modelo do tipo coalescência de vacâncias. É apontada, no entanto uma situação não prevista pelo modelo: a fratura não é induzida na presença de hidrogênio seco à alta pressão embora isso possa ser atribuído à fugacidade do hidrogênio seco não ser tão alta quanto a fugacidade do hidrogênio gerado no processo de corrosão. Além disso, a presença de metano na liga 600 nunca foi confirmada experimentalmente e não há evidência de que as bolhas à frente da ponta da trinca tenham realmente sido observadas [REBAK \& SMIALOWSKA, 1996]. 


\subsection{Mecanismos e modelos de interação entre corrosão e deformação}

Esta família de modelos engloba várias propostas, como "clivagem induzida pela ruptura do filme" de Sieradzki e Newman, "quasi-clivagem assistida pela corrosão" de Flanagan e Lichter, "mecanismo de vacâncias" de Jones e o "modelo de corrosão assistida pela plasticidade" (MCAP, CEPM, "corrosion enhanced plasticity model") de Magnin [MAGNIN apud FOCT, 1999]. Porém somente os dois últimos se aplicam ao caso da liga 600 em água primária a alta temperatura. Isto porque os dois primeiros se aplicam a ligas dúcteis como o AuAg ou o Au-Cu, cuja corrosão ou dissolução seletiva de um dos elementos de liga leva à formação de uma camada porosa e frágil na superfície do material dentro da qual se iniciam as trincas. O que é interessante notar desses modelos é que explicam a propagação de trincas de CST pela abertura sucessiva de barreiras de Lomer-Cottrell (ver Glossário), que sucede a dissolução seletiva que ocorre nas linhas de deslizamento sobre as quais se formam essas barreiras. Esse mecanismo é retomado no MCAP. Cumpre assim para o nosso caso, detalhar o "mecanismo de lacunas" de Jones e o MCAP [JONES apud FOCT, 1999].

\subsubsection{Mecanismo de vacâncias}

Jones propôs um modelo de unificação entre a CST e a CSF, aplicável aos materiais dúcteis e passiváveis e tentou explicar a quasi-clivagem observada em CST e em CSF. A dissolução do filme passivo provocaria um amolecimento local do material por meio da criação e difusão de vacâncias e assim reduziria a tensão necessária à fratura. Esse modelo segue as seguintes sete etapas:

- O filme passivo rompe pelo surgimento de planos de deslizamento.

- A adsorção de espécies como os cloretos retarda a passivação.

- A dissolução anódica da ponta da trinca é acentuada pelo par galvânico entre o metal depassivado e as partes passivas.

- A formação de vacâncias amolece localmente o material e aumenta a mobilidade das discordâncias. 
- Algumas di-vacâncias são formadas e sua difusão é mais rápida do que as lacunas.

- Essas di-vacâncias se acumulam sobre os planos do tipo $\{100\}$ e $\{110\}$.

- A trinca pode assim se iniciar e se propagar nesses planos por clivagem.

Esse modelo foi praticamente abandonado porque ele atribui às divacâncias um papel importante cuja difusão em massa nunca foi observada experimentalmente. Também não consegue prever as zonas de ruptura intergranular, caso da liga 600 e transgranulares sobre os planos $\{111\}$, caso muito freqüente observado em aços inoxidáveis. É interessante citá-lo aqui, no entanto, tendo em vista o papel preponderante que nele é atribuído às vacâncias sobre a plasticidade, interação essa que permite imaginar um transporte eventual de matéria nos contornos de grão -mecanismo de oxidação interna ou um efeito do meio sobre o deslizamento intergranular [FOCT, 1999].

\subsubsection{Mecanismo de corrosão assistida pela plasticidade (MCAP, CEPM)}

Esse mecanismo foi proposto por Magnin no início dos anos 1990 para descrever a CST dos materiais CFC. Inicialmente concebido para explicar a fratura transgranular, foi adaptado para a fratura intergranular. Baseia-se nas interações entre corrosão e deformação na ponta da trinca e mais particularmente sobre o efeito das vacâncias e do hidrogênio sobre a plasticidade. Aplica-se assim às ligas CFC recobertas de um filme passivo e permite principalmente explicar como a ruptura de CST é descontínua na escala microscópica. Ele pode ser dividido em seis etapas, para um exemplo de propagação transgranular da trinca, caso de um aço inoxidável em $\mathrm{MgCl}_{2}$ :

- A deformação plástica na ponta da trinca inicia o processo, gerando degraus de deslizamento que rompem localmente o filme passivo. A dissolução ocorre sobre os planos de deslocamento não protegidos. Simultaneamente há uma produção de hidrogênio originário de reações catódicas de corrosão na ponta da trinca.

- As vacâncias produzidas pela dissolução e também o hidrogênio mono atômico adsorvido aumentam a plasticidade na ponta da trinca e conduzem a um 
amolecimento local do material. A deformação se localiza então sobre os planos de deslizamento $\{111\}$ no ponto extremo da trinca, o que reduz a fragilização.

- Esse amolecimento muito localizado na ponta da trinca gera duas zonas: uma amolecida na ponta da trinca e uma endurecida pelo encruamento inicial ou seqüencial à forte plasticidade na ponta da trinca, situada mais à frente. As discordâncias emitidas sobre os planos $\{111\}$ interagem com os obstáculos presentes na zona endurecida. Esses podem ser precipitados, contornos de grãos ou mais provavelmente discordâncias emitidas durante o carregamento do material, como empilhamentos de discordâncias, barreiras de Lomer, e outros. Esse último tipo de obstáculo está na origem da formação de uma interface móvel entre as zonas amolecidas pelas vacâncias e pelo hidrogênio e endurecidas pelo acúmulo de discordâncias. Essa interface corresponde à frente de difusão do hidrogênio que está no limite da zona amolecida. As discordâncias são emitidas em massa na ponta da trinca, propagam-se rapidamente na zona amolecida e vão se empilhar sobre a zona endurecida. A interface sobre a qual se apóia 0 empilhamento tem assim o papel de obstáculo móvel.

- O valor local do fator de intensidade de tensões para ruptura local $K_{I C}$ pode ser atingido no topo do empilhamento, caso esse obstáculo seja suficientemente forte. A energia de coesão da faceta de superfície onde se produz o empilhamento pode ser diminuída pela presença do hidrogênio, o que facilita se atingir o $\mathrm{K}_{\mathrm{IC}}$. Forma-se então sobre o obstáculo um início de trinca pelo mecanismo de Stroh: conforme item 8.7.3 esse mecanismo de abertura de trinca é baseado no critério de Griffith. Ele prevê que quando a tensão no topo de um empilhamento de discordâncias não foi relaxada pela deformação plástica por causa do obstáculo ser suficientemente resistente, a energia se dissipa sob a forma de energia de superfície pela criação de uma microtrinca. $O$ inicio de trinca corresponde à cavidade formada pela coalescência de discordâncias situadas no topo do empilhamento.

- A energia de coesão do plano $\{111\}$ é diminuída pelo hidrogênio, a ruptura surgindo entre o inicio de trinca e a trinca principal ao longo desse plano. Demonstra-se através de cálculo que as discordâncias são emitidas sobre o plano de deslizamento $\{111\}$ simétrico para iniciar a nova ponta de trinca.

- O processo pode então recomeçar sobre o plano simétrico e se observa mudanças regulares dos planos de fratura $\{111\}$. 
Essas etapas estão ilustradas na Figura 8.7.
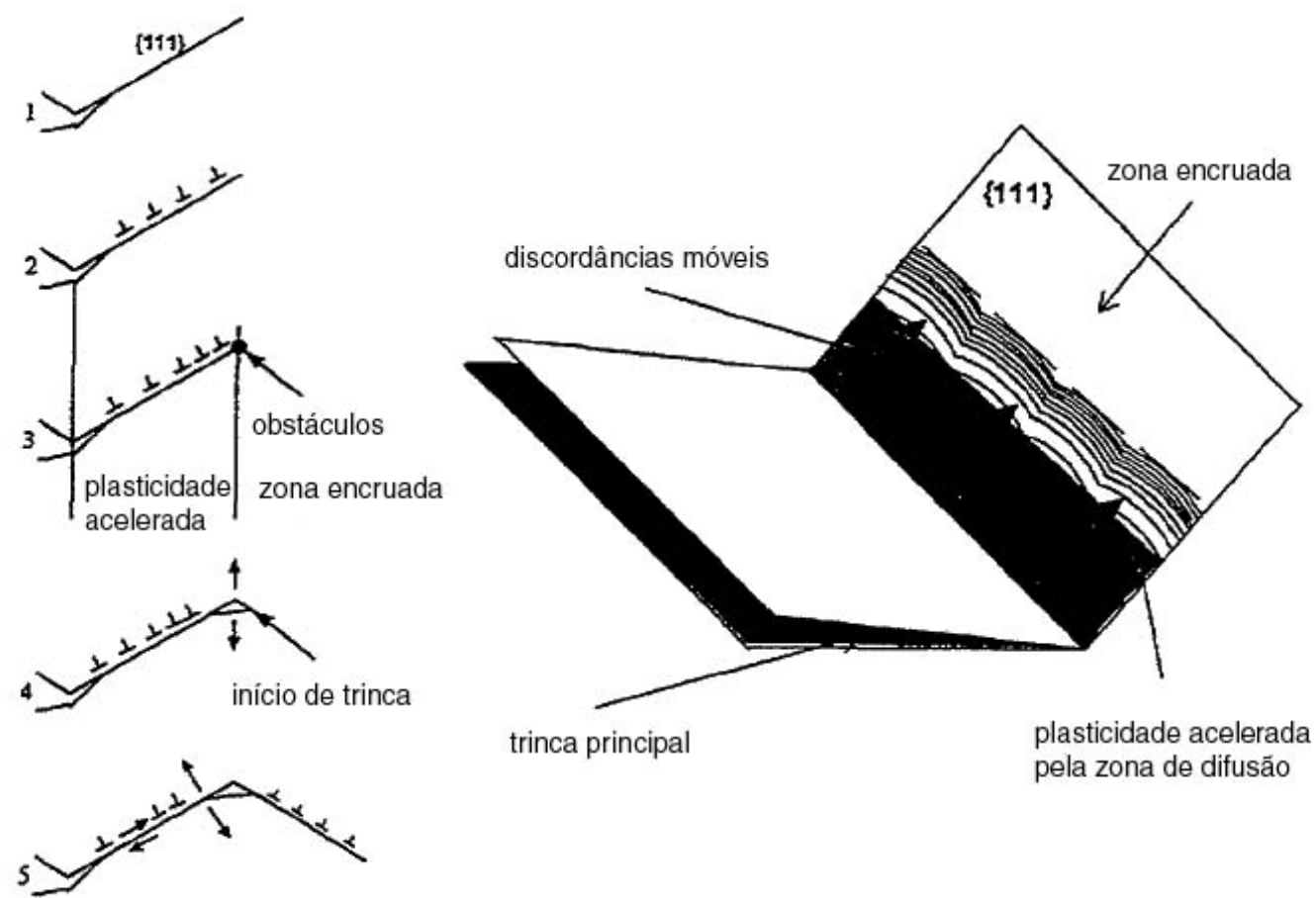

pela zona de difusăo

Figura 8.7. Esquema do MCAP(CEPM), da $1^{a}$. à $5^{a}$. etapa e da formação de empilhamento sobre a interface da zona amolecida com a zona endurecida do obstáculo móvel [FOCT, 1999].

Para explicar as variações morfológicas da fratura intergranular e pseudointergranular, cuja ocorrência é provável no caso da liga 600 em água primária à alta temperatura, é necessária a seguinte complementação nas $4^{\mathrm{a}}$. e $5^{\mathrm{a}}$. etapas acima:

- Se o contorno de grão é orientado mais favoravelmente em relação ao eixo da tensão de tração que o plano $\{111\}$, a tensão no topo do empilhamento é descarregada sobre o contorno de grão. Como a energia de coesão do contorno é diminuída pelo hidrogênio, a trinca pode se propagar intergranularmente até o próximo ponto triplo conforme ilustrado na Figura 2.8. à esquerda.

- No caso contrário ao acima, a propagação da trinca se faz segundo as $4^{\mathrm{a}}$. e $5^{\mathrm{a}}$. etapas da fratura transgranular. A trinca parte da junta, propaga-se sobre um plano $\{111\}$, pára sobre o obstáculo e continua sobre o plano de deslizamento simétrico, sobre o qual são emitidas as discordâncias que propagam a trinca, alcançando o contorno de grão. Obtém-se então a fratura pseudo intergranular, conforme ilustrada na Figura 3.2. 
As principais vantagem desse mecanismo que gera um novo modelo são as seguintes:

- Esse modelo permite integrar os efeitos de sinergia muito fortes entre corrosão e deformação. A deformação é localizada sobre os planos de deslizamento da trinca, evitando a fragilização e a ruptura dúctil.

- É um dos poucos modelos que leva completamente em conta as observações cristalográficas dos planos de ruptura de aços inoxidáveis austeníticos em meios com cloreto.

As principais limitações do modelo são as seguintes:

- Não se aplica quando existem obstáculos suficientemente fortes que não são ultrapassados antes de o $\mathrm{K}_{\mathrm{IC}}$ ser atingido.

- Incompatibilidade entre o aspecto retilíneo das arestas das microfacetas e dos obstáculos ao empilhamento de discordâncias pontuais como precipitados ou barreiras de Lomer.

Foi dada uma resposta às duas restrições acima, há alguns anos, através do conceito de obstáculo móvel. Duas regiões aparecem na ponta da trinca: uma primeira onde se difunde o hidrogênio e as vacâncias e a segunda mais adiante, previsivelmente endurecida: nessa, as discordâncias se fixam sobre a pilha delas e sua mobilidade é fortemente reduzida. Ao contrário, na zona de difusão, as vacâncias anulam as juntas das discordâncias e o hidrogênio segrega sobre os obstáculos diminuindo as constantes elásticas locais $E$ e $v$ do material. Assim a mobilidade das discordâncias torna-se mais elevada na zona amolecida. $O$ empilhamento se forma sobre a frente de difusão, de modo retilíneo, respondendo à segunda observação sobre o aspecto das microfacetas de fratura. Quanto ao primeiro aspecto das restrições ao modelo, sabe-se que a resistência do obstáculo é ligada ao endurecimento previsível do material, ou seja, um material encruado apresentará obstáculos mais fortes e trincará mais rapidamente. No entanto, a fratura depende não só da resistência do obstáculo, mas também do 
valor local de $\mathrm{K}_{\mathrm{IC}}$ : assim se esse for muito elevado, mesmo que o obstáculo seja bem sólido, a trinca poderia não propagar. É o hidrogênio adsorvido na zona amolecida sobre o plano de deslizamento onde se forma o empilhamento, que vai permitir a diminuição do KIC. Château [CHATEAU apud FOCT, 1999] mostrou por simulação que o hidrogênio por sua tendência a segregar nas zonas em expansão, como a região central das discordâncias de borda, tem sua velocidade de difusão aumentada ao longo dos planos de deslizamento e diminui as interações de pares de discordâncias. Isso resulta num aumento da densidade de discordâncias no topo do empilhamento bem como a concentração local de hidrogênio. A tensão necessária para iniciar a trinca pelo mecanismo de Stroh diminui e permite à trinca se propagar antes que o obstáculo seja ultrapassado.

Um resultado bastante significativo é que Foct concluiu que esse mecanismo dá uma explicação satisfatória dos seus experimentos, do efeito do hidrogênio absorvido localmente interagindo com a deformação, através do MCAP, contribuindo de um lado, com a formação de um empilhamento de discordâncias sobre a frente de difusão do hidrogênio - obstáculo móvel, e de outra, ao abaixamento da energia de coesão dos planos e dos contornos de grão.

No entanto, Caron [CARON, 2001] discorda dessa conclusão de Foct afirmando que esse mecanismo explica muito mal seus resultados experimentais obtidos por emissão acústica em liga 600 em água primária, e também sob polarização catódica do mesmo material numa solução de ácido sulfúrico, bem como o comportamento do níquel nesses dois casos. Para esse pesquisador seus resultados se explicam melhor se for utilizado o mecanismo de oxidação interna com algumas modificações em relação ao originalmente proposto por Scott [SCOTT\& LECALVAR, 1993] ou de um mecanismo proposto sobre a formação e a ruptura de zonas frágeis oxidadas nos contornos de grão além da ponta da trinca conforme, por exemplo, o explicado por Rebak e Smialowska para a iniciação, no item 8.6. 


\subsection{Modelos empíricos e numéricos}

\subsubsection{Modelo empírico - comparativo}

Esse modelo foi proposto por Staehle [STAEHLE, 1992a] e consiste na base no plano $(x, y)$ formada pelo diagrama de Pourbaix (potencial versus $\mathrm{pH}$ ) e na ordenada $z$, a fração de resistência à CST.

Esse parâmetro, fração de resistência à CST pode ser explicado como sendo o inverso da susceptibilidade à CST: esse é um parâmetro empírico obtido através de ensaios SSRT ("slow strain rate testing") ou ensaio de taxa de deformação lenta (ETDL). Consiste num ensaio de tração monotônico em que é imposta uma taxa de deformação lenta por meios externos numa seção instrumentada ou numa região entalhada de um corpo de prova de tensão uniaxial ou num corpo de prova pré-trincado por fadiga para a finalidade de avaliação do material à CST. A taxa de deformação para um corpo de prova plano ou liso dada em unidades de extensão dividida pelo comprimento de medição por unidade de tempo - ou a taxa de deformação numa extremidade entalhada de um corpo de prova do tipo entalhado ou a ponta da trinca de um corpo de prova prétrincado por fadiga, é aplicada através de um dispositivo de taxa de deformação lenta e constante - dada em unidades de comprimento por unidade de tempo. Essa taxa de deformação fica normalmente entre $10^{-4}$ e $10^{-7} \mathrm{~s}^{-1}$. Não são conhecidas soluções analíticas rigorosas da taxa de deformação local num entalhe ou numa pré-trinca por fadiga. A taxa de deformação média ou local deve ser lenta o suficiente para dar tempo de atuarem certos processos de corrosão e rápidas o suficiente para produzir falha ou trinca no corpo de prova num período razoável de tempo. Em casos onde são utilizadas taxas de deformação extremamente baixas - da ordem de $10^{-7}$ a $10^{-8} \mathrm{~s}^{-1}$ para corpos de prova de tração lisos - pode ser efetuado um ETDL interrompido onde o corpo de prova é deformado plasticamente na taxa de deformação escolhida e a seguir é submetido a uma taxa de deformação mais rápida até que se produza a falha. Um esquema típico desse ensaio é mostrado na Figura 8.8 [ASTM, 2000]. 


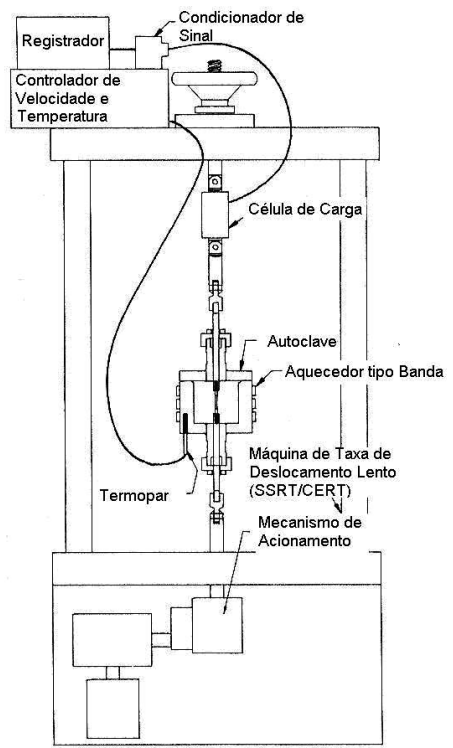

Figura 8.8. Esquema de uma máquina de ETDL - ensaio por taxa de deformação lenta ou "slow strain rate testing": esquema da Norma ASTM G-129-00 [ASTM, 2000].

Para se avaliar os resultados desses ensaios, devem ser utilizadas no mínimo as seguintes razões para uma dada taxa de deformação [ASTM, 2000]:

a) Razão entre o tempo de falha para o material no ambiente de teste $\left(\mathrm{TTF}_{\mathrm{e}}\right)$ ao valor determinado no ambiente de controle, isto é, onde teoricamente não ocorre CST $\left(\mathrm{TTF}_{\mathrm{c}}\right)$.

$$
\mathrm{RTTF}=\mathrm{TTF}_{\mathrm{e}} / \mathrm{TTF}_{\mathrm{c}}
$$

b) Razão entre o alongamento plástico determinado para o material no ambiente de teste $\left(E_{e}\right)$ ao valor determinado no correspondente ambiente de controle $\left(E_{c}\right)$.

$$
\mathrm{RE}=\mathrm{E}_{\mathrm{e}} / \mathrm{E}_{\mathrm{c}}
$$

O uso do alongamento plástico ao invés do alongamento total minimiza as variabilidades entre os resultados de ensaios com diferenças na flexibilidade das máquinas de teste, mais significativas na região elástica da curva constitutiva do material ensaiado. 
c) Razão entre a resistência à tração do entalhe determinado para o material no ambiente de ensaio (NTS $)$ ao valor determinado no correspondente ambiente de controle(NTS N $_{\text {. }}$.

$\mathrm{RNTS}=\mathrm{NTS}_{\mathrm{e}} / \mathrm{NTS}_{\mathrm{c}}$

d) Razão entre o fator de intensidade de tensão limite em deformação plana para trinca ambientalmente assistida determinado para o material no ambiente de ensaio ( $\mathrm{K}_{\mathrm{IEAC}}$ ) com a resistência à fratura em deformação plana determinada para o material no correspondente ambiente de controle $\left(\mathrm{K}_{\mathrm{IC}}\right)$.

$$
\mathrm{RK}_{\mathrm{I}}=\mathrm{K}_{\mathrm{IEAC}} / \mathrm{K}_{\mathrm{IC}}
$$

e) Razão entre o fator de intensidade de tensão limite para trinca ambientalmente assistida determinado para o material no ambiente de ensaio $\left(\mathrm{K}_{\mathrm{EAC}}\right)$ com a resistência à fratura determinada para o material no correspondente ambiente de controle $\left(\mathrm{K}_{\mathrm{C}}\right)$.

$$
\mathrm{RK}=\mathrm{K}_{\mathrm{EAC}} / \mathrm{K}_{\mathrm{C}}
$$

A cada conjunto de ensaios (RTTF, RE, RNTS, RKl, RK) pode-se associar um número compreendido entre 0 (mínima resistência à CST) e 1 (máxima resistência à CST no ambiente de controle), denominado fração de resistência à CST, que será variado no eixo z da Figura 9.1. 


\subsubsection{Modelo semi-empírico-probabilístico}

Retoma-se a equação (7.1.1) em que a velocidade de crescimento da trinca pode ser escrita como:

$$
\mathrm{V}_{\mathrm{CST}}=\mathrm{B} \cdot \sigma^{\mathrm{a}}
$$

em que $B$ é uma constante de proporcionalidade, $4 \leq a \leq 7$ e $\sigma$ é a máxima tensão principal de tração, que inclui a tensão aplicada e a residual [SHAH et al, 1994].

A trinca por CSTAP dá-se também através de um processo termicamente ativado que pode ser descrito por uma correlação de Arrhenius da forma:

$$
\mathrm{V}_{\mathrm{CST}}=\mathrm{C} \cdot \exp [-\mathrm{Q} / \mathrm{RT}]
$$

Nessa expressão, C é uma constante de proporcionalidade, $Q$ é a energia de ativação, $R$ é a constante universal dos gases e $T$ a temperatura. Várias estimativas para a energia de ativação $Q$, para materiais de liga 600 , foram deduzidas de estudos de laboratório e de experiências de campo: sua faixa varia de 163 a $227 \mathrm{~kJ} / \mathrm{mol}$ (39 a $65 \mathrm{kcal} / \mathrm{mol}$ ), com um valor mais precisamente estimado de $209 \mathrm{~kJ} / \mathrm{mol}$ (50 kcal/mol). As estimativas para a energia de ativação para os componentes de liga 600 fabricados a partir de barras podem ser diferentes daquelas dos fabricados de material a partir de tubos. Tanto a iniciação quanto o crescimento da trinca por CSTAP são muito sensíveis à temperatura. Por exemplo, o tempo de iniciação da trinca por CSTAP será tipicamente reduzido de um fator 2 para um acréscimo de $10^{\circ} \mathrm{C}$ numa temperatura de operação de $315^{\circ} \mathrm{C}$, isto é, a trinca se inicia mais cedo [IAEA, 1997]

Combinando-se equações semelhantes às equações (8.10.6) e (8.10.7) e acrescentando-se um fator que considere a influência da variação do pH, obtémse a equação (8.10.8) que representa o modelo fenomenológico ou semi-empírico [STAEHLE, 1992].

$$
\mathrm{t}_{\mathrm{f}}=\mathrm{d}\left[\mathrm{H}^{+}\right]^{-\mathrm{m}} \sigma^{-\mathrm{n}} \exp \left(\frac{\mathrm{Q}}{\mathrm{RT}}\right)
$$


com $t_{f}=$ tempo de falha; $\sigma=$ tensão; $n=$ expoente de tensão; $Q=$ energia de ativação térmica; $T=$ temperatura absoluta; $\mathrm{R}=$ constante universal dos gases; $\left[\mathrm{H}^{+}\right]=$atividade do íon hidrogênio; $m=e x p o e n t e$ da atividade do íon hidrogênio; $d=$ constante

Garud nota uma limitação na equação (8.10.8): o uso da atividade de hidrogênio como um fator de multiplicação implica que se supõe não haver interação entre o efeito desse elemento e os efeitos de tensão ou temperatura, o que pode ser uma simplificação que não reflete a realidade do fenômeno [GARUD, 2004].

Essa equação será transformada e modelada para conveniência de uso e utilização de uma abordagem estatística, conforme mostrado no item 10.1.

Uma simplificação notável e que leva a uma aplicação muito direta é o chamado modelo empírico de tensão, desenvolvido para aplicação na CSTAP da liga 600 por Gorman e outros autores [GORMAN et al., 1994]. Eles partem do seguinte raciocínio para formular esse modelo e sua modelagem: a CSTAP da liga 600 é afetada pela tensão, temperatura, taxa de deformação, tipo de estrutura, tamanho de grão, tratamento térmico, etc. Foi mostrado por Garud, Perkins, Garriga Majo, Gras e outros autores que a taxa de deformação influi sobre a CSTAP da liga 600 mais do que a tensão. Assim, se o efeito da tensão é apenas indireto, a tensão nominal local causa uma taxa de deformação também local que influi sobre a taxa de propagação da CSTAP. Para um tempo de iniciação de trinca ou tempo de iniciação de uma trinca muito pequena da ordem de $10 \mu \mathrm{m}$, a tensão local não deve ser afetada pelo tamanho da trinca e então pode ser calculada facilmente. A relação entre a taxa de deformação è, a tensão $\sigma$ e o tempo $t$ foi formulada por Leclercq e Vaillant de acordo com (8.10.9).

$$
\dot{\mathrm{e}}=\mathrm{A} \sigma^{2,76} \mathrm{t}^{-0,47}
$$

com è é dada em $10^{-6} \mathrm{~h}^{-1}$, t em horas e $\sigma$ em MPa. Na modelagem de dano por taxa de deformação de Garud e Gerber (item 10.2), o dano é calculado por (8.10.10).

$$
D=\int_{0}^{t} \alpha \dot{e}^{p} d t
$$


e se prevê que a falha inicia quando o dano $D$ atinge um valor crítico $D=D_{c}$ e $t=t_{f}$. Substituindo-se (8.10.9) em (8.10.10), tem-se (8.10.11).

$$
D=\int_{0}^{t} \alpha\left(A \sigma^{2,76} t^{-0,47}\right)^{p} d t
$$

Assumindo-se que a tensão é constante, segue (8.10.12) e (8.10.13).

$$
\begin{gathered}
D_{c}=\alpha A^{p} \sigma^{2,76 p} \int_{0}^{t f_{t}-0,47 p} d t \\
D_{c}=[1 /(1-0,47 p)] \alpha A^{p} \sigma^{2,76 p} t_{f}{ }^{1-0,47 p}
\end{gathered}
$$

Supõe-se que $1-0,47 p>0$, uma vez que não é verdade que $D$ decresça com o tempo. Nas experiências de Begley, mostrou-se que $p=0,5$ é um bom ajuste geral para a CSTAP da liga 600. O tempo de falha como função da tensão pode ser estimado da equação (8.10.13) e resulta em (8.10.14).

$$
\mathrm{t}_{f}=\mathrm{C} \sigma^{-\mathrm{n}}
$$

com C uma constante e n expresso pela equação (8.10.15).

$$
n=2,76 p /(1-0,47 p)
$$

Se $p=0,5$, então $n=1,8$.

Conseqüentemente se o modelo de dano por taxa de deformação for um bom modelo da realidade e a taxa de deformação por fluência na liga 600 for bem descrita pela equação (8.10.9), então o efeito da tensão no tempo de falha pode ser representado pela lei do inverso da potência conforme (8.10.14). Demonstrou-se que essa lei tem boa concordância com os dados de laboratório para o tempo de falha à CSTAP da liga 600 como função da tensão [GORMAN et al., 1994]. 
8.10.3. Modelo baseado na teoria da mobilidade superficial acelerada de Galvele

Formulado [GALVELE, 1987] com base nas similaridades existentes entre diferentes fenômenos de fragilização e nas teorias existentes de trincas ambientalmente induzidas, prediz essas trincas antes que elas iniciem: um átomo na ponta da trinca é transportado por difusão superficial de uma região de tensão elevada para uma nova nas bordas da trinca, em que é menos elevada. Assim, a propagação da trinca resulta da captura de vacâncias por uma rede cristalina tensionada na ponta da trinca. A taxa de crescimento da trinca é governada pelo movimento de átomos adsorvidos ao longo das bordas da trinca e o papel do ambiente é o de modificar a difusividade superficial do metal ou da liga. $O$ crescimento da trinca é dado pela expressão (8.10.16).

$$
V_{C S T}=\left(D_{s} / L\right) \cdot\left[\exp \left(\sigma \cdot a^{3} / k \cdot T\right)-1\right]
$$

em que $L$ é o caminho de difusão, $\sigma$ a tensão máxima na ponta da trinca, a o diâmetro atômico, $\mathrm{k}$ a constante de Boltzman, $\mathrm{T}$ a temperatura absoluta e $\mathrm{D}_{\mathrm{s}}$ a difusividade superficial, que pode ser estimada pela fórmula de Gjostein e Rhead, conforme a expressão (8.10.17).

$$
D_{s}=7,4 \cdot 10^{-2} \exp -\left(30 . T_{m} / R . T\right)+1,4 \cdot 10^{-6} \exp -\left(13 . T_{m} / R . T\right)
$$

em que $R=1,987 \mathrm{cal} / \mathrm{mol} . \mathrm{K}$ é a constante universal dos gases e $T_{m}$ o ponto de fusão do componente que reveste a superfície que está em contacto com o meio.

No caso da liga 600 em contacto com a água do circuito primário, esse componente é formado por uma mistura dos óxidos metálicos $\mathrm{Fe}_{3} \mathrm{O}_{4}, \mathrm{NiO}$ e $\mathrm{Cr}_{2} \mathrm{O}_{3}$ [GALVELE, 1987], [REBAK \& SMIALOWSKA, 1995].

De acordo com a magnitude de $D_{s}$, Galvele classifica os compostos de diferentes elementos em inócuos, inseguros e perigosos - neste último caso para 
$D_{s} \geq 10^{-16} \mathrm{~m}^{2} / \mathrm{s}$ o composto causa susceptibilidade do metal ou liga à CST. Na Tabela 8.1 são mostrados os valores de $T_{m}$ e os valores calculados de $D_{s}$, de acordo com a equação (8.10.17), para os três óxidos que formam a camada passiva na liga 600 em três temperaturas [REBAK \& SMIALOWSKA, 1996]. 
Tabela 8.1. $\mathrm{D}_{\mathrm{s}}\left(\mathrm{m}^{2} / \mathrm{s}\right)$ para os óxidos da Liga 600 [REBAK \& SMIALOWSKA, 1996].

\begin{tabular}{ccccc}
\hline \hline Óxido & $\mathrm{T}_{\mathrm{m}}\left({ }^{0} \mathrm{C}\right)$ & \multicolumn{3}{c}{ Temperatura $\left.{ }^{0} \mathrm{C}\right)$} \\
\hline & & 290 & 330 & 350 \\
\hline $\mathrm{NiO}$ & 1990 & $5,24 \cdot 10^{-18}$ & $3,00 \cdot 10^{-1 /}$ & $6,60 \cdot 10^{-17}$ \\
\hline $\mathrm{Fe}_{3} \mathrm{O}_{4}$ & 1597 & $5,11 \cdot 10^{-16}$ & $2,16 \cdot 10^{-15}$ & $4,14 \cdot 10^{-15}$ \\
\hline $\mathrm{Cr}_{2} \mathrm{O}_{3}$ & 2435 & $2,97 \cdot 10^{-20}$ & $2,39 \cdot 10^{-19}$ & $6,15 \cdot 10^{-19}$. \\
\hline
\end{tabular}

Utilizando-se os dados da Tabela 8.1, pode-se chegar às velocidades de propagação $\mathrm{v}_{\mathrm{CST}}$, aplicando-se a equação (8.10.16), calculando-se a tensão $\sigma$ de acordo com (8.10.18) que vem da mecânica da fratura:

$$
K_{I}=\sigma \cdot f(a / b) \cdot \sqrt{ } a
$$

com $f(a / b)=4,0$ e a=10mm. Obtém-se a Figura 8.9, comparativa entre este modelo e os dados experimentais.

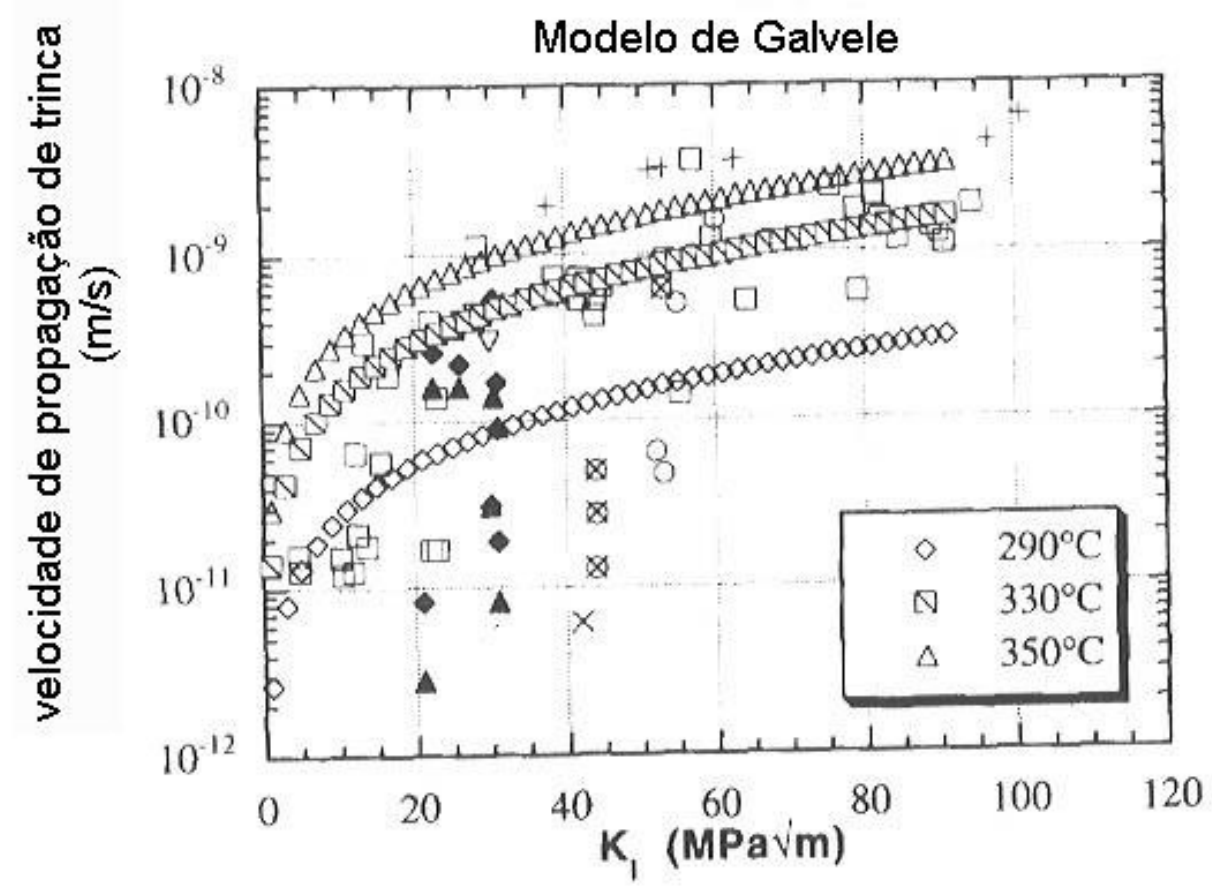

Figura 8.9. Gráfico comparativo entre a velocidade de propagação predita pelo modelo de Galvele e dados experimentais [REBAK \& SMIALOWSKA, 1996]. 
Pode-se tirar as seguintes conclusões da Figura 8.9 [REBAK \& SMIALOWSKA, 1996]:

a) $O$ modelo de Galvele prediz efetivamente a velocidade de propagação a $330^{\circ} \mathrm{C}$ na região de $\mathrm{K}_{\mathrm{l}} \geq 30 \mathrm{MPa} \sqrt{\mathrm{m}}$, onde há uma menor dependência entre velocidade $\mathrm{V}_{\mathrm{CST}}$ e $\mathrm{K}_{\mathrm{I}}$. A $350^{\circ} \mathrm{C}$ na mesma região, os valores são um pouco menores do que os obtidos experimentalmente;

b) O modelo de Galvele como o de Ford e Andresen, não prediz a região de transição entre $\mathrm{K}_{\mathrm{I}}<30 \mathrm{MPa} \sqrt{\mathrm{m}}$ e $\mathrm{K}_{\mathrm{I}} \geq 30 \mathrm{MPa} \sqrt{\mathrm{m}}$;

c) O modelo de Galvele prediz com uma ordem de magnitude maior os valores na região de $\mathrm{K}_{\mathrm{l}}<30 \mathrm{MPa} \sqrt{\mathrm{m}}$, para 330 e $350^{\circ} \mathrm{C}$;

d) $\mathrm{O}$ modelo de Galvele prediz corretamente que a formação de $\mathrm{NiO}$ é condição necessária para que ocorra CSTIG. Quando o NiO não se forma por causa da alta pressão parcial de hidrogênio ou por causa das baixas temperaturas, menores do que $250^{\circ} \mathrm{C}$, a trinca não se produz, pois essa temperatura é abaixo da temperatura de equilíbrio de formação do $\mathrm{NiO}$ : só se formarão $\mathrm{Cr}_{2} \mathrm{O}_{3}$ e $\mathrm{Fe}_{3} \mathrm{O}_{4}$ na superfície metálica. O óxido de cromo forma então uma camada interna protetora que controlará a susceptibilidade à CST. $\mathrm{O} \mathrm{Cr}_{2} \mathrm{O}_{3}$ tem um coeficiente de mobilidade de superfície de $2,71 \cdot 10^{-21} \mathrm{~m}^{2} / \mathrm{s}$, que se for considerado junto com um valor de $\mathrm{K}_{\mathrm{l}}=20 \mathrm{MPa} \sqrt{\mathrm{m}}$, resulta numa velocidade de propagação de trinca de $2.10^{-15} \mathrm{~m} / \mathrm{s}$, que é muito baixa para ser detectada em laboratório;

e) O modelo de Galvele prediz que a energia aparente de ativação $Q$ para CST na faixa de 290 a $350^{\circ} \mathrm{C}$ é $118 \mathrm{~J} / \mathrm{mol}$ a $\mathrm{K}_{\mathrm{l}}=20 \mathrm{MPa} \sqrt{\mathrm{m}}$ e $\mathrm{Q}$ decresce pouco com o aumento de $\mathrm{K}_{\mathrm{l}}$ : essas predições são razoáveis;

f) O modelo de Galvele prediz o efeito do trabalho a frio (TF), tratamento térmico (TT) e pH indiretamente através de alterações nos valores de $D_{s}$ para variações nesses parâmetros. Por exemplo, quando o pH do ambiente cresce à 
temperatura constante, o filme passivo tende a se dissolver havendo um aumento na sua mobilidade superficial; 0 trabalho a frio torna 0 material eletroquimicamente mais reativo havendo mais formação de $\mathrm{NiO}$, alterando principalmente o equilíbrio do filme passivo;

g) O modelo de Galvele pode explicar o efeito benéfico dos carbonetos precipitados nos contornos de grãos quanto à prevenção da CST, através da formação exclusiva na superfície de $\mathrm{Cr}_{2} \mathrm{O}_{3}$, que como se viu em d) anterior previne a CST. Pode-se também analisando a Tabela 2, verificar que os valores de $\mathrm{D}_{\mathrm{s}}$ nas três temperaturas em relação à formação de $\mathrm{Cr}_{2} \mathrm{O}_{3}$ são de 2 ordens de magnitude menores em relação à formação de $\mathrm{NiO}$, conseqüentemente suas respectivas velocidades de propagação de trinca mantém essa mesma relação de ordem de grandeza;

h) $O$ modelo de Galvele não explica a iniciação de trinca e seu longo período de incubação no caso da liga 600 em água do circuito primário a alta temperatura;

Finalmente se observou uma recente polêmica sobre esse modelo, envolvendo Gutman [GUTMAN, 2003] e o seu autor Galvele [GALVELE, 2003]: Gutman faz uma análise detalhada do modelo de Galvele, apontando contradições internas e proposições mutuamente excludentes na formulação do mesmo, como o fato da mobilidade superficial que é o motor desse modelo, ser explicada mecanicamente através de mecanismos - inicialmente o mecanismo de fluência de Nabarro-Herring e depois o mecanismo de nucleação de vacâncias de HirthNix -basicamente aplicáveis a processos de volume e não a processos de superfície. Além do mais, nesses processos, Gutman alega que o de Hirth-Nix não considera o fluxo de vacâncias como o de Nabarro-Herring, não podendo assim obviamente ser utilizado para explicar o processo motor do mecanismo mobilidade superficial de Galvele, que obrigatoriamente envolve fluxo. Galvele rebateu as críticas de Gutman relembrando os postulados com os quais concebeu seu modelo: por exemplo, "a temperatura na qual a CST ocorre é menor do que 0,5 Tm", cuja principal conseqüência é que a difusão em volume no material pode ser ignorada. Assim os movimentos de átomos que substituem o soluto, 
vacâncias, etc., dentro do metal praticamente não existem e deve ser considerado apenas o processo de superfície, que inclusive não é somente de superfície já que Galvele considera quatro ou cinco camadas atômicas. Contra a segunda crítica de Gutman acima, Galvele alega que a segunda parcela (entre colchetes) do produto matemático na equação (8.10.16), pode ser utilizada para explicar mais de um mecanismo, no caso, tanto o de Nabarro-Herring, quanto o de HirthNix, mais isto não quer dizer que Galvele tenha utilizado ambos para suportar seu modelo. Utilizou apenas o de Nabarro-Herring.

A grande vantagem desse tipo de polêmica é aprofundar a discussão sobre os diversos modelos, inclusive "desconstruindo-os" e passamos assim a ter um melhor embasamento e uma melhor compreensão sobre eles. Naturalmente, todos os modelos têm limitações e nessa discussão entre Gutman e Galvele ficase sabendo das suas verdadeiras limitações, como o de por exemplo, a dificuldade de se descrever o que acontece na ponta da trinca em nível molecular, que conseqüentemente o modelo de Galvele não prevê.

\subsubsection{Modelo numérico de Rebak e Smialowska}

A partir de dados disponíveis de crescimento de trinca para a liga 600, esses pesquisadores estudaram as relações independentes entre crescimento de trinca e temperatura, trabalho a frio, fator de intensidade de tensões e pH obtendo coeficientes numéricos. Sem fazer quaisquer previsões de mecanismos específicos, isto é, empiricamente, foram obtidas equações separadas para as regiões I (em que $K_{I} \leq 30 \mathrm{MPa} \sqrt{ }$ ) e II (em que $K_{I}>30 \mathrm{MPa} \sqrt{\mathrm{m}}$ ). Essas são (8.10.19) e (8.10.20).

$$
\begin{gathered}
\mathrm{V}_{\mathrm{CST}}(\mathrm{I})=1,31 \cdot 10^{-12} \cdot \mathrm{K}_{\mathrm{I}}^{1,09} \cdot \mathrm{TF}^{0,75} \\
\mathrm{~V}_{\mathrm{CST}}(\mathrm{II})=1,66 \cdot 10^{-8} \cdot \mathrm{K}_{\mathrm{I}}^{0,38} \cdot \mathrm{TF}^{0,38} \cdot \mathrm{pH}^{1,67} \cdot \mathrm{e}^{(-44479 / \mathrm{R} \cdot \mathrm{T})}
\end{gathered}
$$

Notar que a equação (8.10.20) relaciona a velocidade de propagação de trinca como função de parâmetro mecânico $\left(\mathrm{K}_{\mathrm{l}}\right)$, do material (TF) e ambientais $(\mathrm{pH}, \mathrm{T})$. O efeito do TF é representado em (8.10.19) e (8.10.20) para a percentagem de encruamento - pode ser obtida uma outra relação com TF sob 
outras condições de introdução da deformação plástica em relação à tensão aplicada durante o ensaio. $\mathrm{O}$ efeito do $\mathrm{pH}$ em alta temperatura é linear na região entre $\mathrm{pH}$ neutro e $\mathrm{pH}=9$ [REBAK \& SMIALOWSKA, 1996].

As equações (8.10.19) e (8.10.20) podem ser combinadas numa única equação(8.10.21) representando todo o espectro de $\mathrm{K}_{\mathrm{l}}$.

$$
\mathrm{V}_{\mathrm{CST}}=\mathrm{V}_{\mathrm{CST}}(\mathrm{I}) \cdot \mathrm{x}+\mathrm{V}_{\mathrm{CST}}(\mathrm{II}) \cdot(1-\mathrm{x})
$$

com $\mathrm{X}=1$ para $\mathrm{K}_{\mathrm{I}} \leq 20 \mathrm{MPa} \sqrt{\mathrm{m}} ; 0<\mathrm{X}<1$ para $20<\mathrm{K}_{\mathrm{I}}<40 \mathrm{MPa} \sqrt{\mathrm{m}}$ e $\mathrm{x}=0$ para $\mathrm{K}_{\mathrm{I}} \geq 40$ MPa $\sqrt{ } m$ [REBAK \& SMIALOWSKA, 1995], [REBAK \& SMIALOWSKA, 1996].

Na Figura 8.10 é mostrado o efeito do TF em relação à velocidade de propagação de trinca para $\mathrm{pH}=8$ e $\mathrm{T}=330{ }^{\circ} \mathrm{C}$. 


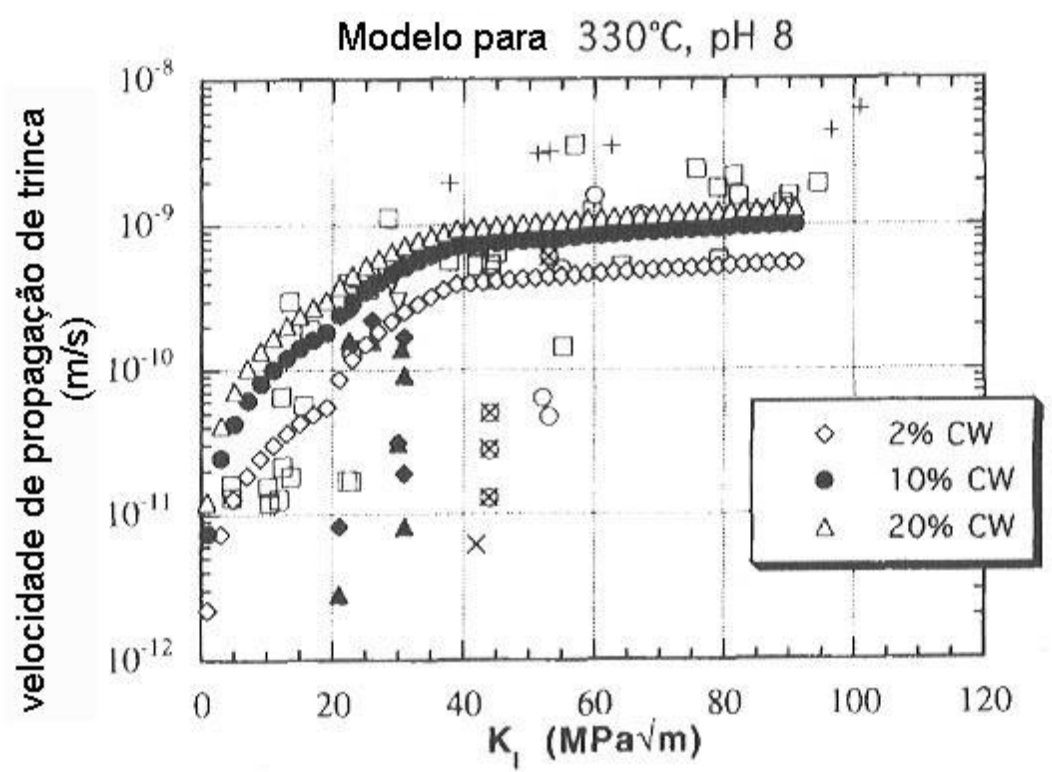

Figura 8.10. Gráfico comparativo entre a velocidade de propagação predita pelo modelo numérico de Rebak \& Smialowska et al. e dados experimentais [REBAK \& SMIALOWSKA, 1996].

O método numérico é prático e de uso simples, similar ao algoritmo utilizado no método de Andresen e Ford, equação (8.3.10). No entanto na equação (8.10.21) é representada a velocidade de propagação de trinca de modo multivariável para maior abrangência. A modelagem numérica representa também de modo claro a transição entre as regiões I e II, ao contrário das modelagens propostas para os modelos de Galvele, Ford e Andresen e Scott e Le Calvar.

Os mesmos autores obtiveram para a liga 600 laminada e recozida à baixa temperatura, na faixa $330-360^{\circ} \mathrm{C}$, em solução aquosa com pH $=7$ a 8 e em vapor a $400^{\circ} \mathrm{C}$ a equação (8.10.22) para a velocidade de propagação da trinca em função de KI [REBAK \& SMIALOWSKA, 1996].

$$
\mathrm{V}_{\mathrm{CST}}=3,43 \cdot 10^{-13} \cdot \mathrm{K}_{\mathrm{I}}^{1,83}
$$

Os conjuntos de dados experimentais obtidos e reunidos pelos pesquisadores estão mostrados na Figura 8.11, bem como a curva expressa analiticamente pela equação (8.10.22). 


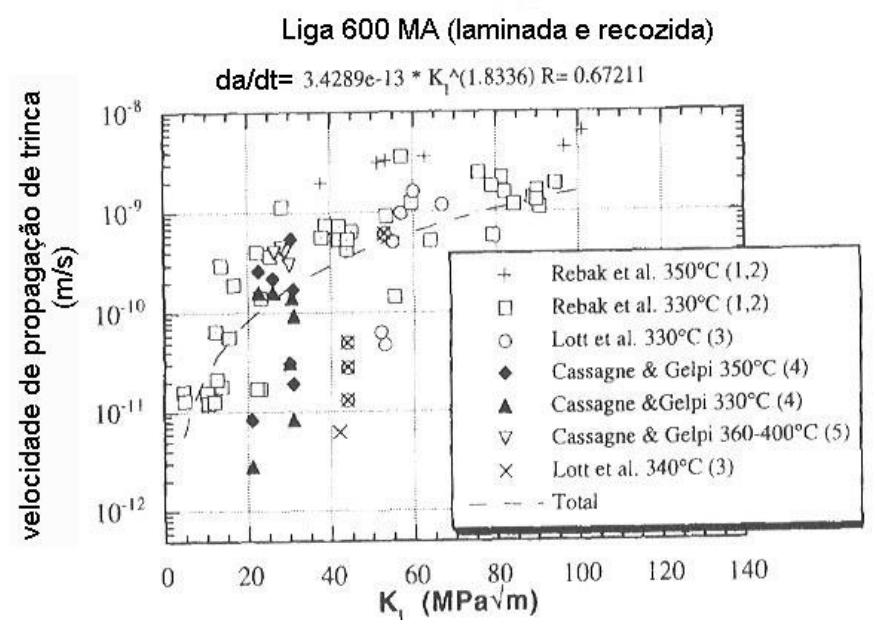

Figura 8.11. Dados experimentais recolhidos para o gráfico $V_{\text {CST Versus }} K_{I}$ para amostras de tubos de liga 600 ensaiados com carga constante [REBAK \& SMIALOWSKA, 1996].

\subsubsection{Modelo numérico de Scott}

Scott propôs um modelo numérico para propagação de trincas por CST em liga 600 para tubos geradores de vapor a partir de dados de ensaios devidamente corrigidos, em amostras trabalhadas a frio e a $325^{\circ} \mathrm{C}$, da forma da expressão (8.10.23) [GÓMEZ BRICEÑO \& SERRANO, 2005].

$$
\mathrm{da} / \mathrm{dt}=2,26 \cdot 10^{-12}(\mathrm{~K}-9)^{1,16}
$$

com da/dt=velocidade de propagação de trinca em $\mathrm{m} / \mathrm{s}, \mathrm{K}$ o fator de intensidade de tensão em MPa. $\sqrt{ }$. Notar que Scott considera o valor limiar desse fator, $K_{\text {ICST }}$ = $9 \mathrm{MPa} . \sqrt{\mathrm{m}}$, valor confirmado por Foster e outros.

Um tópico interessante sobre esse modelo é que diversos pesquisadores propuseram o mesmo tipo de modelo para diversos materiais em diferentes condições de meio, alguns dos quais serão listados a seguir, pois interessam particularmente a pesquisa desenvolvida neste trabalho.

$$
\mathrm{da} / \mathrm{dt}=0,3(\mathrm{~K}-9)^{0,10}
$$

que corresponde ao modelo da EdF a partir de dados de plantas e laboratórios para a CSTAP da liga 600 a $290^{\circ} \mathrm{C}$, com da/dt em $\mu \mathrm{m} / \mathrm{h}$ e K em MPa.. $\mathrm{m}$. 
Foram também estudados outros materiais de interesse dentro da CST dos bocais do MAB, que não se desenvolveu nesse trabalho, mas podem ser utilizados para futuras pesquisas e desenvolvimentos. Assim, a Westinghouse propôs um modelo para a CSTAP das ligas 182 e 82 (os materiais de solda utilizados na construção do sistema dos bocais do MAB) que nada mais é do que a equação de Scott corrigida de um fator 5 , considerando as energias de ativação das ligas 600 e 182 semelhantes em torno de $Q=130 \mathrm{~kJ} / \mathrm{mol}$ [GÓMEZ BRICEÑO \& SERRANO, 2005].

\subsubsection{Modelo numérico de Lee e Hwang}

Há ainda esse modelo numérico utilizando dados experimentais para se obter, através de uma distribuição estatística de iniciação de defeitos de Weibull integrada sobre a superfície do bocal do MAB em liga 600, a probabilidade de iniciação da trinca em função do tempo. Obteve-se assim, um modelo de iniciação de trincas por CSTAP. O modelo foi validado através da aplicação de testes em corpos de prova subdivididos em espécimes estatisticamente significativos cujos tamanhos foram dimensionados através do método de Monte Carlo [SEUNG-GI LEE \& IL SOON HWANG, 1999].

\subsubsection{Comparação entre modelos}

Pode-se resumir as vantagens e limitações dos principais modelos expostos que dispõem de modelagem, conforme a Tabela 8.2. Nas colunas Avaliação e Aplicabilidade; Vantagens; Limitações foram efetuadas análises críticas desses modelos, incluindo considerações sobre os respectivos materiaismeios a que se aplicam. 
Tabela 8.2. Vantagens e limitações dos principais modelos

\begin{tabular}{|c|c|c|c|c|c|}
\hline Modelo (ano) & Referência & Avaliação e Aplicabilidade & Vantagens & Limitações & Comentários \\
\hline $\begin{array}{l}\text { Semi-empírico- } \\
\text { probabilístico de } \\
\text { Staehle }\end{array}$ & $\begin{array}{l}\text { [GORMAN et } \\
\text { al., 1994] }\end{array}$ & $\begin{array}{l}\text { A construção do modelo permite que ele } \\
\text { seja de fácil aplicação, embora seja } \\
\text { simplificado. O modelo é semi-flexível e } \\
\text { pode ser aplicável a outros materiais } \\
\text { além da liga } 600 \text { e outros meios além da } \\
\text { água do circuito primário a alta } \\
\text { temperatura, nos casos onde a tensão } \\
\text { tem um efeito preponderante na evolução } \\
\text { da trinca de CST: para isso é necessário } \\
\text { adaptar-se a modelagem (item 10.1) a } \\
\text { parâmetros adequados aos diferentes } \\
\text { casos; inclusive pode-se mudar a parte } \\
\text { estatística, utilizando outras distribuições } \\
\text { quando for o caso: por exemplo, se } \\
\text { houver preponderância na iniciação por } \\
\text { pites, a distribuição mais adequada a ser } \\
\text { utilizada é a de Poisson [STAEHLE, } \\
\text { 2001]. }\end{array}$ & $\begin{array}{l}\text {-Modelagem de parte } \\
\text { matemática relativamente } \\
\text { simples. } \\
\text {-Dispõe de uma parte } \\
\text { semi-empírica } \\
\text { determinística e de outra } \\
\text { probabilística, englobando } \\
\text { essas duas naturezas de } \\
\text { fenômenos. }\end{array}$ & $\begin{array}{l}\text {-Dados de entrada do modelo } \\
\text { na parte determinística, } \\
\text { relativamente aos materiais, } \\
\text { não são fáceis de serem } \\
\text { achados, mesmo com os } \\
\text { fabricantes. } \\
\text {-Exigem vários ensaios, para } \\
\text { modelagem da parte } \\
\text { probabilística. Staehle indica } \\
\text { um mínimo de sete ensaios } \\
\text { [STAEHLE, 1992a]. }\end{array}$ & $\begin{array}{l}\text { Iniciou-se a utilização desse modelo } \\
\text { na formulação da superposição } \\
\text { com a região de resistência à CST } \\
\text { (somente a parte determinística). }\end{array}$ \\
\hline $\begin{array}{l}\text { Semi-empírico por } \\
\text { taxa de deformação } \\
\text { de Garud e Gerber }\end{array}$ & $\begin{array}{l}\text { [GORMAN et } \\
\text { al., 1994], } \\
\text { [BEGLEY, } \\
\text { 1990] }\end{array}$ & $\begin{array}{l}\text { O modelo prediz o dano por taxa de } \\
\text { deformação na liga } 600 \text { na CSTAP, a } \\
\text { partir de resultados de ensaios } \\
\text { SSRT/CERT. O modelo é semi-flexível e } \\
\text { pode ser aplicável a outros materiais } \\
\text { além da liga } 600 \text { e outros meios além da } \\
\text { água do circuito primário a alta } \\
\text { temperatura, nos casos onde a fluência e } \\
\text { a taxa de deformação têm um efeito } \\
\text { preponderante na evolução da trinca de } \\
\text { CST (a tensão é necessária para gerar } \\
\text { apenas uma taxa de deformação e } \\
\text { fluência): para isso é necessário adaptar- } \\
\text { se a modelagem (item 10.2) a } \\
\text { parâmetros adequados aos diferentes } \\
\text { casos. É um modelo adequado a ensaios } \\
\text { de SSRT/CERT. Necessário elaborar } \\
\text { programa de aplicação envolvendo } \\
\text { planilhas em Excel e resolução de } \\
\text { sistemas de equações diferenciais. }\end{array}$ & $\begin{array}{l}\text {-Adequado para ensaios } \\
\text { SSRT/CERT. } \\
\text {-Aplicação prática } \\
\text { imediata modelando o } \\
\text { dano, independente se é } \\
\text { iniciação ou propagação } \\
\text { da trinca por CSTAP. }\end{array}$ & $\begin{array}{l}\text {-Ensaios de SSRT/CERT em } \\
\text { pelo menos duas } \\
\text { temperaturas. }\end{array}$ & \\
\hline
\end{tabular}

Tabela 8.2. Vantagens e limitações dos principais modelos (continuação) 


\begin{tabular}{|c|c|c|c|c|c|}
\hline Modelo (ano) & Referência & Avaliação e Aplicabilidade & Vantagens & Limitações & Comentários \\
\hline $\begin{array}{l}\text { Tempo de iniciação } \\
\text { simplificado de } \\
\text { Garud }\end{array}$ & $\begin{array}{l}\text { [GARUD, } \\
\text { 1997] }\end{array}$ & $\begin{array}{l}\text { O modelo prediz o tempo de iniciação na } \\
\text { liga } 600 \text { na CSTAP, a partir de resultados } \\
\text { de ensaios de carga constante. O modelo } \\
\text { é semi-flexível e pode ser aplicável a } \\
\text { outros materiais além da liga } 600 \text { e } \\
\text { outros meios além da água do circuito } \\
\text { primário a alta temperatura, nos casos } \\
\text { onde a tensão tem um efeito } \\
\text { preponderante na evolução da trinca de } \\
\text { CST. É um modelo interessante para se } \\
\text { estudar efeitos de diferentes tratamentos } \\
\text { termomecânicos, como encruamento } \\
\text { (trabalho a frio). }\end{array}$ & $\begin{array}{l}\text {-Aplicação rápida } \begin{array}{r}\text { e } \\
\text { prática na parte } \\
\text { matemática. }\end{array} \\
\begin{array}{l}\text {-Bem validado na } \\
\text { literatura. }\end{array}\end{array}$ & $\begin{array}{l}\text { Necessidade de ensaios de } \\
\text { carga constante. }\end{array}$ & $\begin{array}{l}\text { Iniciou-se a utilização desse modelo } \\
\text { na formulação da superposição } \\
\text { com a região de resistência à CST. } \\
\text { (aproximando-se os resultados de } \\
\text { ensaios de SSRT/CERT às } \\
\text { condições de carga constante: } \\
\text { tensão "constante" considerada } \\
\text { como a média entre o limite de } \\
\text { escoamento e o limite de } \\
\text { resistência } \sigma_{m}=\left(\sigma_{e}+\sigma_{u}\right) / 2 \text {, e a } \\
\text { média entre dois experimentos nas } \\
\text { mesmas condições. }\end{array}$ \\
\hline $\begin{array}{l}\text { Dano por taxa de } \\
\text { deformação de } \\
\text { Boursier }\end{array}$ & $\begin{array}{l}\text { [BOURSIER et } \\
\text { al., 1995] }\end{array}$ & $\begin{array}{l}\text { O modelo exprime o tempo de iniciação } \\
\text { por taxa de deformação e é aplicável } \\
\text { imediatamente a resultados de ensaios } \\
\text { SSRT/CERT. Embora os autores tenham } \\
\text { estudado apenas a liga } 600 \text {, o modelo é } \\
\text { semi-flexível e pode ser aplicável a } \\
\text { outros materiais e outros meios além da } \\
\text { água do circuito primário a alta } \\
\text { temperatura, nos casos onde a fluência e } \\
\text { a taxa de deformação têm um efeito } \\
\text { preponderante na evolução da trinca de } \\
\text { CST: são necessárias outras } \\
\text { modelagens específicas por caso } \\
\text { (material, meio) a ser estudado. }\end{array}$ & $\begin{array}{l}\text {-Aplicação imediata } \\
\text { ensaios SSRT/CERT. }\end{array}$ & $\begin{array}{l}\text {-Aplicação } \\
\text { limitada numa } \\
\text { deformação. }\end{array}$ & $\begin{array}{l}\text { Iniciou-se a utilização desse modelo } \\
\text { na formulação da superposição } \\
\text { com a região de resistência à CST. }\end{array}$ \\
\hline $\begin{array}{l}\text { Empírico- } \\
\text { comparativo } \\
\text { de Staehle }\end{array}$ & $\begin{array}{l}\text { [STAEHLE, } \\
\text { 1992a] }\end{array}$ & $\begin{array}{l}\text { Modelo semi-quantitativo que pode ser } \\
\text { construído rapidamente a partir de } \\
\text { ensaios SSRT/CERT. }\end{array}$ & $\begin{array}{lrr}\text { Construção relativamente } & \text { renas } \\
\text { simples, mas exige } \\
\text { grande número de } \\
\text { ensaios em cada } \\
\text { temperatura de interesse. }\end{array}$ & $\begin{array}{l}\text { Há necessidade de grande } \\
\text { quantidade de dados } \\
\text { experimentais. }\end{array}$ & $\begin{array}{l}\text { Iniciou-se a utilização desse modelo } \\
\text { para a superposição com a região a } \\
\text { região de resistência à CST. }\end{array}$ \\
\hline
\end{tabular}


Tabela 8.2. Vantagens e limitações dos principais modelos (continuação)

\begin{tabular}{|c|c|c|c|c|c|}
\hline Modelo & Referência & Avaliação & Vantagens & Limitações & Comentários \\
\hline \multirow{2}{*}{$\begin{array}{c}\text { Dissolução por } \\
\text { mecanismo de } \\
\text { deslizamento / } \\
\text { ruptura do filme } \\
\text { passivo }\end{array}$} & $\begin{array}{l}\text { [ANDRESEN \& } \\
\text { FORD, 1988]. }\end{array}$ & $\begin{array}{l}\text { A hipótese mecanística do modelo é } \\
\text { razoável, embora seja simplista, não } \\
\text { considerando efeitos de parâmetros } \\
\text { como T, TF, TT, etc. }\end{array}$ & $\begin{array}{l}\text {-Adequado para regiões } \\
\text { onde } \mathrm{K}_{\mathrm{l}}<30 \mathrm{MPa} \cdot \sqrt{\mathrm{m}} \text {. }\end{array}$ & $\begin{array}{l}\text {-Não adequado para a região } \\
\text { de transição onde } K_{1} \approx 30 \mathrm{MPa} \\
\sqrt{\mathrm{m}} \text {. }\end{array}$ & $\begin{array}{l}\text { É um modelo amplamente aplicado } \\
\text { na engenharia de equipamentos, } \\
\text { tendo sido desenvolvido no Centro } \\
\text { de P\&D da General Electric Co. }\end{array}$ \\
\hline & & $\begin{array}{l}\text { O modelo foi concebido para ser } \\
\text { aplicável a outros materiais além da liga } \\
600 \text { : aços inoxidáveis } 304 \text { e } 316 \mathrm{~L} \text {, aços } \\
\text { de baixa liga A533B e A508 e liga } 182 \\
\text { em meio água do circuito primário a alta } \\
\text { temperatura, pressupondo a ruptura do } \\
\text { filme passivo por mecanismo de } \\
\text { deslizamento das camadas sub- } \\
\text { superficiais do material; nesse } \\
\text { mecanismo, o avanço da trinca está } \\
\text { relacionado pela lei de Faraday aplicada } \\
\text { a reações de corrosão (dissolução, } \\
\text { passivação e corrosão espontânea que } \\
\text { ocorrem na ponta da trinca quando o } \\
\text { filme passivo é rompido pela deformação } \\
\text { crescente do metal base: esse } \\
\text { comportamento pode variar de modo } \\
\text { complexo para diferentes meios e } \\
\text { materiais [ANDRESEN \& FORD, 1988]. }\end{array}$ & $\begin{array}{l}\text {-Prediz bem o decréscimo } \\
\text { do fator de intensidade de } \\
\text { tensões para CST, com o } \\
\text { ambiente mais agressivo } \\
\text { [REBAK\&SMIALOWSKA, } \\
\text { 1995]. }\end{array}$ & $\begin{array}{l}\text {-Para o parâmetro } \dot{\varepsilon}_{\mathrm{pt}} \text { existe } \\
\text { um bom entendimento teórico } \\
\text { e formulação geral mas não } \\
\text { muitos dados experimentais } \\
\text { ou expressões absolutas } \\
\text { [REBAK\&SMIALOWSKA, } \\
\text { 1995]. }\end{array}$ & \\
\hline
\end{tabular}


Tabela 8.2. Vantagens e limitações dos principais modelos (continuação)

\begin{tabular}{|c|c|c|c|c|}
\hline \multirow[t]{5}{*}{$\begin{array}{l}\text { Teoria da } \\
\text { mobilidade } \\
\text { superficial } \\
\text { acelerada }\end{array}$} & \multirow[t]{5}{*}{$\begin{array}{c}\text { [GALVELE, } \\
1987]\end{array}$} & \multirow{5}{*}{$\begin{array}{l}\text { O modelo está baseado em princípios } \\
\text { metalúrgicos de movimento de } \\
\text { discordâncias e vacâncias em torno da } \\
\text { ponta da trinca por CST; a velocidade de } \\
\text { propagação da trinca é estimada em } \\
\text { função de tensão, parâmetros } \\
\text { geométricos, temperatura e coeficiente } \\
\text { de auto-difusão superficial (Ds). O modelo } \\
\text { foi concebido para uma vasta gama de } \\
\text { combinações material-meio, como ligas } \\
\text { de cobalto em haletos, cobre em } \\
\text { cloratos, percloratos, nitratos; ligas } \\
\text { FeCrNi, como aço inoxidável, em haletos } \\
\text { Além disso, o modelo pode prever o } \\
\text { efeito assistido do hidrogênio, que } \\
\text { interagindo com as vacâncias aumenta a } \\
\text { auto-difusão do material [GALVELE, } \\
\text { 1987]. No caso da liga 600, o modelo } \\
\text { prediz que a formação do NiO é } \\
\text { necessária para que ocorra a corrosão } \\
\text { intergranular que dá início à trinca por } \\
\text { CST [REBAK \&SMIALOWSKA, 1996]. }\end{array}$} & \multirow{5}{*}{$\begin{array}{l}\text {-Adequado para regiões } \\
\text { onde } \mathrm{K}_{\mathrm{I}}>30 \mathrm{MPa} . \sqrt{\mathrm{m}} \\
\text {-Pode explicar o efeito } \\
\text { benéfico dos carbonetos } \\
\text { depositados r nos } \\
\text { contornos de grãos } \\
\text { [REBAK\&SMIALOWSKA, } \\
\text { 1995]. }\end{array}$} & $\begin{array}{l}\text {-Não adequado para a região } \\
\text { de transição onde } \mathrm{K}_{1} \approx 30 \\
\text { MPa. } 3 \text { m[REBAK\&SMIALOW - } \\
\text { SKA }\end{array}$ \\
\hline & & & & $\begin{array}{l}\text { SKA, 1995]. } \\
\text {-Há dificuldades em se achar } \\
\text { dados de } D_{S} \text { na literatura } \\
\text { [GALVELE, 1987]. }\end{array}$ \\
\hline & & & & $\begin{array}{l}\text {-Não prevê os efeitos de } \\
\text { encruamento, } \mathrm{pH} \text { ou } \\
\text { tratamento térmico [REBAK } \\
\text { \&SMIALOWSKA, 1996]. }\end{array}$ \\
\hline & & & & $\begin{array}{l}\text {-Não explica a iniciação da } \\
\text { CSTAP da liga } 600 \text { [REBAK } \\
\text { \&SMIALOWSKA, 1996]. }\end{array}$ \\
\hline & & & & $\begin{array}{l}\text {-Sua formulação teórica foi } \\
\text { discutida por [GUTMAN, 2003] } \\
\text { e [GALVELE, 2003]. }\end{array}$ \\
\hline
\end{tabular}


Tabela 8.2. Vantagens e limitações dos principais modelos (continuação)

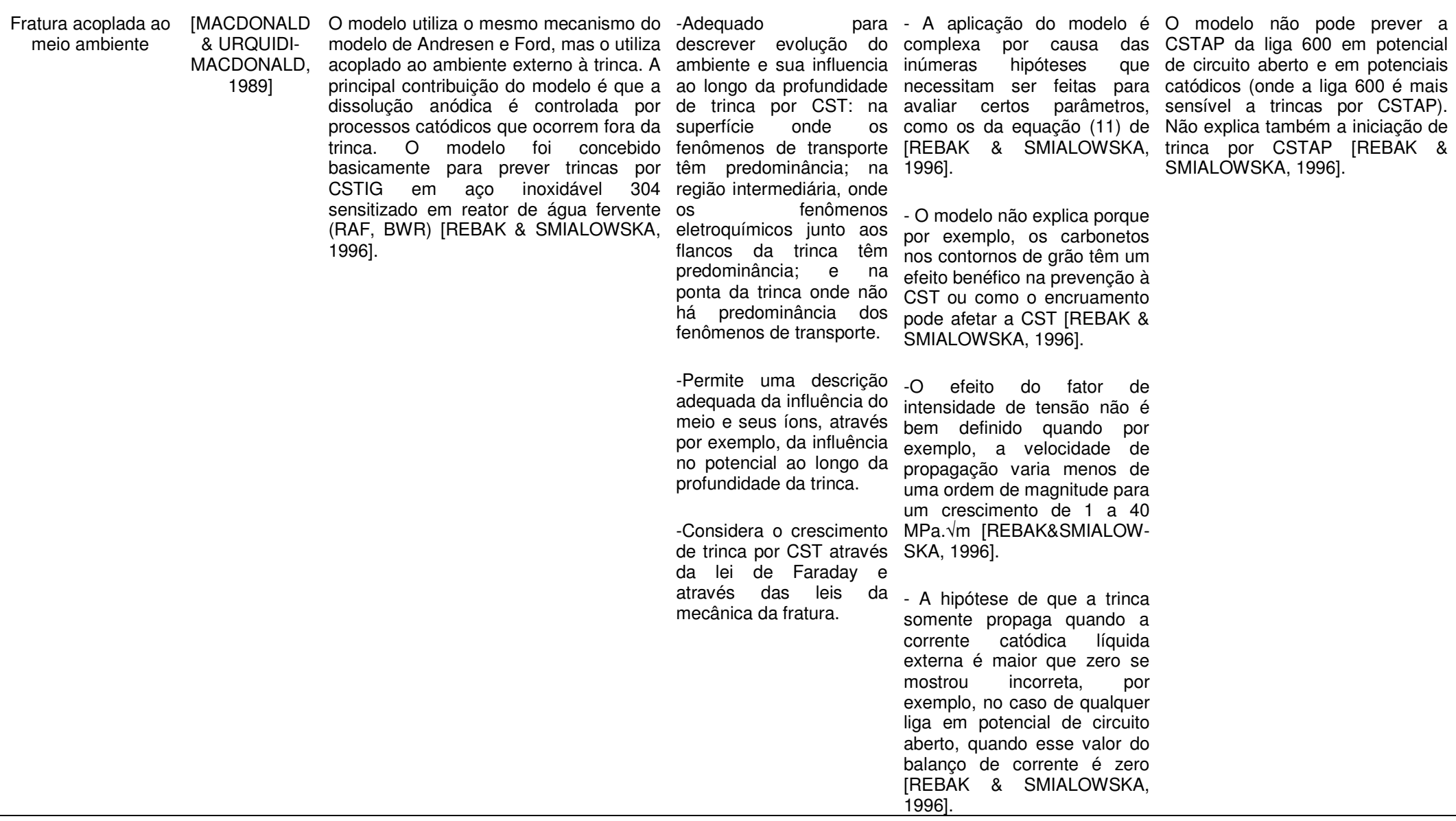


Tabela 8.2. Vantagens e limitações dos principais modelos (continuação)

Mecanismo de oxidação interna

Modelo [REBAK\& SMIALOWSKA 1995]

\section{[SCOTT \& LE} CALVAR, 1993]

explicar a CSTAP da liga 600 e exprime equado para a região um outro mecanismo que pode explicar TREBAK\& SMIALOWSKA sse fenômeno: através da fragilização 1996].

intergranular causada pela difusão do oxidação seletiva em elementos de liga menos nobres do que o metal base; e través da formação de bolhas de $\mathrm{CO} / \mathrm{CO}_{2}, \mathrm{CH}_{4}$ ou apenas $\mathrm{O}_{2}$ adsorvido. essa teoria, mas não uma validação propriamente dita [SCOTT\&LE
CALVAR,1993],[REBAK\& SMIALOWSKA 1996]. oxigênio na matriz do metal: essa causa Há evidências experimentais que levam a

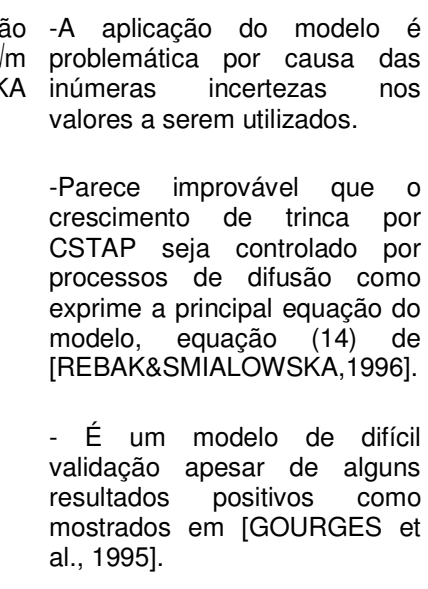
experimentais, estabelo uma descrição aplicacão (domínio de quantidade de dados matemática do fenômeno com o validade), inclusive na experimentais e respectivos respectivo ajuste estatístico, gerando a região de transição 20 tratamentos estatísticos. $\begin{aligned} & \text { respectivo ajuste estatístico, gerando a região de transição } 20 \\ & \text { modelagem. }\end{aligned}$
$\mathrm{MPa} . \sqrt{\mathrm{m}}<\mathrm{K}_{\mathrm{l}}<40 \mathrm{MPa} \cdot \sqrt{\mathrm{m}}$,

onde falham os modelos -Não há descrição dos de Andresen e Ford, mecanismos envolvidos. Galvele e Scott e L
Calvar [REBAK\&SMIALOWSKA, 1996]. 


\section{SUPERPOSIÇÃO MODO COM AMBIENTE}

Esse item foi exposto de maneira genérica em 2.5, mas dentro da proposição de modelagem desta Tese ele precisa ser tratado de maneira específica para a liga 600 em água primária a alta temperatura. Para isso será necessário fazer uma breve revisão de como esse diagrama foi concebido: sua idéia se deve a Staehle e está explicada em diversos trabalhos [STAEHLE\&GORMAN, 1989]; [STAEHLE, 1991]; [STAEHLE, 1992a]; [STAEHLE, 1992b]; [STAEHLE, 1995], [STAEHLE, 2001].

Staehle parte do diagrama "duplo" de Pourbaix $\left(\mathrm{pH}, \mathrm{V}_{\mathrm{T}}\right)$, que é a superposição dos respectivos diagramas de Pourbaix do $\mathrm{Fe}$ e Ni aplicados às mesmas condições ambientais para a liga 600. Staehle ressalta que, no caso, o diagrama de Pourbaix do níquel puro é bem adequado para o estudo da CST da liga 600, uma vez que a cinética, domínio e conseqüências da reatividade nos contornos de grão relacionados com a segregação de enxofre mostram o mesmo comportamento tanto no níquel puro quanto na liga 600 [STAEHLE et al., 1981]. Cabe aqui um esclarecimento: existem muito poucos diagramas de Pourbaix levantados para ligas. Consultando as bases de dados disponíveis em 2002, achou-se apenas o trabalho de Lemire e McRae [LEMIRE \& McRAE, 2001] sobre a construção de um diagrama de Pourbaix para a liga 690, novo material com muito maior resistência à CST e que vem substituindo a liga 600 em novos projetos de reatores do tipo RAP. Consultou-se também R. J. Lemire, autor responsável por esse trabalho, sobre a existência de algum levantamento semelhante para a liga 600 :

1) Havia um grupo no Canadá que estava trabalhando no diagrama para a liga 600 (nada havia publicado até 2002);

2) O diagrama construído para a liga 690 em [LEMIRE \& McRAE, 2001] precisava ser revisado, uma vez que nele foram apontadas inconsistências.

Isso justifica a utilização do diagrama de Pourbaix "duplo" $\mathrm{Fe}-\mathrm{Ni}$, a $300^{\circ} \mathrm{C}$, conforme proposto por Staehle, em meio água do circuito primário de reator de água pressurizada. Ressalte-se ainda que embora a liga 600 seja uma liga $\mathrm{Ni}-\mathrm{Cr}$ $\mathrm{Fe}$, o diagrama do $\mathrm{Cr}$ não é considerado na superposição por Staehle, porque provavelmente já foi por ele considerado como passivo, conforme comunicação 
particular em 2004, com a profa. Dra. Idalina V. Aoki da EPUSP. O uso desse diagrama é válido também porque ele será uma base orientadora e indicativa de regiões onde provavelmente aparecerão trincas de CST. Isto quer dizer, que sempre essas regiões deverão ser validadas. Assim, adotou-se para a base do modelo, formada pelos eixos x,y, o diagrama de Pourbaix "duplo" Fe-Ni, cujas equações.analíticas estão levantadas na literatura [BEVERSKOG\&PUIGDOMENECH, 1997], [CHEN, 1983], [COWAN \& STAEHLE, 1971], [POURBAIX,1974].

\subsection{Construção do diagrama de Pourbaix para alta temperatura}

Resumidamente o diagrama de Pourbaix para altas temperaturas, pode ser assim construído:

1) Determinação das reações químicas do material com o meio considerados [POURBAIX,1974], conforme (9.1).

$$
\mathrm{Ox}+\mathrm{ze} \leftrightarrow \mathrm{Red}
$$

com Ox e Red a representação genérica dos componentes da reação química que se encontram nos estados oxidado e reduzido respectivamente; $z=0$ número de elétrons e trocados nessa reação [WOLYNEC, 2003].

2) Determinação das equações de equilíbrio eletroquímico a partir da equação de Nernst (9.2).

$$
\mathrm{E}_{\mathrm{e}}=\mathrm{E}^{0}+\{(\mathrm{RT}) /(\mathrm{zF})\} \ln \{[\mathrm{Ox}] /[\mathrm{Red}]\}
$$

com $E_{e}=$ potencial de equilíbrio da reação química reversível (9.1); $E^{0}=$ potencial de eletrodo padrão; $R=$ constante universal dos gases; $T=$ temperatura absoluta do meio e F=constante de Faraday [WOLYNEC, 2003].

3) Determinação dos potenciais padrão $E^{0}$ à temperatura do meio (no caso, altas temperaturas) que não são disponíveis experimentalmente e precisam ser calculadas teoricamente: utilizando-se a relação (9.3) 


$$
\Delta G^{0}=-n F E^{0}
$$

com $\Delta G^{0}=$ variação da energia de Gibbs no potencial padrão, $n=$ número de moles de elétrons envolvidos no processo.

O potencial de eletrodo padrão de uma reação eletroquímica em qualquer temperatura $T$ pode ser referido ao eletrodo padrão de hidrogênio pela equação derivada da termodinâmica (9.4), que exprime a energia livre de uma substância [CRISS\&COBBLE, 1964a].

$$
\Delta G^{0}{ }_{T 2}=\Delta G^{0}{ }_{T 1}+\int_{\mathrm{T} 1}{ }^{T 2} \Delta C_{P} d T-T_{2} \int_{T 1}{ }^{T 2}\left(\Delta C_{P} / T\right) d T-\Delta T \Delta S^{0}{ }_{T 1}
$$

Infelizmente os $C_{P}$ não são disponíveis para a maior parte das espécies, tendo então que ser calculados teoricamente pelo método de Criss e Cobble, baseado no Princípio de Correspondência da Entropia lônica [CRISS\&COBBLE, 1964a], [CRISS\&COBBLE, 1964b], [COBBLE, 1964]. Esse Princípio permite normalizar os valores da literatura da entropia iônica a $25^{\circ} \mathrm{C}$ para uma escala de entropia absoluta à mesma temperatura e depois relacioná-la através de relação linear com as entropias absolutas a uma outra temperatura $T_{2}$ : está formulado na equação (9.5).

$$
\mathrm{S}_{\mathrm{T} 2}^{0}(\mathrm{i}, \mathrm{abs})=\mathrm{a}\left(\mathrm{T}_{2}\right)+\mathrm{b}\left(\mathrm{T}_{2}\right) \mathrm{S}^{0}{ }_{25}(\mathrm{i}, \mathrm{abs})
$$

com $\mathrm{S}^{0}{ }_{\mathrm{T} 2}(\mathrm{i}, \mathrm{abs})=$ entropia absoluta da espécie i à temperatura $\mathrm{T}_{2}$ e $\mathrm{S}_{25}^{0}(\mathrm{i}, \mathrm{abs})=$ entropia absoluta da espécie i à $25^{\circ} \mathrm{C}$. Assim, pode-se transformar (9.4) em (9.6) [CRISS\&COBBLE, 1964b].

$$
\Delta G^{0}{ }_{T 2}=\Delta G^{0}{ }_{T 1}-\Delta T \Delta S^{0}{ }_{T 1}+\Delta C_{P}{ }^{M T 2} I_{T 1}\left[\Delta T-T_{2} \ln \left(T_{2} / T_{1}\right)\right]
$$

$\operatorname{com} \Delta \mathrm{C}_{\mathrm{P}}{ }^{\mathrm{M}}{ }^{\mathrm{T}} \mathrm{I}_{\mathrm{T} 1}=$ valor médio da capacidade calorífica $=(9.7)$.

$$
{ }_{\mathrm{T} 1} \int^{\mathrm{T} 2} \Delta \mathrm{C}_{\mathrm{P}}{ }^{\mathrm{M}} \mathrm{dT} / \mathrm{T}_{1} \int^{\mathrm{T} 2} \mathrm{dT}={ }_{\mathrm{T} 1} \int^{\mathrm{T} 2} \mathrm{C}_{\mathrm{P}} \mathrm{d} \ln \mathrm{T} / \mathrm{T}_{\mathrm{T}} \int^{\mathrm{T} 2} \mathrm{~d} \ln \mathrm{T}
$$


Para espécies não-iônicas ou substâncias puras, $S^{0}$ e $C^{0}{ }_{P}$ são facilmente disponíveis em manuais. Para espécies iônicas, o valor médio da capacidade calorífica é $=(9.8)$.

$$
\left.\Delta C_{P}{ }^{M T 2} I_{T 1}=\left[S^{0}\left(T_{2}\right)-S^{0}\left(T_{1}\right)\right] / \ln \left(T_{2} / T_{1}\right)\right]
$$

O valor $\Delta G^{0}{ }_{T}$ calculado por (9.6) é convertido em $E^{0}$ através da equação (9.3). Se $\mathrm{T}_{2} \geq 200^{\circ} \mathrm{C}$, o valor médio da capacidade calorífica calculado segundo a equação de razão logarítmica (9.8), apresentará erros significativos e para contornar o problema, os valores de $\Delta G^{0}$ para essa faixa de temperaturas, devem ser calculados em degraus de $50^{\circ} \mathrm{C}$ utilizando os valores obtidos nesses incrementos de tal modo que sempre o valor posterior seja igual ao anterior, em cálculos sucessivos [CRISS\&COBBLE, 1964b]. A aderência desse método é excelente de acordo com Cowan e Staehle. Calculados os $E_{T}^{0}$, obtém-se as diferentes equações para as reações que permitirão a construção do diagrama de Pourbaix. No artigo de Cowan e Staehle estão determinadas analiticamente as equações para o sistema $\mathrm{Ni}-\mathrm{H}_{2} \mathrm{O}$ e construídos os respectivos diagramas de Pourbaix para as temperaturas de $300^{\circ} \mathrm{C}, 200^{\circ} \mathrm{C}, 100^{\circ} \mathrm{C}$ e $25^{\circ} \mathrm{C}$ [COWAN \& STAEHLE, 1971].

Existem aplicativos avançados que calculam os diagramas de Pourbaix para diversas substâncias, meios e temperaturas, como o Thermocalc ${ }^{\odot}$ com 0 banco de dados TCAQ2 ou AQS. No Brasil, há também em desenvolvimento ou parcialmente desenvolvidos, programas como o de Tanaka e Auada [TANAKA\&AUADA, 1991]. 


\subsection{Diagrama tridimensional de resistência à CST}

Staehle construiu o diagrama tridimensional de resistência à CST (Figura 9.1), para liga 600 laminada e recozida na condição de baixa temperatura, em água do circuito primário na faixa $300^{\circ} \mathrm{C}-325^{\circ} \mathrm{C}$, a partir da integração dos dados de muitas das mais importantes publicações descrevendo esse fenômeno nessas condições, com o diagrama "duplo" de Pourbaix acima referido. A fração de resistência à CST é definida como a resistência do material disponível contra esse tipo de falha. Ela pode ser considerada aproximadamente como uma fração da tensão de escoamento útil em função do potencial e do $\mathrm{pH}$ e não se relaciona propriamente a valores específicos. Por isso a Figura 9.1 é considerada como sendo semi-quantitativa. Deve-se ressaltar que poderiam ser utilizados outros parâmetros para desenvolver dentro dessa metodologia: como a velocidade de propagação da trinca em alguma tensão ou intensidade de tensão. A seleção do parâmetro mais adequado a ser utilizado neste ponto não está bem claro ainda, uma vez que seria desejável integrar os fatores controladores de iniciação e propagação [STAEHLE\&GORMAN, 1989].

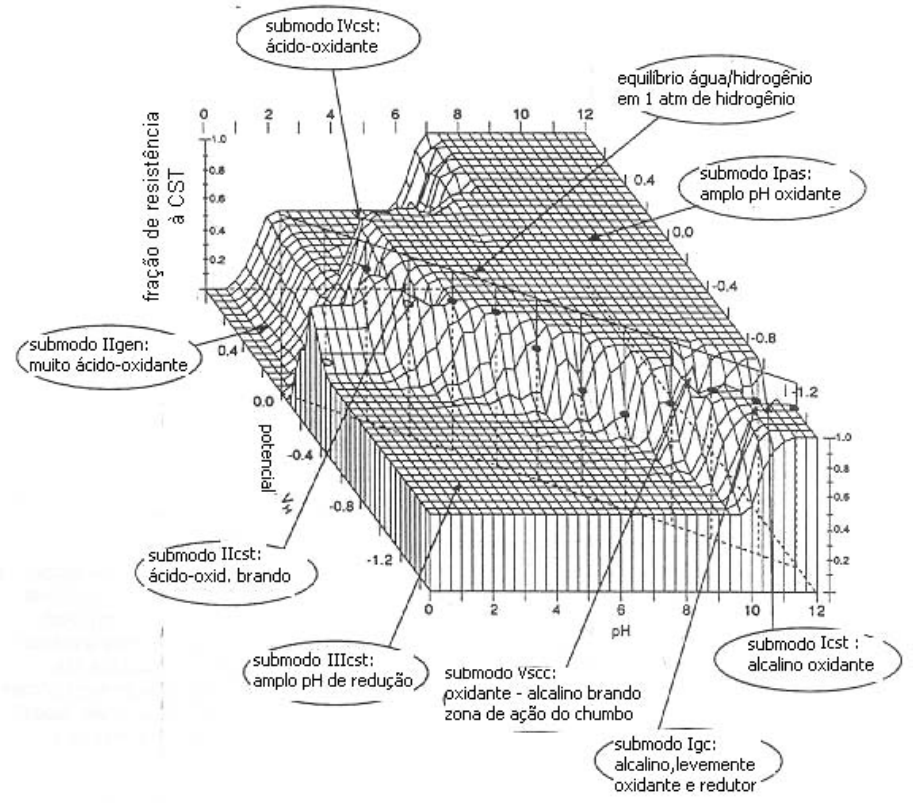

Figura 9.1. Diagrama modal tridimensional para a liga $600 \mathrm{em}$ água pura a $300^{\circ} \mathrm{C}$, indicando a fração de resistência útil à CST versus potencial \& pH (base). O plano vertical mostra a localização da região de equilíbrio água/hidrogênio em condição padrão. As zonas de corrosão estão demarcadas [STAEHLE, 1992a]. 


\subsection{Discussão das regiões de submodos}

O diagrama da Figura 9.1 tem algumas características importantes que convém serem ressaltadas [STAEHLE\&GORMAN, 1989]:

1) O papel de grande parte das espécies específicas que causam CST pode ser interpretado em termos de seus efeitos no potencial e $\mathrm{pH}$;

2) A localização da linha de equilíbrio padrão do hidrogênio é representada como um plano, as linhas verticais mostram cada unidade de $\mathrm{pH}$ e $\mathrm{O}$ tracejado é mostrado onde o plano intersecta a superfície de intensidade em cada unidade inteira de $\mathrm{pH}$;

3) A representação gráfica tridimensional mostra as características topográficas da resistência útil versus $\mathrm{pH}$ e potencial: é denominada "superfície de intensidade de CST";

4) A representação topográfica da CST não depende dos mecanismos atômicos da CST. Ele é apenas uma visão integrada de engenharia de uma superfície de intensidade que também não mostra a morfologia da CST, por exemplo, CSTIG ou CSTTG. Além do mais não define o ponto no qual a tensão utilizável é tomada, por exemplo, depois de uma hora ou milhares de horas. O tipo de medição e o corpo de prova não estão definidos. Assim vê-se que há muito a contribuir a esse universo de dados de modo que possa ser confiavelmente integrado;

5) Na Figura 9.1 considera-se apenas um tipo de tratamento térmico e uma única temperatura. Pode-se então imaginar que um número bem maior de gráficos é necessário para um sistema simples de ligas sobre uma faixa de temperaturas e tratamentos térmicos. Na Figura 9.2 são mostrados os gráficos necessários a várias temperaturas. No entanto, pode-se esperar que à medida que essa integração for refinada, muito da complexidade desse potencial seja simplificado. 


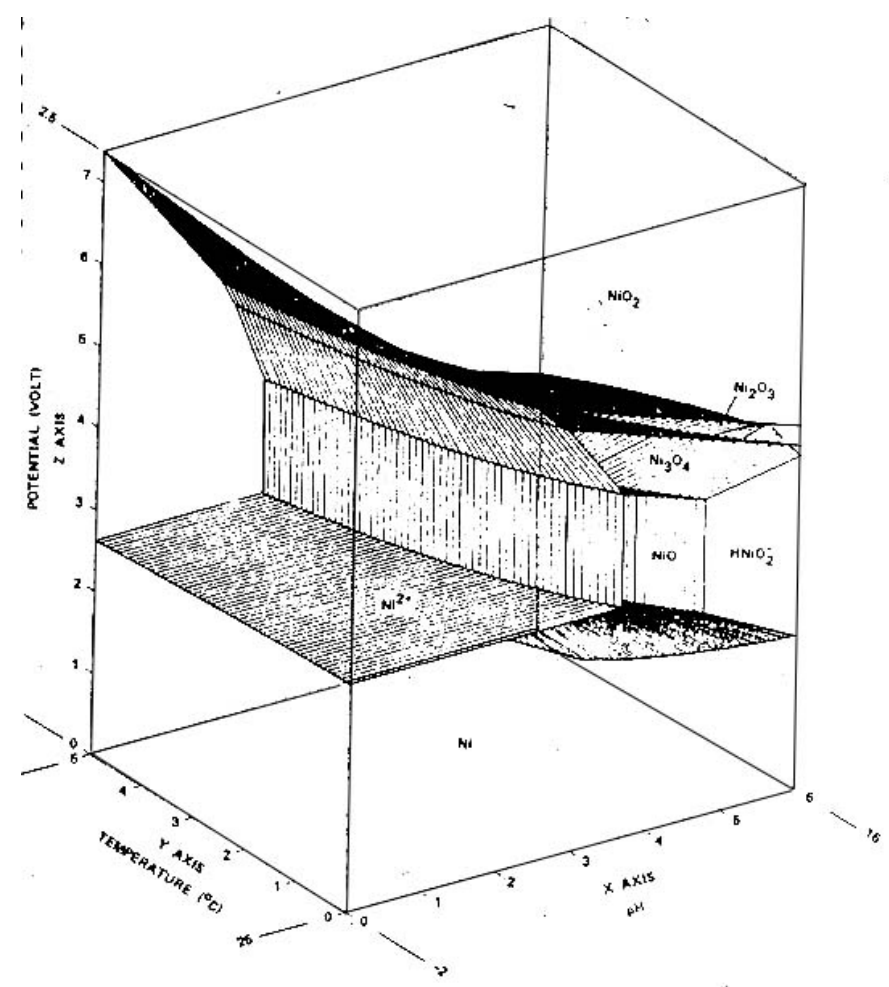

Figura 9.2. Diagrama de Pourbaix, potencial versus $\mathrm{pH}$ para o níquel em água pura a diversas temperaturas [CHEN, 1983].

A seguir serão discutidas as regiões de submodos mais importantes do diagrama da Figura 9.3 [STAEHLE\&GORMAN, 1989], que é a base topográfica da Figura 9.1. 


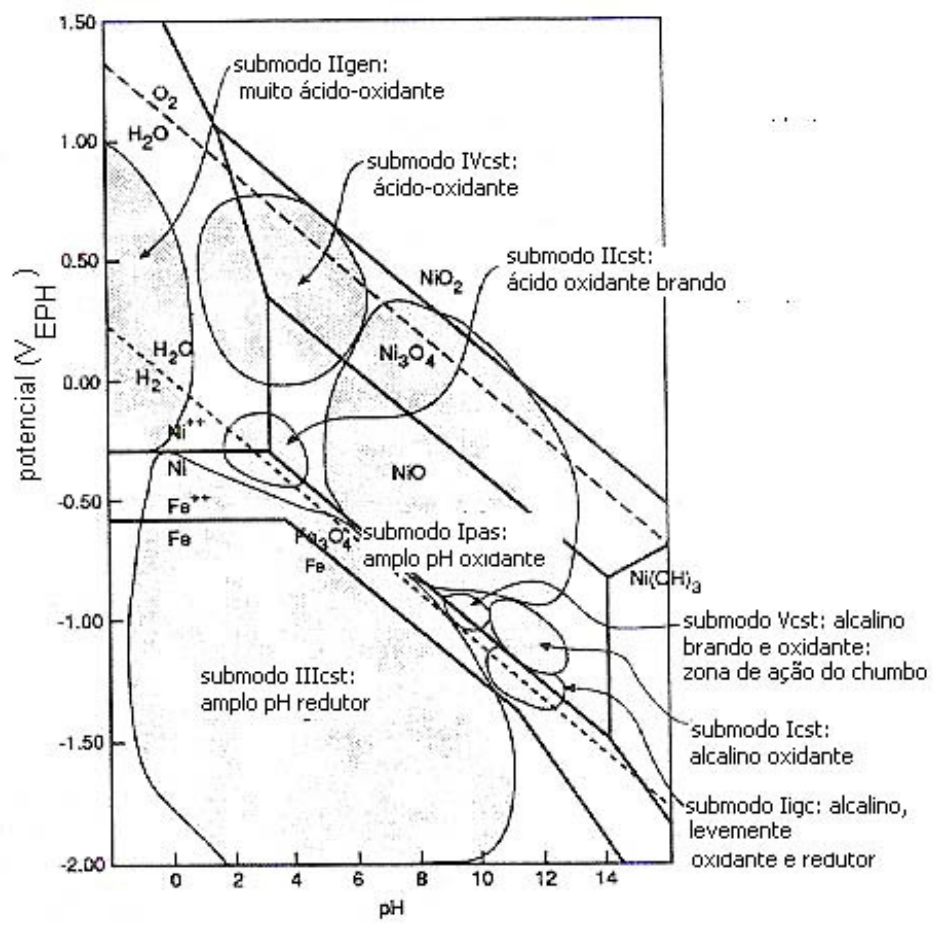

Figura 9.3. Submodos de corrosão para a liga 600 na faixa de $300^{\circ} \mathrm{C}$ plotados num diagrama potencial $\mathrm{pH}$ para o ferro e o níquel determinado para essa faixa de temperatura. Corresponde à base do diagrama tridimensional da Figura 9.1 [STAEHLE\&GORMAN, 1989],[STAEHLE, 1992a].

1) Região de redução da água (submodo III $\mathrm{CST}_{\text {) }}$ - CSTIG. Topograficamente é semelhante a um planalto com resistência útil à CST na faixa de $50 \%$ da tensão de escoamento. Essa zona foi descrita com base nos trabalhos de Smialowska, Jacko e Coriou [STAEHLE, 1992a], que atentaram para ela respectivamente, utilizando eletrodos de potencial controlado por deslocamento, variando a pressão de cobertura de hidrogênio e através de pares galvânicos. Esses experimentos e outros mostraram que a intensidade da CST é desprezível por volta de $50 \mathrm{mV}$ acima da linha de hidrogênio, mas já é perceptível sobre a própria linha. Finalmente, a $50 \mathrm{mV}$ acima dessa linha, ela atinge a máxima intensidade. Isso foi descrito por Smialowska e sua representação está na Figura 5.5, originalmente de [TOTSUKA \& SMIALOWSKA, 1988]. A topografia do planalto se estende significativamente nas direções ácida e alcalina. Os dados que suportam esse planalto não são muitos mas apenas sugerem essa topografia. O trabalho de Lumsden provavelmente se aplica para definição da região e os dados de Coriou aplicam-se à direção alcalina [STAEHLE, 1992a]. Alguns trabalhos sobre o efeito do 
ín tiossulfato também provavelmente se aplicam aqui. Deve-se ressaltar que essa zona é a que maior interesse apresenta dentro de nossa pesquisa.

2) Região alcalina branda e oxidante — de CST por chumbo (submodo $\mathrm{V}_{\mathrm{CST}}$ ) - CSTIG e CSTTG. Movendo-se para uma faixa mais ácida, identifica-se uma região de ação do chumbo eventualmente dissolvido em água pura, que pode levar tanto à CSTIG quanto à CSTTG. Ela se baseia sobre poucos experimentos onde a liga 600 trincou rapidamente por CSTIG e CSTTG. Staehle é da opinião que não é propriamente o chumbo na forma de íons que provoca essa trinca, mas sim que ela é apenas um caso particular da região alcalina oxidante, levemente deslocada para um ambiente mais próximo da linha padrão associada com diferentes processos mecanísticos que atuam na região alcalina oxidante original.

3) Região topográfica de planalto (submodo $I_{\mathrm{PAS}}$ ) -Corresponde ao planalto superior (Figura 9.1) onde a liga 600 preserva sua tensão de escoamento integralmente. Agrawal [STAEHLE, 1992a] mostrou que existe uma região similar a essa para 0 aço inoxidável em solução cáustica. Nela, provavelmente ocorre o melhor desempenho possível da liga 600.

4) Região alcalina oxidante (submodo $V_{C S T}$ ) - CSTIG. Topograficamente tem a forma de um vale iniciando do lado de $\mathrm{pH}$ mais alto onde a mínima resistência útil fica em torno de $150 \mathrm{mV}$ acima da linha padrão do hidrogênio. Esse ambiente é agressivo e a mínima tensão utilizável fica na faixa de $20 \%$ da tensão de escoamento. Ele termina por volta de pH 10 a 10,5. Abaixo dessa faixa de potencial que engloba a CST há também uma faixa onde ocorre corrosão intergranular que não necessita de tensão (não está indicada na Figura 9.3). Ela vai de 50 a $100 \mathrm{mV}$ abaixo da linha padrão de hidrogênio, aproximadamente sobre a mesma faixa de $\mathrm{pH}$. Essa região foi extensivamente estudada. 
5) Região de oxidação ácida (submodo $\mathrm{IV}_{\mathrm{CST}}$ ) - CSTIG. Aparece como um vale com a sua parte mais profunda, ou seja, com a parte menos utilizável, ligeiramente acima da linha de hidrogênio. Essa região não está bem consolidada por dados experimentais. Ela começa como um vale com valores fracamente ácidos e expande para incluir uma larga faixa de potenciais altamente oxidantes. Essa expansão foi definida pelo trabalho da equipe da empresa Mitsubishi.

6) Região de dissolução ácida não oxidante (submodo $\|_{G E N}$ ) - Não é região de CST, mas de corrosão generalizada provocada por solução acida, já que o níquel nela se dissolve, embora aqui não se leve em consideração que pode haver alguma contribuição da passivação em meio ácido desse metal.

Na Figura 9.1 não estão definidos os mecanismos de corrosão, apenas a variação de sua intensidade com o pH e o potencial. No entanto, pode-se associar algumas postulações mecanísticas, como por exemplo, o planalto de redução da água, estaria associado com a fragilização por hidrogênio: na realidade, essa pode se aplicar ou não. Por exemplo, o enxofre, nitrogênio, carbono e fósforo formam espécies solúveis em potencial negativo. Além do mais, há muitos caminhos pelos quais o hidrogênio pode interagir nos contornos de grãos, como se viu no item 8.7. Fica nítido que os processos que ocorrem na região de redução de água são diferentes daqueles que ocorrem no vale de oxidação cáustica [STAEHLE\&GORMAN, 1989].

\subsection{Discussão da topografia do diagrama tridimensional}

Staehle e Gorman tiram as seguintes conclusões a partir da análise das Figuras 9.1 e 9.2 e das suas derivadas, Figura 9.4 (diferentes cortes da Figura 9.1) e Figura 9.5, com cortes em três valores de $\mathrm{pH}$ de interesse [STAEHLE\&GORMAN, 1989]: 


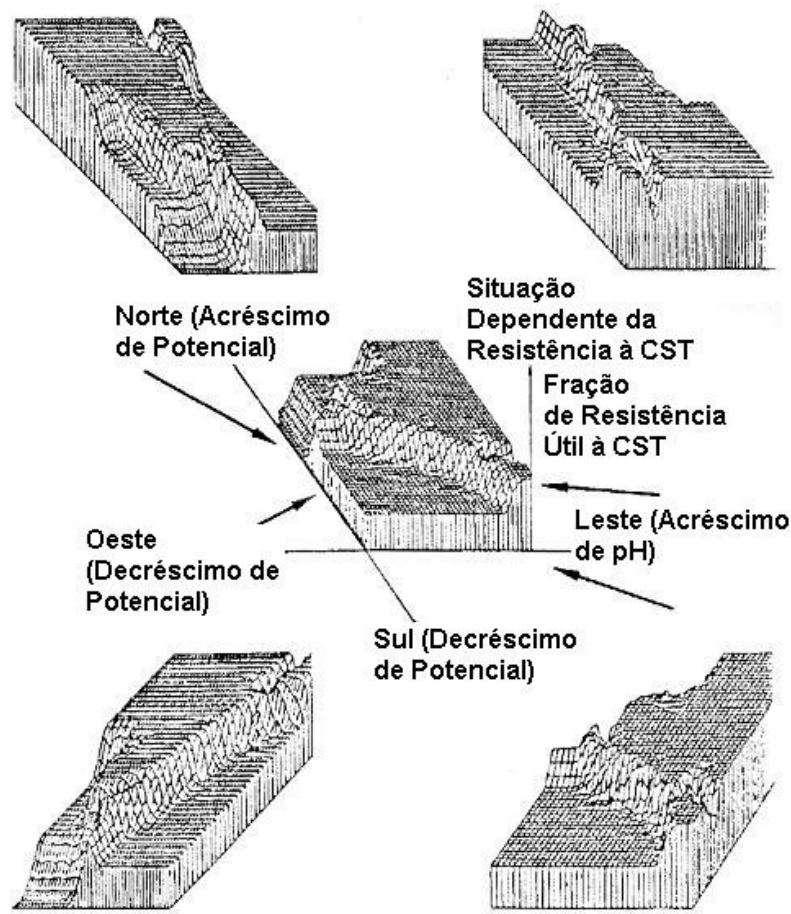

Figuras 9.4. Diferentes cortes da Figura 9.1 [STAEHLE\&GORMAN, 1989].

1) $\mathrm{O}$ corte da Figura 9.5, efetuado no $\mathrm{pH}$ neutro ilustra melhor o contorno entre o planalto superior onde a intensidade da CST é pequena e a planície inferior onde a CST é significativa. Entendendo o corte, é possível entender algumas das controvérsias concernentes ao trabalho de Coriou pioneiro no estudo da CST da liga 600 em água pura a alta temperatura, por isso cognominada algumas vezes de corrosão por efeito Coriou - no período 19591970 e ainda algumas controvérsias concernentes aos papéis do hidróxido de lítio e do ácido bórico na água primária de RAP. 


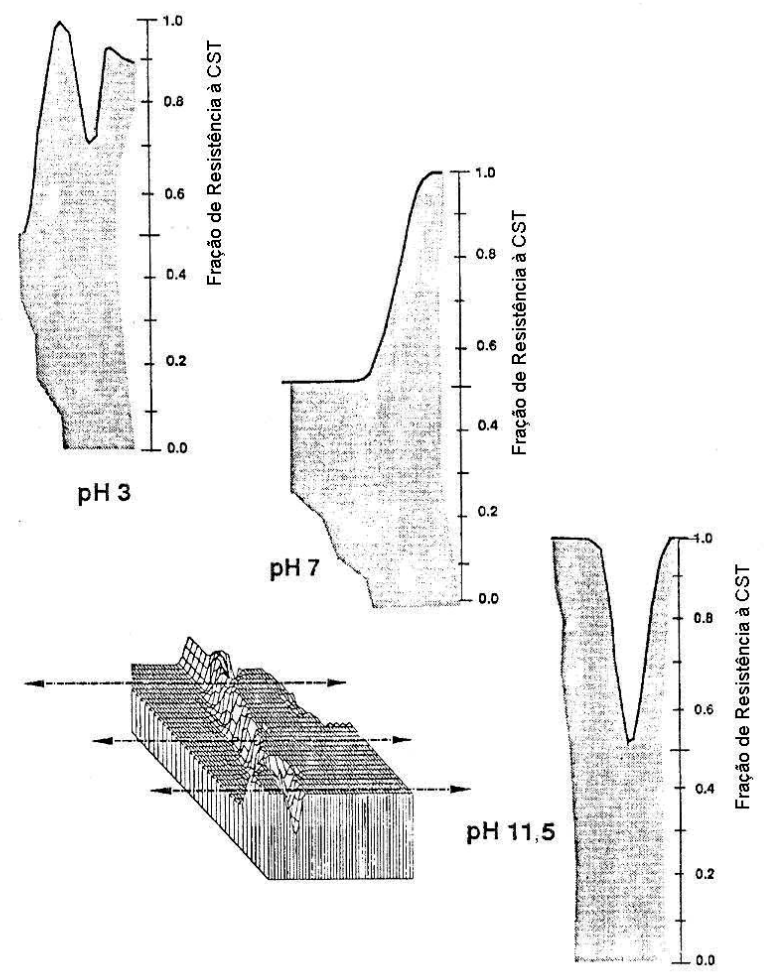

Figura 9.5. Cortes bi-dimensionais da Figura 9.1, onde é mostrada a fração de tensão de escoamento versus potencial em três valores constantes de pH [STAEHLE\&GORMAN, 1989].

2) O mesmo corte acima referido consolida o trabalho de Smialowska, sugerindo que CST em água pura é um fenômeno realmente associado com potenciais eletroquímicos na ou abaixo da linha padrão de hidrogênio. $\mathrm{Na}$ área cinza também há atividade do hidrogênio.

3) Durante os anos 1960 vários pesquisadores tiveram dificuldade de reproduzir o trabalho pioneiro de Coriou. Esse demonstrou em 1965 que foram necessárias muitos milhares de horas para surgir a CST; no entanto, ele prova que esses ensaios poderiam ser acelerados quando sujeitos à deformação constante ao invés da carga constante, previamente utilizada. Posteriormente Coriou demonstrou que a CST na liga 600 poderia ser acelerada através de um par galvânico com o aço carbono (menos nobre do que a liga 600), enquanto que com o ouro (mais nobre do que a liga 600), a CST foi retardada. Esse comportamento respondia claramente as primeiras dúvidas dos experimentos de 
Coriou, que foi consolidado e estendido pelo trabalho de Smialowska dez anos depois. Isso também é confirmado pela análise do corte no $\mathrm{pH}$ neutro da Figura 9.5 .

4) Esse mesmo corte subsidia a aplicação de novos materiais como a liga 690, com teor de cromo bem mais alto do que a liga 600: a explicação vai além da melhoria da qualidade do filme passivo nas ligas com maior teor de cromo; podem haver outros benefícios com relação à composição química nos contornos de grãos.

Embora na Figura 9.1 não se defina um ambiente de engenharia, esse pode ser definido analogamente através de novos ensaios nas diferentes condições em relação a essa Figura: composição da água, tratamento termomecânico da Liga, temperatura, etc. Desse modo, as condições termodinâmicas de contorno ficam bem estabelecidas [STAEHLE\&GORMAN, 1989].

Para uma superfície livre isenta de condições de corrosão por frestas, as condições de $\mathrm{pH}$ e potencial podem ser razoavelmente bem definidas [STAEHLE\&GORMAN, 1989]:

1) Sem presença de oxigênio, o potencial é definido pela linha padrão de hidrogênio associada com uma atividade definida de hidrogênio e pelo $\mathrm{pH}$ global da água;

2) $O$ potencial de hidrogênio será influenciado pelo hidrogênio desprendido da corrosão ou pelo hidrogênio acrescentado no meio. O potencial pode então flutuar significativamente por causa disso;

3) Quando se adiciona oxigênio, muda-se o potencial. O efeito do oxigênio em potencial de circuito aberto foi bem estudado para aço inoxidável, porém menos para o Inconel. O máximo acréscimo no potencial pela adição de oxigênio fica em torno de $500 \mathrm{mV}$;

4) O potencial muda para a direção negativa quando se adiciona hidrazina à água. Sabe-se disso qualitativamente, mas quantitativamente não há estudos para avaliar essa mudança;

5) O potencial de uma superfície livre será afetado pela velocidade como também a cinética de redução do oxigênio ou da oxidação de hidrazina. 
Isso da mesma forma, não foi estudado. Sabe-se que a adição de hidrazina acelera muito a CST das superfícies livres;

6) Se a liga 600 for acoplada galvanicamente com o aço carbono, o potencial é diminuído de tal forma que pode haver uma grande aceleração na CST.

Para uma superfície de liga 600 coberta com depósitos ou na condição de corrosão em frestas, os seguintes fatores controlam o potencial, $\mathrm{pH}$ e outros fatores químicos [STAEHLE\&GORMAN, 1989]:

1) Numa fresta monometálica sem transferência de calor e sem efeitos galvânicos, o pH da fresta será aproximadamente aquele definido pelo equilíbrio entre os íons metálicos e o óxido de proteção da superfície. O potencial será alterado na extensão onde a fresta é ativa e onde há processos de oxidação externa. Essas situações foram pouco estudadas;

2) Numa fresta bimetálica sem transferência de calor o potencial será alterado na direção do metal mais ativo. Os processos externos de oxidação influenciarão o processo;

3) Numa fresta com depósito ou depósito de solda, a química da superfície será dominada pela química do depósito e a taxa de reação do metal dependerá das condições externas do óxido, bem como dos efeitos do depósito sobre a película passiva na superfície do metal;

4) Numa fresta onde há transferência de calor a composição do meio local será muito alterada pelas impurezas no meio e nos processos de concentração. Serão atingidas concentrações ácidas ou cáusticas, dependendo das impurezas externas. Os potenciais nessas frestas dependem dos efeitos galvânicos, condições externas de oxidação, formação de produtos de corrosão e deformação metálica na fresta. 


\subsection{Vantagens e limitações do uso do diagrama tridimensional}

Pode-se resumir as vantagens do uso do diagrama da seguinte forma [STAEHLE\&GORMAN, 1989]:

1) Podem ser feitas estimativas razoáveis das condições eletroquímicas através da utilização dos diagramas de Pourbaix ou potencial-pH;

2) Assim o objetivo do controle ambiental e da seleção do material serão aqueles onde a resistência à CST é alta;

3) Essa abordagem gráfica permite uma unificação de linguagens do pesquisador e do engenheiro. Eles podem visualizar mudanças imediatamente, sem precisar entender os mecanismos. Aliás, esses podem ser entendidos através das grandes linhas do referido diagrama;

4) Os engenheiros de diferentes formações podem entender melhor 0 comportamento do sistema analisando o diagrama tri-dimensional da Figura 9.1. Por exemplo, porque a adição de hidrazina para evitar CST em frestas cáusticas pode acelerar a CST em superfícies livres de liga 600 em geradores de vapor.

Quanto às limitações, pode-se comentar o seguinte [STAEHLE, 1992b]:

1) As intersecções dos modos de corrosão com a definição do meio ambientes, isto é, a base do diagrama tridimensional correspondente ao diagrama de Pourbaix delimitado com os modos/submodos de corrosão (Figura 9.3), não estão estatisticamente descritos, e os efeitos desses ambientes precisam ser considerados separadamente. Esta também é uma razão importante para que esse diagrama precise ser sempre validado do ponto de vista experimental;

2) Embora os efeitos de diferentes espécies químicas na água possam ser traduzidos em termos de potencial-pH, a equivalência de testes em potencial de circuito aberto e em potenciais controlados precisam ser estabelecidos para validar um domínio abrangente. Pode ainda haver espécies químicas cuja presença não se reflita nesse tipo de diagrama;

3) Se for utilizada a velocidade de propagação de trinca como coordenada de intensidade de CST (eixo z), alguns métodos devem ser desenvolvidos para considerar os três estágios de propagação; 
4) Diagramas separados precisam ser desenvolvidos para ligas diferentes e diferentes tratamentos térmicos. Isso pode acarretar um trabalho considerável, que pode ser limitado por razões práticas.

Staehle sugeriu alguns desenvolvimentos futuros para esse diagrama [STAEHLE, 1992b]:

1) Desenvolver novas teorias de CST que possam sintetizar de modo abrangente esse diagrama tridimensional: isso traria um grande avanço para entendimento e generalização dos vários modos de corrosão;

2) Melhorar o valor desse diagrama, do ponto de vista qualitativo, através de padronização de ensaios de validação e melhor definição dos modos, estabelecendo seus contornos de maneira mais precisa;

3) Um grande trabalho precisa ser feito para definir com precisão os ambientes estudados. Muito mais atenção precisa ser dada na medição das propriedades ambientais nos quais os materiais são expostos: considerar geometrias locais, células eletroquímicas considerando maiores distâncias de influências de potenciais diferentes, efeitos de transferência de calor e efeitos de fluxo;

4) Há uma série de outras informações que ainda podem ser retiradas desses diagramas, que podem ser compiladas e utilizadas como guias de projeto.

Finalmente, cumpre ressaltar que há alguma variação no gráfico da Figura 9.3, conforme autores como Scott e Combrade, que apresentaram um gráfico com regiões de submodo mais limitadas, conforme demonstra a Figura 1 de [SCOTT\&COMBRADE, 1996]. Essa variação deve-se talvez a experimentos e condições particulares de validação desse gráfico por esses autores. 


\section{TÉCNICAS DE MODELAGEM}

A relação geral para modelagem do dano por CST pode ser expressa a partir da equação (8.1), como (10.1) [STAEHLE, 2001].

$$
X=A\left[H^{+}\right]^{n}[x]^{p} \sigma^{m} e^{(E-E 0) / b} e^{Q / R T} t^{q}
$$

com: $x=$ profundidade da penetração da trinca por CST; $A=$ parâmetro relacionado com a composição e a estrutura do material; $\left[\mathrm{H}^{+}\right]=$concentração do cátion hidrogênio, relacionada com o $\mathrm{pH} ;[\mathrm{x}]=$ concentração de espécies no ambiente; $\sigma=$ tensão; $E=$ =potencial eletroquímico; $E_{0}=$ potencial de referência de acordo com a composição do material e o meio ambiente; T=temperatura; $t=$ tempo; $\mathrm{n}, \mathrm{p}, \mathrm{m}, \mathrm{b}, \mathrm{q}=\mathrm{constantes}$ exponenciais.

No entanto, para essa expressão tornar-se de uso prático, normalmente ela é simplificada em determinados conjuntos de casos particulares. A partir daí surgem diversas técnicas de modelagem.

Estão detalhadas a seguir as técnicas de modelagem aplicáveis a ETDL e carga constante a partir dos seguintes modelos: o empírico-probabilístico de Staehle, o semi-empírico de dano por taxa de deformação de Garud e Gerber [BEGLEY, 1990], [GORMAN et al., 1994], o de dano por taxa de deformação simplificado de Garud. Além dessas, foi considerada uma técnica de modelagem que independe do modelo adotado para comportamento da trinca por CST: é a modelagem aplicada a ETDL de Santarini que é aplicada diretamente às trincas produzidas em corpos de prova submetidos a ensaios ETDL [SANTARINI, 1989] e a recente técnica de modelagem utilizando o diagrama mecânico -eletroquímico de Vankeerberghen [VANKEERBERGHEN, 2004].

Detalhou-se essas modelagens pelas seguintes razões:

1) São técnicas aplicáveis a ETDL, que o país tem instalado para estudo de aplicação na área nuclear no CDTN - Centro de Desenvolvimento de Tecnologia Nuclear localizado em Belo Horizonte;

2) São modelagens relativamente complexas que precisam ser trabalhadas a partir de seus respectivos modelos;

3) A modelagem utilizando o diagrama mecânico -eletroquímico de Vankeerberghen representa uma novidade recente especialmente concebida que 
junta os aspectos mecânicos e eletroquímicos da CST e que pode ser uma alternativa à modelagem que está sendo proposta neste trabalho;

4) Dentro da proposta deste trabalho, utilizamos também a modelagem a partir do modelo por taxa de deformação de Boursier, que não houve necessidade de detalhar em função de sua aplicação imediata aos ETDL.

10.1. Técnica de modelagem aplicada ao modelo semi-empírico-probabilístico de Staehle

Um modelo particularmente interessante é o semi-empírico utilizado conjuntamente com parâmetros estatísticos [STAEHLE, 1992a]:

$$
\mathrm{t}_{\mathrm{f}}=\mathrm{d}\left[\mathrm{H}^{+}\right]^{-\mathrm{m}} \sigma^{-\mathrm{n}} \exp \left(\frac{\mathrm{Q}}{\mathrm{RT}}\right)
$$

com $t_{f}=$ tempo de falha; $\sigma=$ tensão; $n=$ expoente de tensão; $Q=$ energia de ativação térmica; $T=$ temperatura absoluta; $\mathrm{R}=$ constante universal dos gases; $\left[\mathrm{H}^{+}\right]=$atividade do íon hidrogênio; $m=$ expoente da atividade do íon hidrogênio; $d=$ constante.

Por exemplo, de acordo com Staehle, Gras [GRAS (a) apud STAEHLE, 1992a] chegou a uma particularização da equação (10.1.1) através da sumarização de dados de laboratório e de campo para tubos geradores de vapor de liga 600.

$$
\mathrm{t}_{\mathrm{f}}=\mathrm{k} \sigma^{-4} \exp (22000 / \mathrm{T})
$$

com $t_{f}=$ tempo de falha $(s) ; k=$ constante que vale 0,02 para tubos altamente susceptíveis e 0,1 para tubos menos susceptíveis; $T=$ temperatura absoluta(K) e $\sigma=$ tensão (MPa).

O modelo semi-empírico-probabilístico de Staehle [GORMAN et al.,1994] é uma simplificação da expressão (10.1.1) que pode ser colocada sob forma mais conveniente de uso como:

$$
\mathrm{t}_{\mathrm{f}}=\mathrm{At}_{\text {ref }}\left(\frac{\sigma}{\sigma_{\text {ref }}}\right)^{\mathrm{n}} \exp \left[\left(\frac{\mathrm{Q}}{\mathrm{R}}\right)\left(\frac{1}{\mathrm{~T}}-\frac{1}{\mathrm{~T}_{\text {ref }}}\right)\right]
$$


com: $\mathrm{A}=$ constante adimensional que reflete $\mathrm{o}$ efeito das propriedades mecânicas e metalúrgicas do material no tempo para atingir $1 \%$ de CSTAP; $t_{\text {ref }}=$ tempo para atingir uma fração selecionada de CSTAP para o caso em referência; $\sigma_{\text {ref }}=$ tensão de referência; $T_{\text {ref }}=$ valor de referência de temperatura.

Esse modelo semi-empírico é determinístico, porém pode ser tornado probabilístico, ampliando seu alcance para análise de um número grande de falhas, através da introdução de parâmetros estatísticos.

A distribuição estatística de Weibull de três parâmetros $\left(\beta, \theta, t_{0}\right)$ é expressa pela equação (10.1.4).

$$
f(t)=\left[\beta /(t-\theta)^{\beta}\right]\left(t-t_{0}\right)^{\beta-1} \exp \left\{-\left[\left(t-t_{0}\right) /\left(\theta-t_{0}\right)\right]^{\beta}\right\}
$$

com: $t=$ tempo; $t_{0}=$ parâmetro de locação ou tempo de iniciação; $\theta=$ =parâmetro de escala ou característica de Weibull. Quando $\theta=t, F(\theta)=0,632 ; \beta=$ parâmetro de forma ou freqüentemente chamado de inclinação de Weibull, quando a distribuição acumulativa de Weibull F, é linearizada; a distribuição acumulativa de Weibull é dada por (2.16.1.5) [STAEHLE, 2001].

$$
F(t)=P\left\{t^{\prime} \leq t\right\}=\int_{0}^{t} f(t) d t
$$

Estatisticamente expressos os três parâmetros são conforme as equações (10.1.6), (10.1.7) e (10.1.8) [STAEHLE, 2001].

$$
\begin{gathered}
\Theta=A_{\theta}\left[H^{+}\right]^{n \theta}[x]^{p \theta}[M]^{r \theta} \sigma^{m \theta} e^{(E-E 0 \theta) / b \theta} e^{-Q \theta / R T} \\
\beta=A_{\beta}\left[H^{+}\right]^{n \beta}[x]^{p \beta}[M]^{r \beta} \sigma^{m \beta} e^{(E-E O \beta) / b \beta} e^{-Q \beta / R T} \\
t_{0}=A_{t 0}\left[H^{+}\right]^{n t 0}[x]^{p t 0}[M]^{r t 0} \sigma^{m t 0} e^{(E-E t o) / b t 0} e^{-Q t o / R T}
\end{gathered}
$$

com: $\mathrm{A}=$ constante; $\mathrm{H}^{+}=$íon de atividade do hidrogênio; $\mathrm{x}=$ concentração de espécies ativas,

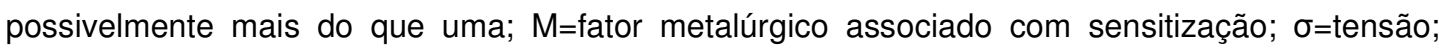
$\mathrm{E}=$ potencial eletroquímico; $\mathrm{E}_{0}=$ constante eletroquímica sendo ou o potencial de corrosão ou 0 potencial de equilíbrio termodinâmico; $b=$ constante eletroquímica; $Q=e n e r g i a$ aparente de ativação; $R=$ constante universal dos gases; $T=$ temperatura absoluta; $n, p, m, r, q=$ constantes.

O tempo de iniciação $t_{0}$ algumas vezes não é utilizado na aplicação da distribuição de Weibull, especialmente se há menos do que sete pontos dados. 
Nesse caso, usa-se a distribuição de Weibull de dois parâmetros, ao invés da distribuição de Weibull de três parâmetros [STAEHLE, 1992].

A distribuição estatística de Weibull de dois parâmetros também pode descrever a variação de CSTAP, como função do tempo:

$$
\mathrm{F}=1-\exp \left[-\left(\frac{\mathrm{t}}{\theta}\right)^{\mathrm{b}}\right]
$$

com $F=$ fração da população de componentes considerados e susceptíveis ao mesmo modo de defeito de CSTAP; $t=$ tempo normalmente expresso em anos efetivos de plena carga (AEPC); $b=$ inclinação de Weibull, um parâmetro determinado pela análise de dados do defeito; $\theta=$ tempo característico de Weibull que corresponde ao tempo em que $63,2 \%$ dos componentes apresentaram CSTAP.

Esse parâmetro pode ser escrito como $t_{f}=t_{1 \%}$ :

$$
\theta=\frac{\mathrm{t}_{1 \%}}{(0,0101)^{1 / b}}
$$

As equações (10.1.9) e (10.1.10) combinadas resultam em (10.1.11):

$$
F=1-\exp \left[-0,0101\left(\frac{t}{t_{1 \%}}\right)^{b}\right]
$$

$\mathrm{O}$ valor de $t_{1 \%}$ junto com um valor apropriado para a inclinação de Weibull $b$ determina a completa predição para CSTAP como função do tempo usando a equação (10.1.9). Mais detalhes dessa modelagem e exemplos resolvidos podem ser encontrados em [STAEHLE, 1992] e [GORMAN et al., 1994]. 
10.2. Técnica de modelagem aplicada ao modelo semi-empírico de dano por taxa de deformação de Garud e Gerber

O modelo semi-empírico de taxa de deformação de Garud e Gerber é essencialmente baseado na teoria em que a taxa de deformação antes da tensão é considerada a sua principal causa mecânica [GORMAN et al., 1994].

O principal parâmetro do modelo de Garud e Gerber é o de dano D que inclui os estágios de iniciação e propagação das trincas. Esse modelo parte de uma teoria semi-empírica da CST, de que se pode fazer uma analogia com o critério de Tresca referente à plasticidade [BEGLEY, 1990]. A sua base é a consideração da taxa de deformação ao invés da tensão como principal variável mecânica. Assim, a taxa de deformação é a força motriz num modelo de dano que permite predições quantitativas na vida útil dependente da CST. É definida uma função de dano mecânico $D$ associada a um componente submetido a um regime de taxa de deformação. Quando essa função de dano atinge um valor crítico, a CST é predita. O valor crítico da função de dano depende do material e meio considerados.

A equação (8.4.1) pode ser escrita como (10.2.1) (se $p=0,5$ por motivo de homogeneidade dimensional de $[D]=[$ comprimento]).

$$
D=\int_{0}^{t} f(\dot{e}) d t
$$

com t=tempo; è = taxa de deformação= de/dt ; $D=$ dano; $f=$ função de dano.

Note-se que o dano $D$, como definido nessa equação é uma função do tempo t. $O$ modelo pressupõe que quando $D$ atinge um valor crítico $D_{c}$, o defeito ocorre ou a trinca inicia. $D_{c}$ depende do material, microestrutura e meio.

A função de dano utilizada por Garud é da forma dada abaixo:

$$
f(\dot{e})=\alpha \dot{e}^{p}
$$

com a e p constantes para uma combinação específica de material-meio. A determinação experimental dessas duas constantes pode ser feita com o uso de 
"slow strain rate test" (SSRT) ou ensaio de taxa de deformação lenta (ETDL). Se $\dot{e}=$ constante, então das equações (10.2.1) e (10.2.2), segue:

$$
D_{c}=\alpha \dot{e}^{p_{t}}
$$

com $t_{f} 0$ tempo de surgimento do defeito.

Fazendo-se diversos ETDL com diferentes taxas de deformação èं se os correspondentes tempo de defeito $t_{f}^{i}$ pode-se estimar $p$ e a razão $D_{c} / \alpha$. Isto pode ser feito pela plotagem dos pontos de dados $\left(\dot{e}_{i}, t_{f}^{j}\right)$ num gráfico bilogarítmico ajustando-se uma linha reta através desses pontos. A constante $D_{c}$ é selecionada de modo a ter algum sentido físico e a é calculado do valor de $D_{c} e$ da razão $D_{c} / \alpha$. Por exemplo, $D_{c}$ pode ser alguma porcentagem determinada de espessura de parede que corresponde a um limite como tamanho mínimo de defeito CSTAP detectável em inspeção. A taxa de deformação atua dependendo das propriedades do material, geometria e carga. Numa situação onde se tenha tensão nominal constante atuando sobre a região de CSTAP, a taxa de deformação é devida principalmente à fluência. Para se obter o tempo de defeito predito pelo modelo de dano por taxa de deformação sob uma tensão conhecida, é necessário se obter a taxa de deformação em função do tempo. Assim é necessário um modelo constitutivo. Garud utiliza as equações constitutivas de Bodner Partom. No entanto, outras equações constitutivas podem ser utilizadas [GORMAN et al., 1994].

Para se estimar os parâmetros de Bodner Partom a partir de ensaios de taxa de deformação lenta (ETDL), deve-se seguir a rotina a seguir descrita [GORMAN et al., 1994].

As equações constitutivas de Bodner Partom permitem a estimativa da deformação e da taxa de deformação no tempo t, dada o histórico de tensões, ou inversamente, permitindo a estimativa da tensão como função do tempo, dado o histórico de tensões. São mostradas abaixo, (10.2.4) a (10.2.34).

Na equação (10.2.4), a taxa de deformação é dividida numa parte elástica e outra não elástica:

$$
\dot{\mathrm{e}}(\mathrm{t})=\dot{\mathrm{e}}=\dot{\mathrm{e}}_{\mathrm{e}}+\dot{\mathrm{e}}_{\mathrm{n}}
$$

Assim é necessário ajustar os dados experimentais de tensão verdadeira x deformação verdadeira de acordo com (10.2.4). Isso pode ser feito através da 
equação constitutiva de Bodner-Partom que assume (10.2.4), onde a tensão aplicada uniaxial $\sigma$ é relacionada com a taxa de deformação não elástica e $\dot{\mathrm{n}}_{\mathrm{n}}$ de acordo com (10.2.5).

$$
\dot{\mathrm{e}}_{\mathrm{n}}=\frac{2 \mathrm{D}_{0}}{\sqrt{3}} \exp \left[-\frac{1}{2}\left(\frac{\mathrm{Z}}{\sigma}\right)^{2 \mathrm{n}}\right]
$$

com $D_{0}$ uma constante, $n$ um parâmetro dependente da temperatura e $Z$ uma função relacionada com a resistência à deformação.

Quando o efeito de recuperação na temperatura do meio que é alta, é desprezível (isto é, quando não há uma recuperação lenta da estrutura cristalina por aniquilação das discordâncias e redistribuição ou relaxamento das tensões internas, conforme explicação de Lemaître e Chaboche [LEMAîTRE \& CHABOCHE, 1990]), a função de resistência à deformação $Z$ segue (10.2.6) [BEGLEY, 1990].

$$
Z=Z_{1}-\left(Z_{1}-Z_{0}\right) \exp \left(-m W_{p}\right)
$$

com a densidade de energia inelástica igual a (10.2.7) [BEGLEY, 1990].

$$
\mathrm{W}_{\mathrm{P}}=\int \sigma \mathrm{de}_{\mathrm{n}}
$$

Segundo Garud, as constantes dependentes da temperatura na equação acima podem ser escritas como:

$$
\begin{gathered}
n=a / T \\
m=m_{0} T+c_{0} \\
Z_{0}=Z_{1}\left(m_{1} T+c_{1}\right)
\end{gathered}
$$

Portanto as constantes do material na modelagem de Bodner-Partom são: $D_{0}, a$, b, $z_{1}, m_{1}, c_{1}, m_{0}$ e $c_{0}$.

Para uma taxa de deformação constante e inelástica $\dot{e}_{n}=R_{1}$, segue-se da equação (10.2.5) que a razão $\sigma / Z$ é constante, por exemplo igual a $C_{1}$, dado por (10.2.11). 


$$
\mathrm{C}_{1}=\left[2 \ln \left(2 \mathrm{D}_{\mathrm{o}} / \mathrm{R}_{1} \sqrt{ } 3\right)\right]^{-1 / 2 \mathrm{n}}
$$

Garud retira dos autores Merzer e Bodner citados em [GORMAN et al., 1994], a expressão (10.2.12) para a tensão em função da deformação inelástica quando a taxa de deformação plástica é constante.

$$
1 / \sigma=1 / \sigma_{s}+\left(1 / \sigma_{0}-1 / \sigma_{s}\right) \exp \left(-m \sigma_{s} e_{n}\right)
$$

$\operatorname{com} Z_{0}=$ valor inicial de $Z$ e:

$$
\begin{gathered}
\sigma_{\mathrm{s}}=\mathrm{C}_{1} \mathrm{Z}_{1} \\
\sigma_{0}=\mathrm{C}_{1} \mathrm{Z}_{0} \\
\mathrm{e}_{\mathrm{n}}=\mathrm{e}-\sigma / \mathrm{E}
\end{gathered}
$$

Assim precisa-se de no mínimo duas curvas de tensão versus deformação utilizando-se ETDL em diferentes temperaturas mas com mesma taxa de deformação plástica $\dot{e}_{n}=R_{1}$ para se estimar as constantes acima formuladas. A equação (10.2.12) é utilizada para estimar as constantes $\mathrm{m}, \sigma_{0}$ e $\sigma_{\mathrm{s}}$ em cada temperatura. A equação (2.16.2.12) pode ser linearizada como (10.2.16).

$$
\ln \left(1 / \sigma-1 / \sigma_{s}\right)=\ln \left(1 / \sigma_{0}-1 / \sigma_{s}\right)-m \sigma_{s} e_{n}
$$

e escrita na forma de equação linear

$$
y=A+B x
$$

com :

$$
\begin{gathered}
x=\sigma_{s} e_{n} \\
y=\ln \left(1 / \sigma-1 / \sigma_{s}\right) \\
A=\ln \left(1 / \sigma_{0}-1 / \sigma_{s}\right) \\
B=-m
\end{gathered}
$$


Notar que $\sigma_{\mathrm{s}}$ também é incógnita. Para calcular as constantes que ajustam uma determinada curva de tensão-deformação (SSRT), seleciona-se da curva vários pontos de dados de coordenadas genéricas $\left(\sigma, e_{n}\right)$ e se assume um valor para $\sigma_{s}$,calculando-se o coeficiente de correlação e as constantes A e B pelo método dos mínimos quadrados. Por tentativa e erro seleciona-se um valor para $\sigma_{\mathrm{s}}$ que maximiza o coeficiente de correlação. Esses resultarão nas constantes para a primeira temperatura $T_{1}$, isto é, $\sigma_{\mathrm{s} 1}, \sigma_{01}$ e $\mathrm{m}\left(\mathrm{T}_{1}\right)$. Repetindo-se o procedimento acima para a segunda curva de tensão-deformação numa temperatura diferente $\mathrm{T}_{2}$, com a mesma taxa de deformação plástica resultará noutro conjunto de constantes, isto é, $\sigma_{\mathrm{s} 2}, \sigma_{02}$ e $\mathrm{m}\left(\mathrm{T}_{2}\right)$.

As constantes $m_{0}$ e $c_{0}$ são calculadas pela equação (10.2.9) que permite uma estimativa de $m_{0}$ e $c_{0}$ através de um sistema de duas equações a duas incógnitas (10.2.22) e (10.2.23).

$$
\begin{aligned}
& \mathrm{m}\left(\mathrm{T}_{1}\right)=\mathrm{m}_{0} \mathrm{~T}_{1}+\mathrm{c}_{0} \\
& \mathrm{~m}\left(\mathrm{~T}_{2}\right)=\mathrm{m}_{0} \mathrm{~T}_{2}+\mathrm{c}_{0}
\end{aligned}
$$

Então:

$$
\begin{gathered}
m_{0}=\left[m\left(T_{2}\right)-m\left(T_{1}\right)\right] /\left(T_{2}-T_{1}\right) \\
c_{0}=m\left(T_{1}\right)-m_{0} T_{1}
\end{gathered}
$$

A constante a (equação 10.2.8) é calculada da razão $\sigma_{\mathrm{s} 2} / \sigma_{\mathrm{s} 1}$. Notar que por causa de $Z_{1}$ ser independente da temperatura, a razão $\sigma_{\mathrm{s} 2} / \sigma_{\mathrm{s} 1}$ é igual à razão $C_{1}\left(T_{2}\right) / C_{1}$ $\left(\mathrm{T}_{1}\right)$.

$$
\sigma_{\mathrm{s} 2} / \sigma_{\mathrm{s} 1}=\mathrm{C}_{1}\left(\mathrm{~T}_{2}\right) / \mathrm{C}_{1}\left(\mathrm{~T}_{1}\right)
$$

Das equações (10.2.8), (10.2.11) e (10.2.26) resulta (10.2.27).

$$
\sigma_{\mathrm{s} 2} / \sigma_{\mathrm{s} 1}=\left[2 \ln \left(2 \mathrm{D}_{\mathrm{o}} / \mathrm{R}_{1} \sqrt{ } 3\right)\right]^{-(\mathrm{T} 2-\mathrm{T} 1) / 2 \mathrm{a}}
$$

Linearizando (10.2.27) através de aplicação de logaritmos resulta a expressão (10.2.28). 


$$
\mathrm{a}=\left\{-\left(\mathrm{T}_{2}-\mathrm{T}_{1}\right) / 2\right\}\left\{\ln \left[2 \ln \left(2 \mathrm{D}_{\mathrm{o}} / \mathrm{R}_{1} \sqrt{ } 3\right)\right] / \ln \left(\sigma_{\mathrm{s} 2} / \sigma_{\mathrm{s} 1}\right)\right\}
$$

As constantes $m_{1}$ e $C_{1}$ são calculadas a seguir: seja $Z_{01} \circ$ valor de $Z_{0}$ para 0 ensaio a $T_{1}$ e $Z_{02}$ o valor correspondente para o teste na temperatura $T_{2}$. Segue da equação (10.2.14), as equações (10.2.29) e (10.2.30).

$$
\begin{aligned}
& Z_{01}=\sigma_{01} /\left(C_{1} T_{1}\right) \\
& Z_{02}=\sigma_{02} /\left(C_{1} T_{2}\right)
\end{aligned}
$$

Das equações (10.2.10), (10.2.29) e (10.2.30) resulta o sistema de duas equações (10.2.31) e (10.2.32) a duas incógnitas.

$$
\begin{aligned}
& Z_{01} / Z_{1}=m_{1} T_{1}+c_{1} \\
& Z_{02} / Z_{1}=m_{1} T_{2}+c_{1}
\end{aligned}
$$

sendo as constantes $m_{1}$ e $c_{1}$ obtidas de (10.2.33) e (10.2.34).

$$
\begin{gathered}
\mathrm{m}_{1}=\left(\mathrm{Z}_{02}-\mathrm{Z}_{01}\right) /\left[\mathrm{Z}_{1}\left(\mathrm{~T}_{2}-\mathrm{T}_{1}\right)\right] \\
\mathrm{c}_{1}=\left(\mathrm{Z}_{01} / \mathrm{Z}_{1}\right)-\mathrm{m}_{1} \mathrm{~T}_{1}
\end{gathered}
$$

Assim são obtidas as constantes do material na modelagem de Bodner-Partom: $D_{0}, a, b, Z_{1}, m_{1}, c_{1}, m_{0}$ e $c_{0}$. As equações acima podem ser dispostas numa planilha Microsoft Excel e serem rapidamente obtidos essas constantes.

Alguns cuidados devem ser tomados para executar os ETDL/SSRT e os cálculos equivalentes mostrados [GORMAN et al., 1994]:

1) Diferentes espécimes da mesma corrida de material a ser ensaiada à mesma temperatura e taxa de deformação proporcionará diferentes curvas tensão -deformação: essas diferenças são devidas à variabilidade nas propriedades locais dos espécimes e na imprecisão dos dispositivos de medição. Assim, recomenda-se que espécimes da mesma corrida de material sejam ensaiados em cada temperatura, de modo a se obter uma curva tensão-deformação média. Portanto, vários pontos de cada ensaio na mesma temperatura e taxa de 
deformação devem ser usados quando se calcula o ajuste dos parâmetros $\mathrm{m}, \sigma_{\mathrm{s}} \mathrm{e}$ $\sigma_{0}$ através do método dos mínimos quadrados;

2) É recomendado que os ETDL/SSRT sejam realizados até o máximo valor de deformação possível: isso melhorará a estimativa dos parâmetros.

Para se calcular a deformação elástica, deve-se considerar o seguinte: a função de resistência à deformação (10.2.6) pode ser escrita na sua forma diferencial no tempo como (10.2.35).

$$
D Z / d t=m(Z 1-Z) \sigma \dot{e}_{n}
$$

Retomando (10.2.4) integrada no tempo tem-se (10.2.36).

$$
e=e_{e}+e_{n}
$$

A deformação elástica está relacionada com a tensão pela Lei de Hooke:

$$
e_{e}=\sigma / E
$$

A tensão utilizada efetiva deve ser a obtida pela divisão da força aplicada pela área efetivamente solicitada. Essa área efetiva é a área inicial menos a redução em área causada pelo dano efetivo acumulado $D$, como calculado pela equação (10.2.1). Conseqüentemente, essa tensão efetiva $\sigma$ depende da tensão nominal $\sigma_{\text {nom }}$ e do dano acumulado $D$.

$$
\sigma=g_{1}(D) \sigma_{\text {nom }}
$$

com $g_{1}(D)$ a razão de áreas da seção tranversal inicial pela seção de área efetiva. Por exemplo, para um elemento plano de espessura $h$, sujeito à tensão e se 0 dano D for uma trinca de certa profundidade em cada lado, a seção inicial transversal será bh, sendo b a largura da amostra e a área efetiva transversal é b(h-2D). Nessa situação a função $g_{1}(D)$ é a seguinte: 


$$
g_{1}(D)=1 /(1-2 D / h)
$$

O efeito da redução de seção tranversal é importante no cálculo do tempo para atingir um dano de tamanho significativo. No entanto, para calcular o tempo de iniciação de trincas não há necessidade de incluir os seus efeitos de redução de área. Nessa situação a tensão efetiva é igual à tensão nominal e a função $g_{1}(D)=1$.

A constante a da equação (10.2.3) é considerada como sendo dependente da temperatura e é dada pela relação de Arrhenius:

$$
\alpha=\alpha_{0} \exp (-Q / R T)
$$

com $\alpha_{0}$ e $Q$ parâmetros dependentes da relação material-meio, $R$ a constante universal dos gases e T a temperatura absoluta.

É conveniente reescrever a equação (10.2.40) como (10.2.41).

$$
\alpha=\alpha_{\text {ref }} \exp \left[Q / R\left(1 / T-1 / T_{\text {ref }}\right)\right]
$$

com $\alpha_{\text {ref }} \mathrm{O}$ valor de $\alpha$ quando $\mathrm{T}=\mathrm{T}_{\text {ref }}$ que é a temperatura de referência.

As equações acima formam um sistema de equações diferenciais de primeira ordem como demonstrado a seguir.

Derivando-se a equação (10.2.38) em relação ao tempo, tem-se (10.2.42).

$$
\mathrm{d} \sigma / \mathrm{dt}=\mathrm{g}_{1} \mathrm{~d} \sigma_{\mathrm{nom}} / \mathrm{dt}+\mathrm{dD} / \mathrm{dtg}_{2} \sigma_{\mathrm{nom}}
$$

com $g_{2}=\mathrm{dg}_{1} / \mathrm{dD}$.

Derivando as equações (10.2.36) e (10.2.37) tem-se (10.2.43).

$$
\mathrm{de} / \mathrm{dt}=(1 / \mathrm{E}) \mathrm{d} \sigma / \mathrm{dt}+\mathrm{de} \mathrm{e}_{\mathrm{n}} / \mathrm{dt}
$$

Das equações (10.2.42) e (10.2.43) resulta (10.2.44). 


$$
\mathrm{de} / \mathrm{dt}=(1 / \mathrm{E}) \mathrm{g}_{1} \sigma_{\mathrm{nom}}+(\mathrm{dD} / \mathrm{E}) \mathrm{g}_{2} \sigma_{\mathrm{nom}}+\mathrm{de}_{\mathrm{n}} / \mathrm{dt}
$$

Das equações (10.2.1) e (10.2.2) resulta (10.2.45).

$$
\mathrm{dD} / \mathrm{dt}=\alpha \dot{e}^{\mathrm{p}}
$$

Das equações (10.2.44), (10.2.45) e (10.2.5) resulta (10.2.46).

$$
\mathrm{de} / \mathrm{dt}=(1 / \mathrm{E}) \mathrm{g}_{1} \mathrm{~d} \sigma_{\mathrm{nom}} / \mathrm{dt}+\left(\alpha \dot{e}^{\mathrm{p}} / \mathrm{E}\right) \mathrm{g}_{2} \sigma_{\mathrm{nom}}+2 \mathrm{D}_{0} / \sqrt{3} \exp \left[-0,5(Z / \sigma)^{2 \mathrm{n}}\right]
$$

deve-se notar que esta última equação não pode ser solucionada por um valor de è numa forma fechada para um valor arbitrário de $\mathrm{p}$. Experimentos conduzidos por Begley [BEGLEY, 1990] mostraram que $p=0,5$ é um bom ajuste geral para CSTAP da liga 600 . No caso de $p=0,5$, a equação (10.2.46) pode ser resolvida para é numa forma fechada. Isso é mostrado a seguir.

Seja y uma variável auxiliar definida como (10.2.47).

$$
y=\dot{e}^{0,5}
$$

Assim a equação (10.2.46) pode ser escrita como uma equação de segundo grau em y:

$$
y^{2}-b y+c=0
$$

com:

$$
\begin{gathered}
b=(\alpha / E) g_{2} \sigma_{n o m} \\
C=(-1 / E) g_{1} d \sigma_{n o m} / d t-2 D_{0} / \sqrt{ } 3 \exp \left[-0,5(Z / \sigma)^{2 n}\right]
\end{gathered}
$$

O valor de y é calculado pela expressão (10.2.51).

$$
y=\left(b+\sqrt{ } b^{2}-4 c\right) / 2
$$


Uma vez que è não é negativo, só a raiz positiva é utilizada na equação (10.2.51).

Um sistema de equações diferenciais de primeira ordem é assim obtido:

$$
\begin{gathered}
d e / d t=y^{2} \\
d \sigma / d t=g_{1} d \sigma_{\text {nom }} / d t+\alpha y g_{2} \sigma_{\text {nom }} \\
d Z / d t=m\left(Z_{1}-Z\right) \sigma 2 D_{0} / \sqrt{ } 3 \exp \left[-0,5(Z / \sigma)^{2 n}\right] \\
d D / d t=\alpha y
\end{gathered}
$$

Devido ao fato de que o sistema de equações acima descreve o tempo de evolução das variáveis dependentes $(\varepsilon, \sigma, Z$ e D), é necessário indicar as condições iniciais e a variação da variável independente $\sigma_{\text {nom }}$ como função do tempo. Assumindo-se simplesmente que é uma tensão nominal que cresce de zero até um valor $\sigma_{\text {nomx }}$ numa razão constante $r$ e aí estabiliza neste valor. Matematicamente a tensão nominal é assumida como sendo (10.2.56).

$$
\sigma_{\text {nom }}=\left\{\text { rt para } \mathrm{t}<\mathrm{t}_{\mathrm{x}}\right\}, \sigma_{\text {nom }}=\left\{\sigma_{\text {nomx }} \text { para } \mathrm{t} \geq \mathrm{t}_{\mathrm{x}}\right\}
$$

com $t=0$ tempo, $t_{x}=\sigma_{\text {nomx }} / r, r=$ razão de variação de tensão selecionada.

As condições iniciais são dadas pelos parâmetros: $\varepsilon(0)=0 ; \sigma(0)=0 ; Z(0)=Z_{0}$ (parâmetro do modelo de Bodner-Partom); $\mathrm{D}(0)=0$.

O sistema de equações diferenciais acima é numericamente integrável utilizando o método de Runge-Kutta com controle adaptável de incremento, [PRESS et al., 1989]. Qualquer subrotina adequada que possa resolver os problemas de valor inicial descritos por um sistema de equações diferenciais de primeira ordem, pode ser utilizado para resolver o problema acima. Press e outros autores [PRESS et al., 1989] apresentam várias subrotinas para problemas de valor inicial. A subrotina ODEINT, por exemplo, pode ser utilizada. 
Uma vez sendo o sistema acima integrado, são calculados os valores numéricos das variáveis dependentes $(D, Z, \sigma, e)$ como função do tempo. Conseqüentemente, o tempo de falha pode ser calculado pelo valor encontrado do tempo quando $D$ é igual a $D_{c}$.

O procedimento acima descrito para o cálculo do tempo de início de defeito pode ser repetido para diferentes valores da tensão nominal $\sigma_{\text {nomx }}$.

Obtém-se assim a curva de tempo de início de defeito como função da tensão.

Em resumo, Garud e Gerber formalizaram o conceito de taxa de deformação como força motriz no modelo de dano que permite previsões quantitativas da vida sob CST através de uma função de dano definida como sendo dependente do regime de taxa de deformação a que foi submetido um componente. A CST é predita quando a função de dano atinge um valor crítico. $O$ valor crítico do dano depende tanto do material quanto do ambiente a que o componente está submetido. A principal vantagem do modelo de Gerber e Garud é que não é necessário distinguir entre a iniciação e a propagação da trinca [BEGLEY, 1990].

Exemplos resolvidos dessa modelagem podem ser encontradas em [GORMAN et al., 1994]. 
10.3. Técnica de modelagem aplicada ao modelo de dano por taxa de deformação simplificado de Garud

Com relação ao modelo de dano por taxa de deformação de Garud e Gerber existe uma modelagem simplificada de tempo de iniciação de trinca desenvolvida através de diversas aplicações de engenharia. Esse modelo simplificado tem três parâmetros: resistência mecânica, resistência do material à CST e energia aparente de ativação. Esses parâmetros são deduzidos para quatro condições do material: baixa temperatura de recozimento, alta temperatura de recozimento, tratado termicamente e encruado. Para o tempo de iniciação de uma pequena trinca, foi demonstrado que os efeitos da tensão, temperatura e microestrutura são bem caracterizados pela modelagem simplificada. Como dito anteriormente, a base do modelo de dano por taxa de deformação é a ruptura local do filme passivo, mesmo seguida de depassivação - repassivação e sua interação com a deformação local, impulsionando a evolução de dano por CST. Essa nova modelagem, desenvolvida em tubo de parede fina com espessura de parede de cerca de $1 \mathrm{~mm}$, sob tensão uniaxial $\sigma$ e com o tempo de iniciação de falha $t_{i}$ definido como a falha nesse tubo de parede fina, pode ser expressa na equação (10.3.1) e segue a seguinte evolução retirada de [GARUD, 1997].

$$
t_{i}=\alpha_{i} \exp \left(Q_{i} / R T\right) \cdot \ln \left[A\left(\sigma_{y} / \sigma\right)\right]
$$

com $t_{i}=$ tempo de iniciação, $\alpha_{i}=$ parâmetro de resistência à CST (dimensão de tempo); $Q_{i}=$ energia de ativação aparente; $R=$ constante universal dos gases $(1,987 \mathrm{cal} / \mathrm{mol}) ; T=$ temperatura absoluta em K; $A=$ parâmetro dependente da interação material-meio; $\sigma_{y}=$ resistência ao escoamento do material na temperatura ambiente e $\sigma=$ tensão aplicada uniforme e axial.

Ao primeiro fator da expressão (10.3.1), dá-se a denominação de $\lambda$.

$$
\lambda=\alpha_{i} \exp \left(Q_{i} / R T\right)
$$

e

$$
t_{i}=\lambda \ln \left[A\left(\sigma_{Y} / \sigma\right)\right]
$$


sendo $\lambda$ também um parâmetro dependente da interação material-meio (dimensão de tempo): nele está envolvido o efeito da microestrutura do material na CST relacionado com o tempo de falha no nível da tensão de escoamento.

$$
\lambda=\mathrm{t}_{\mathrm{Y}} / \ln \mathrm{A}
$$

Para o nível de tensão de $\sigma_{y}$, a expressão de $t_{i}$ em (10.3.3) toma a forma (10.3.5).

$$
t_{Y}=\left(\alpha_{i} \ln A\right) \exp \left(Q_{i} / R T\right)
$$

As etapas dessa modelagem aplicadas à liga 600 em alta temperatura podem ser resumidas de acordo com o que segue:

1) Para a temperatura fixa de $325^{\circ} \mathrm{C}$, os valores preditos de $t_{i}$ em vários níveis de tensão foram utilizados para estimar os parâmetros $\lambda$ e $A$ utilizando-se a equação (10.3.3);

2) Para a tensão fixada de escoamento à temperatura ambiente, os valores preditos de $t_{i}$ em várias temperaturas foram utilizados para determinar $Q_{i}$ e $\alpha_{i} \ln A$ utilizando-se a equação (10.3.5);

3) Utilizando-se $\alpha_{i} \ln A$ (etapa 2) e A (etapa 1), o valor de $\alpha_{i}$ é estimado para cada condição do material sob CSTAP;

4) Para confirmar a consistência interna, $\alpha_{i}$ (da etapa 3 ) e $Q_{i}$ (da etapa 2) são utilizados na equação (10.3.2) para estimar os valores do parâmetro $\lambda$ na etapa 1. Esses devem estar em bom acordo um com o outro confirmando a validade da forma funcional proposta nas equações (10.3.2) e (10.3.3).

Para se verificar a validade geral desse modelo simples, isto é, a aderência da equação (10.3.1), os resultados de simulação para todas as tensões e temperaturas foram utilizados para derivar os valores melhores ajustados por regressão não linear dos parâmetros do modelo $A, \alpha_{i}$ e $Q_{i}$ para duas condições do material. Ou seja, os seguintes passos são seguidos para uma dada condição do material:

1) Os valores de $t_{i}$ são estimados utilizando simulações do modelo em várias tensões e temperaturas; 
2) Todos os valores de $t_{i}$ são melhor ajustados juntos utilizando a equação (10.3.1) como um ajuste por regressão não linear e multivariável, para derivar os três parâmetros $A, \alpha_{i}$ e $Q_{i}$ do modelo simplificado representado por essa equação.

A seguir são mostrados alguns resultados dessa modelagem nas Tabelas 10.1 e 10.2 e Figuras 10.1 e 10.2 . 
Tabela 10.1. Características microestruturais e propriedades de quatro condições de material liga 600 para as quais foram feitas simulações do modelo de dano por taxa de deformação e dependência de tensão [GARUD, 1997].

\begin{tabular}{|c|c|c|c|c|c|}
\hline \multirow[t]{3}{*}{$\begin{array}{l}\text { Condição } \\
\text { do material }\end{array}$} & \multirow[t]{3}{*}{$\begin{array}{l}\text { Características } \\
\text { microestruturais }\end{array}$} & \multicolumn{2}{|c|}{$\begin{array}{l}\text { Escoamento/resistência } \\
\text { estimados à temperatura } \\
\text { ambiente }\end{array}$} & \multicolumn{2}{|c|}{$\begin{array}{l}\text { Parâmetros do modelo } \\
\text { equação (10.3.3) }\end{array}$} \\
\hline & & Escoamento $\left(\sigma_{\mathrm{Y}}\right)$ & Resistência $\left(\sigma_{\mathrm{R}}\right)$ & A & $\lambda$ \\
\hline & & $\mathrm{MPa}$ & $\mathrm{MPa}$ & - & dias \\
\hline MA & $\begin{array}{l}\text { Laminado e recozido à } \\
\text { baixa temperatura, } \\
\text { pequeno tamanho de } \\
\text { grão, muitos carbonetos } \\
\text { intragranulares e } \\
\text { poucos intergranulares. }\end{array}$ & 405,48 & 718 & 1,791 & 1518 \\
\hline HTMA & $\begin{array}{l}\text { Recozimento final à alta } \\
\text { temperatura, grande } \\
\text { tamanho de grão, } \\
\text { contornos de grãos com } \\
\text { precipitados } \\
\text { carbonetos. }\end{array}$ & 386,16 & 710 & 1,733 & 6880 \\
\hline TT & $\begin{array}{l}\text { Tratado termicamente à } \\
\text { cerca de } 710^{\circ} \mathrm{C} \text {, } \\
\text { carbonetos } \\
\text { intergranulares } \\
\text { uniformes e na maioria } \\
\text { dos contornos. }\end{array}$ & 386,16 & 710 & 1,730 & 15389 \\
\hline CW & $\begin{array}{l}\text { Laminado e recozido e } \\
\text { expandido com roletes } \\
\text { até a condição } \\
\text { trabalhada a frio. }\end{array}$ & 559,25 & 805 & 1,198 & 3808 \\
\hline
\end{tabular}




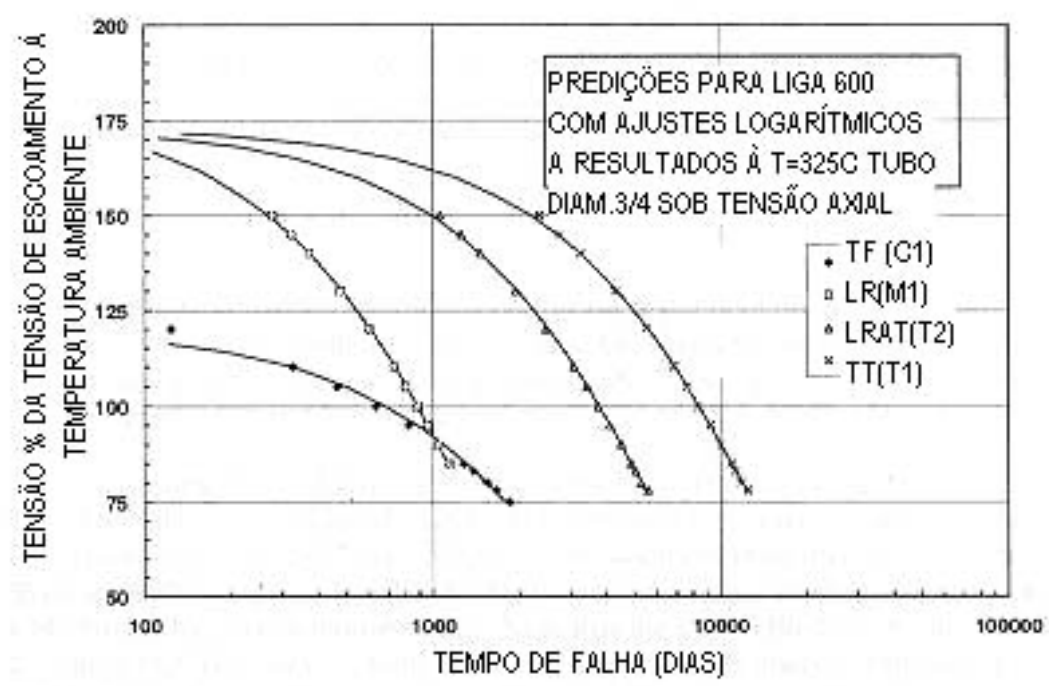

Figura 10.1. Relação simplificada para a dependência com a tensão do tempo de iniciação para a CSTAP sugerida pelas estimativas do modelo de dano por taxa de deformação para quatro condições de material da liga 600 [GARUD, 1997].

Garud mostra em seu trabalho os gráficos comparativos entre os resultados da vida prevista utilizando o modelo completo e a vida prevista utilizando o modelo simplificado: os valores são praticamente coincidentes.

Esse pesquisador ainda faz a validação da sua modelagem através de dados da literatura, estabelecendo correlações para os parâmetros de modelo através de regressões baseadas no método dos mínimos quadrados: são montadas tabelas de comparação dos resultados experimentais da literatura e da modelagem desenvolvida, resultados da regressão para o modelo do parâmetro $A$ em termos de propriedades de resistência mecânica e temperatura, comparação gráfica da modelagem simplificada e dados de ensaios da literatura , comparação da estimativa de tempos de iniciação de falha na condição do nível de tensão de escoamento entre a modelagem simplificada e ensaios publicados na literatura, comparação da estimativa de tempos de falha com todos os dados disponíveis entre a modelagem simplificada e ensaios publicados na literatura, correlação derivada entre parâmetro $A$ e razão de tensões $\sigma_{R} / \sigma_{Y}$, gráficos comparativos entre tempos de falha /tempos de iniciação com dados da literatura e das previsões da modelagem simplificada utilizada, versus $\sigma / \sigma_{Y}$ para material encruado ou seja, com limite de escoamento aumentado através de deformação. 
Garud parece ser assim o único autor que faz uma avaliação exaustiva de seu modelo e seu trabalho é uma fonte valiosa e importante de dados e referências para a CSTAP da liga 600 em alta temperatura.

Tabela 10.2. Avaliação da dependência com a temperatura derivada dos tempos de falha estimados através do modelo de dano por taxa de deformação constante para as falhas por CSTAP para as condições de liga 600 da Tabela 10.1 [GARUD, 1997].

\begin{tabular}{ccccc}
\hline \hline & \multicolumn{3}{c}{$\begin{array}{c}\text { Estimativa do modelo de dano por taxa de } \\
\text { deformação para o tempo de iniciação em dias } \\
\text { na tensão }\end{array}$} \\
\cline { 2 - 5 }$\sigma_{y}$ conforme Tabela 10.1 para a \\
respectiva condição.
\end{tabular}

Deve-se ressaltar finalmente que esse autor sugere outras avaliações como ele fez aqui, para outros conjuntos de dados, mesmo para um nível de tensões único e bem conhecido com informações de propriedades mecânicas. $E$ principalmente em outras condições de água primária - o que significa diferentes potenciais e $\mathrm{pH}$ - bem como outros níveis de encruamento. 


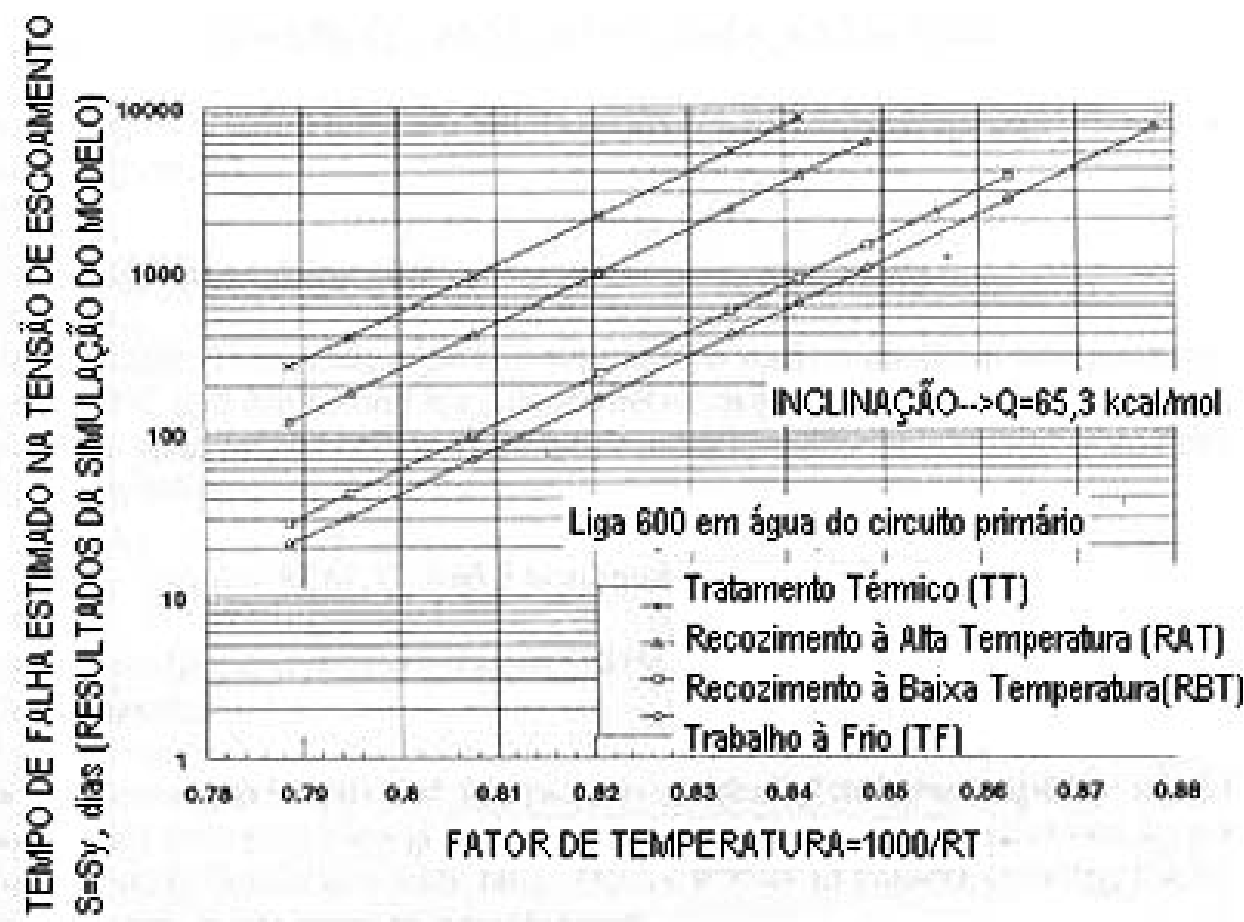

Figura 10.2. Relação simplificada para a dependência com a temperatura do tempo de iniciação para a CSTAP sugerida pelas estimativas do modelo de dano por taxa de deformação sob tensão constante para quatro condições de material da liga 600 [GARUD, 1997].

10.4. Técnica de modelagem aplicada a ensaios de taxa de deformação lenta (constante) de Santarini

Santarini e colaboradores desenvolveram uma técnica de modelagem de trincas de CSTIG, a partir de ensaios de taxa de deformação lenta e constante (ETDL) em corpos de prova de liga 600 e liga 690. Esses corpos de prova seguem a convenção geométrica mostrada na Figura 10.3, e os dados dos experimentos geram uma informação morfológica que é expressa pela distribuição de profundidades de traço da trinca determinada em sua seção longitudinal. Santarini mostra que essa informação pode ser deconvoluída para gerar uma modelagem da iniciação e da velocidade de propagação da trinca explicada a seguir [SANTARINI, 1989]. 


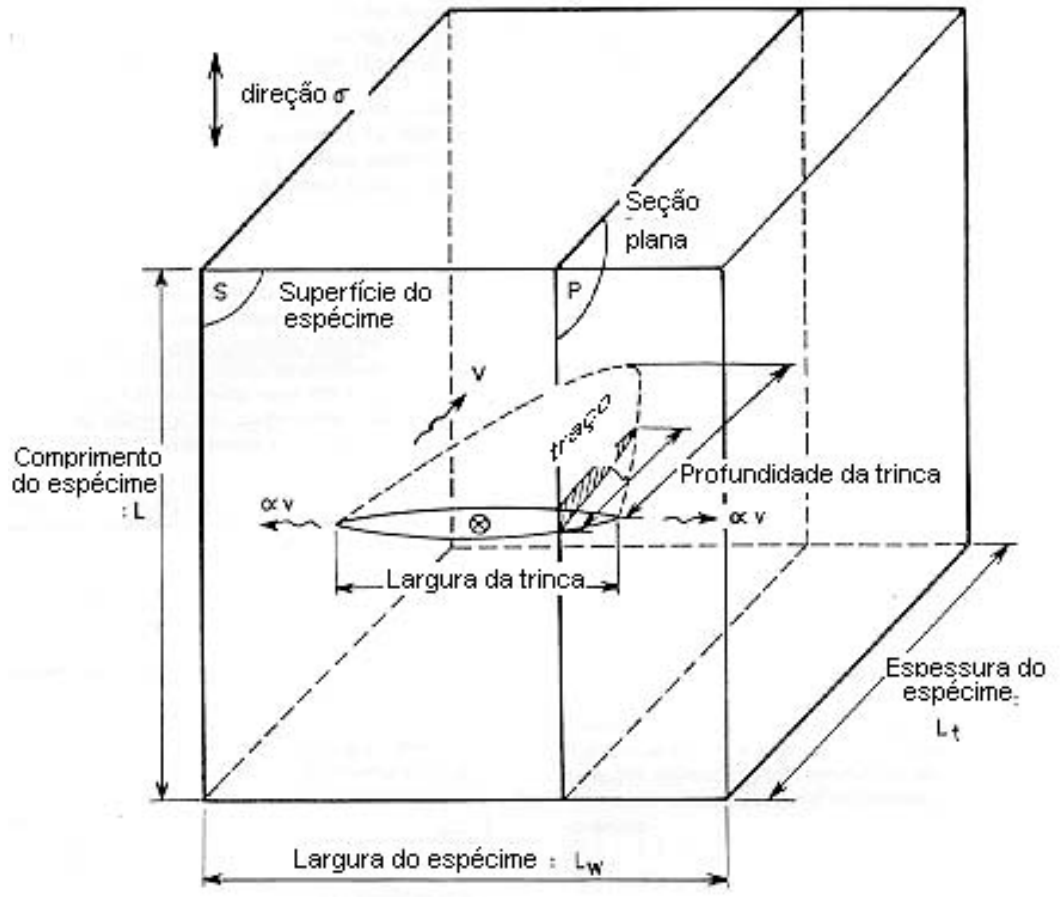

Figura 10.3. Convenção geométrica aplicável a corpos de prova de ensaios de taxa de deformação constante [SANTARINI, 1989].

Para se explicar como esse método funciona, é necessário antes introduzir alguns conceitos. A função $\mathrm{N}(\mathrm{I}, \mathrm{T})$ caracteriza a distribuição de profundidade do traço da trinca, que é o número de traços de profundidade maior do que I que aparece num corpo de prova calibrado de comprimento $L_{0}$ num tempo T (Figura 10.3). Essa função é o dado experimental primário para a determinação dos outros parâmetros e se mostra que ela contém toda a informação necessária para a modelagem: no entanto essa informação precisa ser decodificada, isto é, deconvoluída. Para isso são necessárias algumas hipóteses básicas sobre a morfologia da trinca e duas considerações estatísticas. O autor postula que a probabilidade de iniciação da trinca é análoga a da desintegração radioativa com uma meia-vida de abertura de contornos de grão igual a In $2 / p$, sendo $p$ a probabilidade de iniciação de trinca por unidade de tempo. Portanto para o caso geral de ETDL, $p=p(t)$, ou seja função do tempo. Para a velocidade de propagação de trinca, o autor mostra que ela é uma função de dois parâmetros $t$ e $\mathrm{l}: \mathrm{v}=\mathrm{v}(\mathrm{t}, \mathrm{l})$. $\mathrm{O}$ tempo de iniciação $\mathrm{t}_{\mathrm{i}}$ para a trinca, considerando-se T o tempo total do ETDL para atingir a profundidade I, é uma função de I e T que pode ser escrita como: 


$$
P\left[t_{i}(I, T)\right]=\left[-\varepsilon_{0}^{2} / 2 \alpha \lambda_{0} L_{0}\right] .[\partial N(I, T) / \partial I]
$$

com $\mathrm{P}$ sendo a fração de contornos de grãos superficiais disponíveis que no tempo t realmente iniciaram trincas (ou seja a integral com relação ao tempo da probabilidade de iniciação de trinca por unidade de tempo), $\varepsilon_{0} \circ$ tamanho médio de grão, a a razão entre a meia largura da trinca e sua profundidade, $\lambda_{0}$ a fração do numero total de contornos de grãos superficiais disponíveis para fratura.

Essa expressão pode ser simplificada considerando-se a condição de contorno de que o tempo de iniciação da trinca após o tempo final $\mathrm{T}$ tem profundidade nula, isto é, $\mathrm{t}_{\mathrm{i}}(0, \mathrm{~T})=\mathrm{T}$ :

$$
\left.P(T)=\left[-\varepsilon_{0}^{2} / 2 \alpha \lambda_{0} L_{0}\right] .[\partial N(0, T) / \partial]\right]
$$

A função $P$ é assim diretamente relacionada com a inclinação do gráfico de $N(I, T)$ para $l=0$. Por derivação então se obtém:

$$
p(T)=\left[-\varepsilon_{0}^{2} / 2 \alpha \lambda_{0} L_{0}\right] \cdot\left[\partial^{2} N(0, T) / \partial I \partial T\right]
$$

Observa-se que a função de iniciação $p$ é proporcional à segunda derivada da função experimental $\mathrm{N}(\mathrm{l}, \mathrm{T})$. Para se obter a função $p(t)$, deve-se simplesmente substituir $t$ por $T$ na função experimental da equação (10.4.3) obtida em ETDL interrompidos, isto é, antes que ocorra a ruptura final. No caso em que p é constante nos ETDL, a seguinte relação é obtida:

$$
p=\left[-\varepsilon_{0}^{2} / 2 \alpha \lambda_{0} L_{0}\right] \cdot[\partial \mathrm{N}(0, T) / \partial l]
$$

Considerações similares sobre a velocidade de propagação de trinca, levam à seguinte relação:

$$
v(l, T)=-\left(-\partial^{2} N / \partial \mid \partial T\right) /\left(\partial^{2} N /\left.\partial\right|^{2}\right)
$$

Portanto, a substituição de $t$ por $\mathrm{T}$ nas derivadas parciais da função experimental $\mathrm{N}(\mathrm{I}, \mathrm{T})$, dá diretamente a velocidade de propagação, $\mathrm{v}(\mathrm{I}, \mathrm{T})$. 
Outra função utilizada é $M(I, T)$ ou o número de trincas por unidade de largura de profundidade maior do que $\mathrm{I}$.

$$
M(I, T)=[-1 / 2 \alpha] \cdot[\partial \mathrm{N}(I, T) / \partial I]
$$

Nota-se que $M(I, T)$ e $N(I, T)$ são relacionadas pela derivação. Ambas as funções são necessariamente positivas e decrescentes com relação a I. A primeira e a segunda derivada de $\mathrm{N}$ para $\mathrm{T}$ constante são assim respectivamente negativa e positiva. A função $\mathrm{N}$ precisa também satisfazer as seguintes condições de contorno:

$$
\mathrm{N}\left(\mathrm{I}_{\max }, \mathrm{T}\right)=0 \text { e } \partial \mathrm{N}\left(\mathrm{I}_{\max }, \mathrm{T}\right) / \partial \mathrm{l}=0
$$

sendo $I_{\max }$ a profundidade máxima da trinca ou do traço da trinca [SANTARINI, 1989].

Outras relações importantes derivadas de $\mathrm{N}(\mathrm{I}, \mathrm{T})$ são os chamados parâmetros de dano pois caracterizam quantitativamente os diferentes aspectos do dano da CSTIG causada no ETDL:

$$
A(T)=\left(1 / L_{0}\right) \cdot \int_{0}^{I \max (T)} N(I, T) d l
$$

define a área total da trinca por área de superfície no tempo final T.

$$
I_{c}(T)=-N(0, T) /[\partial N(0, T) / \partial \mid]
$$

define a profundidade média da trinca no tempo final $\mathrm{T}$.

$$
\mathrm{I}_{\mathrm{t}}(\mathrm{T})=\int_{0}^{\operatorname{lmax}(\mathrm{T})} \mathrm{N}(\mathrm{I}, \mathrm{T}) \mathrm{d} / \mathrm{N}(0, \mathrm{~T})
$$

define a profundidade média do traço da trinca no tempo final $\mathrm{T}$.

Resumindo, o ponto chave desta modelagem é a existência de uma relação biunívoca entre a função $\mathrm{N}(\mathrm{I}, \mathrm{T})$ determinada por uma série de ETDL interrompidos, todos efetuados com a mesma taxa de deformação, e o par de funções $p(t)$ e $v(I, T)$ caracterizando o comportamento da trinca em qualquer um desses ETDL. As equações (10.4.3) e (10.4.5) proporcionam os meios de cálculo 
de $p(t)$ e $v(l, t)$ a partir de $N(l, t)$. Reciprocamente supostas as condições mecanísticas baseadas em resultados de testes extras, as funções $p(t)$ e $v(l, t)$ assumidas como sendo conhecidas, a solução da equação diferencial $d y / d t=v(y, t)$ resulta em $\mathrm{t}_{\mathrm{i}}(\mathrm{I}, \mathrm{T})$; então a partir da equação (10.3.1) é possível calcular $\partial \mathrm{N}(\mathrm{I}, \mathrm{T}) / \partial \mathrm{l}$ e finalmente chegar a $\mathrm{N}(\mathrm{I}, \mathrm{T})$ por integração. Santarini ressalta que nem sempre é fácil de achar $\mathrm{N}(\mathrm{I}, \mathrm{T})$ sugerindo um método iterativo.

Uma grande vantagem desse método de modelagem é que ele pode ser dividido em quatro níveis independentes, sendo que o primeiro nível já é bastante útil; a partir desse, vai-se aperfeiçoando a modelagem até o nível quatro:

$1^{0}$ nível - Caracterização dos ETDL interrompidos: as funções encontradas nesse nível são puramente empíricas, caracterizando o comportamento da trinca numa série de ensaios interrompidos todos feitos com a mesma taxa de deformação.

$2^{0}$ nível -Caracterização integral dos ETDL interrompidos: as funções encontradas nesse nível caracterizam os ensaios feitos com diferentes taxas de deformação num determinado meio, sendo funções também empíricas.

$3^{0}$ nível-Caracterização intrínseca dos parâmetros de trinca obtidos nos ETDL interrompidos: as funções encontradas são funções de parâmetros mecânicos e/ou morfológicos. Por exemplo, a taxa de deformação é constante, o alongamento é proporcional ao tempo, a tensão média é função de potencia do tempo, o fator de intensidade de tensão é função de l e t, etc. Nesse nível é possível caracterizar plenamente a trinca numa dada condição físico-química e fazer predições em qualquer condição mecânica e não somente naquelas dos ETDL. Deve-se ressaltar que a passagem do $2^{0}$ nível para o $3^{0}$ nível exige uma interpretação do mecanismo a ser adotado e não simplesmente uma dedução.

$4^{4}$ nível-Caracterização da dependência dos parâmetros intrínsecos de trinca obtidos nos ETDL com os fatores físico- químicos: ambientais (temperatura, concentração de íons, etc) e metalúrgicos (composição da liga, tratamento térmico, etc). Nesse estágio obtém-se a modelagem completa para o comportamento da trinca de CSTIG. 
Cada passagem de nível conforme descrito, pode exigir a execução de mais ensaios, podendo estes duplicarem ou triplicarem em número desde o estágio inicial.

Santarini consolida seu método, através da pesquisa dos domínios de validade, feita com testes de hipóteses, como comprovar se a fração de contornos de grão superficiais são uniformemente distribuídos ou qual a influência da variação das dimensões dos grãos durante a deformação.

O pesquisador dá um exemplo semelhante com o material e meio que se estudam nesta Tese: liga 600 industrial, laminada e recozida entre $960^{\circ} \mathrm{C}$ e $1000^{\circ} \mathrm{C}$, imersa em água do circuito primário de RAP a $360^{\circ} \mathrm{C}$ com a seguinte formulação: $2 \mathrm{mg} \cdot \mathrm{kg}^{-1} \mathrm{Li}(\mathrm{LiOH}) ; 1000 \mathrm{mg} \cdot \mathrm{kg}^{-1} \mathrm{~B}\left(\mathrm{H}_{3} \mathrm{BO}_{3}\right) ; 0,05 \mathrm{MPa} \mathrm{H}_{2}$ à temperatura ambiente resultando numa concentração de cerca de $10^{-2} \mathrm{~mol} \mathrm{~kg}^{-1} \mathrm{na}$ água liquida a $360^{0} \mathrm{C}$. As taxas de deformação utilizadas foram de $10^{-7} \mathrm{~s}^{-1} ; 2,5.10^{-7}$ $\mathrm{s}^{-1} ; 5.10^{-7} \mathrm{~s}^{-1} ; 7,5.10^{-7} \mathrm{~s}^{-1}$ e $10^{-6} \mathrm{~s}^{-1}$. Os testes interrompidos foram feitos com $2,5.10^{-7} \mathrm{~s}^{-1}$. Para o primeiro nível de modelagem, obteve-se o seguinte par de funções:

$$
\begin{array}{ll}
N=N_{2}\left(1-I / I_{2}\right)^{n}+N_{3} & \text { para I menor do que } I^{*} \\
N=N_{1}\left(1-I / I_{1}\right)^{n} & \text { para I maior do que } I^{*}
\end{array}
$$

com $n=4$ e valor de transição do parâmetro $l=I^{*}$ entre 40 e $70 \mu m$.

O pesquisador enfatiza que foram feitas diversas tentativas de ajuste para se achar essas funções.

Na Figura 10.4 é ilustrada a qualidade desse ajuste: as curvas são calculadas por valores médios de $\mathrm{N}$ e os círculos representam determinações extremas experimentais, através das quais é feito um ajuste estatístico. Quando não são misturados, esses círculos são ligados por segmentos de reta verticais. 


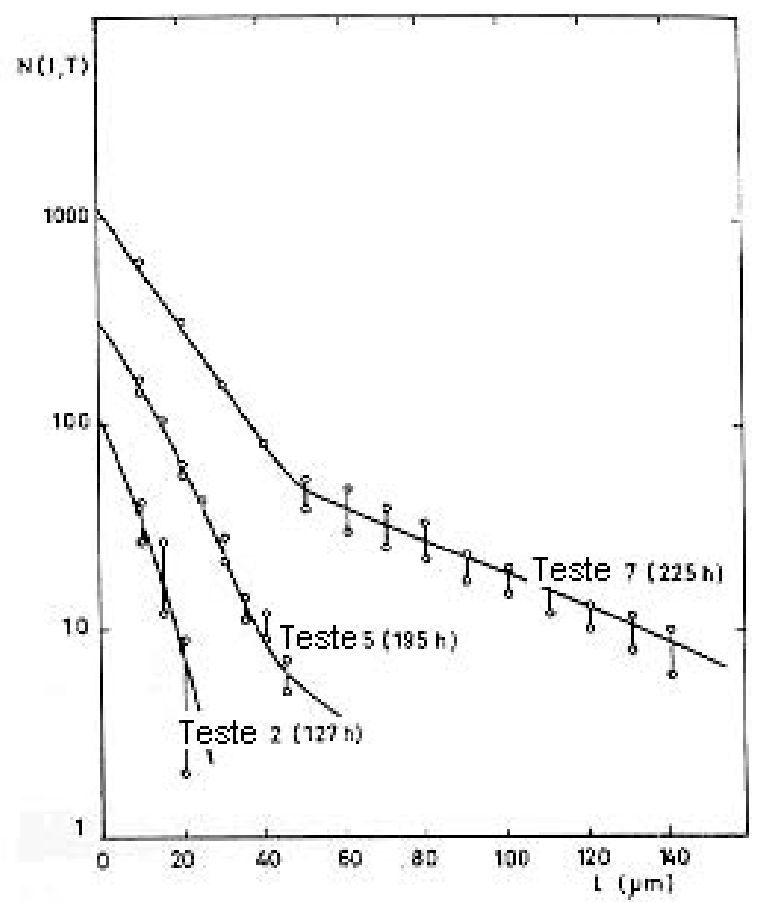

Figura 10.4. Algumas distribuições de profundidade de traço a partir de ensaio de corpos de prova por taxa de deformação constante è $=2,5 \cdot 10^{-7} \mathrm{~s}^{-1}$ [SANTARINI, 1989].

Um problema apontado pelo autor é o espalhamento ("scattering") provocado pelas irregularidades superficiais das amostras que são retiradas de materiais industriais: pode haver dificuldades para o ajuste até que, por exemplo, a equação (10.4.12) torne-se inadequada para a deconvolução de $N(I, T)$ [SANTARINI, 1989].

Para o quarto e último nível de modelagem, Santarini obteve o seguinte par de funções:

$$
\begin{gathered}
p(t)=1 / t_{00}\left(\sigma / \sigma^{*}\right)^{\top} \\
v(I, T)=u_{00} \cdot \dot{e}^{v} H\left(I^{*}-I\right)+u_{10} \cdot \dot{e}^{v} H\left(I^{*}-I\right)
\end{gathered}
$$

com parâmetro intrínseco de iniciação $t_{00} \approx 43$ horas; constante $\sigma^{*} \approx 1600 \mathrm{MPa}$; expoente $\mathrm{T} \approx 5$; parâmetro intrínseco de propagação $u_{00} \approx 9,6 \mu \cdot h^{-1}$; expoente $v \approx 1 / 2$; profundidade da camada superficial $I^{*} \approx 60 \mu \mathrm{m}$ e parâmetro intrínseco de propagação $\mathrm{u}_{10} \approx 160 \mu \cdot \mathrm{h}^{-1} ; \mathrm{H}=\mathrm{H}(\mathrm{x})$ é a função de Heaviside, ou seja, $H(x)=0$ para $x<0 ; H(x)=1$ para $x>0$. 
Na Figura 10.5 é ilustrado um resultado da modelagem para a função $\mathrm{N}(\mathrm{I}, \mathrm{T})$ versus I .

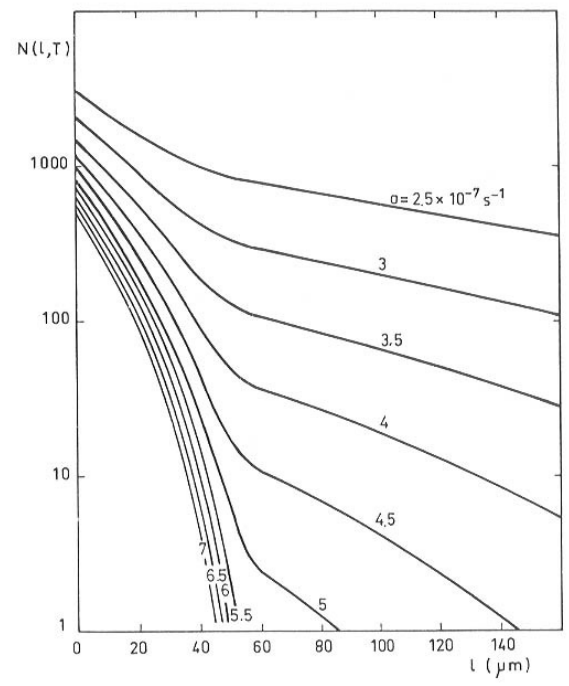

Figura 10.5. ETDL feitos até a ruptura com diferentes taxas de deformação: representado um conjunto de curvas computadas N(I,T) [SANTARINI, 1989].

É ainda importante ressaltar o seguinte:

1) A relação (10.4.14) entre a velocidade de propagação da trinca e a taxa real de deformação pode ser embasada por modelos mecanísticos de ruptura do filme passivo;

2) Nas relações (10.4.13) e (10.4.14), é mostrado que muito provavelmente, a iniciação da trinca é função somente da tensão enquanto que a propagação é função somente da taxa de deformação [SANTARINI, 1989].

Nota-se ainda que o item 2) acima pode embasar o modelo de dano por taxa de deformação de Garud e Gerber, conforme item (8.4). 
10.5. Técnica de modelagem utilizando o diagrama mecânico-eletroquímico de Vankeerberghen

Vankeerberghen propôs um diagrama bi-dimensional, denominado mecânico-eletroquímico, onde é representado em abcissa o fator de intensidade de tensões e em ordenada o potencial de eletrodo, constituindo uma curva funcional que será associada com uma velocidade de propagação de trinca por CST [VANKEERBERGHEN, 2004].

Esse diagrama é independente do mecanismo desse tipo de trinca, mas para se chegar às variáveis de carregamento mecânico representadas na abcissa, é necessário utilizar algum modelo mecanístico existente, como por exemplo, o de Ford e Andresen. Vankeerberghen desenvolveu um diagrama baseado nas principais variáveis de intensidade de tensão, potencial eletroquímico na ponta da trinca e uma variável exprimindo a influência do hidrogênio. Um diagrama é válido somente para uma combinação particular de material-meio, mas podem ser construídos vários diagramas de acordo com diferentes condições, como tratamento termomecânicos diversos.

Vankeerberghen deduz duas equações, (10.5.1) e (10.5.2), para conformar o contorno da curva do diagrama mecânico-eletroquímico, a partir das equações para o modelo de dissolução por mecanismo de deslizamento/ruptura do filme passivo (Andresen \& Ford), lei de Faraday e algumas hipóteses.

$$
\begin{gathered}
v_{C S T}=\left[M i_{0} / \rho z F(1-n)\right] \cdot \exp (\alpha F E / R T) \cdot\left(t_{0} / \varepsilon_{f}\right)^{n} \dot{e}^{n} \\
\left.\dot{e}=\left[\beta \cdot \sigma_{Y} \cdot m \cdot v_{C S T} / E \cdot(m-1) \cdot r\right] \cdot\left\{1+\ln \left[(N / r)\left(K_{l} / \sigma_{Y}\right)^{2}\right]\right\} \cdot\left\{\ln \left[(\lambda / r)\left(K_{l} / \sigma_{Y}\right)^{2}\right]+1 / 2\left[\ln (\lambda / r)\left(K_{l} / \sigma_{Y}\right)^{2}\right]\right]^{2}\right\}
\end{gathered}
$$

sendo $M=$ massa atômica; $\rho=$ densidade; $z=$ carga; $E=$ =ódulo de Young; $\sigma_{Y}=$ tensão de escoamento; $m=e x p o e n t e$ de Ramberg-Osgood; $r=$ posição da deformação da ponta da trinca; $\beta, \lambda$ $=$ constantes do modelo; $\mathrm{F}=$ constante de Faraday; $\mathrm{R}=$ constante universal dos gases; $T=$ temperatura; $t_{0}=$ tempo de recomposição do filme passivo; $n=$ constante de decaimento da corrente; $\varepsilon_{f}=$ deformação de ruptura do filme passivo; $\hat{1}_{0}=$ coeficiente de densidade de corrente; $\alpha=$ coeficiente de carga elétrica. 
Na figura 10.6 está ilustrado o diagrama mecânico-eletroquímico para a CST de um aço inoxidável tipo 304 em água a $288^{\circ} \mathrm{C}$, calculado utilizando-se as equações (10.4.1) e (10.4.2) e dados retirados de [SATOH et al., 1998].

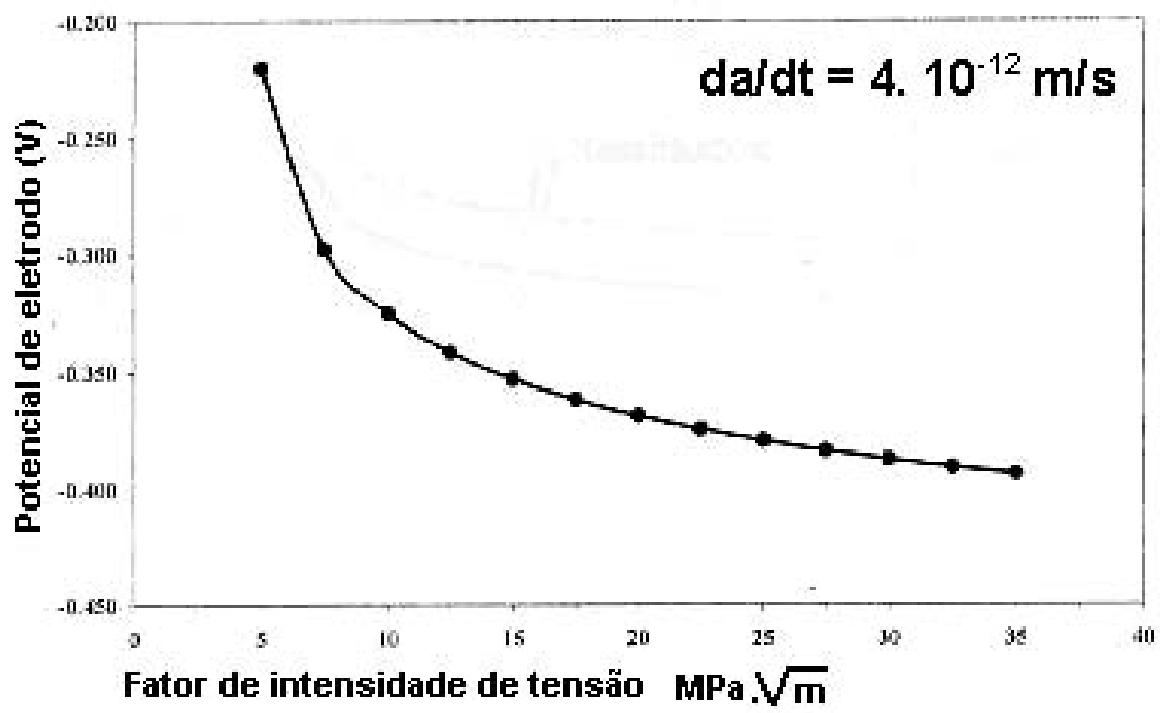

Figura 10.6. Diagrama mecânico-eletroquímico para a CST de um aço inoxidável tipo 304 em água a $288^{\circ} \mathrm{C}$; velocidade de crescimento de trinca $==4.10^{-12} \mathrm{~m} / \mathrm{s}$ [VANKEERBERGHEN, 2004].

Essa metodologia de modelagem está sendo viabilizada através do uso de aplicativo recentemente desenvolvido, o CEC-"computational electrochemistry software", que pode fazer a interação num modelo global dos vários processos envolvidos na CST em água pura a alta temperatura, resultante do método desenvolvido por Gavrilov em sua Tese de Ph.D. defendida em 2003 na Universidade de Vrije em Bruxelas, de simulação por elementos finitos da CST em meio aquoso [VANKEERBERGHEN, 2004]. 


\section{CONSTRUÇÃO DOS MODELOS PROPOSTOS}

\subsection{Domínio de aplicação dos modelos}

Fazer a modelagem no amplo domínio que seria desejável para a construção de Figura equivalente a 11.1, é uma tarefa fora do âmbito dessa pesquisa: é necessário restringir sensivelmente o domínio de sua aplicação, para um caso particular a ser estudado.

Escolheu-se uma faixa de $\mathrm{pH}=5,8$ a 8,0 que corresponde aos dados para a usina nuclear brasileira do tipo RAP, operada pela Eletronuclear (RJ), Angra 1 [GORMAN\&STAEHLE, 1989]. Notar que com o aumento de temperatura do meio, é necessário corrigir o pH. Isso já foi considerado nos dados, pois seu valor normal à temperatura ambiente é 6,8 a 7,4 [EPRI, 2002].

No entanto, cabe um importante comentário sobre o meio ambiente onde se desenvolve a fratura da liga 600 por CSTAP e da influência do pH na iniciação e propagação desse tipo de defeito: como a água do circuito primário se transforma em vapor ("flashing"), o hidróxido de lítio e o ácido bórico podem se concentrar perto da interface líquido/vapor. Esses componentes concentrados formam metaborato de lítio, $\mathrm{LiBO}_{2}$ que precipita. Com o aumento da concentração de hidróxido de lítio, o $\mathrm{pH}$ na temperatura de $330^{\circ} \mathrm{C}$ chega a $8,0 / 8,6$. Quando o ciclo do combustível chega ao fim, com muito menos ácido bórico no circuito primário, o pH pode atingir 9,4. O mesmo cálculo foi feito considerando um vazamento muito pequeno, atingindo-se um pH máximo em torno de 8,0 (alcalino) e um pH mínimo em torno de 4,0 a 6,0 (ácido), este último limitado pela precipitação de $\mathrm{B}_{2} \mathrm{O}_{3}$. $\mathrm{Na}$ água pura a $313^{\circ} \mathrm{C}$, o $\mathrm{pH}$ é 5,8 . Alguns outros estudos no entanto consideram que o boro precipita como boroferrita de níquel, $\mathrm{Ni}_{2} \mathrm{FeBO}_{5}$, ao invés do metaborato. A boroferrita, sendo muito menos solúvel em água do que o metaborato, restringe muito a possível mudança do $\mathrm{pH}$ para ácido, relativo ao valor normal para essa água. Experiências realizadas pelos franceses detectaram outros complexos de boratos: $\mathrm{Li}_{2} \mathrm{~B}_{4} \mathrm{O}_{7}, \mathrm{FeB}_{4} \mathrm{O}_{7}\left(8 \mathrm{H}_{2} \mathrm{O}\right)$ e $0 \mathrm{Li}_{3} \mathrm{~B}_{5} \mathrm{O}_{8}$ $(\mathrm{OH})_{2}$, de modo que o pH da fase líquida à alta temperatura foi estimado através do aplicativo MULTEQ, entre 7,0 e 8,0. Foi simulado para a primeira experiência realizada, um vazamento de $1 \mathrm{l} / \mathrm{h}$ e a interpretação na queda inicial da temperatura no início da trinca foi muito complexa: esse fato pode inclusive afetar o tipo de 
precipitado formado. Na segunda experiência, foi estimado um $\mathrm{pH}$ mínimo entre 4,3 a 4,7 para $300^{\circ} \mathrm{C}$. Embora, como notamos, os valores mínimos e máximos de pH possam chegar a 4,0 e 9,4 respectivamente, limitou-se o domínio deste estudo na faixa de 5,8 a 8,0, sendo o $\mathrm{pH}$ mínimo igual ao esperado para água pura a $313^{\circ} \mathrm{C}$ e o $\mathrm{pH}$ máximo limitado a $7,5-8,0$, que é a faixa em que se opera o reator na grande maioria do tempo. Os valores acima de 8,0 a 9,4 só seriam atingidos no final do ciclo do combustível. O grupo americano do "Materials Reliability Program" (MRP), assim resolve esse problema: não considera a corrosão alcalina (isto é, a existência do submodo $\mathrm{I}_{\mathrm{CST}}$ mostrado na Figura 11.1) mas para levar em consideração o efeito de um pH elevado,no caso de propagação de defeitos iniciados no diâmetro externo do bocal ("OD flaws"), situação em que uma contaminação alcalina é mais provável, sugere que se multiplique por 20 valor da velocidade de propagação de trinca. Em suma, o comportamento da velocidade de propagação da trinca em função do pH pode ser resumida como (11.1.1) [EPRI, 2002].

$$
V_{t}=A \cdot\left[p_{T} / 7,5\right]^{2}
$$

com: $V_{t}=$ velocidade de propagação da trinca; $A=$ constante; $\mathrm{pH}_{\mathrm{T}}=\mathrm{pH}$ à temperatura $\mathrm{T}$; validade para $7,5 \leq \mathrm{pH}_{\mathrm{T}} \leq 9$ e $30 \leq \mathrm{K}_{\mathrm{I}} \leq 60 \mathrm{MPa} \sqrt{\mathrm{m}}$.

Andresen lembra também que o potencial dentro da trinca é sempre mais baixo do que na superfície porque a cinética de consumo do oxigênio em alta temperatura é muito rápida, baixando também muito rapidamente o potencial nas trincas: essas são muito estreitas e profundas e normalmente preenchidas com óxidos, o que impede a difusão do oxigênio para seu interior [ANDRESEN, 2005].

Do mesmo modo Staehle e colaboradores ressaltam que um pequeno aumento no oxigênio dissolvido pode facilmente tirar a liga 600 da sua condição benigna lançando-a numa condição sensível à CST (por exemplo, fazendo elevar o potencial da região l PAS $_{\text {para }} \mathrm{IV}_{\mathrm{CST}}$ ( Figura 11.1) [STAEHLE et al., 1981].

Não se discute aqui sobre impurezas (cloretos e sulfatos) que poderiam eventualmente contaminar a água do circuito primário, pois não há efeito significativo desses contaminantes que possam ser previstos [EPRI, 2002]. 
A Figura 11.1 corresponde à compilação de dados experimentais e plotagem dos submodos de corrosão sobre o Diagrama de Pourbaix "duplo" Fe-Ni para a liga 600 à alta temperatura. Essa é a região em que se trabalha nesta pesquisa, considerando principalmente (mas não exclusivamente) o submodo de corrosão $\mathrm{III}_{\mathrm{CST}}-$ Amplo $\mathrm{pH}$ redutor.

O estabelecimento do contorno desse submodo deve ser delimitado por dados provenientes da literatura, dados provenientes dos experimentos desta pesquisa, ajustados estatisticamente por valores esperados $\left\langle\mathrm{X}_{\mathrm{i}}>=\operatorname{pdf}\left(\mathrm{V}_{\mathrm{i}}, \mathrm{pH}_{\mathrm{i}}\right)\right.$ resultantes da função de distribuição de probabilidade (pdf) dos valores dos ipontos a serem considerados para delimitar esse contorno. Esse tópico porém está fora do escopo desta pesquisa.

\subsection{Método e hipóteses para construção dos modelos}

Foram propostos modelos construídos da seguinte maneira:

A sua base é o diagrama de Pourbaix, potencial-pH para o níquel superposto ao do ferro (simplificação para o da liga 600) onde estão traçados os submodos de CST, a partir de dados experimentais de diversos pesquisadores, em água do circuito primário a alta temperatura (Figura 11.1) [STAEHLE, 1992].

Em seguida acrescentou-se uma dimensão adicional a esse diagrama, tornando-o tridimensional, correlacionando através do eixo adicional, os seguintes modelos propostos:

1) O modelo empírico-comparativo que utiliza no eixo $z$ sobre o diagrama da Figura 11.1, uma variável a que se denominou "fração de resistência" já utilizado e montado por Staehle [STAEHLE, 1992a]. A novidade introduzida nesta Tese é o início da construção deste modelo através dos dados obtidos no CDTN.

A fração de resistência à CST nesta proposição foi quantificada como sendo a razão de tempo de falha no meio de interesse/meio neutro: esse é um dos parâmetros obtidos através de ensaios CERT/SSRT ("slow strain rate testing") ou ensaio de taxa de deformação lenta (ETDL). 
Tendo em vista que a construção destes diagramas exige uma quantidade de experimentos muito grande para validá-los, melhor seria utilizar um modelo da cinética de iniciação e/ou propagação de trincas já existente e aceito para explicar o fenômeno como recomendação futura do próprio Staehle para prosseguimento de sua pesquisa.

2) Modelo semi-empírico-probabilístico de Staehle [GORMAN et al, 1994]. Elaborada a parte determinística do modelo. A parte teórica está explicada conforme itens 8.10.2 e 10.1 (modelagem);

3) Modelo simplificado de tempo de iniciação de Garud [GARUD, 1997] A parte teórica está explicada conforme item 10.3 (modelagem);

4) Modelo de dano por taxa de deformação de Boursier [BOURSIER et al., 1995]. A parte teórica está explicada conforme item 8.1 e nesse mesmo item as equações de modelagem.

Nos itens 1), 2), 3) e 4) está a contribuição desta Tese, acoplando outros modelos às regiões dos submodos definidos por Staehle. 


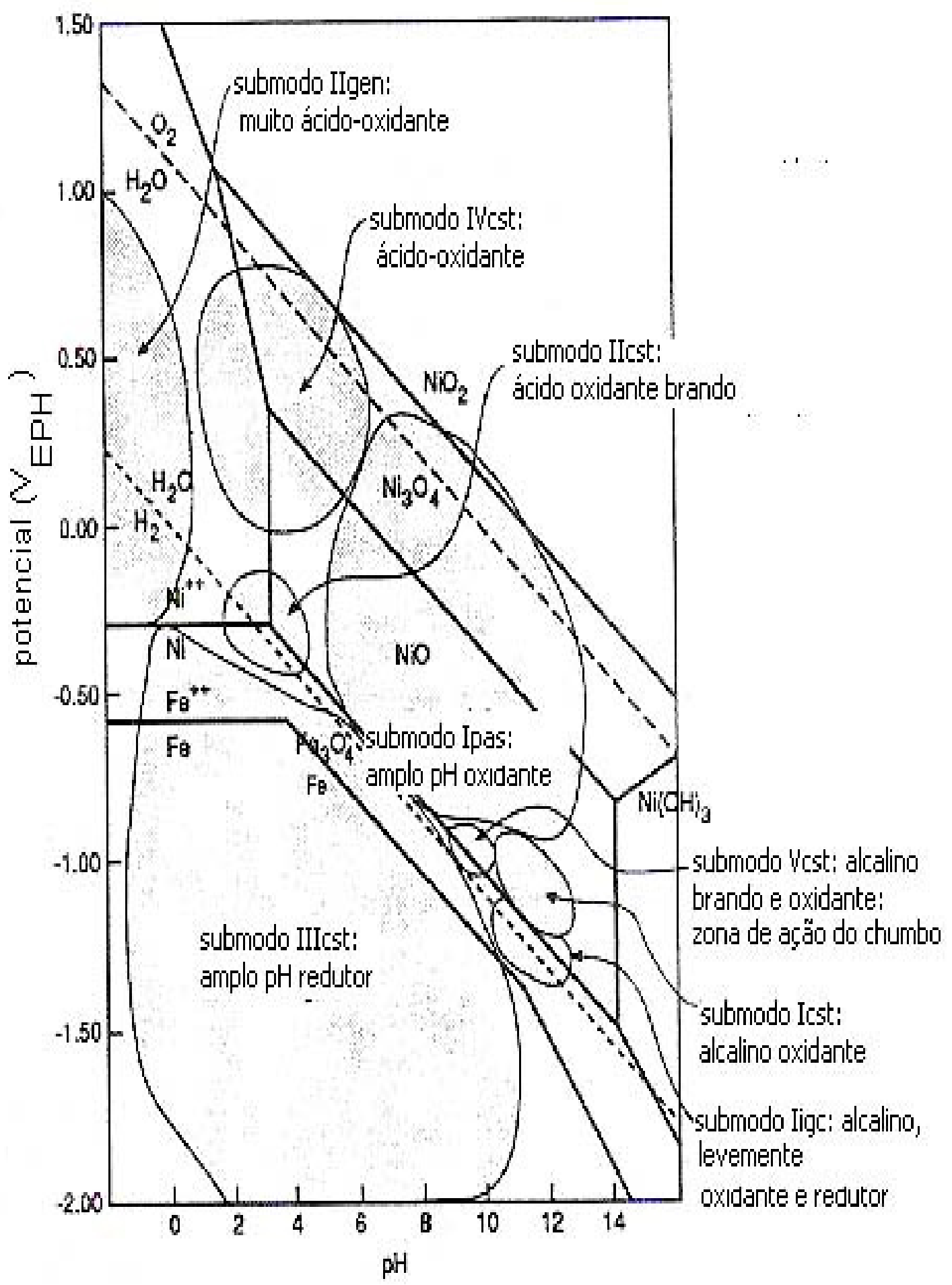

Figura 11.1. Diagrama de Pourbaix bidimensional Ex pH para a liga 600 na faixa de $300^{\circ} \mathrm{C}$ utilizada como base sobre a qual foram marcadas as regiões de submodos de corrosão. [STAEHLE, 1992a]. 


\section{PARTE EXPERIMENTAL}

Para se iniciar a aplicação dos modelos e se obter as respectivas modelagens foram utilizados ensaios experimentais de taxa de deformação lenta em condições de CSTAP, com amostras de liga 600 laminadas e recozidas a partir de material para fornecimento industrial, isto é não homogêneo, policristalino e não trabalhadas a frio.

Foram ainda utilizados dados de uma modelagem semi-empíricaprobabilística retirada da literatura [USNRC, 2001] e colocada em forma gráfica adequada, para ilustrar a potencial aplicação desse modelo de forma analógica a unidades no caso brasileiro.

A seguir são descritos os ensaios experimentais e os dados extraídos da literatura.

\subsection{Ensaios experimentais no CDTN}

Foi avaliada a susceptibilidade à corrosão sob tensão da liga de níquel 600 LTMA - "Low Temperature Mill Annealed", isto é, laminada e recozida à baixa temperatura (comercialmente denominada Inconel $600 \mathrm{MA}$ ) em ambiente do circuito primário de reator nuclear tipo RAP. Esse tipo de tratamento consiste numa recristalização do material após sua fabricação: por exemplo, para um tubo de diâmetro nominal $70 \mathrm{~mm}$ de liga 600 , ele é aquecido a $815^{\circ} \mathrm{C}$ durante 1 hora e resfriado ao ar. Para mais informações sobre esse tratamento, pode ser consultado o boletim [SPECIAL METALS, 2004].

O material foi caracterizado mecânica e metalograficamente e os espécimes foram confeccionados seguindo as recomendações dentro da norma ASTM G 129-95 [SCHVARTZMAN et al., 2005].

Foram feitos ensaios com taxa de deformação lenta de $3,0 \times 10^{-7} \mathrm{~s}^{-1}$ (ETDL ou SSRT, "Slow Strain Rate Test" ou CERT, "Constant Extension Rate Test'), conforme mostrado no item 8.10.1. Nas Figuras 12.1 e 12.2 são mostrados respectivamente uma foto da instalação no CDTN e o esquema do circuito de água do equipamento utilizado. 


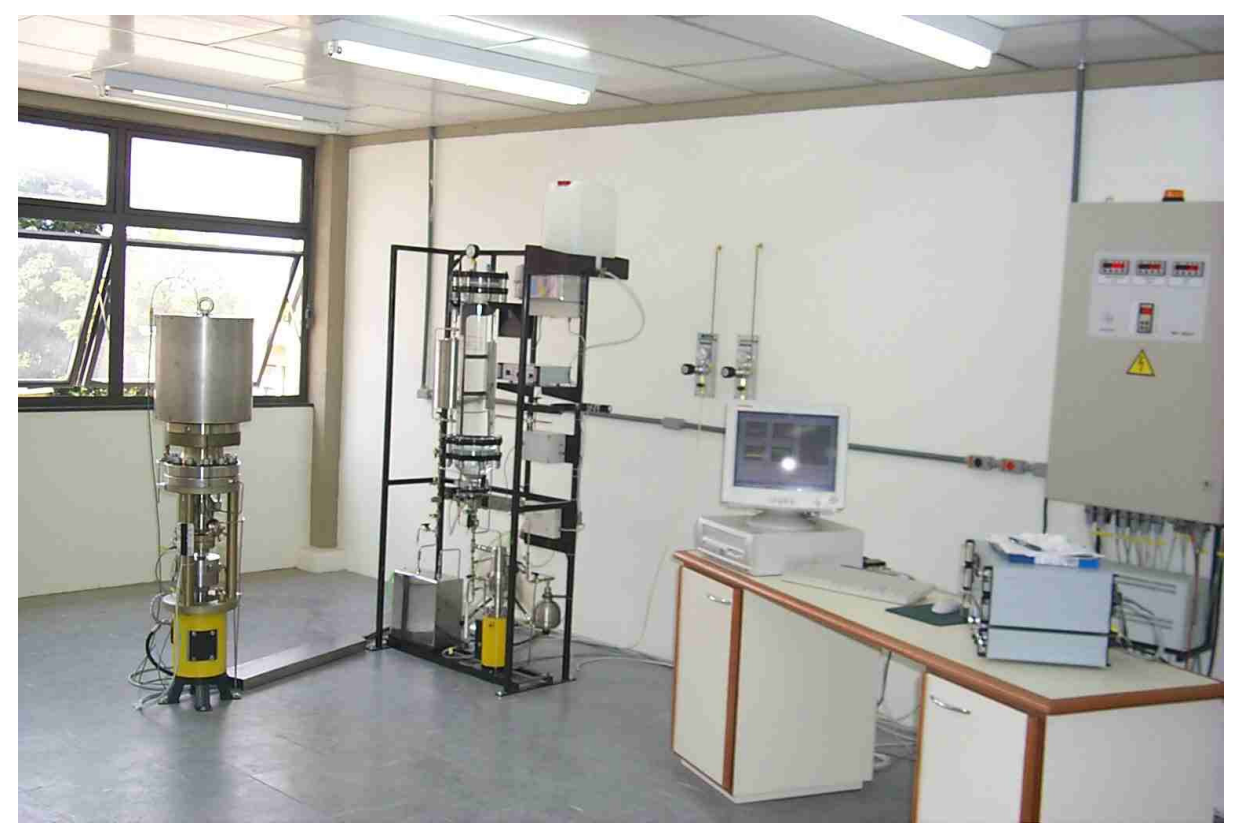

Figura 12.1. Instalação no CDTN para ensaios de corrosão sob tensão No centro, dentro da estrutura metálica fica o conjunto autoclave-eletrodo de alta temperatura, onde é ensaiado o espécime por SSRT; à esquerda, conjunto da bomba de circulação de água [SCHVARTZMAN et al., 2003].

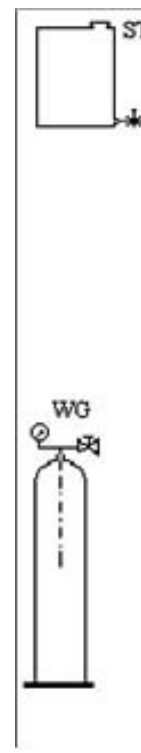

- Autoclave CM - Medidor de condutividade $\mathrm{CO}$ - Resfriador

DS - Estação de desmineralização OX - Oxímetro

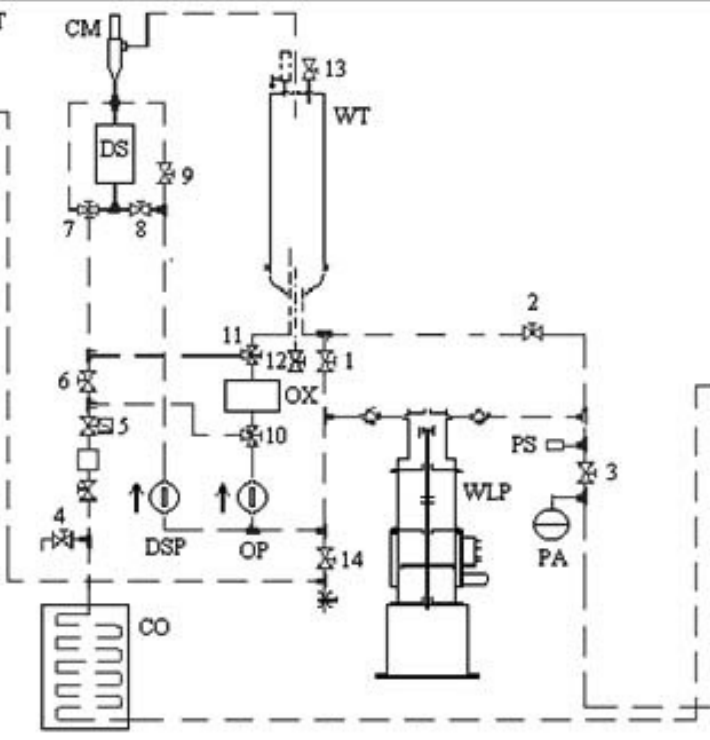

OP - Bomba de circulação do oxímetro EP - Bomba de circulação de filtro cambiável

HTE - Eletrodo de alta temperatura

PA - Acumulador de pressão

OS - Sensor de pressão

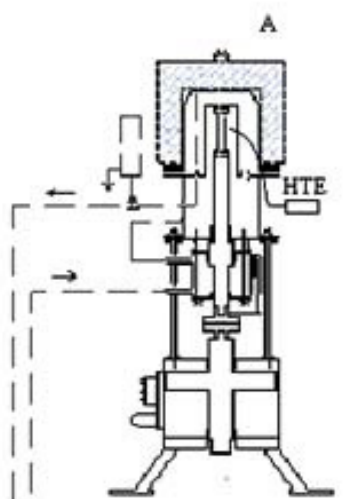

ST - Service tank WG - Gás de trabalho WLP - Bomba do circuito de água WT - Tanque de serviço

Figura 12.2. Esquema do circuito de água do equipamento de ensaios de CST instalado no CDTN [SCHVARTZMAN et al.,2003]. 
A instalação de ETDL (SSRT/CERT) foi desenvolvida em conjunto pelo Nuclear Research Institute Rež (NRI) da República Tcheca e CDTN dentro de um projeto patrocinado pela Agencia Internacional de Energia Atômica (IAEA) como um sistema universal para todos os principais ensaios de corrosão sob tensão, regidos pelas normas internacionais da ASTM, ISO e DIN. Ela é composta de uma autoclave com um sistema de tração servo-hidráulico, controlado por deslocamento ou carga e de um circuito hidráulico com um sistema de medição e tratamento químico da água. $O$ deslocamento é medido por meio de um sensor de posição linear (método: linear variable differential transformer - LVDT) e a carga por meio de um célula de carga. A autoclave é aquecida por meio de um forno elétrico controlado continuamente por um sistema de PID (sistema de controle proporcional, integral e derivativo). Durante a execução do experimento são realizadas medições de carga, deslocamento, tamanho de trinca, parâmetros termohidráulicos e parâmetros químicos. Um aplicativo desenvolvido no ambiente LabVIEW $^{\circledR}$ é utilizado pela aquisição de dados e sua representação gráfica. O potencial eletroquímico é medido por meio de um eletrodo do tipo $\mathrm{Ag} / \mathrm{AgCl}$, projetado para permitir uma operação contínua em condições de alta temperatura e pressão. A partir desses ensaios, foi realizada uma avaliação da susceptibilidade à corrosão sob tensão do Inconel 600MA em ambiente de reator nuclear. Foram comparados os resultados obtidos em meio inerte $\left(\mathrm{N}_{2}\right)$ e em ambiente similar ao do circuito primário de um reator nuclear. Nas curvas tensãodeformação foi mostrado o efeito do ambiente do RAP no comportamento mecânico do Inconel 600MA, sendo confirmadas pelas análises fractográficas obtidas por microscopia eletrônica de varredura (MEV).

Os ensaios foram realizados pela equipe do CDTN, com taxa de deformação de $3 \times 10^{-7} \mathrm{~s}^{-1} \mathrm{em}$ meio inerte (nitrogênio) e ambiente similar ao do circuito primário do reator da Usina de Angra 1 à temperatura de $303 \stackrel{\circ}{\mathrm{C}}$ e pressão de 100 bar. Foram obtidas as curvas tensão-deformação e tensão-tempo para cada ensaio. Os espécimes ensaiados foram submetidos a análises fractográficas através de microscopia eletrônica de varredura. $A$ avaliação da susceptibilidade à CST do Inconel 600MA foi realizada por meio da comparação dos resultados obtidos no meio inerte e no meio de interesse. Verificou-se que nestas condições de ensaio que os espécimes de Inconel 600MA apresentaram fratura de CST em toda a sua extensão, nas suas regiões laterais (Figura 12.7). 
O ensaio de taxa de deformação lenta de um corpo de prova durante exposição em condições ambientais apropriadas foi desenvolvido para acelerar o processo de CST em laboratório. Ele é realizado sob lento aumento de deformação $\left(10^{-5}\right.$ a $\left.10^{-9} \mathrm{~s}^{-1}\right)$. A descrição mais detalhada deste ensaio é dada na norma ASTM G129-95. Sua principal vantagem é a rapidez com que a susceptibilidade à CST de uma liga particular num meio determinado pode ser avaliada. Ensaios de deformação lenta têm essencialmente substituído o uso dos ensaios de carga constante devido à variabilidade nos tempos de fratura e o longo tempo de ensaio necessário para definir o valor limiar da CST ( $\mathrm{K}_{\mathrm{ICST}}$ ), abaixo do qual não ocorre o fenômeno de corrosão sob tensão.

Esse trabalho apresenta uma avaliação da suscetibilidade à corrosão sob tensão do Inconel 600MA em ambiente de reator nuclear, utilizando o ensaio de taxa de deformação lenta - SSRT. São comparados os resultados obtidos em meio inerte $\left(\mathrm{N}_{2}\right)$ e em ambiente similar ao do circuito primário de um reator nuclear. As curvas tensão-deformação mostram o efeito do ambiente RAP no comportamento mecânico do Inconel 600MA, sendo confirmadas pelas análises fractográficas obtidas por microscopia eletrônica de varredura (MEV) [SCHVARTZMAN et al., 2005].

Além desses, foram realizados ensaios eletroquímicos específicos para se determinar o potencial em que ficaram as amostras de liga $600 \mathrm{MA}$, enquanto submetidas às condições da água do circuito primário à alta temperatura. Eles estão descritos em [MORAGA, G.A., 2006],

\subsection{Materiais}

Nos ensaios de CSTAP foram utilizados espécimes de Inconel 600MA. Nas Tabelas 12.1 e 12.2 são apresentadas a composição química e as propriedades mecânicas respectivamente e na Figura 12.3 é mostrada sua microestrutura.

Tabela 12.1. Composição química do Inconel 600 MA (\% peso) [SCHVARTZMAN et al., 2005].

\begin{tabular}{ccccccccccccc}
\hline \hline $\mathrm{C}$ & $\mathrm{Mn}$ & $\mathrm{P}$ & $\mathrm{S}$ & $\mathrm{Si}$ & $\mathrm{Ni}$ & $\mathrm{Cr}$ & $\mathrm{Co}$ & $\mathrm{Cu}$ & $\mathrm{Fe}$ & $\mathrm{Al}$ & $\mathrm{Ti}$ & $\mathrm{Nb}$ \\
\hline 0,042 & 0,22 & 0,008 & 0,0002 & 0,18 & 75,05 & 15,61 & 0,10 & 0,03 & 8,81 & 0,08 & 0,20 & 0,20 \\
\hline
\end{tabular}


Tabela 12.2. Propriedades mecânicas do Inconel 600 MA [SCHVARTZMAN et al.,2005].

\begin{tabular}{cccccc}
\hline $\begin{array}{c}\text { Temperatura } \\
\left({ }^{\circ} \mathrm{C}\right)\end{array}$ & $\begin{array}{c}\sigma_{\mathrm{Y}} \\
(\mathrm{MPa})\end{array}$ & $\begin{array}{c}\sigma_{\mathrm{R}} \\
(\mathrm{MPa})\end{array}$ & $\begin{array}{c}\text { Deformação } \\
(\%)\end{array}$ & $\begin{array}{c}\text { Redução de área } \\
(\%)\end{array}$ & $\begin{array}{c}\text { Dureza } \\
\mathrm{HB}\end{array}$ \\
\hline 22 & 302 & 632 & 38,5 & 62 & 170 \\
\hline 300 & 254 & 567 & 38,6 & 58 & N.D. \\
\hline
\end{tabular}

$\sigma_{Y}$ - limite de escoamento; $\sigma_{R}$ - limite de resistência.

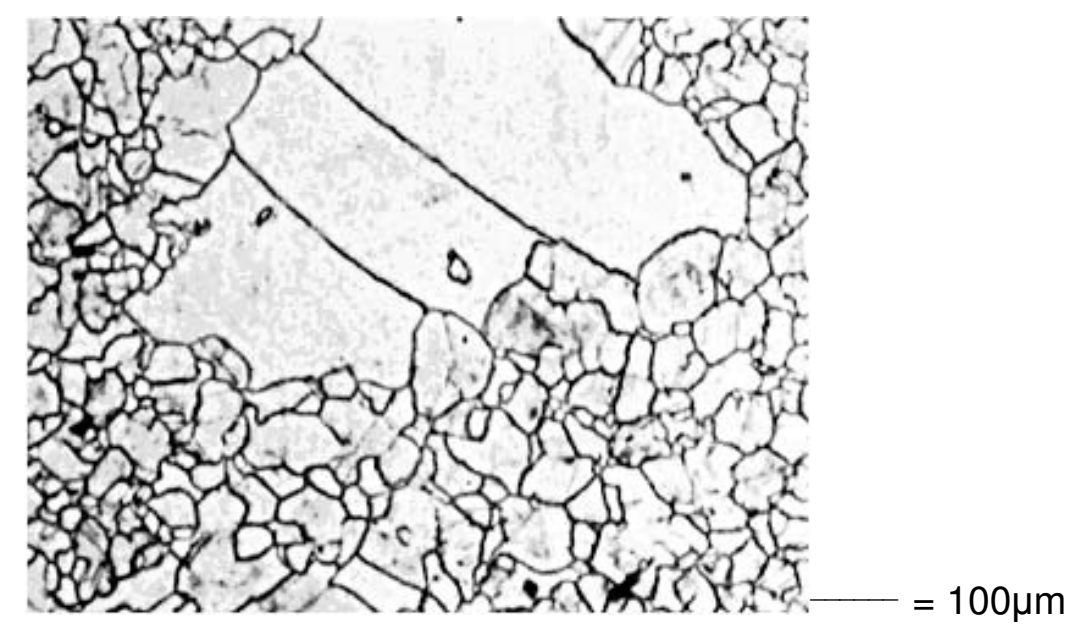

Figura 12.3. Microestrutura do Inconel 600MA como recebido. Micrografia em ácido fosfórico a $10 \% .100$ vezes [SCHVARTZMAN et al.,2005].

O meio utilizado nos ensaios de CST foi uma solução com água deionizada contendo composição química similar a do ambiente do circuito primário de um RAP em operação. Esta solução contém 1000-1200ppm de ácido bórico, 2,2 - 2,5 ppm de hidróxido de lítio, 25- $35 \mathrm{~cm}^{3} \mathrm{CNTP}_{2} / \mathrm{kg} \mathrm{H}_{2} \mathrm{O}$, menos de $5 \mathrm{ppb}$ de $\mathrm{O}_{2}$. Durante os ensaios o pH da solução foi mantido entre 6,9 e 7,4.

Neste trabalho foram utilizados espécimes de tração conforme mostrado na Figura 12.4. 

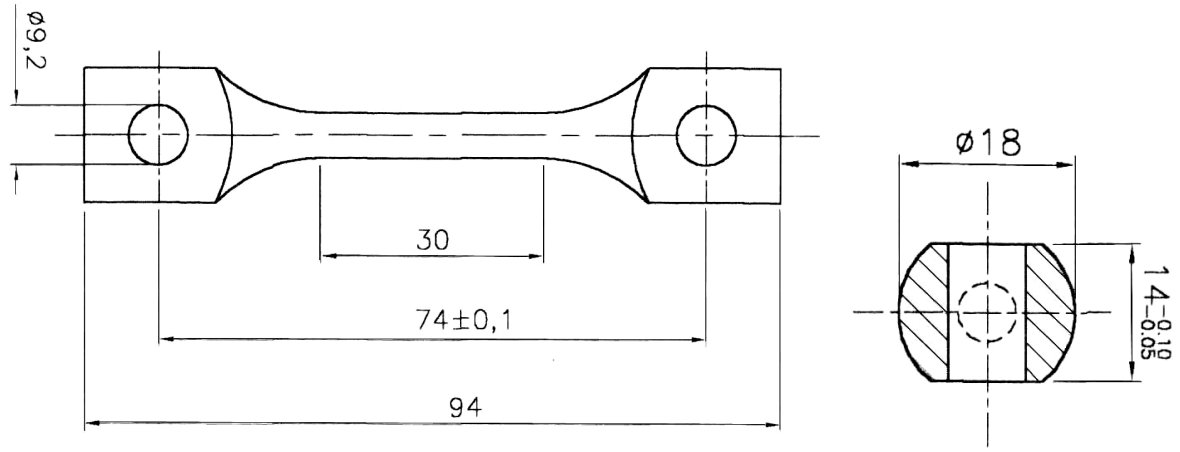

Figura 12.4. Espécime de tração utilizado nos ensaios de taxa de deformação lenta (ETDL) [SCHVARTZMAN et al.,2005].

Os ensaios foram feitos à temperatura nominal de $303^{\circ} \mathrm{C}$, pressão nominal de $10 \mathrm{MPa}$, com circulação da água a uma vazão de aproximadamente $0,4 \mathrm{l} / \mathrm{h}$. Foi realizado o monitoramento "on line" de carga e deslocamento. Os três ensaios foram realizados com uma taxa de deformação lenta inicial de $3 \times 10^{-7} \mathrm{~s}^{-1}$, gerando uma velocidade de ensaio de $33 \mu \mathrm{m} / \mathrm{h}$. O SSRT 01 foi realizado em meio inerte $\left(\mathrm{N}_{2}\right)$ e os ensaios SSRT 02 e 03 foram feitos em solução em água de RAP [SCHVARTZMANN et al., 2005].

\subsection{Resumo dos resultados dos ensaios}

Na Figura 12.5 apresenta-se a curva tensão-deformação obtida a partir dos ensaios SSRT 01 no meio inerte, SSRT 02 e SSRT 03 no meio similar ao do circuito primário de um RAP. No meio inerte o Inconel $600 \mathrm{MA}$ alcançou uma deformação de 55,8 \% enquanto que no meio de RAP alcançou deformações menores, $53,5 \%$ e $54,1 \%$ nos ensaios 02 e 03 respectivamente. Houve maior redução de área no espécime do ensaio $01,55,5$ \%, com relação aos ensaios 02 e $03,50,9 \%$ e: $51,0 \%$ respectivamente. Na Figura 12.6 apresenta-se a curva tensão-tempo a qual mostra o tempo de duração dos ensaios e verifica-se que no meio RAP o tempo de ensaio foi menor. No ensaio 01 o tempo foi de 21,3 dias (511,2 horas) em relação aos ensaios 02 de 20,1 dias (482,4 h) e 03 de 20,6 dias $(494,4 \mathrm{~h})$ [SCHVARTZMAN et al.,2005]. 


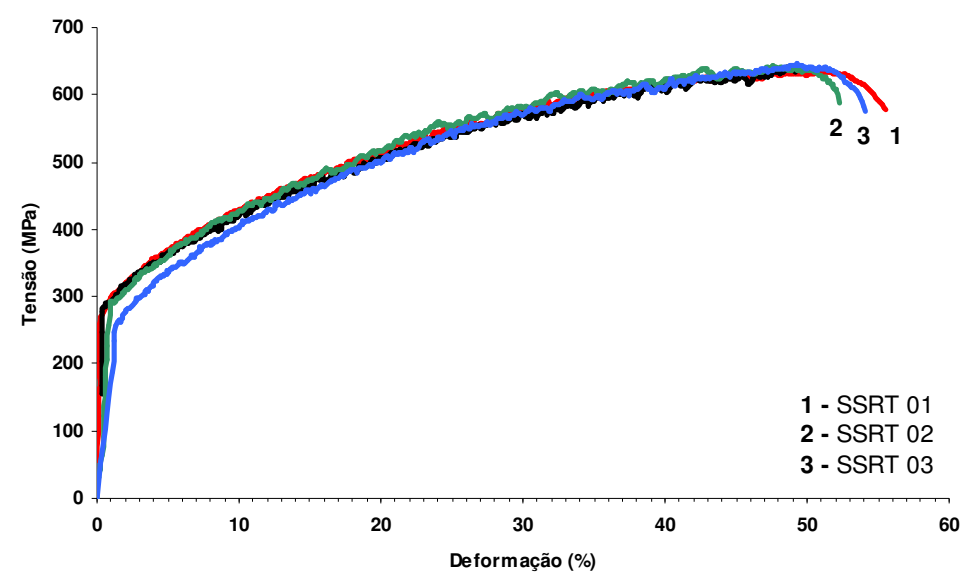

Figura 12.5. Curva tensão-deformação dos espécimes de Inconel 600 MA. Ensaios de taxa de deformação lenta, SSRT $01\left(\mathrm{~N}_{2}\right)$, SSRT 02 e 03 (ambiente de RAP) à $303{ }^{\circ} \mathrm{C}$ e $10 \mathrm{MPa}$. Taxa de deformação inicial de $3,0 \times 10^{-7} \mathrm{~s}^{-1}$ [SCHVARTZMAN et al.,2005].

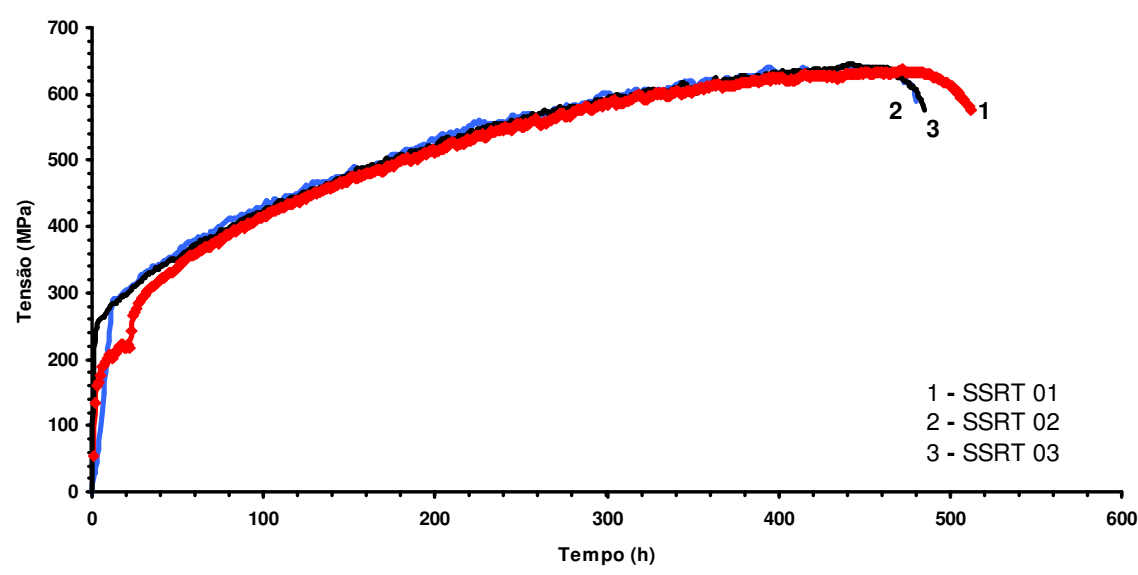

Figura 12.6. Curva Tensão-Tempo dos espécimes de Inconel $600 \mathrm{MA}$. Ensaios de taxa de deformação lenta, SSRT $01\left(\mathrm{~N}_{2}\right)$, SSRT 02 e 03 (ambiente de RAP) à $303{ }^{\circ} \mathrm{C}$ e $10 \mathrm{MPa}$. Taxa de deformação inicial de $3,0 \times 10^{-7} \mathrm{~s}^{-1}$ [SCHVARTZMAN et al.,2005].

Na Figura 12.7 (a) é apresentada uma comparação de alongamento como resultado da deformação no ensaio, entre o espécime 1, original de material como recebido e o espécime 2 ensaiado em SSRT/CERT. Na Figura 12.7 (b) é apresentada uma comparação entre os espécimes rompidos nos ensaios de SSRT/CERT em meio neutro (SSRT 01) e em meio RAP. Na Figura 12.7 (c) é mostrada uma referência de localização das micrografias mostradas nas Figuras 12.8 a 12.12 [CDTN, 2005]. 


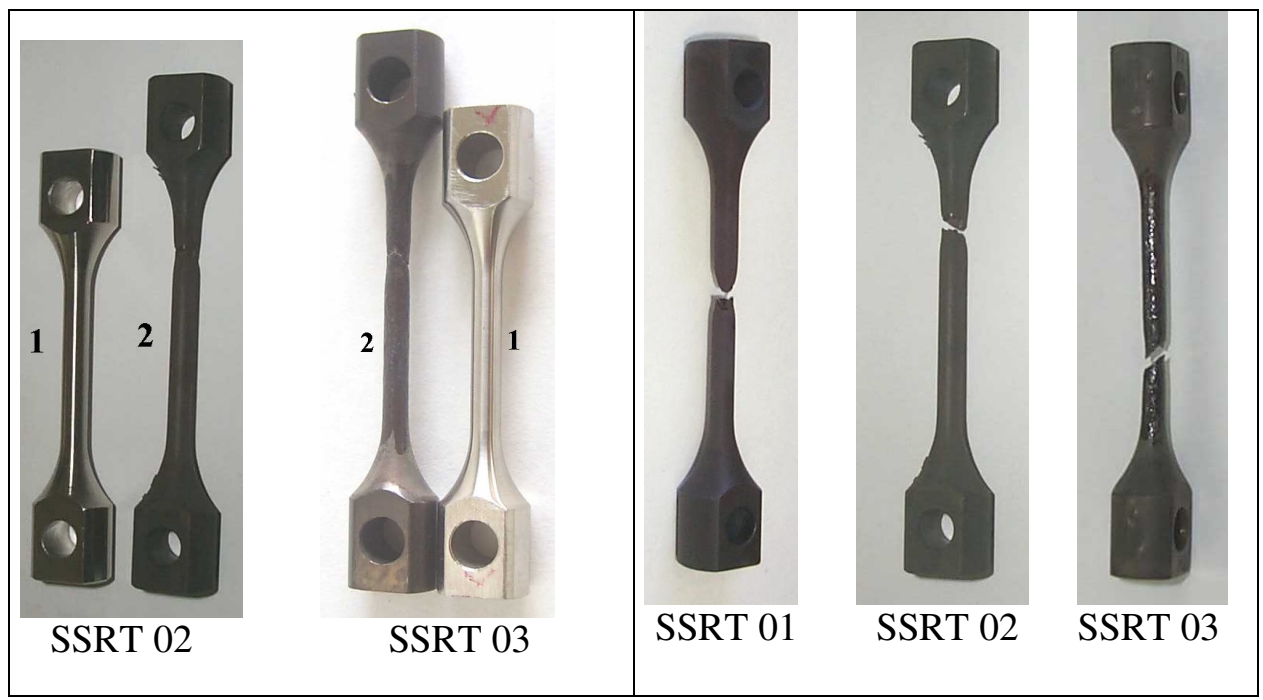

(a)

(b)

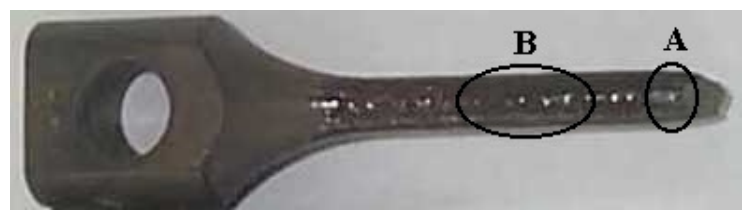

(c)

Figura 12.7. Espécimes de Inconel 600MA. Ensaios de tração SSRT 01 (meio neutro: $\mathrm{N}_{2}$ ), SSRT 02 e 03 (meio PWR). $303^{\circ} \mathrm{C}$. Taxa de deformação: $3,0 \times 10^{-7} \mathrm{~s}^{-1}$. Pressão: 10 bar. (a) Comparação de alongamento entre espécime de material como 1-recebido e 2-ensaiado em SSRT; (b) Comparação entre espécimes rompidos nos três ensaios; (c) Referência de localização das microfractografias efetuadas no microscópio eletrônico de varrredura [CDTN, 2005].

As propriedades mecânicas do Inconel 600 MA e os parâmetros dos ensaios de SSRT estão apresentados na Tabela 12.3. A diferença entre os resultados obtidos para os corpos-de-prova em meio inerte e em meio de RAP foi considerada desprezível utilizando-se a taxa de deformação de $3,0 \times 10^{-7} \mathrm{~s}^{-1}$. Esta taxa foi suficiente para produzir a iniciação de trinca, mas insuficiente para provocar a propagação por CST, o que é comprovado nas análises fractográficas. Observa-se também que as razões: tempo de ensaio, deformação e redução de área para os dois meios apresentam valores bem próximos de 1,0. Isto não foi interpretado como uma baixa susceptibilidade do Inconel 600 MA à CST no meio em estudo, mas sim devido ao fato de ter ocorrido somente a iniciação de trincas nos espécimes ensaiados em função da taxa de deformação não suficientemente baixa [SCHVARTZMAN et al.,2005]. 
Tabela 12.3. Resultados obtidos nos ensaios SSRT do Inconel $600 \mathrm{MA}$ em ambiente de reator nuclear e em meio neutro $\left(\mathrm{N}_{2}\right)$. Taxa de deformação: $3 \times 10^{-7} \mathrm{~s}^{-1}$ [SCHVARTZMAN et al., 2005], [CDTN, 2005].

\begin{tabular}{lccc}
\hline Ensaio & SSRT 01 & SSRT 02 & SSRT 03 \\
\hline Meio & Nitrogênio & RAP(PWR) & RAP(PWR) \\
\hline Tempo de Ensaio (dias) & 21.3 & 20.1 & 20.6 \\
\hline Velocidade de Ensaio $(\mu \mathrm{m} / \mathrm{h})$ & 34,1 & 33,0 & 33,0 \\
\hline Pressão $(\mathrm{MPa})$ & 2,05 & 10 & 10 \\
\hline Limite de Escoamento $(\mathrm{MPa})$ & 275 & 292 & 265 \\
\hline Limite de Resistência $(\mathrm{MPa})$ & 647 & 648 & 650 \\
\hline Deformação $(\%)$ & 55.8 & 53.5 & 54.1 \\
\hline Redução de área $(\%)$ & 55.5 & 50.9 & 51 \\
\hline Razão de Tempo de falha & --- & 0.94 & 0.97 \\
\hline Razão de Deformação & --- & 0.96 & 0.97 \\
\hline Razão de redução de área & --- & 0.92 & 0.92 \\
\hline Tenacidade $\left(\mathrm{kJ} / \mathrm{m}^{3}\right)$ & 29,51 & 27,49 & 27,89 \\
\hline
\end{tabular}

Na Figura 12.8 são mostrados os perfis de trincamento dos espécimes ensaiados em SSRT no meio neutro e em meio do RAP: todas as rupturas ocorreram a $45^{\circ}$, típicas rupturas mecânicas uma vez que a taxa de deformação não foi suficiente para produzir a trinca por CST nessa região [CDTN, 2005].

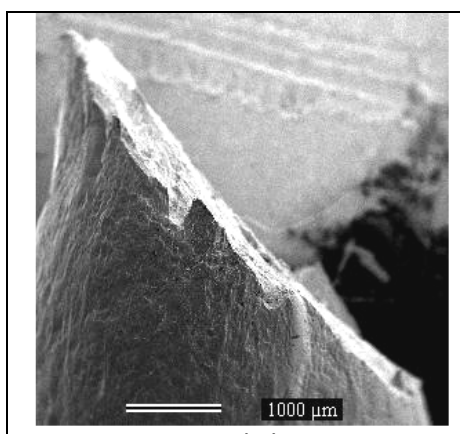

(a)

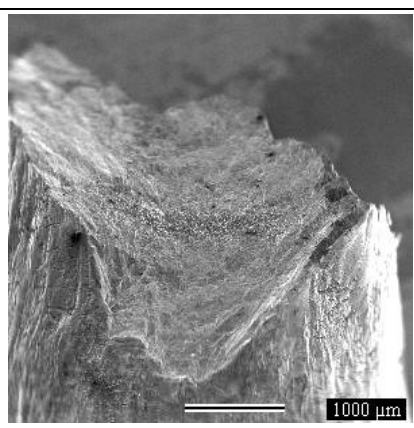

(b)

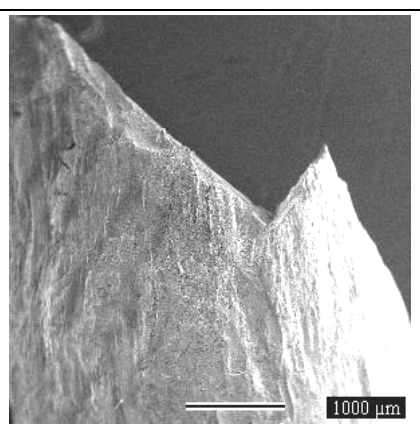

(c)

Figura 12.8. Perfis de fratura dos espécimes de Inconel 600 MA, MEV aumento de 100 vezes. Ensaios de tração (a) SSRT $01\left(\mathrm{~N}_{2}\right)$, (b) SSRT 02 (RAP), (c) SSRT 03 (RAP). $303 \stackrel{\circ}{\circ} \mathrm{C}$. Pressão: 10 bar. Taxa de deformação: $3,0 \times 10^{-7} \mathrm{~s}^{-1}$ [CDTN, 2005].

O meio do RAP causou o processo de fratura lateral dos espécimes de Inconel 600MA (região A da Figura 12.7.c) submetidos aos ensaios com taxa de deformação lenta do espécime de $3,0 \times 10^{-7} \mathrm{~s}^{-1}$ e velocidade de ensaio $33,0 \mu \mathrm{m} / \mathrm{h}$ 
como é mostrado na Figura 12.9. Nota-se, nitidamente, o efeito do meio quando se compara a superfície do espécime ensaiado em meio inerte - (a) SSRT 01, na qual se observa apenas ondulações resultantes da deformação plástica - com as superfícies dos espécimes ensaiados no meio do RAP - (b) SSRT 02 e (c) SSRT 03 , as quais apresentam uma grande quantidade de trincas. As trincas são transversais em relação à direção de carregamento. Com essa taxa de deformação, porém, não houve propagação da trinca [SCHVARTZMAN et al.,2005].

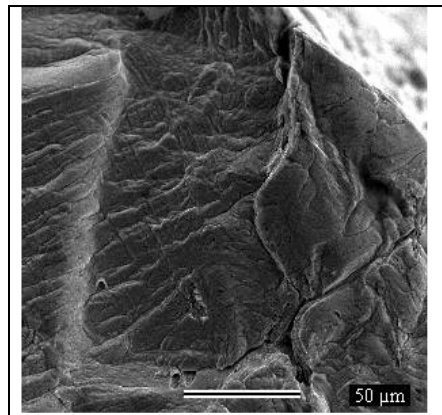

(a)

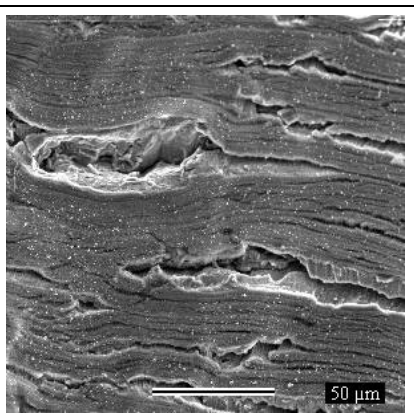

(b)

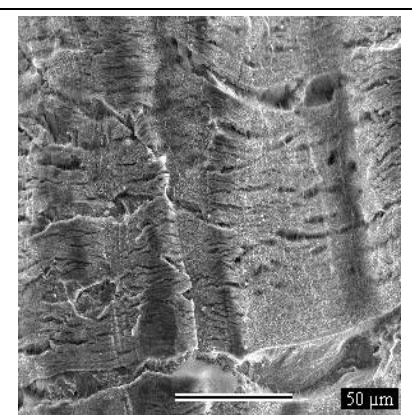

(c)

Figura 12.9. Microfratografias MEV, aumento de 500 vezes. Superfícies laterais dos espécimes de Inconel $600 \mathrm{MA}$. Ensaios com taxa de deformação lenta a $303^{\circ} \mathrm{C}$ e $10 \mathrm{MPa}$. Taxa de deformação de $3,0 \times 10^{-7} \mathrm{~s}^{-1}$. (a) SSRT $01\left(\mathrm{~N}_{2}\right)$, (b) SSRT 02 (ambiente de RAP), (c) SSRT 03 (ambiente de RAP) [SCHVARTZMAN et al.,2005].

Na Figura 12.10 são mostradas as superfícies laterais dos espécimes ensaiados conforme mostrado na região B da Figura 12.7(c). No espécime ensaiado em meio neutro conforme Figura 12.10 (a) a região está isenta de trincas e comparando-a com a mostrada na Figura 12.9 (a), está menos deformada por estar fora da região de estricção (A da Figura 12.7.(c)). Nas regiões mostradas em 12.10 (b) e 12.10 (c) pode-se observar a presença de trincas de CST ao longo da extensão dos espécimes, em razão do efeito adicional do meio do RAP [CDTN, 2005]. 


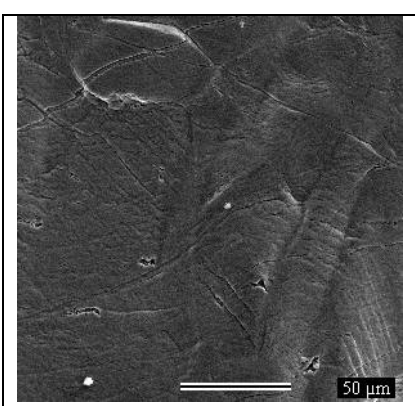

(a)

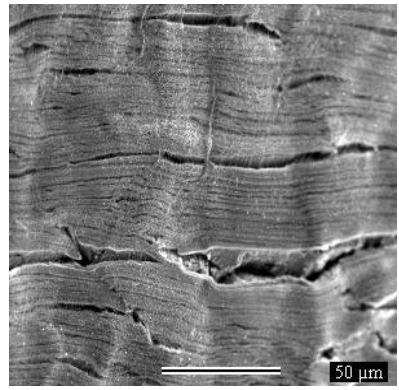

(b)

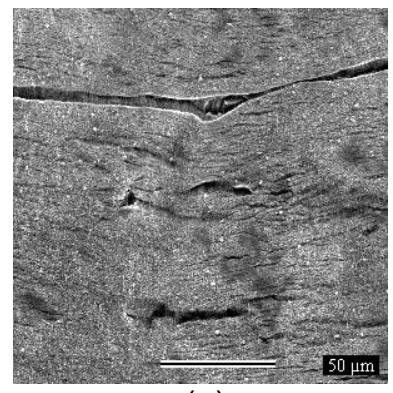

(c)

Figura 12.10. Microfratografias MEV, aumento de 500 vezes. Superfícies laterais dos espécimes de Inconel 600 MA. Ensaios de tração (a) SSRT $01\left(\mathrm{~N}_{2}\right)$, (b) SSRT 02 (RAP), (c) SSRT 03 (RAP). $303^{\circ} \mathrm{C}$. Pressão: 10 bar. Taxa de deformação: $3,0 \times 10^{-7} \mathrm{~s}^{-1}$ [CDTN, 2005].

Na Figura 12.11 são mostradas as superfícies de fratura do espécime ensaiado em meio neutro conforme (a) e dos espécimes ensaiados em meio do RAP conforme (b) e (c). Em nenhum deles foram detectadas as zonas de propagação de trincas por CST devido a que foram ensaiados com uma taxa de deformação relativamente elevada propiciando que houvesse apenas ruptura mecânica e não houvesse tempo suficiente de propagação. Assim em toda extensão as superfícies de ruptura apresentaram aspecto de fratura dúctil confirmada pela presença de dimples (pequenas cavidades) conforme mostrados na Figura 12.12 [CDTN, 2005].

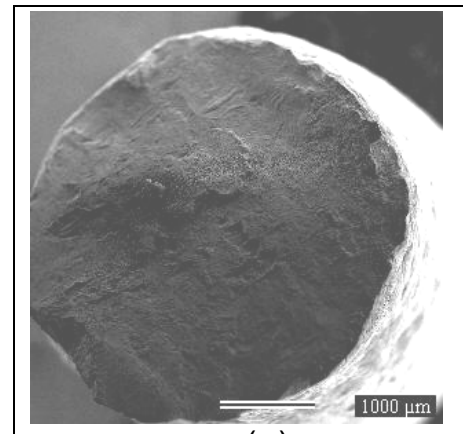

(a)

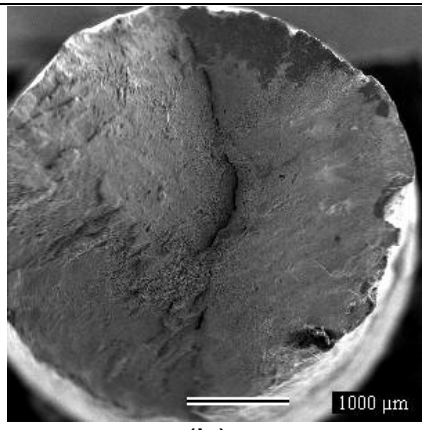

(b)

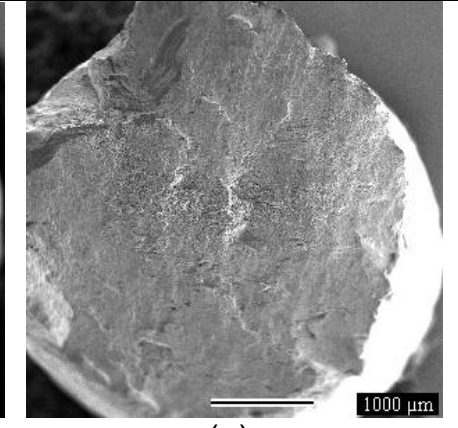

(c)

Figura 12.11. Microfratografias MEV, aumento de 20 vezes. Superfícies de fratura dos espécimes de Inconel 600 MA. Ensaios de tração lenta (a) SSRT 01 (N2), (b) SSRT 02 (RAP), (c) SSRT 03 (RAP) $303 \stackrel{\circ}{\circ}$. Pressão: 10 bar. Taxa de deformação: $3,0 \times 10^{-7} \mathrm{~s}^{-1}$ [CDTN, 2005]. 


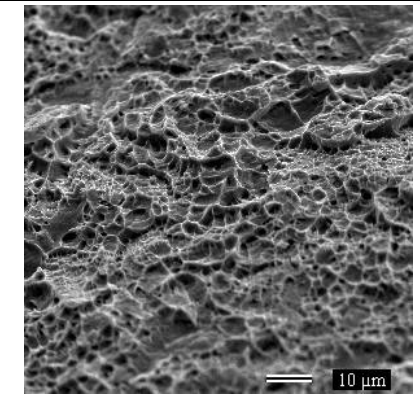

(a)

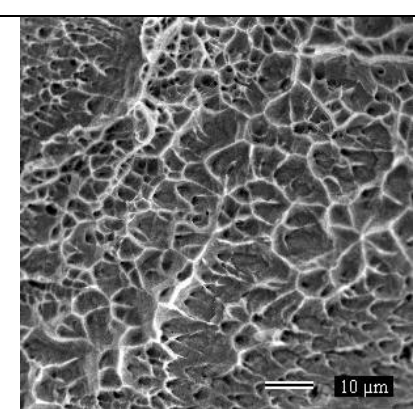

(b)

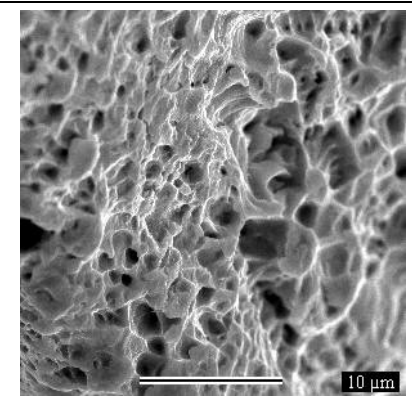

(c)

Figura 12.12. Microfratografias MEV, aumento de 1000 vezes. Superfícies laterais dos espécimes de Inconel 600 MA. Ensaios de tração (a) SSRT $01\left(\mathrm{~N}_{2}\right.$ ), (b) SSRT 02 (RAP), (c) SSRT 03 (RAP). $303 \stackrel{\circ}{\circ}$. Pressão: 10 bar. Taxa de deformação: $3,0 \times 10^{-7} \mathrm{~s}^{-1}$ : notar a aparência de coalescência de microvazios [CDTN, 2005].

O resultado estimado para o potencial da liga 600 nas condições de água primária à alta temperatura foi de $-621 \mathrm{mV}_{\mathrm{SHE}}$ (eletrodo padrão de hidrogênio) no $\mathrm{pH} 7,3$, conforme calculado na secção seguinte 12.4 .

12.4. Cálculo estimativo do potencial medido pelo CDTN em relação ao padrão de hidrogênio e observações sobre o valor encontrado

Para efetuar esse cálculo partiu-se do seguinte:

1-A temperatura do meio de ensaio foi $303^{\circ} \mathrm{C}$.

2- Pode-se considerar o $\mathrm{pH}$ do meio $\sim 7,3$, de acordo com o gráfico $\mathrm{pH} \times \mathrm{T}$ enviado pelo CDTN conforme Figura12.13.

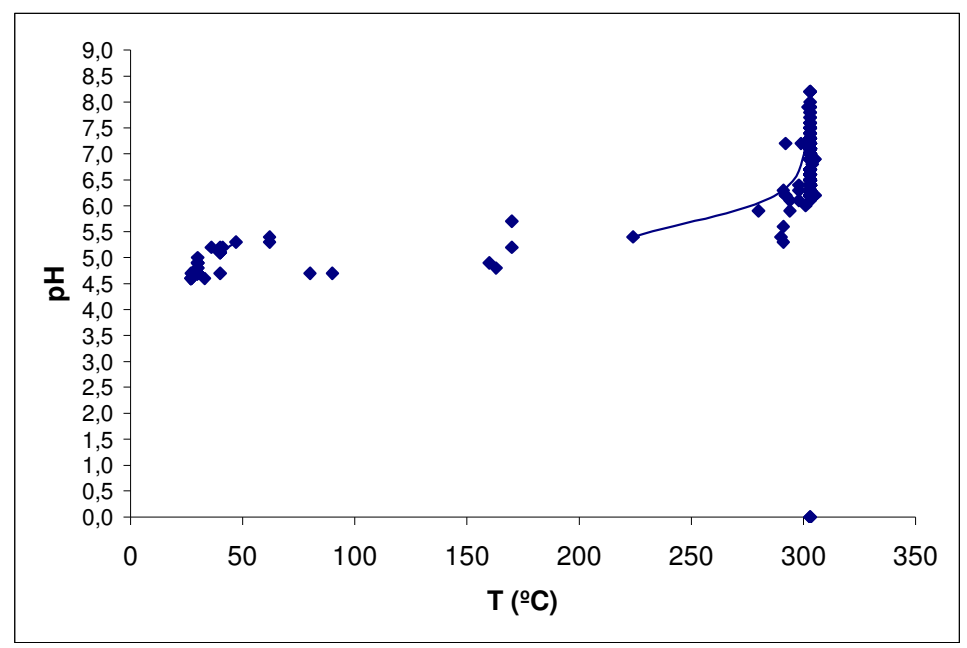

Figura 12.13. Gráfico do $\mathrm{pH}$ em função da temperatura para água do circuito primário fornecido pelo CDTN [CDTN, 2005]. 
3-Para se transformar o potencial aberto do eletrodo de referência de liga $600 \mathrm{em}$ meio água primária a alta temperatura obtido no ensaio eletroquímico em potencial padrão de hidrogênio $V_{S H E}$, deve-se utilizar a seguinte equação:

4- $O$ eletrodo utilizado foi um fio de platina. Aplicando-se a equação de Nernst:

$$
\mathrm{E}=\mathrm{E}_{0}-(2,303 \mathrm{RT} / \mathrm{F}) \mathrm{pH}-2,303 \mathrm{RT} \log \mathrm{p}_{\mathrm{H} 2}
$$

E substituindo nas equações acima $\mathrm{pH}=7,3$ e $\mathrm{T}=303^{\circ} \mathrm{C}$ (576K), constante de Faraday $F=96,494 \mathrm{kC} / \mathrm{mol}$ e constante universal dos gases $R=8,31 \mathrm{~J} / \mathrm{mol} . \mathrm{K}$, obtém-se a equação (12.4.2).

$$
\mathrm{E}=\mathrm{E}_{0}-0,114 \times 7,3-0,057 \log \mathrm{p}_{\mathrm{H} 2}
$$

5-É necessário então se estimar a pressão parcial de hidrogênio (em atm) a $303^{\circ} \mathrm{C}$, para resolver a equação acima, já que $2<\mathrm{E}_{0}<6 \mathrm{mV}$.

6-O hidrogênio é mantido a uma pressão de $25 \mathrm{~cm}^{3} / \mathrm{kg} \mathrm{H}_{2} \mathrm{O}$ a $25^{\circ} \mathrm{C}$. Essa condição gera uma determinada solubilidade do $\mathrm{H}_{2}$ na solução a alta temperatura. Como o sistema é fechado, supõe-se que na autoclave a $303^{\circ} \mathrm{C}$ haja uma correspondente solubilidade de $\mathrm{H}_{2}$, que deve ser estimada com base na literatura.

7- Utilizou-se a fórmula (12.4.3) sugerida por [CARON, 2001], para relacionar a concentração de hidrogênio à CNTP $\left(\left[\mathrm{H}_{2}\right]\right)$ com a pressão parcial de hidrogênio $\mathrm{P}_{\mathrm{H} 2}$ à alta temperatura:

$$
\left[\mathrm{H}_{2}\right]=\left(R \cdot \mathrm{T}_{0}\right) \mathrm{P}_{\mathrm{H} 2} /\left(\mathrm{P}_{0} \cdot \mathrm{K}_{\mathrm{H}} \cdot \mathrm{M}_{\mathrm{H} 2 \mathrm{O}}\right)
$$

com $\mathrm{R}=$ constante universal dos gases $\left(1,986 \mathrm{cal} / \mathrm{mol} .{ }^{0} \mathrm{~K}\right) ; \mathrm{T}_{0}=$ temperatura padrão $\left(25^{\circ} \mathrm{C}\right)$; $\mathrm{P}_{0}=$ pressão padrão $\left(10^{5} \mathrm{~Pa}\right)$; $\mathrm{M}_{\mathrm{H} 2 \mathrm{O}}=$ massa molar da água e $\mathrm{K}_{\mathrm{H}}=$ constante de Henry para soluto $\mathrm{H}_{2}$ e solvente $\mathrm{H}_{2} \mathrm{O}$ à alta temperatura, no caso $303^{\circ} \mathrm{C}$.

8-Para calcular $\mathrm{K}_{\mathrm{H}}=$ constante de Henry, utilizou-se a metodologia sugerida em [IAPWS, 2004], que sugere a fórmula (12.4.4) seguinte: 


$$
\ln \left(k_{H} / p^{*}{ }_{1}\right)=A / T_{R}+B T^{0,355} / T_{R}+C\left(T_{R}\right)^{-0,41} \exp T
$$

com $\mathrm{T}=1-\mathrm{T}_{\mathrm{R}}, \mathrm{T}_{\mathrm{R}}=\mathrm{T} / \mathrm{T}_{\mathrm{c} 1}, \mathrm{~T}_{\mathrm{c} 1}$ =temperatura crítica do solvente como recomendado pela IAPWS (647, $096 \mathrm{~K}$ para a $\mathrm{H}_{2} \mathrm{O}$ ) e $\mathrm{p}^{*}{ }_{1}=$ pressão de vapor do solvente na temperatura de interesse, regida pela relação (12.4.5).

$$
\ln \left(\mathrm{p}^{*}{ }_{1} / \mathrm{p}_{\mathrm{cl}}\right)=\mathrm{T}_{\mathrm{R}}^{-1} \sum_{\mathrm{i}=0}{ }^{\mathrm{n}} \mathrm{a}_{\mathrm{i}} \mathrm{T}^{\mathrm{bi}}
$$

com $n=6$ para a $\mathrm{H}_{2} \mathrm{O}$; $p_{\mathrm{cl}}=$ pressão crítica do solvente como recomendada pela IAPWS (22, 064 MPa para a $\mathrm{H}_{2} \mathrm{O}$ ) e os valores de $a_{i}$ e $b_{i}$ listados na Tabela 1 de [IAPWS, 2004]. Por facilidade $e$ para não ficar repetindo Tabelas e informações outras, está-se anexando todo o documento no Apêndice 2 (que pode ser inclusive obtido diretamente na internet).

Fazendo os cálculos, obteve-se para o caso em estudo, a constante de Henry $\mathrm{K}_{\mathrm{H}}=1,116 \mathrm{GPa}$ a $576,15 \mathrm{~K}$.

9-Voltando à expressão (12.4.3) e substituindo-se os valores citados, obtém-se a pressão parcial de hidrogênio, $\mathrm{p}_{\mathrm{H} 2}=23,77 \mathrm{~Pa}$ ou 0,00023 atm, $\operatorname{logo} \log \mathrm{p}_{\mathrm{H} 2} \sim-3,63$. Nota-se que essa pressão parcial está bastante "conservativa" para essa solução, comparando-se com as pressões parciais de $\mathrm{H}_{2}$ indicadas na Tabela 9 de [CARON, 2001] que indica uma pressão parcial dessa solução a $310^{\circ} \mathrm{C}$, partindo-se de uma concentração parcial de hidrogênio na CNTP de $30 \mathrm{ml} / \mathrm{kg} \mathrm{H}_{2} \underline{0}$, de cerca de $23 \mathrm{kPa}$, ou seja três ordens de grandeza maior. Deve-se levar em consideração no entanto, que não se está considerando o hidrogênio desprendido no eletrodo de liga 600 que pode ser considerável. De qualquer forma, esse hidrogênio adicional por ventura existente na solução irá abaixar o potencial entrando plenamente no

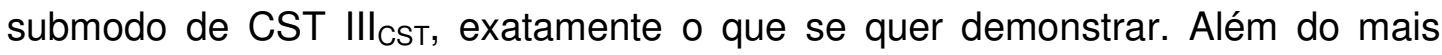
deve-se lembrar a observação de Andresen [ANDRESEN, 2005] de que o potencial é sempre mais baixo no interior da trinca do que na superfície do material (ver item 11.1), para se ver que há plena condição de desenvolvimento da trinca por CSTAP no submodo III $_{\text {CST. }}$.

10- Substituindo-se $\log \mathrm{p}_{\mathrm{H} 2}$ em (12.4.1) obtém-se $E=E_{0}-625 m V_{\mathrm{SHE}}$ e levando-se ainda em consideração que no experimento $E_{0}{ }^{\mathrm{MÉ} I \mathrm{OO}}=4 \mathrm{mV}$, obtém-se o valor de $\mathrm{E}=-621 \mathrm{mV}$ SHE. Isso mostra que esse potencial está na zona limítrofe dos 
submodos IPAS $_{\text {e }} \mathrm{III}_{\mathrm{CST}}$, tendendo um pouco abaixo para a zona III $\mathrm{IST}_{\mathrm{CS}}$, condição esperada do eletrodo, submetido à CSTAP. Portanto, confirmando plenamente Staehle em [STAEHLE, 1992] e outros documentos citados deste autor nesta Tese.

11- Vide reprodução da Figura 11.1 da Tese, a seguir com a marcação do ponto encontrado (Figura 12.14). 


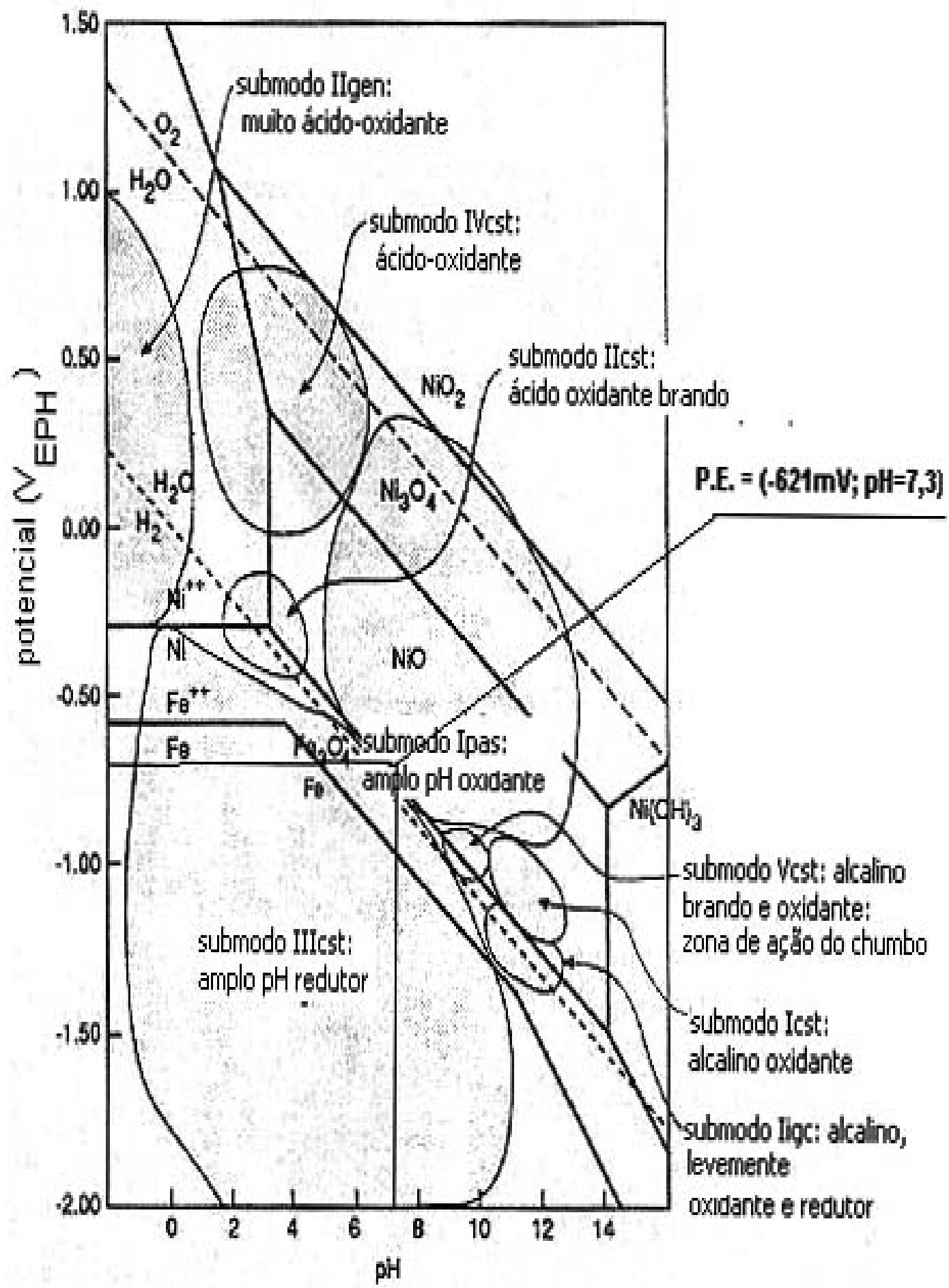

Figura 12.14. Reprodução da Figura 11.1 [STAEHLE, 1992a]: Diagrama de Pourbaix bidimensional $\mathrm{E} \times \mathrm{pH}$ para a liga 600 na faixa de $300^{\circ} \mathrm{C}$ utilizada como base sobre a qual foram marcadas as regiões de submodos de corrosão. Marcado o ponto encontrado nos experimentos eletroquímicos do CDTN. 
12.5. Dados da literatura utilizados para a representação gráfica de modelagem semi-empírica-probabilistica

Utilizou-se para isso, dados extraídos da literatura aplicando os dados existentes em [USNRC, 2001], reproduzidos na Tabela 12.4.

Tabela 12.4. Valores do parâmetro de escala de Weibull baseado em inspeção para inclinação de Weibull $b=1,5$ : utilizados para estimar os possíveis fatores de escala $\Theta$ na população de plantas de usinas. Foi assumido que esses valores de parâmetro de escala seguem uma distribuição lognormal e os valores das sete plantas onde foram detectadas trincas durante suas inspeções nos anos de 2000 e 2001 foram utilizados para estimar os parâmetros log-normais [USNRC, 2001].

\begin{tabular}{ccccc}
\hline Plantas & $\begin{array}{c}\text { Número de bocais } \\
\text { com vazamento }\end{array}$ & $\begin{array}{c}\text { Valores de Anos } \\
\text { Efetivos a Plena } \\
\text { Carga (AEPC) }\end{array}$ & $\begin{array}{c}\text { AEPC em } 315^{\circ} \mathrm{C} \\
\left(600{ }^{\circ} \mathrm{F}\right)\end{array}$ & $\begin{array}{c}\Theta \\
\text { semanas] }\end{array}$ \\
\hline $\begin{array}{c}\text { Oconee } \\
\text { unidade 3 }\end{array}$ & 9 & 20,1 & 21,7 & 82,9 \\
\hline $\begin{array}{c}\text { Oconee } \\
\text { unidade 2 }\end{array}$ & 4 & 20,3 & 22,0 & 152,5 \\
\hline $\begin{array}{c}\text { Oconee } \\
\text { unidade 1 }\end{array}$ & 1 & 20,4 & 21,7 & 463,3 \\
\hline ANO unidade 1 & 1 & 18,0 & 19,5 & 150,4 \\
\hline TMl unidade 1 & $3^{*}$ & 16,8 & 17,5 & 333,0 \\
\hline Crystal River & 1 & 14,9 & 15,6 & \\
unidade 3 & & & & 146,4 \\
\hline Surry unidade & $2^{*}$ & 19,5 & 16,6 & \\
1 & & & & \\
\hline
\end{tabular}

Notas:

1) Valores de AEPC (EFPY) correspondem aos de fevereiro de 2001.

2) Número de bocais com vazamento marcados com * significam informação preliminar.

3) Adotadas para o exemplo adicional a ser plotado: energia de ativação igual ao valor máximo para iniciação de trinca $Q=209 \mathrm{~kJ} / \mathrm{mol}$; tensão média em torno do bocal suposta constante e igual a $138 \mathrm{MPa}$ de acordo com o fabricante Babcock \& Wilcox. Para coeficiente do expoente de tensão foi adotado $n=-4,0$ [GORMAN et al., 1994]. 


\section{RESULTADOS E DISCUSSÃO}

Os resultados obtidos foram os seguintes de acordo com os modelos abaixo:

1) Modelo empírico-comparativo de Staehle

Com relação à CSTAP da liga 600, obtiveram-se os seguintes dados: os valores da Tabela 13.1 dos parâmetros de susceptibilidade à CSTAP [MATIAS\&SCHVARTZMAN, 2005].

Tabela 13.1. Parâmetros de avaliação semi-quantitativa da CSTAP de acordo com ensaios do CDTN [MATIAS\&SCHVARTZMAN, 2005].

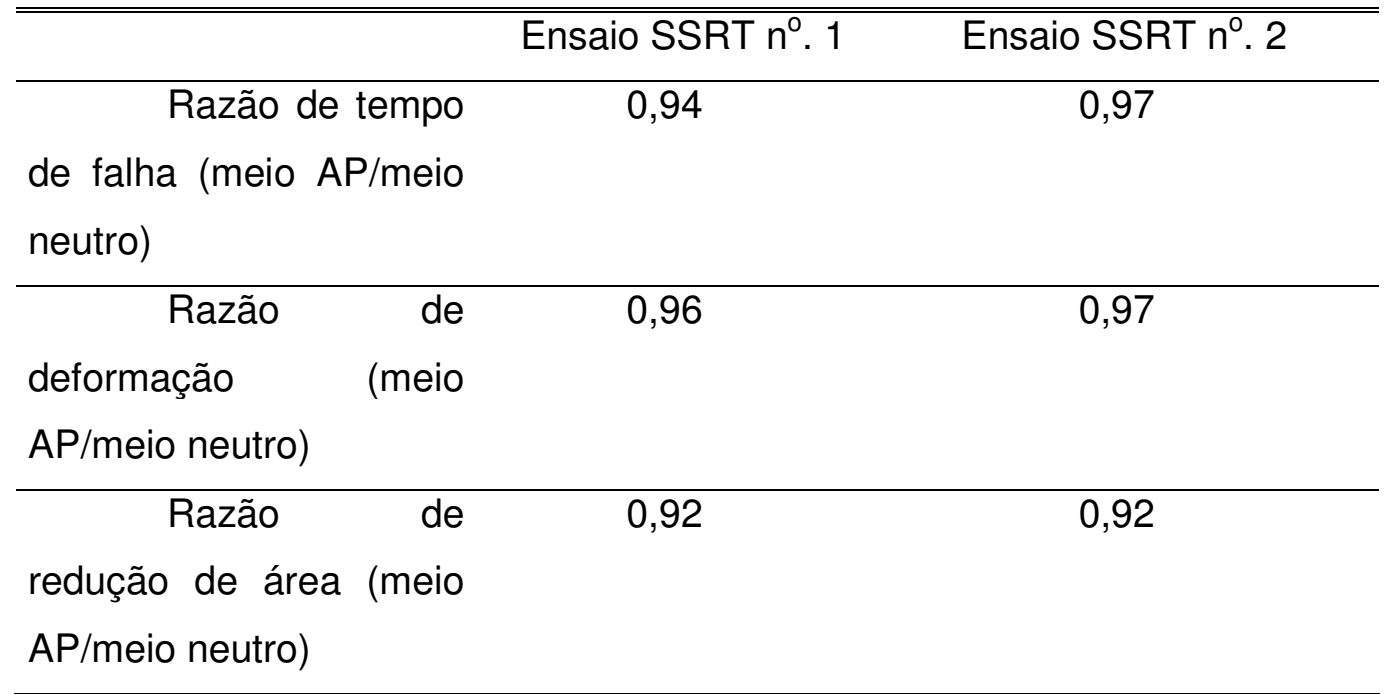

A partir desta informação estabelece-se um número que represente a fração de resistência à CSTAP, como a média aritmética da razão de tempo de falha dos dois ensaios= 0,95 ; este valor pode ser plotado no eixo $z$, fração de resistência à CSTAP, conforme a Figura 12.14. Obteve-se como valor (potencial, $\mathrm{pH})$ para esse ponto, (-621 $\mathrm{mV}_{\mathrm{EPH}}$ e $\left.\mathrm{pH}=7,3\right)$ : esse valor está no limite do

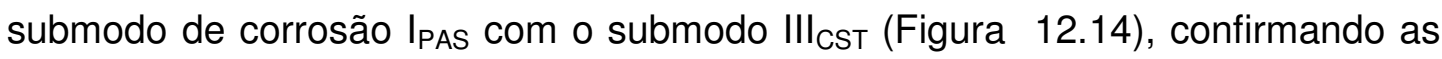
expectativas para a CSTAP da liga 600 na condição de ensaio e dentro do que prevê a literatura. Confirma-se assim a possibilidade da construção do modelo e modelagem empírico-comparativo de Staehle, embora também fique claro porque esse modelo não é prático, pois são necessários muitos ensaios para construí-lo ou validá-lo a partir de dados da literatura, o que já foi iniciado em [STAEHLE, 1992]. 
No entanto, foi nessa mesma referência que se recomendou que se continuasse reunindo esses dados nos diagramas da Figuras 9.1 e 11.1 para que se confirme/consolide seu modelo [STAEHLE, 1992a].

2) Modelo semi-empírico-probabilístico de Staehle

Obtiveram-se dois resultados concernentes a esse modelo, a partir dos dados experimentais e um resultado a partir dos dados da literatura:

a) Formulação da parte determinística do modelo semi-empírico probabilístico, baseado nos resultados obtidos pelo CDTN: esses foram os tempos de iniciação $=482,4 \mathrm{~h}$ e 494, $4 \mathrm{~h}$ em dois ensaios [SCHVARTZMAN et al., 2005]; em virtude da proximidade dos valores obtidos, considerou-se a média aritmética dos mesmos, para a formulação da parte determinística do experimento, conforme equação (13.1.1).

$$
t_{i}=1,45 \cdot 10^{-13} \cdot \sigma^{-4} \cdot \exp (32882,35 / T)
$$

com $t_{i}=$ tempo de iniciação em dias, $\sigma$ =tensão em MPa e T=temperatura absoluta do meio em ${ }^{\circ} \mathrm{K}$; os valores de parâmetros assumidos (não experimentais) da modelagem foram retirados de [GORMAN et al., 1994].

A seguir fornece-se a formulação dessa equação:

- A parte determinística da modelagem semi-empírica-probabilística é regida pela equação (13.1.2).

$$
t_{i}=A^{\prime} \cdot \sigma^{n} \cdot \exp (Q / R T)
$$

De acordo com os experimentos do CDTN, temos os tempos de iniciação de falha iguais a 453,4 horas e 479,5 horas, em dois experimentos. Para achar os parâmetros da equação (12.1.1), consideramos então o tempo de iniciação como sendo a média aritmética desses 2 valores de tempo obtém-se:

$$
t_{i}=(453,4+479,5) /(24.2) \sim 19,43 \text { dias }
$$


Para $Q_{i}$ adotou-se um valor $=65,218 \mathrm{kcal} / \mathrm{mol}$, valor da energia de ativação aparente adotada para a liga 600 LTMA (laminada e recozida à baixa temperatura), extraído da Tabela 2-2 de [GARUD, 1997].

$$
\mathrm{Q}_{\mathrm{i}} / \mathrm{RT}=32822,35 / \mathrm{T}
$$

com T em K.

- Cálculo de A':

Considera-se $n=-4$, parâmetro normalmente adotado para o caso da liga 600 LTMA em condições de CSTAP [GORMAN et al., 1994].

Da equação (13.1.2) sai $A^{\prime}=t_{i} \sigma^{-n} \exp (-Q / R T)$. $\mathrm{R}=$ constante universal dos gases $=0,001987 \mathrm{kcal} / \mathrm{mol}$ e $\mathrm{T}=303^{0} \mathrm{C}=576,15 \mathrm{~K}$.

O valor da tensão residual $\sigma$ para cálculo do parâmetro $A^{\prime}$ foi considerado como sendo o valor médio dos limites inferior e superior da tensão de escoamento, que conforme a Figura 12.4. Assim $\sigma=(300+600) / 2=450 \mathrm{MPa}$.

$A^{\prime}=19,43 .(450)^{4} \exp [-65,218 /(0,001987 \times 576,15)]=1,45.10^{-13}([A]=[$ adimensional $])$

Assim a equação (13.1.2) é parametrizada para o caso em estudo para (13.1.1).

Deve-se ainda comentar que os dados experimentais do CDTN estão compatíveis com os valores da literatura [STAEHLE, 1992a]; [STAEHLE, 2001]; [GARUD, 1997], porém de acordo com valores que podem ser bastante conservadores, isto é, assumindo iniciação de trinca muito precoce. Uma possível explicação para isso é que a iniciação foi detectada muito precocemente por causa das condições de ensaio muito mais críticas do que elas são na realidade de campo, ou seja na própria instalação do RAP; de qualquer modo, isto pode ser investigado fazendose ensaios adicionais, mesmo porque esses seriam úteis para se chegar à formulação da parte probabilística do modelo, que exige pelo menos sete ensaios para que se possa aplicar a distribuição estatística de Weibull.

b) A partir de dados da literatura, estabeleceu-se um gráfico de modelagens semi-empíricas-probabilísticas partindo-se de um exemplo real dado por esses autores e construiu-se o modelo graficamente para algumas plantas 
incluindo o pior e o menos ruim dos casos de defeitos ocorridos até novembro de 2001, de acordo com [USNRC, 2001]. Esses gráficos podem ser vistos na Figura 13.1. Para obter os resultados numéricos com o uso do modelo semi-empírico, foi construída uma planilha do Microsoft Excel, que está reproduzida no Apêndice 2.

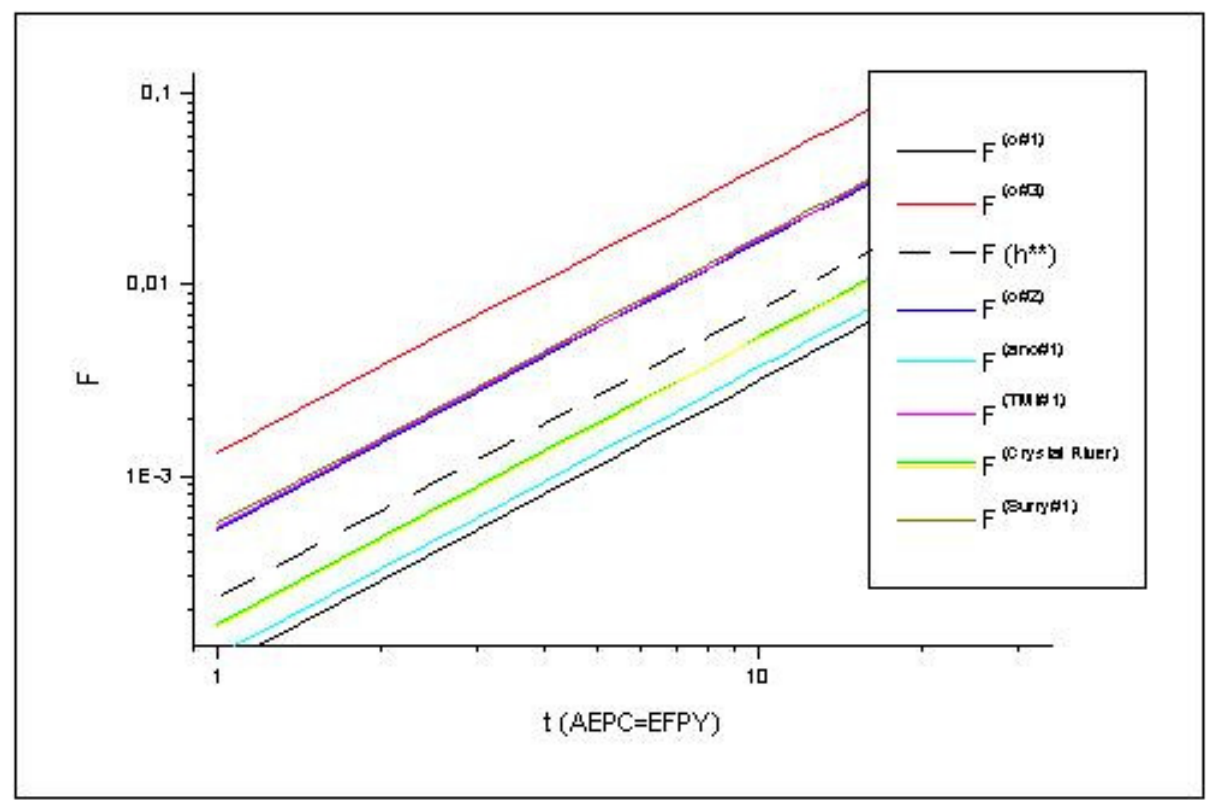

Figura 13.1. Diagrama das retas plotadas para a Tabela 12.4 comparadas com a reta hipotética a partir da modelagem 'semi-empírica nesta pesquisa: o parâmetro de inclinação b de Weibull é igual a 1,5. $\mathrm{F}\left(\mathrm{h}^{\star *}\right)$ é a reta plotada para a hipótese de se assumir distribuição estatística semelhante para os experimentos do CDTN (item 13.2) a)). Os índices sobrescritos do fator F referem-se às unidades de RAP consideradas: Oconee\#1, Oconee\#3, estimativa para o caso em estudo, Oconee \#2, ANO\#1, TMI(Three Mile Island) \#1, Crystal River e Surry \#1: todas usinas nos EUA.

Assim se construíram os gráficos $F$ (falhas acumuladas) em função do tempo de operação dessas usinas. Ressalte-se que essa fração acumulada de falhas refere-se ao total de falhas acumuladas relativas à CSTAP em bocais do MAB em cada uma das usinas. Com base nesse resultado é possível se estimar por analogia, a fração de falhas acumuladas para unidades semelhantes, desde que possam ser aproximadas suas condições de projeto e operacionais.

Sobrepondo essas retas obtidas na Figura 13.1, com um diagrama de Pourbaix marcado com os submodos de CST como o da Figura 11.1, sabendo-se quanto tempo uma unidade de uma planta operou no submodo $\mathrm{III}_{\mathrm{CST}}$, pode-se avaliar o parâmetro $\mathrm{F}$, fração do número de componentes que são susceptíveis ao mesmo tipo de defeito nesse submodo e que pode sofrer CSTAP. 
c) Na Figura 13.1 está mostrada também uma reta hipotética considerando como parte determinística a equação (13.1.1), admitindo-se que fossem feitos maior número de experimentos para ajustá-la estatisticamente e que essa distribuição fosse semelhante às obtidas com as outras retas, isto é com o parâmetro de inclinação de Weibull $b=1,5$. Nesse caso, a reta de resultado mostra-se entre ANO \# 1 e Oconee \#2. Isto significa que nesse caso é possível estabelecer um critério de inspeção intermediário entre essas duas unidades de RAP, para balizar uma inspeção de uma usina onde as condições operacionais e o material sejam análogos aos experimentos realizados no CDTN.

d) Um outro ponto a ressaltar é que o modelo semi-empíricoprobabílistico é muito prático para se desenvolver previsões de CSTAP: se for conhecido o tempo total em que o reator opera num determinado modo de CSTAP, o parâmetro $\mathrm{F}$ pode ser estimado. Assim pode-se relacionar o acúmulo do dano com a variação nos valores de $\left(\mathrm{pH}, \mathrm{V}_{\mathrm{H}}\right)$ no domínio considerado para a CSTAP: esses valores normalmente estão abaixo da linha de equilíbrio para a transformação $\mathrm{Ni} / \mathrm{NiO}$ no caso do submodo de corrosão III CST [SCOTT\&LECALVAR,1993],[FOCT, 1999]. O pH apresenta uma dependência com a velocidade de crescimento de trinca (dD/dt ou CGR="crack growth rate") como é inferido da equação (3) de [EPRI, 2002] e é mostrado na equação (13.1.3).

$$
\frac{\mathrm{dD}}{\mathrm{dt}}=\mathrm{CGR}=\mathrm{C} \cdot\left(\frac{\mathrm{pH}}{7,5}\right)^{2} \quad \text { para } 7.5 \leq \mathrm{pH} \leq 9
$$

Considerando-se a iniciação e a propagação da trinca como um dano é possível que a iniciação possa seguir a mesma lei de tempo integrada com diferente parâmetro de ajuste (constante $C$ ) para iniciação e propagação. Assim deve-se esperá-la na forma (13.1.3) e investigar a variação nessa lei. É esperado um valor menor para o parâmetro $\mathrm{F}$ para um valor menor de $\mathrm{pH}$. Em todo caso é necessário obter a relação entre dano e variação nos valores de $\left(\mathrm{pH}, \mathrm{V}_{\mathrm{H}}\right)$ no domínio da CSTAP, através de ensaios experimentais no SSRT no CDTN. Referente às plantas consideradas na Figura 13.1, pode ser desejável saber onde estavam os valores de $\left(\mathrm{pH}, \mathrm{V}_{\mathrm{H}}\right)$ considerados para cada uma delas operar. 
e) A parte determinística do modelo semi-empírico-probabilístico pode ainda ser considerada uma simplificação do modelo de dano por taxa de deformação quando um dos modelos de comportamento para a fluência da liga 600 é utilizado em sua formulação [LECLERCQ \& VAILLANT apud [GORMAN et al., 1994].

3) Modelo simplificado de tempo de iniciação de Garud

Obteve-se a equação (13.1.4) concernente a esse modelo, com base em parâmetros apresentados em [GARUD, 1997] e [SCHVARTZMAN et al., 2005].

$$
t_{i}=4,88 \cdot 10^{-23} \exp (32822,35 / T) \cdot \ln [1,79(278,5 / \sigma)]
$$

com $\mathrm{t}_{\mathrm{i}}=$ tempo de iniciação em dias; $\sigma=$ tensão em MPa e T=temperatura absoluta do meio em K; os valores de parâmetros assumidos (não experimentais) da modelagem foram retirados de [GARUD, 1997]. Assumiu-se ainda para a formulação da equação (13.1.4), ao invés de uma tensão $\sigma$ aplicada uniforme e axial (porque o modelo original foi concebido para ensaio de tubo em carga constante), uma tensão média $\sigma_{\mathrm{M}}=464 \mathrm{MPa}$, uma vez que a carga no ensaio de SSRT é variável (com deformação constante) sendo esse valor médio correspondendo à média entre o limite superior elástico e a tensão máxima de escoamento atingida no ensaio: assim a modelagem segue as etapas abaixo.

- Nessa modelagem, a equação do tempo de iniciação é dada por (13.1.5).

$$
t_{i}=\alpha_{i} \exp (Q / R T) \cdot \ln \left[A\left(\sigma_{y} / \sigma\right)\right]
$$

- De acordo com os experimentos do CDTN, temos os tempos de iniciação de falha iguais a 453,4 horas e 479,5 horas, em dois experimentos. Para achar os parâmetros da equação (13.1.5), consideramos então o tempo de iniciação como sendo a média aritmética desses dois valores de tempo:

$$
\mathrm{t}_{\mathrm{i}}=(453,4+479,5) /(24.2) \sim 19,43 \text { dias }
$$

- Para calcular o valor de $\alpha_{i}$, deve-se calcular $Q_{i} / R T$, para $T=303^{\circ} \mathrm{C}$. Para $Q_{i}$, adotou-se um valor $=65,218 \mathrm{kcal} / \mathrm{mol}$, valor da energia de ativação aparente 
adotada para a liga 600 LTMA (laminada e recozida à baixa temperatura), extraído da Tabela 2-2 de [GARUD, 1997].

$$
\mathrm{Q}_{\mathrm{i}} / \mathrm{RT} \sim 56,97 \rightarrow \exp \mathrm{Q}_{\mathrm{i}} / \mathrm{RT}=5,51.10^{24}
$$

O valor de A sai da Tabela 2-1 de [GARUD, 1997] e é igual a 1,791 para a liga 600 LTMA.

Da Tabela 12.3 tem-se $\sigma_{y}=278,5 \mathrm{MPa}$, ou seja, a média entre os $\sigma_{\mathrm{y}}$ dos ensaios SSRT 02 e 03) e o valor da tensão residual $\sigma$ foi considerado como sendo o valor médio dos limites inferior e superior da tensão de escoamento, conforme a mesma Tabela. Assim $\sigma=(278,5+649) / 2 \sim 464 \mathrm{MPa}$.

- Substituindo esses valores na equação (13.1.5) sai o valor de $\alpha_{i}=4,88.10^{-23}$ e conseqüentemente o valor parametrizado da equação (13.1.4).

Valem ainda os mesmos comentários do item 2a) e se faz em complemento o seguinte: esse modelo difere basicamente da parte determinística do modelo empírico-probabilístico na sua consideração do logaritmo da tensão (ao invés da tensão elevada à potência -4). O pesquisador Garud em correspondência a nós enviada comentando este trabalho de Tese que apresentamos oralmente no EICM-2 no Canadá em setembro de 2004 [ALY \& al., 2004], considera mais apropriado o uso de logaritmo ao invés da potência que vale numa faixa muito limitada de tensão. Isto foi mostrado nos trabalhos de Garud e Mcllree (1995) e Garud e Pathania (1999) [GARUD, 2004].

4) Modelo de dano por taxa de deformação de Boursier

Obteve-se o resultado (13.1.6) concernente a esse modelo, com utilização dos dados do CDTN [SCHVARTZMAN et al., 2005].

$$
t_{i}=8,28 \cdot 10^{-4} \cdot \dot{e}_{S S R T}{ }^{-0,67}
$$

com $t_{i}=$ tempo de iniciação em dias; $\dot{e}_{S S R T}=t a x a$ de deformação utilizada no ensaio SSRT/CERT correspondente à taxa de deformação aparente ou macroscópica, em s ${ }^{-1}$ e para uma temperatura fixada de $303^{\circ} \mathrm{C}$.

A expressão (13.1.6) corresponde a uma simplificação da expressão (8.1.3) apenas para a fase de iniciação da trinca (velocidade de propagação 0) e considerando-se è SSRT $\leq 2,5 \cdot 10^{-7} \mathrm{~s}^{-1}$, ou seja quando a relação da taxa de 
deformação na ponta da trinca $\dot{e}_{\mathrm{PT}}$ com ésSRT é por volta de 3, conforme Tabela 5 de [BOURSIER et al, 1995]. A formulação da modelagem é mostrada a seguir.

-A taxa de deformação (è) é o parâmetro mais adequado para exprimir a CSTAP da liga 600: Boursier propõe então a equação (13.1.7) [BOURSIER et al., 1995], sendo $\mathrm{t}_{\mathrm{i}}=$ tempo de iniciação [s]; $\dot{e}_{\mathrm{CT}}=$ taxa de deformação na ponta da trinca $\left[\mathrm{s}^{-1}\right] \mathrm{e}$ $\mathrm{K}=$ constante $\left[\mathrm{s}^{-1 / 3}\right]$ :

$$
\mathrm{t}_{\mathrm{i}}=\mathrm{K} \cdot \dot{\mathrm{e}}_{\mathrm{CT}} \mathrm{-0,67}^{-0 .}
$$

-Para $\dot{e}_{\text {app }}=\dot{e}_{S S R T}=3 \cdot 10^{-7} \mathrm{~s}^{-1}$ que foi o valor utilizado para os ensaios com liga 600 no CDTN, temos, para o regime de propagação lenta e considerando a Tabela 5 de [BOURSIER et al., 1995], a equação (13.1.8).

$$
\dot{\mathrm{e}}_{\mathrm{CT}} / \dot{\mathrm{e}}_{\mathrm{app}} \sim 3
$$

- Determinação de K: O tempo de iniciação nos experimentos do CDTN foi $t=19$, 43 dias. Portanto, substituindo os valores de $t_{i}[s]$ e é SSRT $\left[\mathrm{s}^{-1}\right]$ em (13.1.8) e (13.1.7) resulta $\mathrm{K}=71,78\left[\mathrm{~s}^{-1 / 3}\right]$.

Melhor dividir por 3600s $\times 24 \mathrm{~h}$, para se obter $t_{i}$ em [dias] e chega-se a (13.1.6), fixada a temperatura $\mathrm{T}=303^{0} \mathrm{C}$ e válido para $[\mathrm{e}] \leq 2,5.10^{-1} \mathrm{~s}^{-1}$.

Constata-se assim que essa expressão tem aplicação limitada aos ensaios de SSRT numa faixa reduzida de taxa de deformação. No entanto, é possível se pensar numa aplicação de campo utilizando ensaios de extensometria, aplicação para a qual esse modelo desenvolvido poderia servir. 


\section{CONCLUSÕES}

Com relação ao que foi realizado nesta Tese, pode-se tirar as seguintes conclusões:

- É possível utilizar os dados dos ensaios de SSRT para efetuar a modelagem a partir de alguns modelos de CSTAP à alta temperatura da liga 600: neste trabalho foram realizadas as modelagens, baseadas em alguns ensaios realizados no CDTN dos modelos empírico-comparativo, semi-empírico probabilístico (parte determinística), modelo simplificado de tempo de iniciação e modelo de taxa de deformação;

- A utilização dos diagramas de Pourbaix (potencial x pH) para localização das condições termodinâmicas apropriadas para ocorrer os diversos submodos de corrosão, acoplado ao uso de modelos que exprimem a cinética da iniciação e/ou crescimento das trincas, tem a vantagem de melhorar a previsibilidade desse tipo de corrosão bastante complexo, e também de proporcionar uma metodologia de pesquisa para a CSTAP. Essa utilização pode ser estendida a quaisquer tipos de CST, utilizando outros materiais e temperaturas e pode ser o início de elaboração de diagramas funcionais de operação que sinalizam o início de falhas;

- Os dados experimentais do CDTN estão compatíveis com os valores da literatura [STAEHLE, 1992a]; [STAEHLE, 2001]; [GARUD, 1997], porém de acordo com valores que podem ser bastante conservadores, isto é, assumindo iniciação de trinca muito precoce. Uma possível explicação para isso é que a iniciação foi detectada muito precocemente por causa das condições de ensaio muito mais críticas do que elas são na realidade de campo. O potencial de hidrogênio estimado para os ensaios do CDTN (-621 mV) está compatível com a localização na região limítrofe de submodo III $I_{\text {CST }}$ com a região de passivação: região onde normalmente ocorre a CSTAP dos bocais do MAB, de acordo com a literatura [STAEHLE, 1992a], [TOTSUKA \& SMIALOWSKA, 1988].

- A utilização do modelo empírico-comparativo de Staehle, permite que se utilize imediatamente os resultados de susceptibilidade à CST dos ensaios ETDL 
(SSRT/CERT), gerando um modelo semi-quantitativo, mas tem a desvantagem de exigir um grande volume de dados, em diversas temperaturas, para que seja relativamente completo e possa ser utilizável. Recomenda-se classificar e arquivar convenientemente todos os ensaios em SSRT, pois os mesmos poderão ser úteis para construir esse tipo de modelo;

- Quanto ao modelo semi-empírico-probabilístico de Staehle, obteve-se a modelagem da parte determinística para os dados obtidos no CDTN, mas são necessários pelo menos sete ensaios ( $v$. Apêndice 1) para poder ser modelada sua função probabilística taxa de falha acumulada $x$ tempo de operação. Por outro lado, a modelagem efetuada utilizando dados da literatura de diversas usinas, pode servir para se ter uma estimativa inicial de tempo de falha em usinas similares;

- Quanto ao modelo simplificado de tempo de iniciação de Garud, obtevese uma modelagem aproximada porque os ensaios não foram feitos em carga constante e sim com taxa de deformação constante: é um modelo de aplicação muito prática e rápida e está amplamente validado com dados da literatura. Recomenda-se, portanto, caso seja possível e conveniente, efetuar ensaios de carga constante para validação de situações particulares que o possam exigir;

- Quanto ao modelo de dano por taxa de deformação de Boursier, é possível utilizá-lo diretamente a partir de ensaios de SSRT, embora ele seja mais limitado do que os anteriores - exceto o empírico-comparativo que exige muitos ensaios em cada temperatura. 


\section{RECOMENDAÇÕES PARA PROSSEGUIMENTO DA PESQUISA}

Através das aplicações mostradas vê-se que há muito a ser feito em matéria de modelagem da CSTAP da liga 600, podendo ser iniciada uma ou mais linhas de pesquisa no assunto que é de muito interesse principalmente para a indústria: energia, termoeletricidade, metal-mecânica, petroquímica, entre várias. Dispõe-se inclusive de uma poderosa ferramenta de investigações no CDTN, que é a máquina de ensaios ETDL/ SSRT. Nesta Tese foram iniciadas e exemplificadas algumas possíveis modelagens a serem feitas com amostras de liga 600 para investigar a CSTAP. Por motivos didáticos, a seguir dividir-se-ão as recomendações em quatro abordagens distintas:

1- Continuação da investigação de CSTAP na liga 600:

a) Em material como recebido, através de diferentes amostras industriais com diferentes tratamentos térmicos e tratamentos superficiais. Destaca-se aqui a necessidade de se testarem amostras trabalhadas a frio/encruadas. Esses resultados seriam úteis para consolidar também as modelagens obtidas nesta Tese. Destaca-se ainda a conveniência de repetirem-se mais vezes os ensaios nos quais as modelagens foram baseadas, para garantir a reprodutibilidade desses ensaios;

b) Variando as condições do meio onde aparece a CSTAP: teores de oxigênio e hidrogênio dissolvido, substâncias diversas como hidróxido de lítio, ácido bórico, zinco, etc. e ainda a temperatura, $\mathrm{pH}$ e potencial;

c) Considerando-se fases diversas dos defeitos por CSTAP, como iniciação, propagação, falha (combinação de iniciação e propagação) ou simplesmente dano mecânico;

d) Considerando-se diversos modelos ou modelagens. Neste estudo já se aponta para alguns que são bastante interessantes e promissores: modelo empírico-probabilístico de Staehle (efetuar série suficiente de ensaios para poder dar o tratamento estatístico, utilizar variações na composição da amostra como, por exemplo, zonas de transição da liga 600 com liga 82, liga 182, aços inoxidáveis, e outros materiais dissimilares); modelo semi-empírico determinístico de dano por taxa de deformação de Garud e Gerber (completar rotina computacional da modelagem através dos dados de SSRT de acordo com a 
rotina sugerida no item 10.2, efetuar ensaios de SSRT em pelo menos duas diferentes temperaturas do meio para poder servir de entrada para aplicação da rotina computacional de modelagem); modelo de taxa de deformação simplificada de Garud (conforme rotina apresentada no item 10.3, através de ensaios de carga constante que podem ser realizados com o mesmo equipamento para os ETDL/CERT/SSRT); modelo empírico-comparativo (validar diferentes regiões de submodos no diagrama de Pourbaix potencial $\times \mathrm{pH}$ ). Podem ser elaboradas ainda novas modelagens, como por exemplo, para aplicação do modelo de oxidação intergranular para a iniciação de trincas por CSTAP na liga 600 nas zonas superiores do diagrama de Pourbaix, isto é, nas zonas oxidantes;

2- Investigação de CSTAP em outros materiais, meios e temperaturas: por exemplo, podem ser desenvolvidos os itens 1.a a 1.d acima para outros materiais de interesse na indústria, como para os aços inoxidáveis, ligas 82 e 182 além de regiões de transição de soldas dissimilares que apresentam características físicoquímicas particulares;

3- Estudo de aplicações tecnológicas específicas para regiões sujeitas à CSTAP, por exemplo, considerando a influência e histórico do regime operacional: dentro do atual estado de conhecimento é extremamente difícil a definição de um regime operacional seguro para se evitar a CSTAP. No entanto, há estudos feitos para usinas nucleares específicas, tendo como resultados gráficos das regiões de susceptibilidade à CSTAP em função do teor de oxigênio e da temperatura do meio, conforme exemplo mostrado na Figura 15.1 para a Usina de VermontYankee [ROBERTS, 1981].

Com base nesses estudos pode-se inclusive determinar precisamente as medidas mais adequadas para se evitar trincas por CSTAP, como por exemplo a utilização de proteção catódica, ou outras. Pode-se seguir, por exemplo, o roteiro que Gorman e outros pesquisadores estabeleceram para investigar a influência dos transientes de partida durante os quais se produz ambientes ricos em oxigênio e que provocam o aparecimento de CSTIG em partes de liga 600 do circuito secundário de RAP [GORMAN et al., 1998]. 


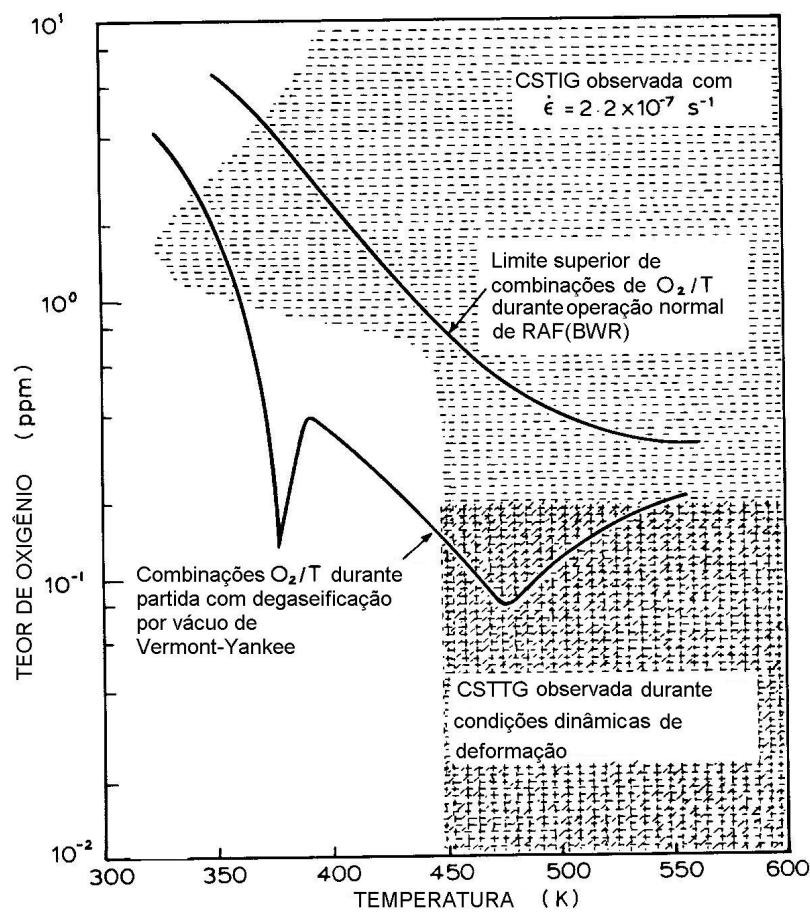

Figura 15.1. Regiões de susceptibilidade à corrosão sob tensão superpostas sobre combinações de temperatura/ teor de oxigênio, para partidas de unidades do tipo RAF (BWR) [ROBERTS, 1981].

4- Formação e treinamento de pesquisadores na área de corrosão sob tensão: nota-se pelos itens anteriores o quanto há para se fazer em relação a pesquisa da CST no Brasil. Na verdade, essa é uma área evitada por boa parte dos candidatos a pesquisadores não só no Brasil, mas inclusive no mundo. Devese ter presente a necessidade de se desenvolver cursos a nível de pós-graduação no assunto, que envolvem profunda interdisciplinaridade entre áreas normalmente distintas do conhecimento: Mecânica da Fratura, Eletroquímica e Corrosão e Materiais. Shipilov por exemplo, propôs um curso independente e interdisciplinar específico sobre Corrosão Sob Tensão, para os alunos da Faculdade de Ciência dos Materiais da Universidade Estatal Lomonosov de Moscou e do Departamento de Metalurgia Física e Tratamento Térmico de Metais na Universidade Técnica Estatal Bauman de Moscou, detalhado em [SHIPILOV, 1996].

5- Modelos e modelagem são excelentes objetos para uma linha de pesquisa, pois há muito o que fazer nesse campo, no Brasil e no mundo: não só desenvolver, validar e aperfeiçoar a aplicação dos quatro modelos acima citados, mas desenvolver outros, como por exemplo, a modelagem através do modelo de 
dano por taxa de deformação de Garud e Gerber, a modelagem através do modelo de oxidação interna—bastante adequado para explicar iniciação de falhas em liga 600 e aços inoxidáveis em submodo de corrosão IV $V_{\text {CST }}$. 


\section{APÊNDICES}




\subsection{APÊNDICE 1: DISTRIBUIÇÃO DE WEIBULL}

Dada uma função $g(x)$ com $g(0)=0$ e monotonicamente crescente ao infinito à medida que $x$ vai ao infinito, pode-se definir uma função cumulativa de probabilidade de acordo com (16.1.1) [MATHPAGES, 2006].

$$
F(t)=1-e^{-g(t)}
$$

A probabilidade é $F(0)=0$ em $t=0$ e cresce monotonicamente a 1,0 quando $t$ tende a infinito. A correspondente densidade de distribuição $f(t)$ é a derivada da expressão (16.1.1) resultando em (16.1.2).

$$
f(t)=g^{\prime}(t) e^{-g(t)}
$$

Pode-se definir a taxa de ocorrência para uma dada densidade de distribuição por (16. 1.3).

$$
R(t)=f(t) /[1-F(t)]
$$

De modo que substituindo-se (16. 1.1) e (16. 1.2) em (16. 1.3), tem-se (16. 1.4).

$$
R(t)=g^{\prime}(t) e^{-g(t)} /\left[1-\left(1-e^{-g(t)}\right)\right]=g^{\prime}(t)
$$

Isso permite que se defina a distribuição de densidade de probabilidade com uma dada função de razão $R(t)$. Uma família útil de funções de razão de dois parâmetros é dada por (16. 1.5).

$$
R(t)=(\beta / \alpha)(t / \alpha)^{\beta-1}
$$

com a e $\beta$ constantes. Essa é chamada família de distribuições de Weibull, em homenagem ao engenheiro sueco Waloddi Weibull (1887-1979) que popularizou seu uso para análise de confiabilidade, especialmente para modos de falha metalúrgicos. O primeiro artigo de Weibull nesse assunto data de 1939 (embora o 
estatístico Emil Gumbel (1891-1966) o tenha estudado desde a década de 1920), mas não atraiu muitas atenções até a década de 1950.

A constante $\alpha$ é chamada de parâmetro de escala porque ela escala a variável t e a constante $\beta$ é chamada parâmetro de forma porque determina a forma da função de razão. Às vezes a variável t é substituída por t-y, onde y é um terceiro parâmetro utilizado para definir um ponto de abscissa zero adequado, como por exemplo, na distribuição de Weibull de três parâmetros que considera a iniciação e a propagação de uma trinca. Se $\beta$ é maior do que 1 , a razão cresce com t, enquanto que se $\beta$ for menor do que 1 a razão decresce com t. Se $\beta=1$ a razão é constante, no caso a distribuição de Weibull torna-se igual à distribuição exponencial. As formas das funções de razão para a família de distribuições de Weibull são ilustradas na figura 16.1 .

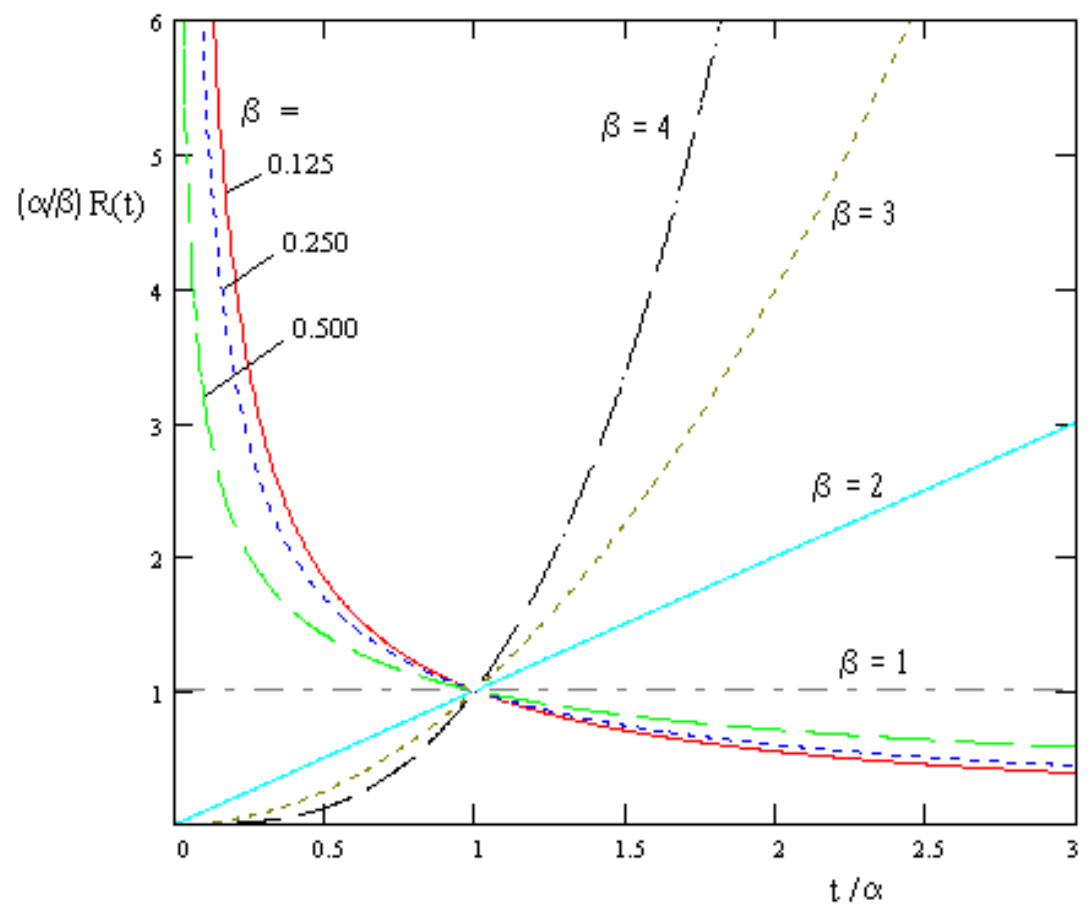

Figura 16.1 Curvas da família de distribuições de Weibull para diferentes parâmetros de forma $\beta$ [MATHPAGES, 2006].

Desde que por (16.1.4) $R(t)=g^{\prime}(t)$, pode-se integrá-la de modo que resulta em (16.1.6). 


$$
g(t)=(t / \alpha)^{\beta}
$$

Fica claro que para quaisquer parâmetros $\alpha$ e $\beta$ positivos, a função $g(t)$ cresce monotonicamente de 0 a infinito, de modo que se pode definir por (A 1.7) uma densidade de distribuição acumulativa que seja válida quando t cresce de 0 a infinito.

$$
F(t)=1-\exp \left[-(t / \alpha)^{\beta}\right]
$$

Com a correspondente densidade de distribuição igual a (16.1.8) [MATHPAGES, 2006].

$$
f(t)=\beta / \alpha(t / \alpha)^{\beta-1} \exp \left[-(t / \alpha)^{\beta}\right]
$$

A distribuição de Weibull acima considerada é chamada de dois parâmetros $(\theta$ e t). Quando for considerado separadamente o tempo de iniciação $\left(\mathrm{t}_{0}\right)$, a distribuição passa a ser a de três parâmetros $\left(\theta, t_{0}, t\right)$. para aplicar esse último tipo de distribuição é recomendado pelo menos 7 ensaios [STAEHLE, 1992].

Mais detalhes e exemplos resolvidos envolvendo a distribuição de Weibull podem ser encontrados no site de [MATHPAGES, 2006]. 
16.2. APÊNDICE 2: PLANILHA EM MICROSOFT EXCEL PARA APLICAÇÃO EM MODELAGEM SEMI- EMPÍRICA-PROBABILÍSTICA

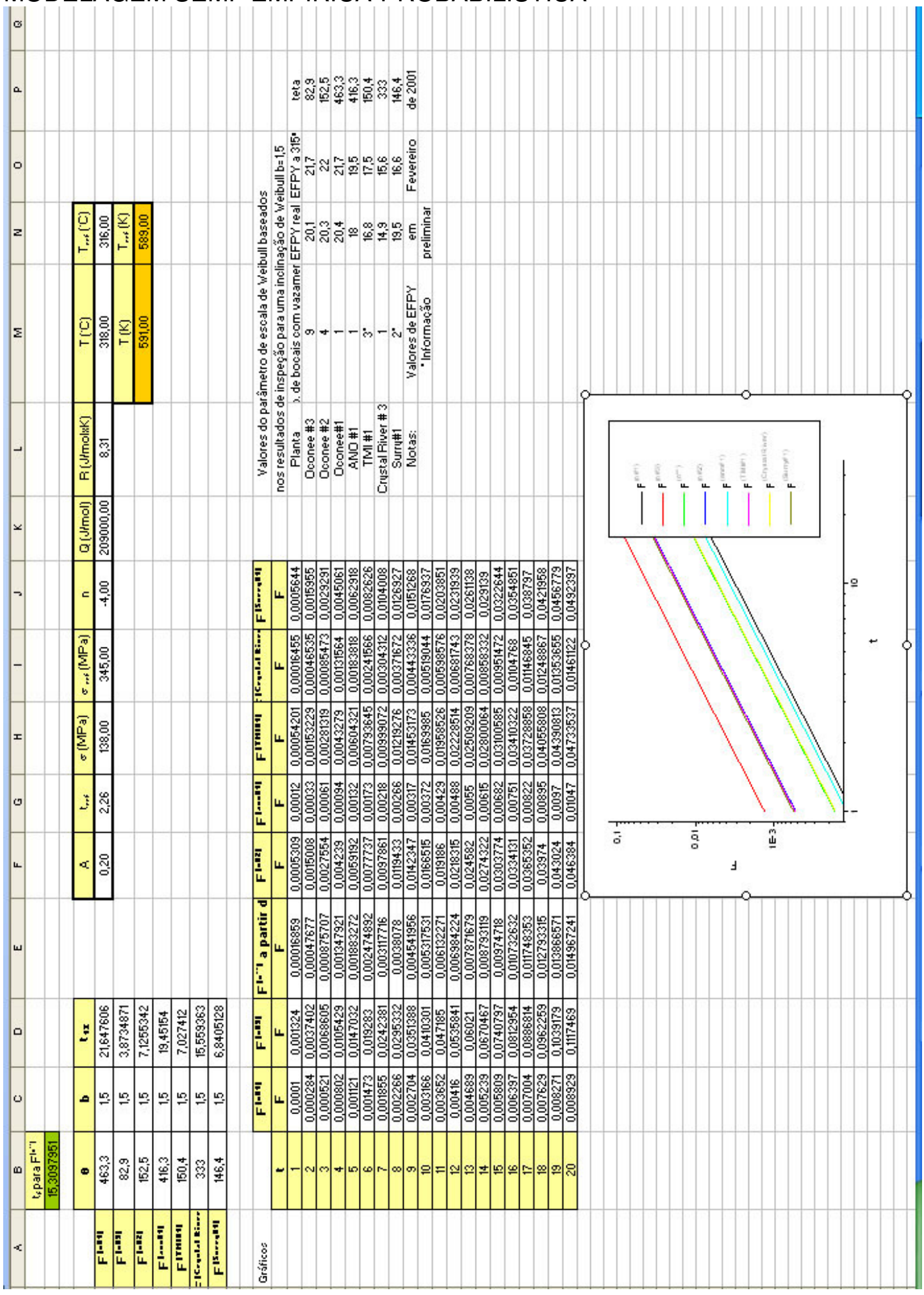




\section{REFERÊNCIAS BIBLIOGRÁFICAS}

1. ABADIE, P. Fissuration par corrosion sous contrainte de l'alliage 600 dans l'eau à haute temperature: contribution d'une approche phénoménologique à la cornpréhension des mécanismes", 1998. Tese (Doutorado)-École des Mines de S' Étienne.

2. ALY, O. F.; ANDRADE, A.H.P., MATTAR NETO, SZAJNBOK, M., TOTH, H.J. Modelling of primary water stress corrosion cracking (PWSCC) at control rod drive mechanism (CRDM) nozzles of pressurized water reactors (PWR), In: ENVIRONMENT-INDUCED CRACKING OF METALS INTERNATIONAL CONFERENCE, 2, Banff, Sept. 19-23, 2004 (no prelo).

3. AMERICAN SOCIETY OF METALS. Metals handbook of corrosion : In:Stresscorrosion cracking .Materials Park, OH: $A S M$ International, 2002. Vol 13 pp. 828-860.

4. ANDERSON, P.M.; RICE, J.R. Acta Metall., v.33, 409, 1985.

5. ANDRESEN, P.L. Critical Processes to Model in Predicting stress Corrosion Response in Hot Water. Power Plant Chemistry, 7(9), p. 541-560, 2005.

6. ANDRESEN, P.L.; CAMPBELL, P.G. The Effects of Crack Closure in High Temperature Water And Its Role in Influencing Crack Growth Data. In: INTERNATIONAL SYMPOSIUM ON ENVIRONMENTAL DEGRADATION OF MATERIALS IN NUCLEAR POWER SYSTEMS-WATER REACTORS,4, August 6-10, 1989, Jekyll Island, Georgia. Proceedings ... NACE, p.4-86 a 4110.

7. ANDRESEN, P.L.; FORD, F.P. Life Prediction by Mechanistic Modeling and System Monitoring of Environmental Cracking of Iron and Nickel alloys in aqueous Systems. Materials Science and Engineering, A103, p. 167-184, 1988.

8. ANDRESEN, P.L.; FORD, F.P. Response to "On the modeling of stress corrosion cracking in iron and nickel base alloys in high temperature aqueous environments. Corros. Sci., v.38, n. 6, p. 1011-1016, 1996.

9. ANGELIU, T. M.; PARAVENTI, D. J.; WAS, G. S. The creep and intergranular cracking behavior of Ni-Cr-Fe alloys in $360^{\circ} \mathrm{C}$ water. Corrosion, v.51, p. 837, 1995.

10. ASM: AMERICAN SOCIETY OF METALS. ASM metals handbook of corrosion, In:Stress-corrosion cracking .Materials Park, OH: ASM International, V. 13 p. 828-860, 2002.

11. ASME: AMERICAN SOCIETY OF MECHANICAL ENGINEERS. Boiler and pressure vessel code: section II, "Materials specifications", Part A, "Ferrous Materials", 1998. 
12. ASTM: AMERICAN SOCIETY FOR TESTING AND MATERIALS. Standard Practice for Slow Strain Rate Testing to Evaluate the Susceptibility of Metallic Materials to Environmentally Assisted Cracking (G 129-00), 2000.

13. ATKINSON, J.D.; YU, J.; CHEN, Z.-Y. An analysis of the effects of sulphur content and potential on corrosion fatigue crack growth in reactor pressure vessel steels. Corros. Sci., v. 38, n. 5, p. 755-765, 1996.

14. BEACHEM, C. D. A new model for hydrogen-assisted cracking (hydrogen embrittlement), Met. Trans., v. 3, p. 427,1972.

15. BEGLEY, J.A., Strain-Rate Damage Model for Alloy 600 in Primary Water, EPRI Report NP-7008, Pittsburg, 1990.

16. BEVERSKOG, B; PUIGDOMENECH, I. Revised Pourbaix Diagrams For Nickel At 25-300 ํ C. Corros. Sci., v.39, p. 969-980, 1997.

17. BHANDARI, S.; PELLISSIER TANON, A. Application of fracture mechanics in the design and operation of PWRs in France. Nuclear Engineering and Design, n.179, p. 109-115, 1998.

18. BIRNBAUM, H. K.; ROBERTSON, I. M.; SOFRONIS, P.; TETER, D. Mechanisms of hydrogen related fracture - a review, CORROSION DEFORMATION INTERACTION - CDI'96, Proceedings...p.172. The Institute of Materials, London, 1997.

19. $\mathrm{BOSCH}, \mathrm{C}$. Étude de la relation entre la corrosion sous contrainte et la fatigue corrosion basse fréquence de l'alliage 600 en milieu primaire des réacteurs à eau sous pression. 1998. Tese (Doutorado)- Universidade de Bordeaux I.

20. BOURSIER, J-M. Fissuration par corrosion sous contrainte des alliages FerNickel-Chrome en milieu primaire de Réacteur à Eau sous Pression, 1993. Tese (Doutorado)- Universidade de Bordeaux I.

21. BOURSIER, J-M., DESJARDINS, D., VAILLANT, F. The influence of strain-rate on the stress corrosion cracking of Alloy 600 in high temperature primary water. Corrosion Sc., v.37, n. 3, p. 493-508, 1995.

22. BRUEMMER, S.M.; WAS, G.S. Microstructural and microchemical mechanisms controlling intergranular stress corrosion cracking in light-water-reactor systems. Journal of Nuclear Materials, v. 216, p.348-363, 1994.

23. BUSO, S.J.; Estudos microestruturais e por microanálise para identificação dos precipitados presentes em amostras da liga de níquel tipo 600 (nacional) após processos de soldagem.2001.Dissertação (Mestrado), Instituto de Pesquisas Energéticas e Nucleares, São Paulo. 
24. CAI,W., BULATOV, V.V., CHANG,J., LI, J., YIP,S. Dislocations Core Effects on Mobility. In: NABARRO, F.R.N., HIRTH,J.P (Ed.). Dislocations in Solids, v.12, p.1, North-Holland: Elsevier, (2004).

25. CARON, D. Influence De L'Hydrogène Sur La Vitesse De Propagation Des Fissures De Corrosion Sous Contrainte Dans L'Alliage 600 En Milieu Primaire Des Réacteurs Nucléaires À Eau Sous Pression. 2001.Tese (Doutorado).Institut National des Sciences Appliquées. Lyon.

26. CDTN: CENTRO DE DESENVOLVIMENTO DE TECNOLOGIA NUCLEAR. Comparação dos Ensaios de Tração-SSRT- Inconel 600. Relatório Interno. Belo Horizonte, 2005.

27. CHAMBREUIL-PARET, A. Corrosion sous contrainte de mono et polycristaux d'aciers inoxydables austénitiques en milieu $\mathrm{MgCl}_{2}$ : analyse microfractographique et recherche d'améliorations du comportement. 1997.Tese (Doutorado). École des Mines de St. Étienne.

28. CHATEAU, J.-P. Vers une quantification de la fissuration en corrosion sous contrainte des matériaux cubic à faces centrées: simulation numérique des interactions hydrogène-plasticité.1999.Tese(Doutorado). École des Mines de Saint-Etienne.

29. CHEN, C. M. Computer-Calculated Potential pH Diagrams to $300^{\circ} \mathrm{C}$. Vol.2.Handbooks of Diagrams. Alliance, Ohio: Babcock and Wilcox Company, 1983. (EPRI NP-3137).

30. CHIAVERINI, V. Aços e ferros fundidos. São Paulo: ABM,1982.

31. COBBLE, J.W. The Thermodynamic Properties of High Temperature Aqueous Solutions. Applications of Entropy Correspondence to Thermodynamics and Kinetics, J. Am. Chem. Soc., v. 86, p. 5394-5401, 1964.

32. COMBRADE, P.; FOUCAULT, M.; VANÇON, D.; MARCUS, P.; GRIMAL, J.; GELPI, A. Effect of sulfur on the protective layers on alloys 600 and 690 in low and high temperature environments. Mémoires et Etudes Scientifiques Revue de Métallurgie, p. 429, 1990.

33. CORIOU, H.; GRALL, L.; MAHIEU, C.; PELAS, M. Sensitivity to Stress Corrosion Cracking and Intergranular Attack of High-Nickel Austenitic Alloys, Corrosion, Vol. 22, n. 10, p. 280-290, 1966.

34.COTTRELL, A. Unified theory for effects of segregated interstitials on grain boundary cohesion. Materials Science and Technology, v.6, n.9, p.807-810, 1990.

35. COWAN, R.L.; STAEHLE, R.W. The Thermodynamics and Electrode Kinetic Behavior of Nickel in Acid Solution in the Temperature Range $25^{\circ}$ to $300^{\circ} \mathrm{C}, \mathrm{J}$. Electrochem. Soc., Vol. $118 \mathrm{~N}^{\circ} .4$, p. 557-567, 1971. 
36. CRISS, C.M., COBBLE, J.W. The Thermodynamic Properties of High Temperature Aqueous Solutions. Entropies of lons up to $200^{\circ}$ and the Correspondence Principle, J. Am. Chem. Soc., v. 86, p. 5385-5390, 1964.

37. CRISS, C.M., COBBLE, J.W. The Thermodynamic Properties of High Temperature Aqueous Solutions. The Calculation of Ionic Heat Capacities up to $200^{\circ}$. Entropies and Heat Capacities above $200^{\circ}, \mathbf{J}$. Am. Chem. Soc., v. 86, p. 5390-5393, 1964.

38. EPRI: ELECTRIC POWER RESEARCH INSTITUTE. Crack Growth Rates for Evaluating Primary Water Stress Corrosion Cracking (PWSCC) of ThickWall Alloy 600 Material: Materials Reliability Program, 2002. (EPRI MRP-55).

39. EYRE, B. Materials technology challenges for power generation in the $21^{\text {st }}$ century. Progress in Materials Science, v.42, p.23-37, 1997.

40. FAIDY, C.; VAGNER, J.; BHANDARI, S.; VAINDIRLIS, M. Life evaluation of CRDM nozzles through mechanical analysis, ASME PVP CONFERENCE, Minneapolis, 1994.

41. FISH, J. S.; LEWIS, N.; PERRY, D.J.; YANG, W.J.; THOMPSON, C.D. Analytical Electron Microscopy Investigations of Primary Water Stress Corrosion Cracking in Nickel Alloys. Schenectady, NY: KAPL Atomic Power Laboratory, 1997 (KAPL-P-000144: K97007).

42. FOCT, F. Mecanismes De Corrosion Sous Contrainte De L'Alliage 600 Polycristallin Et Monocristallin En Milieu Primaire: Role De L'Hydrogen. 1999. Tese (Doutorado)- Institut National Polytechnique de Grenoble. École Nationale Supérieure des Mines de Saint-Étienne.

43. FONTANA, M.G. Corrosion engineering, New York, N.Y.: McGraw-Hill, 1986.

44. FONTANA, M.G. ; GREENE, N.D. Corrosion engineering, New York, N.Y.: McGraw-Hill, 1978.

45. GALVELE, J. R. A Stress Corrosion Cracking Mechanism Based On Surface Mobility. Corros. Sci., v.27, n. 1, p. 1-33, 1987.

46. GALVELE, J. R. Reply to "Notes on the discussion concerning the "surface mobility mechanism" of stress corrosion cracking", by E.M.Gutman. Corros. Sci., 45, p. 2119-2128, 2003.

47. GARDEY, S. Étude de la corrosion generalisée des alliages 600,690 et 800 en milieu primaire. Contribuition à la compréhension des mécanismes. 1998.Tese (Doutorado).Université Pierre et Marie Curie. Paris.

48. GARUD, Y.S. A Perspective On the Predictive Assessment of Stress Corrosion Cracking In Engineering Applications, InterCorr 96 Conference, 1996. 
49. GARUD, Y.S., A Simplified Model for Assessment of SCC Initiation Time in Alloy 600, EPRI Final Report TR-109137, Palo Alto, November 1997.

50. GARUD, Y.S., YG Notes on Aly O.F. Paper on "Modelling of PWSCC at CRDM nozzles of PWR", paper by Aly, O.F., et al., at EICM-2, September 2004, December 2004 (não publicado).

51. GENDRON, T. S.; BUSHBY, S. J.; CLELAND, R. D.; NEWMAN, R. C. Oxidation embrittlement of alloy 600 in hydrogenated steam at $400^{\circ} \mathrm{C}$, Corrosion Deformation Interaction - CDl'96, The Institute of Materials, Proceedings...London , 1997, p. 484.

52. GÓMEZ BRICEÑO, D; SERRANO, M. Aleaciones Base Níquel en Condiciones de Primario de los Reactores Tipo PWR. Rev. SNE, marzo, p. 17-22, 2005.

53. GORMAN, J.A.,MCILREE,A.R.,GAUDREAU, T. BJORNKVIST, L., ANDERSSON, P.-O. Influence of startup oxidizing transients of IGA/SCC in PWR steam generators. In.: INTERNATIONAL STEAM GENERATOR AND HEAT EXCHANGER CONFERENCE, 3, Jun 1998, Toronto. Proceedings... Toronto, Canadian Nuclear Society, 1998, p. 521-534.

54. GORMAN, J.A., STAEHLE,R.W. Prediction of Life of Angra-1 Steam Generators. Dominion Engineering, McLean, Virginia/ North Oaks, Minnesota, 1989.

55. GORMAN, J.A., STAVROPOULOS, K. D., ZEMITIS, W.S., DUDLEY, M. E., PWSCC Prediction Guidelines, EPRI Final Report TR-104030 Project 281215, Palo Alto, July 1994.

56. GOURGUES, A.-F. Interactions mécanique-oxydation à haute ternpérature dans I'alliage 600: application à la fissuration dans le milieu primaire des réacteurs nucléaires à eau sous pression. 1998. Tese (Doutorado)-École Nationale Supérieure des Mines de Paris.

57. GOURGES, A.F, SCOTT, P.M., ANDRIEU, E. A study of the mechanism of primary water stress corrosion cracking of Alloy 600. In: NACE INTERNATIONAL SYMPOSIUM ON ENVIRONMENTAL DEGRADATION OF MATERIALS IN NUCLEAR POWER PLANTS: WATER REACTORS, 7, 6-10 Aug 1995, Breckenridge, CO. Proceedings...Houston, TX. NACE International, 1995, p. 829-838.

58. GRAS, J.M. Stress corrosion cracking of steam generator tubing materials. In: PARKINS SYMPOSIUM ON FUNDAMENTAL ASPECTS OF STRESS CORROSION CRAKING. Proceedings ... Eds. S. M. Bruemmer, E. I. Meletis, R.H. Jones, W.W. Gerberich, F. P. Ford, and R. W. Staehle, TMS, Warrendale, PA [s.d.], p. 411-432. 
59. GRAS, J.M. Stress corrosion cracking behaviour of nickel based alloys in the nuclear industry. In: EUROPEAN CORROSION CONFERENCE, 10, July, 1993, Barcelona, Espanha. Proceedings... Londres, Institute of Materials, 1993, p. 1509-1521.

60. GUTMAN, E..M. Notes on the discussion concerning the "surface mobility mechanism" of stress corrosion cracking. Corrosion Science, v. 45, p. 21052117, 2003.

61. HALL, J.F.;SCOTT, D.B.; WRIGHT, D.A.; PATHANIA, R.S. Cracking of Alloy 600 heater sleeves and nozzles in PWR pressurizers. In.: INTERNATIONAL SYMPOSIUM ON ENVIRONMENTAL DEGRADATION OF MATERIALS IN NUCLEAR POWER SYSTEMS - WATER REACTORS, 5, Monterey, CA ,2529 Aug. 1991, Proceedings... La Grange Park, IL, American Nuclear Society, Inc. 1992, p. 652-660.

62. HALL JR., M.M. Thermally activated dislocation creep model for primary water stress corrosion cracking of NiCrFe alloys. In: INTERNATONAL SYMPOSIUM ON PLANT AGING AND LIFE PREDICTION OF CORRODIBLE STRUCTURES, 15-18 May 1995, Sapporo, Japan. Proceedings... Paper A-I09.

63. HEMPEL, C.A. (ed.). The encyclopedia of electrochemistry. New York, N.Y.: Reinhold Publishing Corporation,1964.

64. HERTZBERG, R.W. Deformation and fracture mechanics of engineering materials, New York, N.Y.: John Wiley \& Sons, 1989.

65. HOANG, P.; GANGADHARAN, S.; RAMALINGAM, S. Primary water stress corrosion cracking inspection ranking scheme for alloy 600 components. Nuclear Engineering and Design, n.181, p. 209-219, 1998.

66. HONG, S - Y; JEONG, I - S; JIN, T. Recent estrategy and progress in Korean nuclear PLIM program. Nuclear Engineering and Design, n.174, p. 25-32, 1997.

67. IAEA: INTERNATIONAL ATOMIC ENERGY AGENCY. Assessment and management of ageing of major nuclear power plant components important to safety: Pressurized water reactor pressure vessels. Vienna: IAEA, 1997. ( IAEA - TECH DOC)

68. IAPWS: THE INTERNATIONAL ASSOCIATION FOR THE PROPERTIES OF WATER AND STEAM. Guideline on the Henry's Constant for Gases in $\mathrm{H}_{2} \mathrm{O}$ and $\mathrm{D}_{2} \mathrm{O}$ at High Temperatures. Kyoto: IAPWS, 2004.

69. JONES, D. A. A unified mechanism of stress corrosion and corrosion fatigue cracking, Met. Trans., v. 16A, p. 1133, 1985.

70. KEATING, F.H. In: SYMPOSIUM ON INTERNAL STRESS IN METALS AND ALLOYS. Proceedings...Londres, Institute of Metals, 1948, p. 311. 
71. KERGARAVAT, J.-F. Influence de la microstructure sur la sensibilité à la corrosion sous contrainte des alliages 600 et 690 en milieu primaire des réacteurs à eau sous pression. 1996. Tese (Doutorado)- Institut National Polytechnique de Grenoble.

72. KNOTT, J.F. Fundamentals of fracture mechanics. New York, N.Y.: Halsted Press, 1976.

73. LECLERCQ, O, VAILLANT F. Étude du Comportement en Fluage à $350^{\circ} \mathrm{C}$ de L'Alliage 600. Eletricité de France: February, 1991. Report HT 40/NTE 1140A.

74. LECOESTER, F. Interactions hydrogène-alliage 600 (NC15Fe) : application au cas des tubes de générateur de vapeur des réacteurs à eau pressurisée, soumis au milieu primaire. 1997. Tese (Doutorado). Universidade de Paris Sud.

75. LEMAITRE, J.; CHABOCHE, J.-L. Mechanics of solid materials, New York, N.Y.: Cambridge University Press, 1990.

76. LEMIRE, R.J.; McRAE, G.A. The corrosion of Alloy 690 in high-temperature aqueous media- thermodynanic considerations. Journal of Nucl. .Mat., v. 294, p. 141-147, 2001.

77. LOGAN, H.L. Journal of Research of the National Bureau of Standards, Washington: v.48, n.99, RP2291, 1952.

78. $\mathrm{LOSCH}$, W. A new model of grain boundary failure in temper embrittled steel. Acta Metallurgica, v.27, p.1885-1892, 1979.

79. MACDONALD, D.D. On the modeling of stress corrosion cracking in iron and nickel base alloys in high temperature aqueous environments. Corros. Sci., v.38, n. 6, p. 1003-1010, 1996.

80. MACDONALD,D.D.;LIU,C.;MANAHAN,M.P. Eletrochemical noise measurements on carbon and stainless steels in high subcritical and supercritical aqueous environments.In: ELETROCHEMICAL NOISE MEASUREMENT FOR CORRO SION APPLICATIONS, 1996, Philadelphia. Proceedings.Philadelphia: ASTM, 1996, p.247-265 (STP1277).

81. MACDONALD, D.D.; URQUIDI-MACDONALD, M. Modeling of the Electrochemistry of Stress Corrosion Cracks in Sensitized Type 304SS in Boiling water Reactors. In: INTERNATIONAL SYMPOSIUM ON ENVIRONMENTAL DEGRADATION OF MATERIALS IN NUCLEAR POWER SYSTEMS-WATER REACTORS, 4, August 6-10, 1989, Jekyll Island, Georgia. Proceedings...NACE, p.4-1 a 4-11. 
82. MAGNIN, T.; CHIERAGATTI, R.; OLTRA, R. Mechanism of brittle fracture in a du -ctile 316 alloy during stress corrosion, Acts. Met., v. 38, n.7, p.1313, 1990.

83.MATHPAGES. The Weibull Distribution. Disponível em www.mathpages.com/home/kmath122/kmath 122.htm. Acesso em abril de 2006.

84. MATIAS, A., SCHVARTZMAN, M.M.A.M. Desenvolvimento de uma metodologia de avaliação da suscetibilidade à corrosão sob tensão em ambiente de reator nuclear, Santos, Proceedings... Santos: INAC, 2005. 1 CD ROM.

85. MEDOFF, J. Primary water stress corrosion cracking of vessel head penetration nozzles, apresentação para o USNRC CEOG Executive Meeting Report, Washington, May 2001.

86. MEYERS, M.A.; BENSON, D.J.; VÖHRINGER, O.; KAD, B.K.; XUE, Q.; FU, H.-H. Constitutive description of dynamics deformation: physically-based mechanisms. Materials Science and Engineering, A322, p. 194-216, 2002.

87. MILLS, W.J; BROWN, C.M. Fracture Toughness of Alloy 600 and an EN82H Weld in Air and Water. Metallurgical and Materials Transactions A, v.32A, p.1161-1174, 2001.

88. MITHIEUX, J.-D. Influence de la teneur en chrome et de la structure des alliages de nickel sur leur comportment en corrosion sous contrainte en milieu primaire des réacteurs à eau pressurisée. 1997. Tese (Doutorado)Institut National Polytechnique de Grenoble.

89. MORAGA, G. Análise Eletroquímica da Liga de Níquel 600 MA, 2006, Belo Horizonte, CDTN, 2006. (RELATÓRIO INTERNO)

90. MOREIRA, P.A.P., ANDRADE, A.H.P., NEVES, C.F.C, SCHVARTZMAN, M.M.A.M. Sistema para realização de ensaios de corrosão sob tensão em condições operacionais de reatores PWR. In: CONFERENCIA INTERNACIONAL DA ABM, 57, 2002, São Paulo, Proceedings... São Paulo: ABM, 2002, 1 CD ROM, p.1144-1154.

91. MOSHIER, W. C.; BROWN, C.M. Effect of Cold Work and Processing Orientation on the SCC Behavior of Alloy 600. West Mifflin, PA: Bettis Atomic Power Laboratory, 1999. (WAPD-T-3227).

92. NAKAGAWA, T; TOTSUKA, N.; TERACHI, T.; NAKAJIMA, N. Influence of Dissolved Hydrogen on Oxide Film and PWSCC of Alloy 600 in PWR Primary Water. Journal of Nuclear Science and Technology, v.40, n.1, p.39-43, 2003.

93. OGINO, Y.; YAMAZAKI, T. Influence of grain boundary penetration of oxygen on hydrogen embrittlement of nickel. Transactions of the Japan Institute of Metals, v.25,n.3, p.150-159, 1984. 
94. ORIANI, R.A. Hydrogen - The versatile embritller, Corrosion, v. 43, n.7, p.390, 1987.

95. PANASIUK, V. Some stages of the development of fracture mechanics in the Ukraine. In: ROSSMANITH, H. P. (Ed.). Fracture research in retrospect, p.351-367, Rotterdam: A.A. Balkema, 1997.

96. PARR, S.W.; STRAUB, F.G. University of Illinois Bulletin, Illinois, p. 177, 1928.

97. PETCH, N.J. The lowering of fracture-stress due to surface adsorption. Phil.Mag., v. 1, p.331, 1956.

98. POURBAIX, M. Atlas of Eletrochemical Equilibria in Aqueous Solutions. Ed. NACE: Houston, Tx; CEBELCOR: Brussels. Houston: NACE, 1974.

99. PRESS, W.H.; FLANNERY, B.P.; TEUKOLSKY, S.A.; VETTERLING, W.T. Numerical Recipes, The Art of Scientific Computing (FORTRAN Version). Cambridge University Press, 1989.

100. RAMANATHAN, L.V. Corrosão e seu controle. São Paulo: Hemus, 1992.

101. REBAK, R. B.; Z. SZKLARSKA-SMIALOWSKA. Mechanism Of Stress Corrosion Cracking Of Alloy 600 In High Temperature Water. In: G. AIREY ET AL. (Eds.), Seventh Symposium on Environmental Degradation of Materials in Nuclear Power Systems - Water Reactors, NACE, Houston, TX, 1995, p.855-865.

102. REBAK, R. B.; Z. SZKLARSKA-SMIALOWSKA. The Mechanism Of Stress Corrosion Cracking Of Alloy 600 In High Temperature Water. Corros. Sci., v. 38, n. 6, p. 971-988, 1996.

103. RINCKEL, M. A. Reactor pressure vessel integrity program. Nuclear Engineering and Design, n.181, p. 17-39, 1998.

104. RIOS, R. Étude des mecanismes de corrosion sous contrainte de l'Alliage 600 (NC15Fe) dans l'eau d' haute temperature 1993. Tese (Doutorado)Université des Sciences et Technologies de Lille.

105. ROBERTS, J. T. A. Structural materials in nuclear power systems. New York, N.Y.: Plenum Press, 1981.

106. ROBERTSON, W.D. ; TATELMAN, A.S. Strengthening mechanisms in solids, Ohio: American Society for Metals, p. 217, 1962.

107. RYAN, M. P; WILLIAMS, D.E.; CHATER, R.J.; HUTTON, B.M; MCPHAIL, D.S. Why stainless steel corrodes. Nature, n.415, p. 770-774, 2002. 
108. SANTARINI, G. Comprehensive Interpretation of CERTs: A Method for the Characterization and the Prediction of IGSCC. Corrosion, v.45, p. 369-381, 1989.

109. SATOH et al.. Journal of Nuclear Materials, v.258-263, p.2054-2058 (279344), 1998.

110. SCHVARTZMAN, M.M.A.M., NEVES, C.F.C., CAMPOS, W.R.C., MOREIRA, P.A.P. Facility for the study of environmentally assisted cracking, COBEM, Anais... CD-ROM, ABM: Belo Horizonte, 2003.

111. SCHVARTZMAN, M.M.A.M., NEVES, C.F.C., MATIAS, A., LOURENÇO, L.I. Avaliação da Susceptibilidade à Corrosão Sob Tensão do Inconel $600 \mathrm{MA}$ em Ambiente de Reator Nuclear, CONGRESSO ANUAL DA ABMINTERNACIONAL, 60, Anais... CD-ROM, ABM: Belo Horizonte, 2005.

112. SCOTT, P. Prediction of alloy 600 component failures in PWR systems. In: PROC. CORROSION 96, Proceedings...Denver,1996.

113. SCOTT, P.M; COMBRADE, P. Review of Crack Propagation Processes in Alloy 600. In: IMPROVING THE UNDERSTANDING AND CONTROL OF CORROSION ON THE SECONDARY SIDE OF STEAM GENERATORS, 9-13 Oct 1995, Airlie, VA. Proceedings... NACE, Houston, TX, 1996, p. 419-429.

114. SCOTT, P.M; LE CALVAR, M. Some Possible Mechanisms of Intergranular Stress Corrosion Cracking of Alloy 600 in PWR Primary Water. In: SIXTH INTERNATIONAL SYMPOSIUM ON ENVIRONMENTAL DEGRADATION OF MATERIALS IN NUCLEAR POWER SYSTEMS-WATER REACTORS, San Diego, CA, August 1-5, 1993. Proceedings ..., p. 657-665.

115. SERRA, E. Stress Corrosion Cracking of Alloy 600, EPRI Special Report NP2114-SR, Palo Alto, November 1981.

116. SEUNG-GI LEE, IL SOON HWANG. Probabilistic Prediction Model for Initiation Time on Alloy 600 CRDM Nozzle. In: KOREAN NUCLEAR SOCIETY AUTUMN MEETING. October, 1999, Seoul, Korea. Proceedings ... KNS.

117. SHAH, V.N.; WARE, A. G. ; PORTER, A. M. Assessment of pressurized water reactor control rod drive mechanism nozzle cracking. Idaho Falls: Idaho National Engineering Laboratory, Oct.1994. (NUREG/CR-6245).

118. SHEN, C.H.; SHEWMON, P.G. Metall.Trans., v.21A, 1261, 1991.

119. SHIPILOV, S.A. Fundamentals of physico-chemical mechanics of fracture: purposes and contents of the new educational course. In: ROSSMANITH, H.P. (Ed.). Teaching and education in fracture and fatigue. London, UK: 1996, E\&FN Spon/Chapman \&Hall, p. 293-299 (ISTLI Special Publication 2). 
120. SINGH, I. B. Pitting characteristics of alloy 600 and alloy 601 in a chloridecontaining acidic environment. Corrosion, v. 57, n.6, p. 483-488, 2001.

121. SPECIAL METALS Bulletin for INCONEL ${ }^{\circledR}$ alloy 600 . Publication Number SMC027, September 2004, site download from www.specialmetals.com.

122. STAEHLE, R.W.; BEGLEY, J.A.; AGRAWAL, A.K.; BECK, F.H.; LUMSDEN, J.B.; BIGGERT, A.S.; DAVIS, C.A. Corrosion and Corrosion Cracking of Materials for Water-Cooled Reactors, EPRI Final Report NP-1741 Project 311-1, Palo Alto, March, 1981.

123. STAEHLE, R.W, J.A.GORMAN. Development and Application of Intensity and Operating Diagrams for Predicting the Ocurrence and Extent of Stress Corrosion Cracking, CORROSION SCIENCE AND ENGINEERING, Proceedings ... Eds. R. A. Rapp, N. A. Gokcen, e A. Pourbaix, CEBELCOR, Brussels, 1989, p. 199-211.

124. STAEHLE, R.W. Environmental Definition. In: MATERIALS PERFORMANCE MAINTENANCE. Proceedings ... R.W.Revie, V.S.Sastri, M.Elboujdaini, E.Ghali, D.L.Piron, P.R.Roberge and P.Mayer, Eds., Pergamon Press, Ottawa, Ontario, Canada, 1991, p.3-43.

125. STAEHLE, R.W. Combining Design and Corrosion for Predicting Life. In: LIFE PREDICTION OF CORRODIBLE STRUCTURES November 5-8, 1991, Kauai, Hawaii. Proceedings ... NACE [s.n.], 1992.

126. STAEHLE, R.W. Development and Application of Corrosion Mode Diagrams. In: PARKINS SYMPOSIUM ON FUNDAMENTAL ASPECTS OF STRESS CORROSION CRAKING. Proceedings ... Eds. S. M. Bruemmer, E. I. Meletis, F. P. Ford, and R. W. Staehle, The Minerals, Metals \&Materials Society, 1992.

127. STAEHLE, R. W. Engineering with advanced and new materials. Materials Science \& Engineering, n. A 198, p. 245-256, 1995.

128. STAEHLE, R.W. Bases for Predicting the Earliest Penetrations Due to SCC for Alloy 600 on the Secondary Side of PWR Steam Generators, NUREG/CR6737 ANL-01/20, RWS 151, USNRC, 2001.

129. STROH, A. N. Adv. Phys., v. 6, p. 418, 1957.

130. SUNG, J. K.; JONES, J. W.; WAS, G. S. Effects of carbon on the lowtemperature creep behavior of Ni-16Cr-9Fe. Met. Trans. A, v. 23 A, p. 1033, 1992.

131. SYMONS, D. M.; BURKE, M.G.; FOSTER, J.P. The Relationship Between Observed Stress Corrosion Cracking Fracture Morphology and Microestructure in Alloy 600. Pittsburgh, PA: Bettis Atomic Power Laboratory-Westinghouse Electric Corporation, 1997. (WAPD-T-3130). 
132. TANAKA, D.K.; AUADA, R.B. Programa para Microcomputador IBM-PC Compatível para Determinação do Diagrama de Pourbaix para Metais em Quaisquer Meios Aquosos. In.: CONGRESSO BRASILEIRO DE CORROSÃO, 16 ${ }^{0}$, Anais...p. 597-609, ABRACO, Rio de Janeiro, 1991.

133. THOMPSON, C. D.; CAREY, D.M.; PERAZZO, N.L. Effects of Hydrogen on Electropotential Monitoring of Stress Corrosion Cracking Growth. Schenectady, NY: KAPL Atomic Power Laboratory, 1997. (KAPL-P-000146: K97009).

134. TIEN, J. K.; NAIR, S. V.; JENSEN, R.R. Dislocation sweeping of hydrogen and hydrogen embrittlement, HYDROGEN EFFECTS IN METALS, Eds. I.M.Bernstein, A.W. Thompson, Proceedings...p.37, The Metallurgical Society of AIME, 1980.

135. TOTSUKA, N.; SMIALOWSKA, S. Hydrogen Induced IGSCC of Ni-Containing FCC Alloys in High Temperature Water. In.: INTERNATIONAL SYMPOSIUM ON ENVIRONMENTAL DEGRADATION OF MATERIALS IN NUCLEAR POWER SYSTEMS-WATER REACTORS, $3^{\text {rd }}$, Eds. G.J.Theus and J.R.Weeks. Proceedings...p.691-696. AIME, New York, 1988.

136. TROIANO, A.R. The role of hydrogen and other interstitial in the mechanical behavior of metals, Trans. ASM, 52, 1960, p. 54.

137. UHLIG, H.H. ; REVIE, R.W. Corrosion and corrosion control, New York, N.Y.: Wiley-Interscience, 1985.

138. UNITED STATES NUCLEAR REGULATORY COMMISSION (USNRC). Preliminary Staff Technical Assessment for Pressurized Water Reactor Vessel Head Penetration Nozzles Associated with NRC Bulletin 2001-1, "Circumferential Cracking of Reactor Pressure Vessel Head Penetration Nozzles". Site download of www.nrc.gov, November 2001.

139. UNITED STATES NUCLEAR REGULATORY COMMISSION (USNRC). Degradation Area of Davis Besse Nozzle \#3 and Degradation Area of Davis Besse Nozzle \#3 Sketch, Figures download of www.nrc.gov/reactors/operating lops-experience/vessel head-degradation/images.html, July 2004, acessado em 07/11/2005.

140. VAN DER SLUYS, W.A., EASON, E.D., GILMAN, J.D. Environment-Sensitive Cracking of Pressure Vessel Steels. In.: INTERNATIONAL SYMPOSIUM ON ENVIRONMENTAL DEGRADATION OF MATERIALS IN NUCLEAR POWER SYSTEMS-WATER REACTORS, 4 ${ }^{\text {th }}$, Ed. D.Cubicciotti. Proceedings...p. 1-371-62, NACE, Houston, 1990.

141. VANKEERBERGHEN, M. A Mechanico-Electrochemical Diagram for Crack Growth Under EAC Conditions. In: CORROSION 2004, Paper n. 04573 published by NACE...Houston, 2004. 
142. WAS, G.S. Micromechanical and Microstructural Effects on Stress Corrosion Cracking of Nickel based Alloys. In: PARKINS SYMPOSIUM ON FUNDAMENTAL ASPECTS OF STRESS CORROSION CRAKING. Proceedings ...1991.

143. WOLYNEC, S. Técnicas eletroquímicas em corrosão. São Paulo: Edusp, 2003. 